\title{
INTEGRATING BIOENERGETICS AND FORAGING BEHAVIOR: THE PHYSIOLOGICAL ECOLOGY OF LARVAL COD (Gadus morhua)
}

by

\author{
James Joseph Ruzicka \\ B.S., Oregon State University, 1988 \\ M.S., University of Hawaii, 1994 \\ Submitted in partial fulfillment of the requirements for the degree of \\ Doctor of Philosophy \\ at the

\section{MASSACHUSETTS INSTITUTE OF TECHNOLOGY and the} \\ WOODS HOLE OCEANOGRAPHIC INSTITUTION
}

MATIRE BIOLOGICAL LABOSATOSY

LIERARY

WOODS HOLE, WASS

W. H. O. I.

June 2004

(C) 2004 James Joseph Ruzicka

All rights reserved.

The author hereby grants to MIT and WHOI permission to reproduce paper and electronic copies of this thesis in whole or in part and to distribute them publicly.

Signature of Author

Jolint Program in Oceanography/Biology

Massachusetts Institute of Technology And Woods Hole Oceanographic Institution

June 2004

Certified by

Dr. Scott M. Gallager

Thesis Supervisor

Accepted by

Dr. John $\overline{\text { Waterbury }}$ Chair, Joint Committee for Biological Oceanography

Woods Hole Oceanographic Institution 


\title{
Integrating Bioenergetics and Foraging Behavior: The Physiological Ecology of Larval Cod (Gadus morhua)
}

by

\author{
James Joseph Ruzicka
}

Submitted in partial fulfillment of the requirements for the degree of Doctor of Philosophy at the Massachusetts Institute of Technology and the Woods Hole Oceanographic Institution, June 2004

\section{$\underline{\text { Abstract }}$}

How do larval cod, Gadus morhua, balance foraging effort against the high cost of swimming in a viscous hydrodynamic regime? A respirometry system was developed to measure the activity metabolism of individual larvae. The cost of swimming was modeled as a power-performance relationship (energy expenditure as a function of swimming speed) and as the cost of transport (the cost to travel a given distance). The cost of transport was high relative to juvenile and adult fish, but larvae swam more efficiently as they grew and became better able to overcome viscous drag.

A large-volume observation system was developed to record foraging behavior in three dimensions. There are two phases of the saltatory search cycle used by larval cod: the burst which serves to position larvae within a new search volume and the pause when larvae search for prey. Burst characteristics did not change under different prey treatments, but pause duration increased while foraging capacity and swimming activity decreased when prey were absent. Longer pause durations could reflect greater effort to visually process each search volume when prey were difficult to find. Reduced swimming activity could also be an energy conservation strategy under unfavorable foraging conditions.

By applying the cost of swimming model to the observed swimming intensity of freely foraging larvae, foraging activity was estimated to account for up to $80 \%$ of routine metabolism. A trophodynamic model was developed incorporating observed foraging behavior and swimming costs to estimate the prey density required to cover all 
metabolic demands. Small larvae $(5 \mathrm{~mm})$ can survive on typical mean Georges Bank prey densities in mildly turbulent conditions. Larger larvae $(>6 \mathrm{~mm})$ can survive even at high turbulence levels.

Simulated alternative foraging strategies predict that when predator-prey contact rates are high, the greatest net energy gain is realized with short pause durations. When predator-prey contact rates are low, larvae should achieve greater net energy gains by remaining at rest for extended periods. Larvae observed foraging in the absence of prey do not change behavior as much as the simulation model predicts, suggesting that they use a prey encounter maximization strategy rather than an energy conservation strategy.

Thesis Supervisor: Scott M. Gallager 


\section{Contents}

Abstract__ 3

Acknowledgements__ 8

Chapter 1: Integrating Bioenergetics and Foraging Behavior: The Physiological Ecology of Larval Cod (Gadus morhua) __ 9

Introduction___ 9

References _ 16

Chapter 2: The Cost of Swimming for Larval Cod __ 19

Introduction 19

Materials and Methods ____ 21

Rearing of larvae __ 21

Treatments _ 22

Optical oxygen measurement system___ 22

Respirometry chambers and measurement cells____ 24

Experimental protocol _ 26

Activity level measurement__ 27

Post-experiment sample handling ___ 27

Results

FOXY stabilization time _ 34

Activity 334

Activity metabolism (power-performance relationship)___ 34

Effect of age, size, and speed___ 35

Specific Dynamic Action___ 36

Discussion

Conclusions _ 55

References _ 63

Chapter 3: The Foraging Behavior of Larval Cod __ 66

Introduction__ 66

Materials and Methods ___ 68

Rearing of larvae 68

Observation tank system _ 69

Processing the video record 75

Experimental treatments and protocol

Classification of behavioral modes _ 77

Results _ 83

Behavior of the individual ___ 83

Effect of the presence or absence of prey______ 88 
Discussion

Larval cod as saltatory predators

Foraging capacity

Other factors that may affect foraging behavior

Conclusions

References

Chapter 4: The Importance of the Cost of Swimming to the Foraging Behavior and Ecology of Larval Cod

Introduction

Materials and Methods

Rearing of larvae

Respirometry

Behavior

Trophodynamic model

Results

Cost of Swimming

Foraging Behavior

Energy use during foraging activity

Trophodynamic model

Discussion

Conclusions

References

\section{Chapter 5: Integrating Bioenergetics and Foraging Behavior: The Physiological}

Ecology of Larval Cod (Gadus morhua)

\section{Conclusion}

Conclusions from chapter 2: "The Cost of Swimming for Larval Cod."

Conclusions from chapter 3: "The Foraging Behavior of Larval Cod."

Conclusions from chapter 4: "The Importance of the Cost of Swimming to the Foraging Behavior and

Ecology of Larval Cod."

Comments on assumptions

Significance of the findings of this laboratory study to larvae in the ocean 180

References 183

Appendix: Formulae used for the calculation of oxygen concentration 


\section{Acknowledgements}

My first thanks go to the members of my dissertation committee. From the Woods Hole Oceanographic Institution: Judy McDowell; Cabell Davis; and my advisor, Scott Gallager. From MIT: Glenn Flierl. And from the National Marine Fisheries Service: Greg Lough. I also thank Jesus Pineda for chairing my defense.

I thank the many people who supplied cod eggs: Edward Trippel (Fisheries and Oceans Canada, St. Andrews Biological Station, St. Andrews, New Brunswick, Canada), Bill Mebane and Scott Lindell (Marine Biological Laboratory, Woods Hole, MA), Nick King (GreatBay Aquaculture, Portsmouth, NH), Danny Boyce (Ocean Sciences Centre, Memorial University of Newfoundland, Canada), and Larry Buckley and Ed Davies (NMFS, Narragansett Laboratory, RI). I also would like to thank Dave Arnold of the Francis Elizabeth, Paul Parker of the Peggy B II, and the Cape Cod Commercial Hook Fishermen's Association for live adult cod during my attempt to establish a small broodstock here at WHOI.

I thank the scientific staff here at WHOI for their advice and help. In particular, I would like to thank Nancy Copley, Bruce Woodin, Dave Kulis, and Erich Horgan. Mark St. Pierre help design and machine the custom parts for the respirometry system.

Finally, I would like to give my deepest thanks to the people at the Environmental Systems Lab at WHOI who helped me along every step of the way in this project: Philip Alatalo and Andy Girard. And thanks are due to Ben Morgan (Llennoco, Inc., Chatham, MA) for providing me with rotifers and much rotifer culturing advice.

This research was funded by grants from the Ocean Life Institute, the Coastal Ocean Institute, the Rinehart Coastal Research Center, and the Cecil H. and Ida M. Green Technology and Innovation Program. Funding was also provided by ONR project N000149610684 and NSF award OCE-9632606 to Scott Gallager. This work would not have been possible without the support of the MIT/WHOI Joint Program Education Office. 


\section{Chapter 1: Integrating Bioenergetics and Foraging Behavior: The Physiological Ecology of Larval Cod (Gadus morhua)}

\section{Introduction}

A population's growth or decline may be best understood by studying the effects of a dynamic environment on its early life stages. Before recruitment into the adult population a larva will grow orders of magnitude in size and pass through several different ecological positions, each with its own selection pressures (Werner \& Gilliam 1984). The conditions experienced during the larval period may have a greater influence on the size and distribution of a population than conditions experienced during the whole of the adult period. Recruitment into marine fish populations is notoriously variable, but the available evidence supports the conclusion that year-class strength is determined by survival through the larval and pelagic postlarval period (Leggett \& DeBlois 1994, Serchuk et al. 1994). Hjort (1914) hypothesized that fish populations are regulated during a brief "critical period" when survival depends on the concentration of prey when larvae must begin to feed. Cushing $(1972,1990)$ suggested more generally that recruitment is regulated by the "match or mismatch" in the timing of seasonal plankton productivity and peak larval abundance. More recently, Houde (1987) demonstrated that variability in recruitment strength can be accounted for by subtle changes in growth and development rate and small variations in mortality over the whole of the larval period. The implication is that understanding population variability will require a sophisticated knowledge of the bioenergetic strategy of larval fish and their behavioral response to a changing environment.

The chances for survival to recruitment are improved when larval fish can maximize their growth rate. Larger larvae are less vulnerable to predation because they are better able to escape predators (Bailey \& Houde 1989), and larger larvae are themselves better 
predators because their search capacity and capture success rate is greater (Hunt von Herbing \& Gallager 2000). The bioenergetic strategy of larval fish is therefore dominated by the need for rapid growth. Activity plays a dual role; successful foraging activity provides the fuel to feed the total metabolic demand including growth, but activity itself also demands energy. However, there is evidence that the costs of both growth and activity are high while the overall aerobic scope to meet all energy demands is very narrow (Wieser et al. 1988). The energy demanding processes of growth and activity may be in conflict.

Accurate measurements of the cost of swimming and accurate descriptions of foraging behavior under variable conditions are necessary for modeling potential energy gain through prey capture rates as well as foraging-related energy expenditures. This research measures the energetic cost of swimming activity and studies the foraging behavior of larval cod, Gadus morhua, under two prey density conditions. The information learned from both sets of studies are used to answer three questions fundamental to our understanding of the survival of fish larvae in a dynamic environment:

Is the cost of activity a substantial and variable component of larval cod's total bioenergetic budget?

Do larvae change their foraging behavior in response to changing foraging conditions, in this case prey density?

If larvae do modify foraging behavior under different prey density conditions; when foraging conditions are poor, how do they compromise between increasing foraging activity to maximize prey encounter rates and reducing activity to conserve energy?

Fish larvae live in a hydrodynamic environment where frictional forces acting against motion are much more important than for juvenile or adult fish (Müller et al. 2000). The cost of swimming is much higher for larvae than would be expected by extrapolating 
allometric cost of transport models for adult and juvenile fish down to larval sizes (Dabrowski 1986b, Kaufmann 1990). The smallest larvae spend most of their time in the viscous flow regime (low $\mathrm{Re}$ ). In this environment viscous forces stop forward motion once larvae stop swimming; high-speed bursts of continuous anguiliform motion is the most efficient swimming strategy (Hunter 1972, Weihs 1980, reviewed by Hunter 1981, Batty 1984). As larvae grow, they enter the intermediate Reynolds number regime $(20<\operatorname{Re}<200)$ and can briefly overcome viscous forces; a quick tail beat allows larvae to benefit from the ensuing glide (Weihs 1980). This style of beat-and-glide swimming is the most efficient and dominant swimming strategy for feeding larvae (Vlymen 1974, Weihs 1980, Videler \& Weihs 1982, Webb \& Weihs 1986).

Isolating activity metabolism from all other metabolic demands is difficult in larval fish. Precise theoretical estimates of swimming costs from hydrodynamic analyses are difficult (Vlymen 1974). The assumptions of hydrodynamic models to calculate thrust and resistance forces acting on swimming fish limit solutions to roughly an order of magnitude level of precision (Webb 1988). Activity metabolism may be isolated empirically by simultaneously monitoring swimming activity and respiration to establish a power-performance relationship (the metabolic rate as a function of swimming speed) and calculate the mass-specific cost of transport. Studies of freshwater larval corregonids and cyprinids by Dabrowski (1986a, 1986b), Kaufmann (1990), Kaufmann and Wieser (1992), and studies of larval cod by Hunt von Herbing and Boutilier (1996) are the only studies to date that have established specific power-performance relations for energy demand as a function of larval swimming intensity.

A simple, sealed respirometry system was developed for this research that allowed the measurement of swimming activity and metabolism of individual larvae. Oxygen concentration was measured using newly developed fiber-optical optode technology (Wang et al. 1999). The cost of swimming was measured and modeled as a powerperformance relationship (energy expenditure as a function of swimming speed, $\mathrm{J} \cdot \mathrm{mg}^{-1} \cdot \mathrm{h}^{-1}$ ) and as the cost of transport (the cost to travel a given distance, $\mathrm{J} \cdot \mathrm{m}^{-1} \cdot \mathrm{mg}^{-1}$ ). The results are consistent with hydrodynamic theory; larval cod swim more efficiently as they 
grow larger and become better able to overcome forces of drag. The cost of transport is high; activity can use a significant but variable proportion of the routine aerobic scope. The results also show that voluntary 'routine' activity is variable for a given size of larva and that the activity level defined as routine should be explicitly described in metabolic studies.

This research is presented in chapter 2 of this dissertation, "The Cost of Swimming for Larval Cod."

Larval cod use a saltatory foraging strategy (unpublished data cited in Browman \& O'Brien 1992, MacKenzie \& Kiørboe 1995, Munk 1995). Saltatory predators travel in short, discrete bursts that serve to position larvae within a new water-parcel. They search for prey only during the periods between swimming bursts (Evans \& O'Brien 1988, Hunt von Herbing \& Gallager 2000). Cruise predators such as larval herring, on the other hand, swim and search for prey continuously (Rosenthal \& Hempel 1970). A saltatory foraging strategy conveys several advantages to larval fish over a cruise foraging strategy. There is an energetic advantage; saltatory, or burst-and-glide, swimming is the most efficient swimming strategy for foraging larvae (Vlymen 1974, Weihs 1980 , Videler \& Weihs 1982, Webb \& Weihs 1986). It provides a more stable visual field; searching for prey during rests or slow glides avoids degradation of visual acuity and perceptive distance as speed increases (Anderson et al. 1997). Saltatory foraging is flexible; both the burst and the pause phases can be modified to suit foraging conditions (O'Brien et al. 1989, O'Brien et al. 1990).

The search phase of the saltatory foraging cycle is more important in terms of time and energetic cost than the pursuit and capture of prey (Drost \& van den Boogaart 1986). A quantitative description of the key components of the search cycle is necessary for estimating the amount of food energy available to larvae in the ocean because, in addition to prey density, foraging strategy directly affects predator-prey contact rates. The goals of this research were: first, to observe the foraging behavior of larval cod in large volumes to reduce confinement effects; second, to observe behavior throughout early development (from 5 to 45 days post-hatch); third, to measure the foraging capacity of 
larval cod (volume searched per unit time); and fourth, to observe if and how larval cod modify their foraging effort in response to different foraging conditions, in this case prey density.

A large-volume observation tank system was developed for this study. Although still an artificial system, the use of a large cylindrical tank $(1.5 \mathrm{~m}$ tall by $0.5 \mathrm{~m}$ diameter $)$ should greatly reduce confinement effects on behavior. Larval activity was recorded using stereo-paired video cameras. This allowed observing individual larvae swimming throughout the tank in three dimensions. Tracking larval positions on a series of video images provides not only measurements of the frequency and duration of different behavioral events but also accurate measurements of the distances and swimming speeds involved. Collecting data from a video record also eliminates any error and bias of human response time that could be introduced when quantifying larval behavior by eye in real time.

There are two phases of the saltatory search cycle, the burst that serves to position larvae within a new search-volume and the pause when larvae search for prey. The burst phase may be described by its speed, duration, and distance traveled. The pause phase can be described by its duration and frequency (or search frequency). Six key behavioral parameters were quantified: pause duration, pause frequency, distance traveled between pauses, burst swimming speed, burst duration, and the fraction of time spent swimming. Three prey treatments were used: no prey, rotifer prey at $100 \mathrm{~L}^{-1}$, and nauplii prey at $100 \mathrm{~L}^{-1}$. Burst characteristics did not change under the different prey treatments, but pause duration increased while foraging capacity (volume searched per unit time) and swimming activity decreased when prey were absent. Longer pause durations could reflect a greater time necessary to visually process each search volume when prey were difficult to find. Reduced foraging capacity and swimming activity could be an energyconservation strategy under unfavorable foraging conditions.

This research is presented in chapter 3 of this dissertation, "The Foraging Behavior of Larval Cod." 
Finally, in order to know the true cost of activity metabolism to larval cod in the ocean, activity levels must be measured in natural (or near natural) foraging conditions. Activity within small respirometry chambers cannot be taken as realistic measures of normal behavior. By applying the power-performance model established in the respirometry study to the swimming intensities of freely foraging larvae observed within the large tank of the behavioral study, the importance of activity metabolism in the overall bioenergetic budget of larval cod was estimated. The estimated amount of energy spent on activity is substantial; excluding the metabolic cost of growth, up to $80 \%$ of total routine metabolism is spent on activity.

Accurate measurements of foraging capacity and improved estimates of the importance of activity metabolism within the overall bioenergetic budget can improve trophodynamic models developed for larval cod. A trophodynamic model was developed incorporating this information to estimate the mean prey density required to cover all metabolic demands. The model predicts that small larval cod $(5 \mathrm{~mm})$ can only survive on the mean Georges Bank prey densities in calm or very mildly turbulent conditions. Larger larvae (6 and $7 \mathrm{~mm})$ can survive even at high turbulence levels $\left(\varepsilon=1 \cdot 10^{-5} \mathrm{~m}^{2} \mathrm{~s}^{-3}\right)$.

Alternative pause duration and burst distance strategies were run through the trophodynamic model to investigate the effect that modifying foraging behavior would have on prey encounter rate and net energy gain. The simulation model predicts that when predator-prey contact rates are high, as when prey density is high or mild turbulence enhances prey encounter rates, the greatest net energy gain is realized when pause durations are kept very short. When predator-prey contact rates are low or under conditions when high turbulence interferes with the pursuit and capture of encountered prey, larvae should achieve greater net energy gains by remaining at rest for extended periods (several seconds). The fact that larval cod observed foraging in the absence of prey do not change behavior as much as the simulation model predicts suggests that they use a prey encounter maximization strategy rather than an energy conservation strategy. The observed strategy makes sense for animals foraging in a dynamic and patchy 
environment where chances of encountering high-density prey patches improve as the volume searched increases.

This research is presented in chapter 4 of this dissertation, "The Importance of the Cost of Swimming to the Foraging Behavior and Ecology of Larval Cod." 


\section{References}

Bailey KM, Houde ED (1989) Predation on eggs and larvae of marine fishes and the recruitment problem. Advances in Marine Biology 25:1-83

Batty RS (1984) Development of swimming movements and musculature of larval herring (Clupea harengus). Journal of Experimental Biology 110:217-229

Browman HI, O'Brien WJ (1992) Foraging and prey search behaviour of Golden Shiner (Notemigonus crysoleucas) larvae. Canadian Journal of Fisheries and Aquatic Science 49:813-819

Cushing DH (1990) Plankton production and year-class strength in fish populations: an update of the match/mismatch hypothesis. Advances in Marine Biology 26:249293

Dabrowski KR (1986a) Active metabolism in larval and juvenile fish: ontogenetic changes, effect of water temperature and fasting. Fish Physiology and Biochemistry 1:125-144

Dabrowski KR (1986b) Energy utilization during swimming and cost of locomotion in larval and juvenile fish. Journal of Applied Ichthyology 3:110-117

Drost MR, van den Boogaart JGM (1986) The energetics of feeding strikes in larval carp, Cyprinus carpio. Journal of Fish Biology 29:371-379

Evans BI, O'Brien WJ (1988) A reevaluation of the search cycle of planktivorous Arctic Grayling, Thamallus arcticus. Canadian Journal of Fisheries and Aquatic Science 45:187-192

Hjort J (1914) Fluctuations in the great fisheries of northern Europe viewed in the light of biological research. Rapports et Procès Verbaux des Réunions, Internationale Conseil pour l'Exploration de la Mer 20:1-228

Houde ED (1987) Fish early life dynamics and recruitment variability. In: Hoyt RD (ed) 10th Annual Larval Fish Conference, Miami FL (USA), p 17-29

Hunt von Herbing I, Boutilier RG (1996) Activity and metabolism of larval Atlantic cod (Gadus morhua) from Scotian Shelf and Newfoundland source populations. Marine Biology 124:607-617

Hunt von Herbing I, Gallager SM (2000) Foraging behavior in early Atlantic cod larvae (Gadus morhua) feeding on a protozoan (Balanion sp.) and a copepod nauplius (Pseudodiaptomus sp.). Marine Biology 136:591-602

Hunter JR (1972) Swimming and feeding behavior of larval anchovy Engraulis mordax. Fishery Bulletin 70:821-838

Hunter JR (1981) Feeding ecology and predation of marine fish larvae. In: Lasker R (ed) Marine fish larvae. Washington Sea Grant Program, Seattle, p 32-77 
Kaufmann R (1990) Respiratory cost of swimming in larval and juvenile cyprinids. Journal of Experimental Biology 150:343-366

Kaufmann R, Wieser W (1992) Influence of temperature and ambient oxygen on the swimming energetics of cyprinid larvae and juveniles. Environmental Biology of Fishes 33:87-95

Leggett WC, DeBlois E (1994) Recruitment in marine fishes: is it regulated by starvation and predation in the egg and larval stages? Netherlands Journal of Sea Research 32:119-134

MacKenzie BR, Kiørboe T (1995) Encounter rates and swimming behavior of pausetravel and cruise larval fish predators in calm and turbulent laboratory environments. Limnology and Oceanography 40:1278-1289

Müller UK, Stamhuis EJ, Videler JJ (2000) Hydrodynamics of unsteady fish swimming and the effects of body size: comparing the flow fields of fish larvae and adults. Journal of Experimental Biology 203:193-206

Munk P (1995) Foraging behaviour of larval cod (Gadus morhua) influenced by prey density and hunger. Marine Biology 122:205-212

Nag AC, Nursall JR (1972) Histogenesis of white and red muscle fibers of trunk muscles of a fish Salmo gairdneri. Cytobios 6:227-246

O'Brien WJ, Browman HI, Evans BI (1990) Search strategies of foraging animals. American Scientist 78:152-160

O'Brien WJ, Evans BI, Browman HI (1989) Flexible search tactics and efficient foraging in saltatory searching animals. Oecologia 80:100-110

Rosenthal H, Hempel G (1970) Experimental studies in feeding and food requirements of herring larvae (Clupea harengus L.). In: Steele JH (ed) Marine food webs. University of California Press, Berkeley, p 344-364

Serchuk FM, Grosslein MD, Lough RG, Mountain DG, O'Brien L (1994) Fishery and environmental factors affecting trends and fluctuations in the Georges Bank and Gulf of Maine Atlantic cod stocks: an overview. ICES Marine Science Symposium 198:77-109

Videler JJ, Weihs D (1982) Energetic advantages of burst-and-coast swimming of fish at high speeds. Journal of Experimental Biology 97:169-178

Vlymen WJ, III (1974) Swimming energetics of the larval anchovy, Engraulis mordax. Fishery Bulletin 72:885-899

Wang W, Reimers CE, Wainright SC, Shahriari M, Morris MJ (1999) Applying FiberOptic Sensors for Monitoring Dissolved Oxygen. Sea Technology 3:69-77

Webb PW (1988) Simple physical principles and vertebrate aquatic locomotion. American Zoologist 28:709-725 
Webb PW, Weihs D (1986) Functional locomotor morphology of early life history stages of fishes. Transactions of the American Fisheries Society 115:115-127

Weihs D (1980) Energetic significance of changes in swimming modes during growth of larval anchovy, Engraulis mordax. Fishery Bulletin 77:597-604

Werner EE, Gilliam JF (1984) The ontogenetic niche and species interactions in sizestructured populations. Annual Review of Ecology and Systematics 15:393-425

Wieser W, Forstner H, Medgyesy N, Hinterleitner S (1988) To switch or not to switch: partitioning energy between growth and activity in larval cyprinids (Cyprinidae: Teleostei). Functional Ecology 2:499-507 


\section{Chapter 2: The Cost of Swimming for Larval Cod}

\section{Introduction}

For larval fish, the bioenergetic strategy is dominated by the need for rapid growth and development, but there is evidence that the overall aerobic scope to meet all energy demands is very narrow. In this context, activity plays a dual role. Successful foraging activity provides the fuel to feed total metabolic demand, but activity also demands energy. Small fish larvae live in a hydrodynamic environment where frictional forces acting against motion are much more important than for adult fish, and the cost of swimming is higher for larvae than it is for adults (Müller et al. 2000). The greater the cost of swimming, the more limited will be the viable alternative foraging strategies and the more limited will be the range of environmental conditions where larvae can survive and grow.

Isolating activity metabolism from all other metabolic demands is difficult in larval fish. Larvae live in a transitional hydrodynamic regime; small fish larvae spend most of their time in the viscous regime but propulsive bursts can bring them into the inertial regime (Fuiman \& Webb 1988). Precise theoretical estimates of swimming costs from hydrodynamic analyses are difficult; models require precise morphometric and kinematic data and are only valid for narrowly defined larval size-classes and swimming behaviors (Vlymen 1974). The assumptions of hydrodynamic models to calculate thrust and resistance forces acting on swimming fish limit solutions to roughly an order of magnitude level of precision (Webb 1988).

Activity metabolism may be isolated empirically by simultaneously monitoring swimming activity and respiration to establish a power-performance relationship (the metabolic rate as a function of swimming speed) and calculate the mass-specific cost of transport. Dabrowski (1986a, 1986b), Kaufmann (1990), Kaufmann and Wieser (1992), and Hunt von Herbing and Boutilier (1996) are the few studies to date that have 
established specific power-performance relations for energy demand as a function of larval swimming intensity. Dabrowski (1986a, 1986b) took advantage of the optomotor response in larval whitefish (Coregonus sp.) to induce them to swim at different speeds within a respirometry chamber set against a moving background of vertical black and white bars. Kaufmann (1990) used a sophisticated swimming chamber and flow-through respirometer to induce larval cyprinids (Chalcalburnus chalcoides and Rutilus rutilus) to swim at controlled rates. Hunt von Herbing and Boutilier (1996) monitored the spontaneous swimming activity of larval cod within an extremely small flow-through respirometry chamber. These empirical studies all concluded that the cost of transport is high for larval fish, much higher than for juveniles or adults.

The present study measures the cost of swimming in larval cod (Gadus morhua) from 5 to 45 days after hatching and seeks to answer the questions: Is the cost of swimming a substantial part of the overall bioenergetic budget? How does the cost of swimming change as larvae grow?

A simple, sealed respirometry system was developed that allowed the measurement of swimming activity and metabolism of individual larvae. Oxygen consumption was measured as the change in end-point oxygen concentration from the start to the end of the incubation period. Oxygen concentration was measured using newly developed fiberoptic optode technology (Wang et al. 1999). Spontaneous swimming activity remained fairly constant over the entire incubation period even in the absence of flow to stimulate swimming. Measurements made in the dark and light assured that a range of swimming velocities and associated metabolic rate measurements were available to develop significant power-performance relationships. A concurrently run set of measurements on fed and unfed larvae allowed the measurement of the contribution of specific dynamic action (meal digestion and assimilation) to the total bioenergetic budget.

This study produced the following contributions and conclusions: 1 . The energetic cost of swimming activity for larval cod from 5 to 45 days after hatching was measured and modeled as a function of size and swimming speed. Swimming cost was measured in 
terms of metabolic rate $\left(\mathrm{J} \cdot \mathrm{mg}^{-1} \cdot \mathrm{h}^{-1}\right)$ and cost of transport $\left(\mathrm{J} \cdot \mathrm{m}^{-1} \cdot \mathrm{mg}^{-1}\right)$. 2. Larval cod swim more efficiently as they grow larger. This is likely the result of larvae being better able to overcome forces of drag as they grow and swim out of a low Reynolds number regime.

3 . The level of routine activity observed within the respirometry chambers takes from $29 \%$ to $57 \%$ of the routine aerobic scope. Activity is a significant part of the total bioenergetic budget. Its importance varies greatly with swimming intensity. 4 . The cost of digesting and assimilating a meal (specific dynamic action) is less than the routine aerobic scope and is unlikely to be high enough to limit aerobic swimming activity.

\section{Materials and Methods}

\section{Rearing of larvae}

For this experiment, three separate batches of cod embryos were reared: one batch was obtained from the cod broodstock maintained by the National Marine Fisheries Service in Narrragansett, RI, one batch was obtained from wild Gulf of Maine cod, stripped and fertilized in the lab, and one batch was obtained from the cod broodstock maintained by Memorial University of Newfoundland. Fertilized embryos were transported back to the Woods Hole Oceanographic Institution for rearing. Embryos were held in black, $120 \mathrm{~L}$ barrels. An airstone was suspended in the center of the barrel $\approx 2.5 \mathrm{~cm}$ off the bottom. One-third of the water was changed daily with filtered $(1 \mu \mathrm{m})$, natural seawater (salinity $=32.5 \%$ ) and the bottom siphoned for debris. Lighting was from fluorescent lamps directly above the barrels on an $11 \mathrm{~h}$-on/13h-off cycle. The light intensity within the rearing barrels was $13.3 \mu$ Einsteins $\cdot \mathrm{m}^{-2} \cdot \mathrm{s}^{-1}$ at the surface to $5.2 \mu$ Einsteins $\cdot \mathrm{m}^{-2} \cdot \mathrm{s}^{-1}$ at the bottom (Biospherical Instruments, Inc. model QSP200L4S, San Diego, CA). Embryos were held at approximately $6.25^{\circ} \mathrm{C}$ and hatched about 3 weeks after spawning. Most hatching occurred within 1 day. At the time of hatching, extra care was taken to remove egg debris and several additional water changes were made. Larvae were retained in the same barrels in which they hatched. Beginning on the third day after hatching, larvae were fed rotifers daily, once per day. After three weeks, the larval diet was supplemented with wild caught zooplankton containing copepod 
nauplii. Larvae were maintained for up to 45 days before use in experiments or termination.

Stock growth rates with respect to total length (mm, fig. 2.1) and dry weight (mg) are summarized in table 2.1. Stock growth rates were modeled exponentially and forced through a standardized size at hatch, $4.9 \mathrm{~mm}$ and $0.035 \mathrm{mg}$. The standardized hatch size was selected from the approximate intercept of the non-forced growth curves.

\section{Treatments}

Two experimental treatments were used: activity level and gut fullness. All data on larval activity were obtained through passive observation. In order to ensure that metabolic rates were measured over a wide range of activity levels, experiments were conducted in a completely darkened lab overnight when activity levels were minimal as well as in a lighted lab during the day. Dark experiments were begun at midnight; light experiments were begun in the early afternoon. Dark and light experiments were run on larvae 5 to 45 days old (from all three cohorts).

In order to measure the specific dynamic action in young larval cod, the respiration rates of individuals with full and with empty guts were measured. Individuals with empty guts were removed from their rearing barrel and placed in a vessel free of food 12 to 15 hours prior to each experiment. This provides time sufficient for the digestive tract to be emptied, eliminating specific dynamic action (SDA; the cost of digesting and assimilating food) from the metabolism of that individual. Individuals with full guts were removed from their rearing barrel immediately prior to their use in each experiment. The fasting and feeding treatments were made in both light and dark experiments on young larvae 5 to 19 days old (from the Gulf of Maine and Newfoundland cohorts).

\section{Optical oxygen measurement system}

Oxygen was measured with the FOXY optical system manufactured by Ocean Optics Inc. (Dunedin, FL; www.oceanoptics.com). A blue LED sends light at $475 \mathrm{~nm}$ through a fiber optic cable to the FOXY-R optode. The tip of the optode is coated with a ruthenium 
complex held within a hydrophobic sol-gel matrix. The light emitted by the LED increases the energy-state of the ruthenium complex causing it to fluoresce at $600 \mathrm{~nm}$. The presence of oxygen quenches the fluorescence via a non-radiative transfer of energy to the oxygen molecule (Wang et al. 1999). The fluorescence is inversely proportional to the oxygen concentration. The fluorescent signal is returned along the fiber-optic cable to spectrometer and recorded as fluorescence intensity.

The 2-channel FOXY configuration used in this study consisted of: FOXY-R optodes with silicone overcoat, bifurcated $600 \mu \mathrm{m}$ fiber (FOXY600-VIS/NIR), rack mount dual miniature blue LED source (R-LS-450-2), multi-channel S2000 Spectrometer (MC-20002), detector collection lens for S2000 (L2), grating \#3 (350-1000nm), 200 $\mu$ slit (SLIT200), multi-bandpass detector (OFLV-350-1000), $1 \mathrm{MHz}$ stackable A/D board (ADC1000--USB-S), and OOISensors software (vers. 1.00.08). OOISensors software was configured as follows: photon integration time $=256 \mathrm{~ms}$, sample averaging $=1$, no boxcar smoothing, bandwidth $=25$ pixels, a dark scan was taken every measurement.

The FOXY system was calibrated every third day using a two-point calibration protocol. The zero oxygen point was set by measuring the fluorescence peak of the optode in seawater deoxygenated after vigorous bubbling with extra dry nitrogen. The high oxygen point was set by measuring the fluorescence peak of the optode in oxygen saturated seawater. The seawater was saturated with oxygen by bubbling with air for well over 1 hour. The oxygen concentration of saturated seawater was calculated using the formulae provided by Forstner and Gnaiger (1983) (appendix). Salinity was measured with a refractometer (Bio-marine, Inc.), and current barometric pressure was acquired from the NOAA data buoy BUZM3 (41 $\left.23^{\prime} 48^{\prime \prime} \mathrm{N} 71^{\circ} 02^{\prime} 00^{\prime \prime} \mathrm{W}\right)$. Calibrations were made in the same seawater and at the same temperature as the respirometry experiments $\left(7^{\circ} \mathrm{C}\right)$. Raw fluorescence data was quantitatively related to oxygen concentration under conditions of constant temperature and pressure by the Stern-Volmer equation (Wang et al. 1999):

$$
\mathrm{I}_{\mathrm{o}} / \mathrm{I}=1+\mathrm{K} \cdot\left[\mathrm{O}_{2}\right]
$$


where,

$\left[\mathrm{O}_{2}\right]=$ oxygen concentration $\left(\mu \mathrm{mol} \cdot \mathrm{L}^{-1}\right)$ (the FOXY system measures oxygen partial pressure which is directly proportional to concentration under conditions of constant temperature and pressure)

$\mathrm{I}_{\mathrm{o}}=$ fluorescence intensity at $\left[\mathrm{O}_{2}\right]=0 \mu \mathrm{moles} \cdot \mathrm{L}^{-1}$

$\mathrm{I}=$ fluorescence intensity in oxygen saturated seawater

$\mathrm{K}=$ Stern-Volmer constant.

The value of the Stern-Volmer constant $(\mathrm{K})$ and $\mathrm{I}_{\mathrm{o}}$ (fluorescence intensity at zero oxygen) were measured during system calibration every third day over which experiments were run (fig. 2.2). $\mathrm{K}$ is dependent upon the chemical composition of the ruthenium complex and upon temperature; it varies between probes and changes slowly as probes age. The value of $I_{o}$ is dependent upon the transmissivity of optical system and is sensitive to bending of the fiber-optic cables and stresses upon the optical junctions. The initial oxygen concentration measured at the start of each experiment was set to the theoretical oxygen saturation concentration by adjusting $I_{o}$, refining the calibration for each experiment:

$$
\mathrm{I}_{\mathrm{o}}=\left(1+\mathrm{K} \cdot\left[\mathrm{O}_{2 \text { saturation }}\right]\right) \cdot \mathrm{I}
$$

where

$I=$ measured fluorescence intensity at the start of an experiment

$\left[\mathrm{O}_{2 \text { saturation }}\right]=$ the theoretical oxygen saturation concentration $\left(\mu \mathrm{mol} \cdot \mathrm{L}^{-1}\right)$.

\section{Respirometry chambers and measurement cells}

Sealed respirometry chambers were constructed specifically for this research (fig. 2.3). A $10 \mathrm{~cm}$ long glass tube $(1 \mathrm{~cm}$ inner-diameter) allowed observation of the swimming activity. The observation tube was threaded at both ends; one end was sealed with a Teflon backed, silicone septa held tightly with a phenolic compression cap, the other was sealed with the water sampling assembly. The water sampling assembly was constructed as follows: a custom machined nylon adapter fit within one opening of the observation 
chamber and was held in place with a nylon compression cap. An air-tight seal was maintained with a viton o-ring. Standard HPLC fittings constructed of oxygen impermeable polyetheretherketone (PEEK) made up the rest of the assembly. 1/8" PEEK tubing joined the nylon adapter to a male luer adapter. The tubing was firmly mounted with VacuTight ${ }^{\mathrm{TM}}$ nuts and ferrules (Upchurch Scientific, Oak Harbor, WA). The whole chamber was sealed with a female luer which had its central thru-hole sealed with epoxy.

The total volume was approximately $6.5 \mathrm{ml}$ for all chambers. The volume of each chamber was measured to the nearest $0.01 \mathrm{ml}$ by the weight difference between the empty chamber and the chamber filled with distilled water.

The oxygen measurement assembly was constructed from standard PEEK HPLC fittings as follows: the optode was mounted with nut and ferrule fittings (Upchurch Scientific) which are in turn threaded into the top port of a tee assembly (the thru-hole was widened to accommodate the $1 / 16$ " diameter optode). The optode tip extends into the center of the flow path of the other two tee assembly ports. Two such assemblies are mounted in parallel to return duplicate readings of each sample. Respirometry chambers are easily attached to the oxygen measurement assembly via luer adapters. The whole oxygen measurement assembly is mounted to a plexiglass base to minimize motion and flexing at the fiber-optic cable connections.

At the end of an experiment, the water sample is drawn out of the respirometry chamber and across the optode tip with a syringe attached to the opposite end of the oxygen measurement assembly. This configuration of respirometry chamber and oxygen measurement assembly is very convenient to use and minimizes exposure of the chamber environment to the outside environment before an oxygen measurement is taken.

The respirometry chambers were tested for leaks, and the oxygen diffusion rate across the chamber walls was measured. Each chamber was filled with $\mathrm{N}_{2}$-purged deoxygenated seawater, sealed, and incubated within an oxygen-saturated $7^{\circ} \mathrm{C}$ water bath. After 18 hours, there was no measurable oxygen diffusion into the system. 


\section{Experimental protocol}

Respirometry chambers were flushed clean with tap water followed by autoclaved seawater prior to each experiment. After a series of five experiments, the chambers were rinsed with $95 \%$ ethanol, distilled water, and then autoclaved seawater. The chambers were placed in $9 \mathrm{~L}$ of temperature-adjusted $\left(7^{\circ} \mathrm{C}\right)$ autoclaved seawater. The seawater was oxygen saturated by vigorous bubbling with air for at least 30 minutes prior to being sealed. Extreme care was taken to purge each chamber of air bubbles and visually confirm the absence of bubbles prior to being sealed. Each experiment typically used seven chambers. Three chambers were loaded with one fasted individual each, two with one fed individual each, and two chambers were used as controls with no fish.

The loaded chambers and controls were placed into a $7^{\circ} \mathrm{C}$ water bath. A Haake heating circulator (model DL30), fitted with an antagonistic chilled water-cooling coil, was used to maintain a constant temperature $\left( \pm 0.02^{\circ} \mathrm{C}\right)$ during the incubation period and to maintain the FOXY optode at the same temperature. The chambers remained sealed for 350 to 650 minutes. At the end of the experiment, the chamber was attached to the measurement cell, and the seawater within the respirometry chamber was drawn with a syringe into the cell. The initial oxygen concentration within the chambers was measured from a control chamber that was temperature-equilibrated for one-half hour within the water bath at the start of the experiment.

The oxygen concentration of each chamber was measured every 1.6 seconds for a 10 minute period. Raw data from the FOXY optode was recorded as light intensity at the $600 \mathrm{~nm}$ fluorescence peak. Oxygen concentration is calculated from the median fluorescence intensity over a 2 minute period after the system has stabilized. The point at which the system stabilized for every sample injection and for both of the two optodes was determined by eye (fig. 2.4). The system stabilizes 80 seconds after a sample injection (see results).

The oxygen consumption rate $\left(\mu \mathrm{mole} \mathrm{O}_{2} \cdot \mathrm{h}^{-1} \cdot \operatorname{larva}^{-1}\right)$ was calculated as the difference in the oxygen consumption rate of each respirometry chamber minus the oxygen consumption rate in the blank chamber. Oxygen consumption rates were normalized by 
dry weight to determine the weight-specific metabolic rate $\left(\mu\right.$ mole $\left.\mathrm{O}_{2} \cdot \mathrm{ml}^{-1} \cdot \mathrm{mg}^{-1}\right)$. The metabolic rate of each larva was then converted to its energy equivalent in Joules using a generalized oxycaloric equivalent of $1 \mu$ mole $\mathrm{O}_{2}=0.450 \mathrm{~J}$ (Gnaiger 1983).

\section{Activity level measurement}

The activity of each larva was quantified in five minutes blocks throughout the 6-hour incubation period for a total of fifteen minutes per larva. A video camera (PULNiX model TM-7EX with zoom lens set at $28 \mathrm{~mm}$ ) was oriented two feet above the respirometry cells. The cells were lit from below by an infra-red diode array. The light was dispersed by a fresnel lens to provide an even, 6 inch diameter light field. The use of an infra-red light source allowed observation in dark conditions without stimulating swimming activity. Swimming activity over the duration of each respirometry experiment was recorded on SVHS videotape. The analog video record was digitized as a wavelet file by an Integral Technologies video frame-grabber card (running Integral Technologies software XVCR vers. 1.5 and XMUX vers. 1.2) installed in a desktop computer. Individual frames were extracted from the wavelet file as bitmap files using custom software.

Matlab (The MathWorks 1998) routines were written to process the bitmap files. The position of each larva at the point on the head between the eyes was recorded manually every 2 seconds of each five minute observation block. From data on larval position over time, swimming speed $\left(\mathrm{mm} \cdot \mathrm{s}^{-1}\right)$ was measured. The mean activity level of all 5-minute observation blocks was used to infer the overall mean activity level of the entire 6-hour experimental period.

\section{Post-experiment sample handling}

Length and weight data was collected from each larva after every experiment. A video camera with a macro-lens provided focused images of a back-lit larvae within a field of view $20 \mathrm{~mm}$ in diameter. Video images were saved as TIFF files, and the total length of each larva was measured to the nearest $0.1 \mathrm{~mm}$ using NIH Image vers. 1.62. 
Larvae were living when imaged. Larvae were then placed in TRIS buffer, frozen in liquid nitrogen, and stored at $-70^{\circ} \mathrm{C}$. To obtain dry weights, individual larvae were thawed, rinsed in chilled distilled water, refrozen, and freeze-dried for 8 to 12 hours (Labconco Freeze Dryer 5). Dry weights were measured to the nearest $\mu \mathrm{g}$ on the same day larvae were removed from the freeze-dryer (Cahn microbalance, model C-33). Reweighing of a sub-sample showed that the freeze-drying process was complete. 
Figure 2.1. Total length of each stock as a function of age. Stock code letters are as defined in table 2.1. Error bars represent \pm 1 standard deviation.

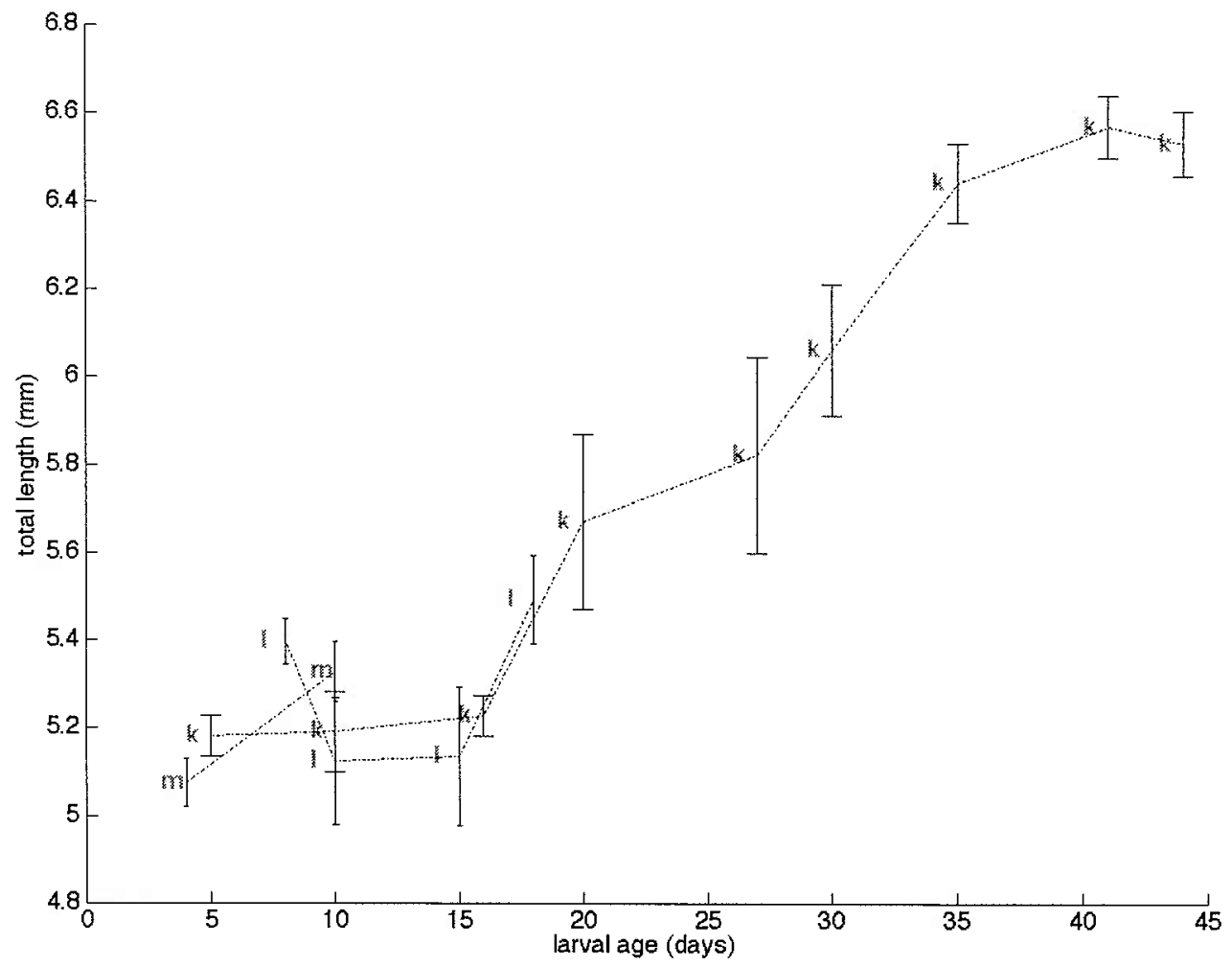


Table 2.1. Larval cod stock growth rates with respect to total length (mm, fig. 2.1) and dry weight (mg). Stock growth rates were modeled exponentially and forced through a standardized size at hatch selected from the approximate average intercept of non-forced growth curves $(4.9 \mathrm{~mm}$ and $0.035 \mathrm{mg})$. Stock names are given as identifier code letter, brood-stock source, and hatch date.

\begin{tabular}{|rlcc|}
\hline & & $\begin{array}{c}\text { growth in length } \\
\mathbf{l}_{\text {age }}=\mathbf{4 . 9} \cdot \mathbf{e}^{\text {rage) }} \\
\mathbf{r}\end{array}$ & $\begin{array}{c}\text { growth in weight } \\
\mathbf{W}_{\text {age }}=\mathbf{0 . 0 3 5} \cdot \mathbf{e}^{\text {rage) }} \\
\mathbf{r}\end{array}$ \\
\hline $\mathrm{k}$ & Rhode Island $(3 / 24 / 03)$ & 0.0069 & 0.0612 \\
1 & Memorial University $(5 / 11 / 03)$ & 0.0063 & 0.0894 \\
$\mathrm{~m}$ & Gulf of Maine $(5 / 26 / 03)$ & 0.0065 & 0.0957 \\
\hline
\end{tabular}


Figure 2.2. The two-point calibration curves for both optodes (master and slave) of the FOXY oxygen measurement system used in this research (equation 1 ). $\mathrm{I}_{\mathrm{o}}=$ fluorescence intensity at $\left[\mathrm{O}_{2}\right]=0 \mu$ moles $\cdot \mathrm{L}^{-1}, \mathrm{I}=$ fluorescence intensity in oxygen saturated seawater, and the slope of the line is the Stern-Volmer constant $(\mathrm{K})$.

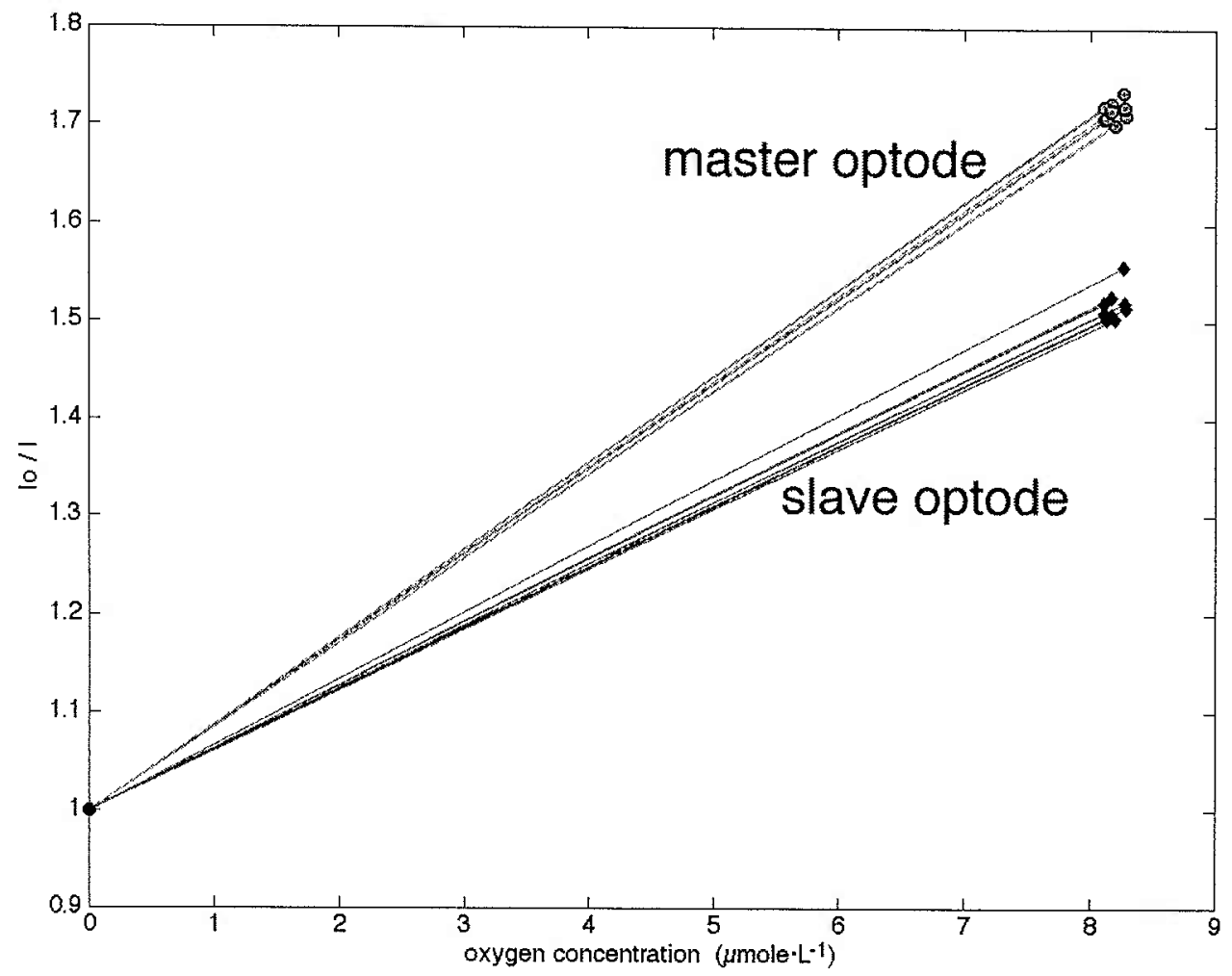


Figure 2.3. Respirometry chamber. Each chamber was either loaded with a single larva, sealed, and incubated for approx. 6h. At the end of an experiment, the respirometry chamber is fit onto the oxygen measurement assembly.via luer fittings. A water sample was drawn out of the chamber and across the optode tip with a syringe attached to the opposite end of the oxygen measurement assembly. Most parts are standard HPLC fittings. (PEEK = polyetheretherketone.)

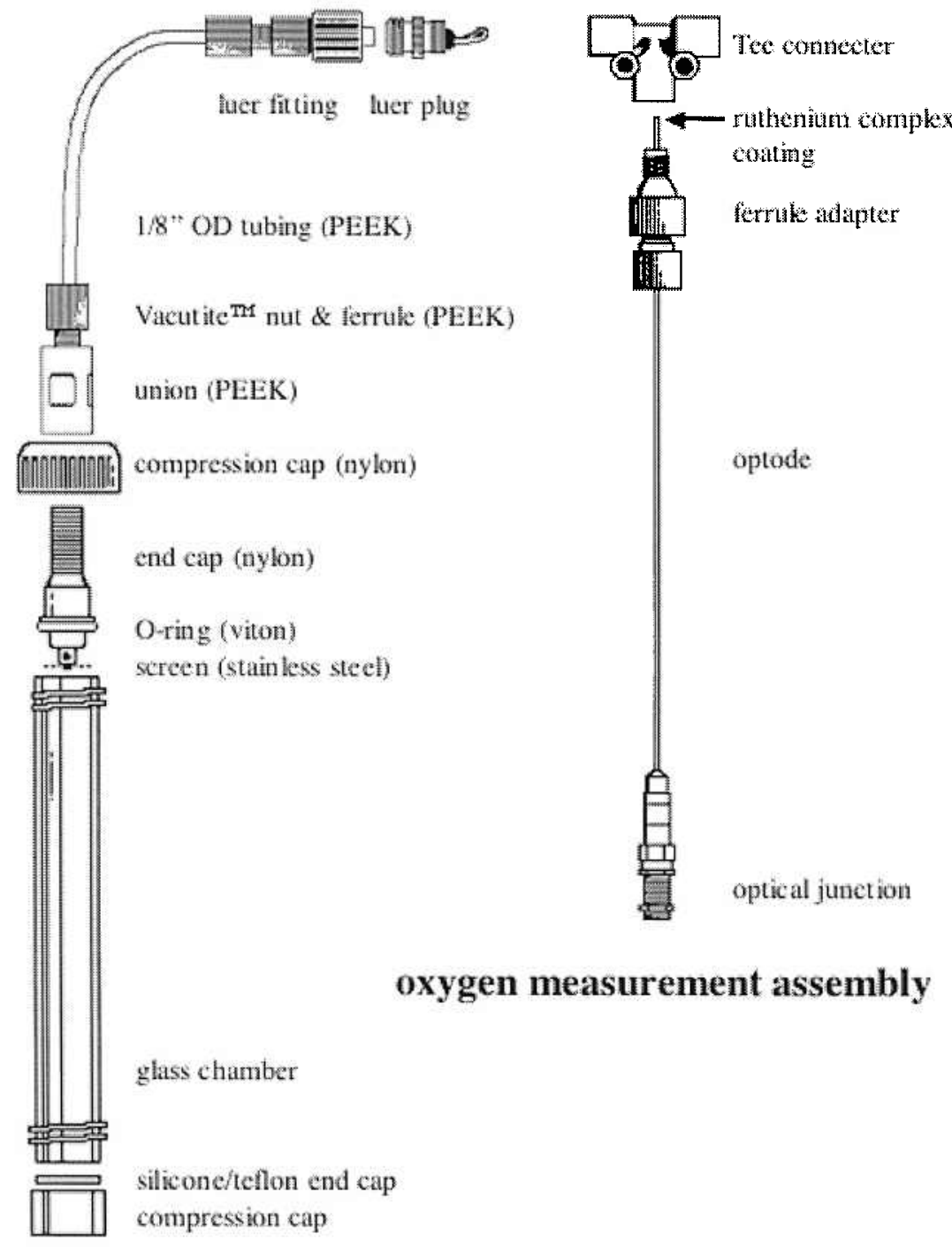

respirometry chamber 
Figure 2.4. Raw data obtained from the FOXY optical oxygen measurement system. This trace is for one of the forty individual experiments conducted in this study. It shows data from paired optodes for 2 blanks and 4 larvae.
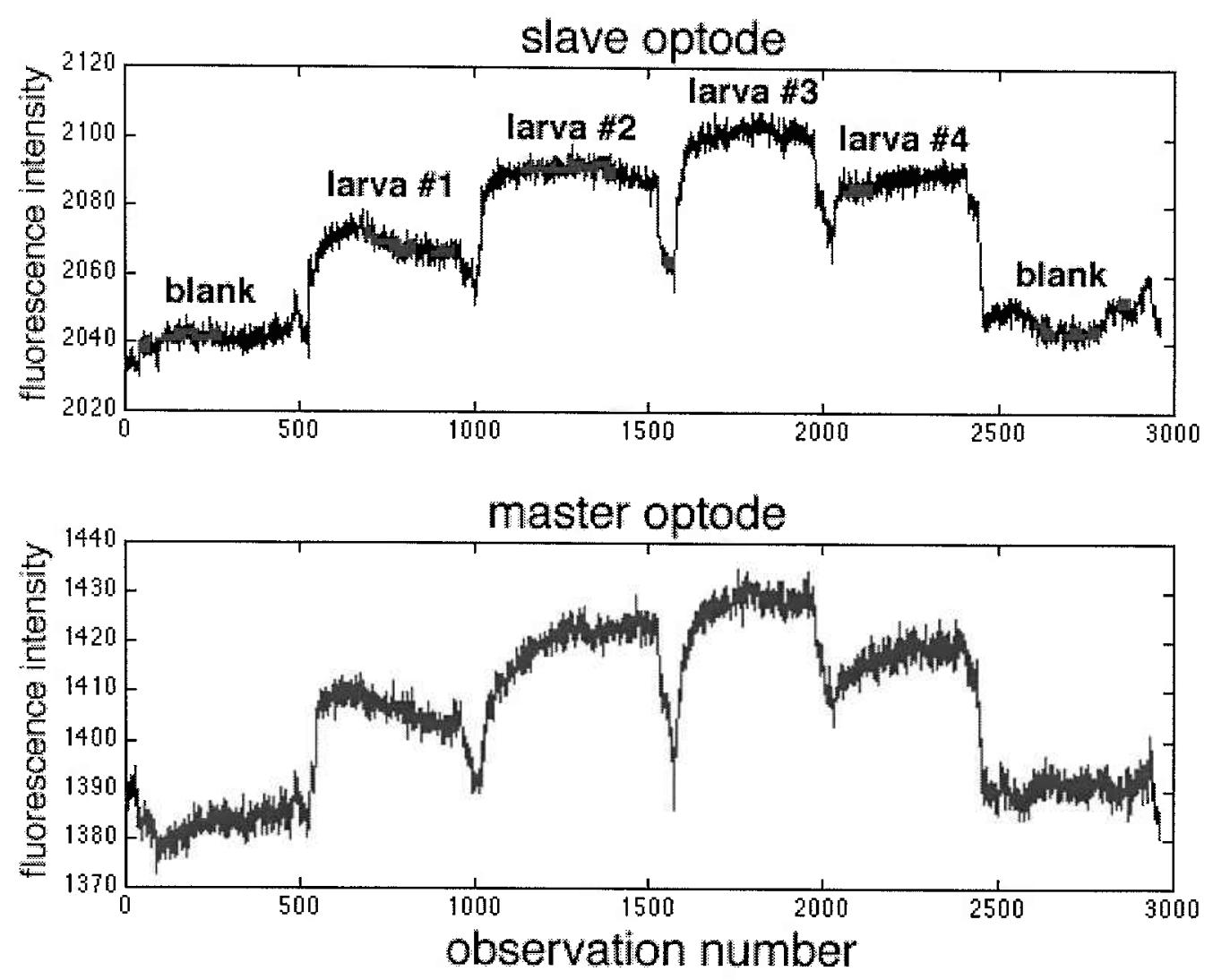


\section{$\underline{\text { Results }}$}

\section{FOXY stabilization time}

The time required for the optode to stabilize after the injection of a fresh sample was determined from the fluorescence profiles recorded during optode calibrations. The time taken from the start of the sample injection to the point at which the fluorescence intensity stabilizes was measured for 40 injections. The stabilization of fluorescence intensity was judged by eye. Mean stabilization time was 76.66 seconds ( $s t d=42.48$; $n=40)$.

\section{Activity}

Larvae within the sealed respirometry chambers remained active over the entire experimental period. Figure 2.5 shows the swimming speed profile of an individual larva during one five-minute observation block. Larval swimming behavior in the lighted experiments was characterized as alternating periods of rest and bursts of swimming activity. Larvae remained active in the dark, but their activity was significantly reduced compared to activity in lighted experiments (t-test, $\mathrm{P}<<\underline{0.0001}$, $\mathrm{df}=105$, data were normally distributed after log-transformation) (fig. 2.6).

The feeding treatment had no effect on activity level. A comparison of the mean swimming speed of fasted and fed larvae, 5 to 19 days old, in lighted experiments shows no significant difference in the activity level (t-test, $P=0.3144$, $d f=79$, data were normally distributed after log-transformation).

\section{Activity metabolism (power-performance relationship)}

The measured weight-specific total metabolic rate increased linearly and significantly with larval swimming speed (fig. 2.7). The relationship between total metabolic rate and activity level for each larval group are described with a linear least-squares regression. In each case, graphical analyses of standardized residuals show that the assumptions of a linear-regression are met (i.e., homogeneous variance and normal distribution of the 
dependent variable). The relationships between total metabolic rate and swimming speed are highly significant for both the young larvae (5-19 days old) and the older larvae (3445 days old) and for both the fasted and fed larvae (table 2.2).

\section{Effect of age, size, and speed}

The power-performance relationship between total metabolic rate and swimming speed does not remain constant as larvae grow (fig. 2.7). An ANCOVA comparison (Kleinbaum et al. 1998) was made between the two size classes of fasted larvae: small larvae 5 to 19 days old (median weight $=0.043 \mathrm{mg}$ ) and larger larvae 34 to 45 days old (median weight $=0.120 \mathrm{mg}$ ). The power-performance relation for the large larvae has a significantly lower slope $\left(\mathrm{F}_{1,112}=18.9779, \mathrm{P}<<\underline{0.0001}\right)$ and lower intercept $\left(\mathrm{F}_{1,112}=\right.$ $59.4978, \mathrm{P}<<\underline{0.0001}$ ) than the relation for the small larvae (table 2.3; the assumptions of normality and homoscedasticity are met). This shows that both the weight-specific basal metabolic rate and the cost of swimming activity are lower for larger larvae. A multiple regression model was then fit to the data with total metabolic rate as the dependent variable and dry weight and swimming speed as the independent variables. The best fit to the data was established by a 4-term model with a linear relationship between metabolism and swimming speed and a power-relationship between metabolism and dry weight (table 2.2 middle).

The total metabolic rate may be plotted against weight in the combined 5 to 45 day old data set to show that the total metabolic rate declines allometrically as larvae grow (fig. 2.8). The data were divided into two speed classes: 0.0 to $2.0 \mathrm{~m} \cdot \mathrm{h}^{-1}$ and 2.0 to $9.0 \mathrm{~m} \cdot \mathrm{h}^{-1}$ (table 2.4 top). An ANCOVA comparison of the two speed classes shows that the faster swimming larvae spent significantly more energy than the more slowly swimming larvae across the full size range of larvae studied (equal slopes, $F_{1,112}=0.3083$, $\mathrm{P}=0.5799$; equal elevations, $\mathrm{F}_{1,112}=19.4603, \mathrm{P}<<\underline{0.0001}$; table 2.5).

The total metabolic rate $\left(\mathrm{J} \cdot \mathrm{mg}^{-1} \cdot \mathrm{h}^{-1}\right)$ includes both basal metabolism and the added cost of swimming. Isolating the cost of swimming activity from the total metabolic rate requires knowledge of the basal metabolic rate and how the basal rate changes as larvae 
grow. The metabolic rate of fasted larvae observed in the dark, when swimming activity is at its lowest, may be taken as an approximation of the basal metabolic rate (fig. 2.9, table 2.2 bottom). This rate is not the true basal rate because it still includes a small activity component, but it is the closest direct measurement of basal metabolism possible without introducing unintended side-effects with the use of anaesthetics. Basal metabolism may also be indirectly estimated by extrapolating the power-performance relationship to zero activity; this estimate is shown in figure 2.9 against the dark experiment measurements.

The activity metabolism was calculated for every individual by subtracting the estimated basal metabolic rate. Only unfed larvae were included in the analysis in order to eliminate the contribution of food assimilation and growth costs to the total metabolism. An allometric model was fit to the relation between activity metabolism and dry weight (fig. 2.10 , table 2.4 middle) (individuals with negative active metabolic rates were excluded from analysis before log-transformation). An ANCOVA comparison of two speed classes $\left(0.0\right.$ to $2.0 \mathrm{~m} \cdot \mathrm{h}^{-1}$ and 2.0 to $\left.9.0 \mathrm{~m} \cdot \mathrm{h}^{-1}\right)$ shows that faster swimming larvae spent significantly more energy on swimming than slower larvae across the full size range of larvae studied (equal slopes, $\mathrm{F}_{1,91}=0.9565, \mathrm{P}=0.3307$; equal elevations, $\mathrm{F}_{1,91}=$ $16.7938, \mathrm{P}=\underline{0.0001}$; table 2.5). The net cost of transport (COT) is the net energy required for a larva to travel a given distance $\left(\mathrm{J} \cdot \mathrm{mg}^{-1} \cdot \mathrm{m}^{-1}\right)$. The cost of transport for each individual larva was calculated as its active metabolic rate normalized by its mean swimming speed. An allometric model was again fit to the relation between activity metabolism and COT (fig. 2.11, table 2.4 bottom). The COT declined rapidly as larvae grew and swam more efficiently but did not change with swimming speed (ANCOVA: equal slopes, $F_{1,91}=0.2781, P=0.5992$; equal elevations, $F_{1,91}=0.2768, P=0.6001$; table 2.5).

\section{Specific Dynamic Action}

A comparison of the fed and fasted larval groups (5 to 19 days old) can reveal important information about the cost of specific dynamic action (SDA). The intercept of 
the power-performance relation represents the metabolic rate of larvae at rest. In the fasted larvae, where assimilation of food within the gut is completed, this is the basal metabolic rate. In the recently fed larvae, the intercept is the basal metabolic rate plus the cost of breaking down and assimilating the meal (fig. 2.12). The intercept of the fed group is significantly higher than the fasted group while the slopes, which reflect how energy dissipation rate increases with activity, are not significantly different (ANCOVA: equal slopes, $F_{1,119}=0.4114, P=0.5225$; equal elevations, $F_{1,119}=8.9472, P=\underline{0.0034}$; table 2.5). For these cod larvae, the basal metabolic rate is therefore $0.033 \mathrm{~J} \cdot \mathrm{mg}^{-1} \cdot \mathbf{h}^{-1}$ $( \pm 0.013)$, and the cost of SDA is $0.021 \mathrm{~J} \cdot \mathrm{mg}^{-1} \cdot \mathbf{h}^{-1}$. 
Figure 2.5. The swimming speed profile $\left(\mathrm{mm} \cdot \mathrm{s}^{-1}\right)$ of an individual larva during one 5minute observation block (6.4mm total length, 43 days-old).

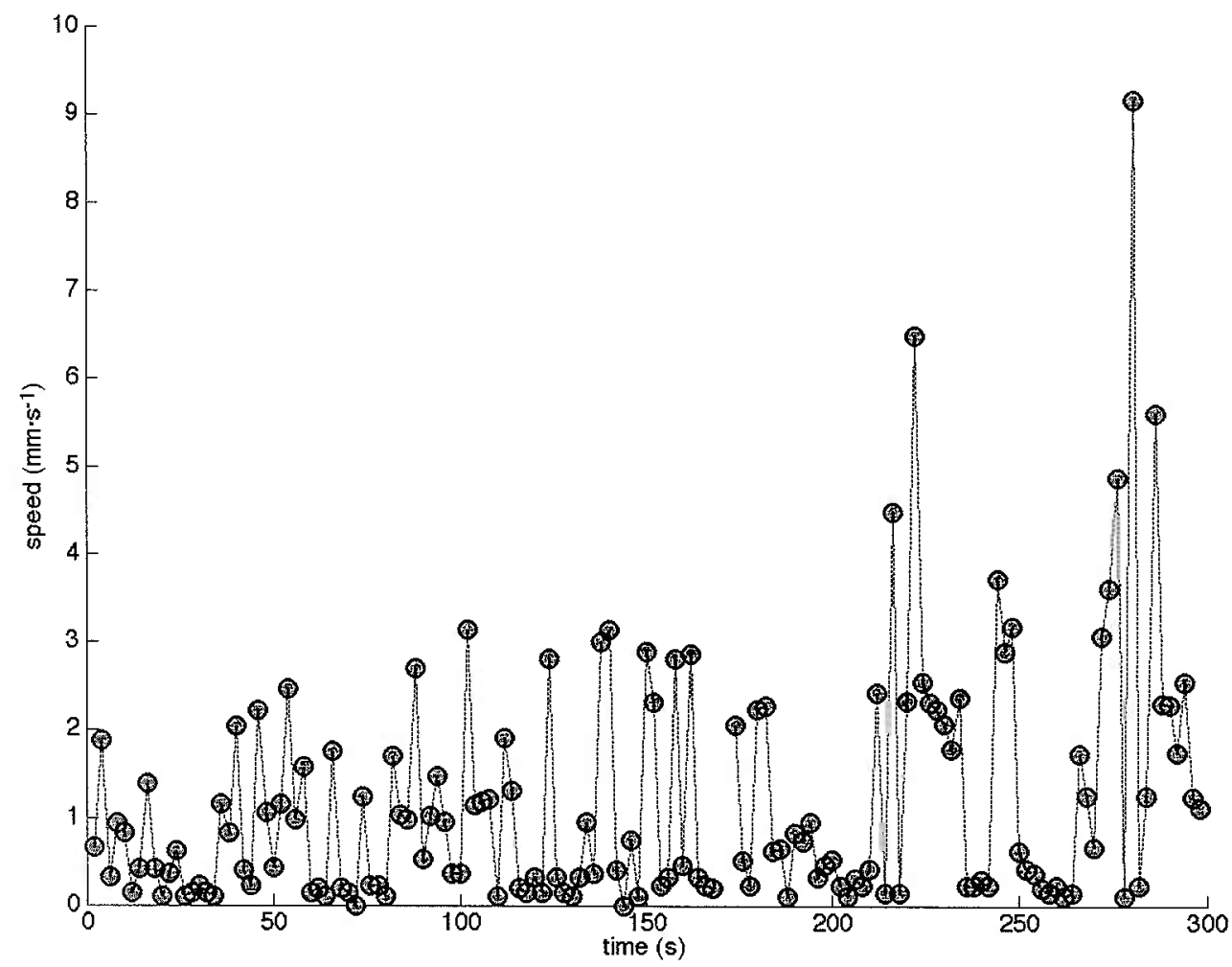


Figure 2.6. Mean individual swimming speeds $\left(\mathrm{m} \cdot \mathrm{h}^{-1}\right)$ in dark and illuminated experiments. ('+' symbols denote outliers more extreme than 1.5 times the inter-quartile range).

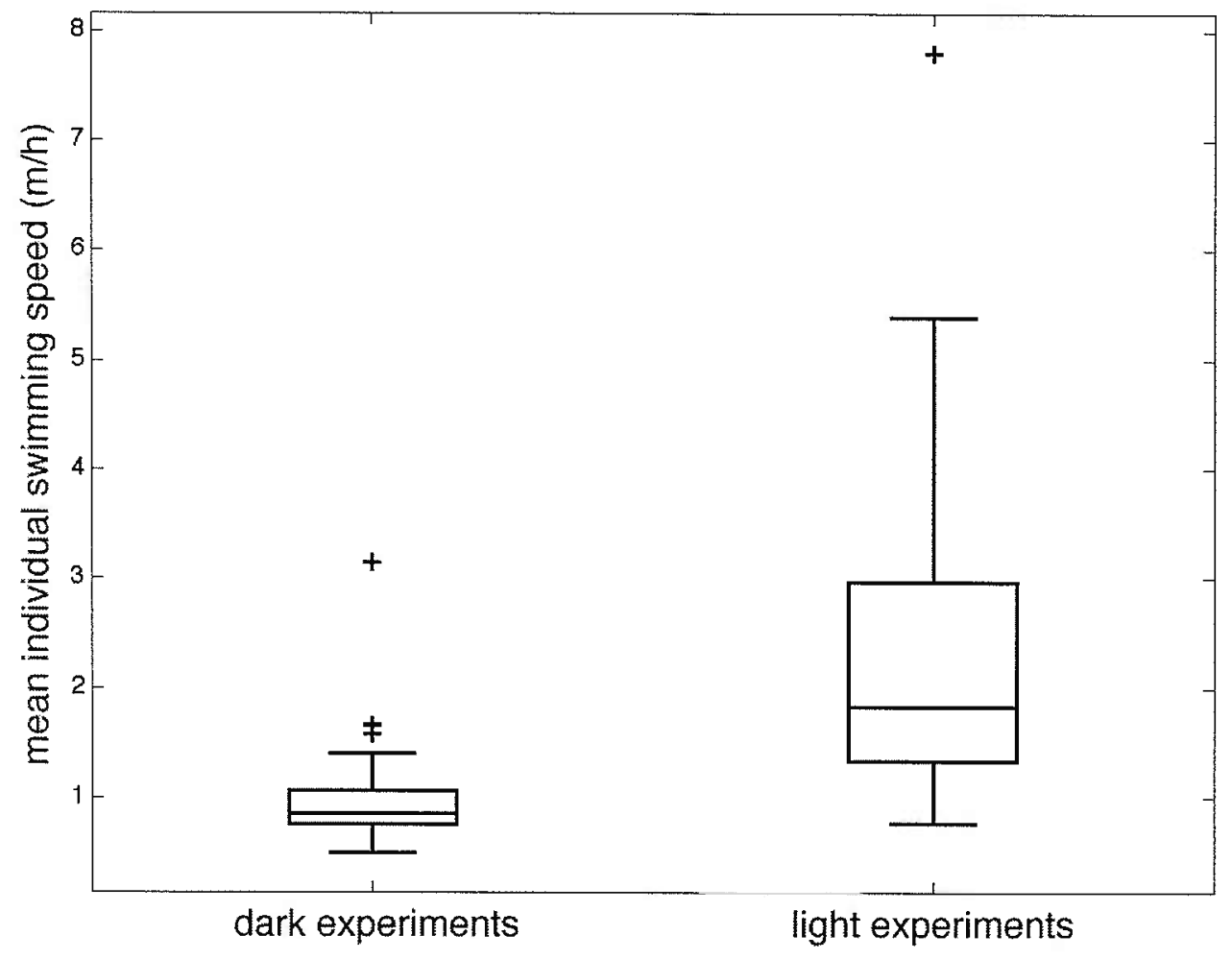


Figure 2.7. Power-performance relationship between total metabolic rate and individual mean swimming speed; fasted larvae 5-19 days old and fasted larvae 34-45 days old. Regressions are shown with their $95 \%$ confidence intervals.

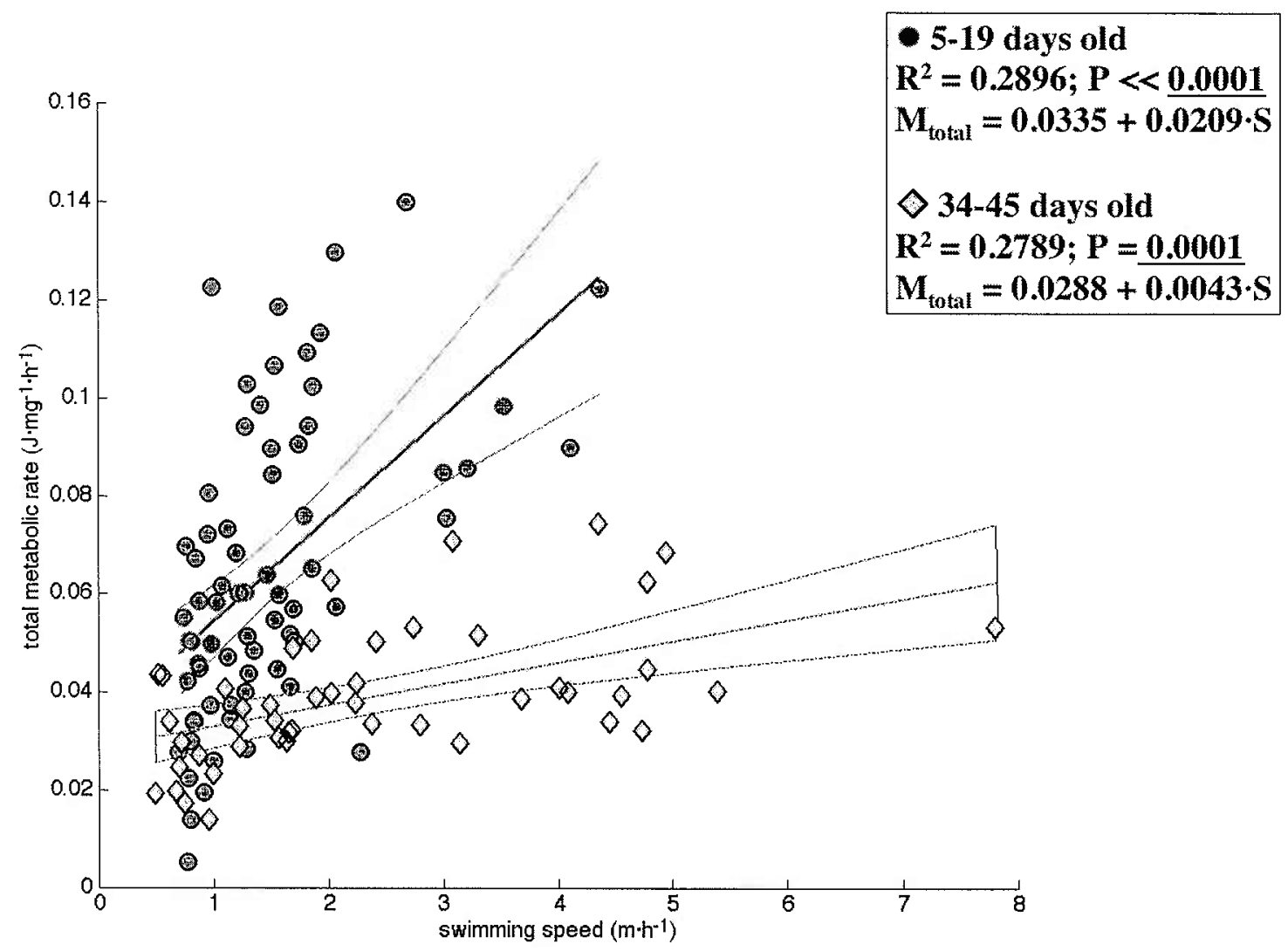



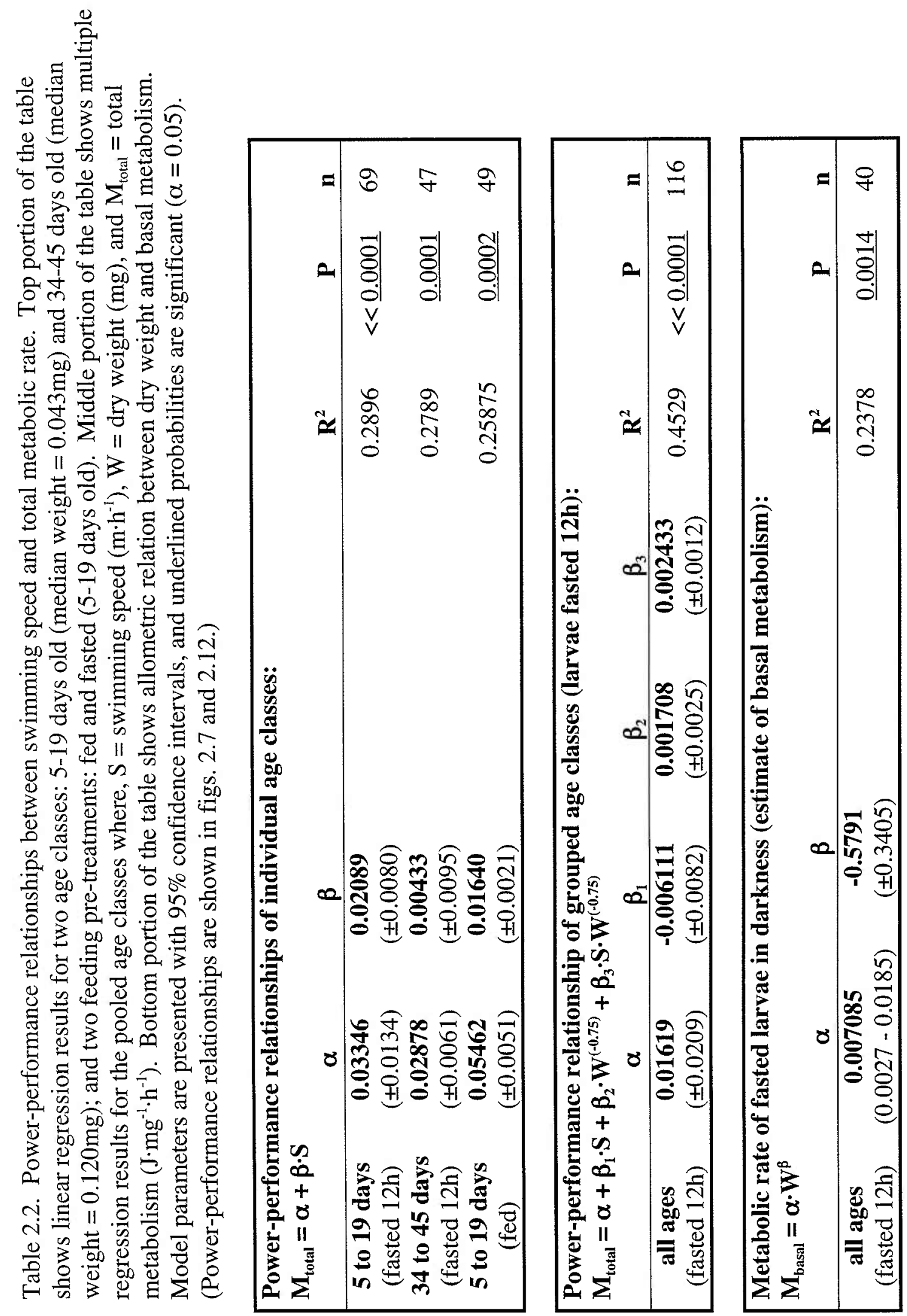


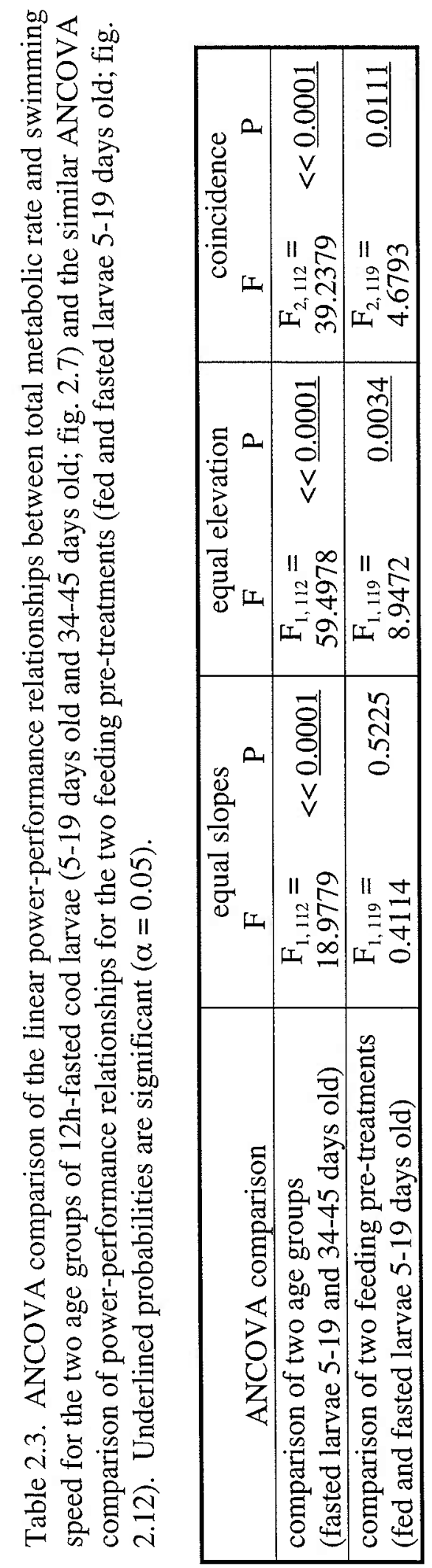




\section{Discussion}

The respirometry system developed and used here was designed to measure the metabolic rates of individual cod larvae 5 to 45 days post-hatch, and it allowed the simultaneous measurement of swimming activity. The treatments, fasted and fed, high activity levels in the light, and minimal activity levels in the dark, allowed the isolation and measurement of each of the three major components of the metabolic budget: basal metabolism, activity metabolism, and specific dynamic action. Activity metabolism was measured in general as a proportion of the entire bioenergetic budget and in detail as cost of transport function, i.e., What is the energetic cost of swimming a given distance and how does that cost change as larvae grow and as swimming speed increases?

Basal metabolism is the minimum observable metabolic rate; it is the energy spent by a non-feeding, resting individual (Fry 1971, Brett 1972). Basal metabolic costs include protein turnover for maintenance and repair, maintaining hydrostatic balance, and active ion transport to maintain trans-membrane ionic gradients. Two estimates of basal metabolism were made in this study. Interpolating to a level of zero activity using the power-performance relationships derived for both size classes (the metabolic rate as a function of swimming speed, top of table 2.2) the basal metabolic rate is estimated as $0.033 \mathrm{~J} \cdot \mathrm{mg}^{-1} \cdot \mathrm{h}^{-1}( \pm 0.013)$ for larvae 5 to 19 days old and $0.029 \mathrm{~J} \cdot \mathrm{mg}^{-1} \cdot \mathrm{h}^{-1}( \pm 0.006)$ for larvae 35 to 45 days old. Alternatively, the energy dissipation rate measured at minimal activity levels (the dark experiments) may be used as an estimate of basal activity, and many studies use this as a pragmatic definition (Rombough 1988). The estimated basal rate still includes a small activity component because activity in the darkness is not zero. In the present study, data from the dark experiments show that the weight-specific basal metabolic rate declines allometrically as larvae grow from $0.045 \mathrm{~J} \cdot \mathrm{mg}^{-1} \cdot \mathrm{h}^{-1}$ at 5 days (mean weight $=0.041 \mathrm{mg}$ ) to $0.025 \mathrm{~J} \cdot \mathrm{mg}^{-1} \cdot \mathrm{h}^{-1}$ at 40 days (mean weight $=0.115 \mathrm{mg}$ ) (fig. 2.9) .

How do these results compare to the work of others? Solberg and Tilseth (1984) and Finn et al. (1995) measured the basal rates of 5-day old cod larvae in the dark. Converting their results to units of $\mathrm{J} \cdot \mathrm{mg}^{-1} \cdot \mathrm{h}^{-1}$ and using $0.041 \mathrm{mg}$ as the mean dry-weight 
of a 5-day old larva (present study), they measure 0.041 to $0.044 \mathrm{~J} \cdot \mathrm{mg}^{-1} \cdot \mathrm{h}^{-1}$ and $0.053 \mathrm{~J} \cdot \mathrm{mg}^{-1} \cdot \mathrm{h}^{-1}$ as the basal metabolic rate of a 5-day old larva (Solberg and Tilseth and Finn et al., respectively). This is comparable to the value of $0.045 \mathrm{~J} \cdot \mathrm{mg}^{-1} \cdot \mathrm{h}^{-1}$ measured in present study. Hunt von Herbing and Boutilier (1996) interpolated their powerperformance model to zero activity and found basal metabolic rates range from 0.017 to $0.029 \mathrm{~J} \cdot \mathrm{mg}^{-1} \cdot \mathrm{h}^{-1}$ (Newfoundland and Scotian Shelf populations, respectively; 1 to 40 days old, measured at $10^{\circ} \mathrm{C}$ ). This range is lower than the basal rate of 0.029 to $0.033 \mathrm{~J} \cdot \mathrm{mg}^{-1} \cdot \mathrm{h}^{-1}$ found by similar interpolation of identically aged larvae in the present study (though measured here at $7^{\circ} \mathrm{C}$ ). Differences with respect to the Hunt von Herbing and Boutilier study will be addressed below.

Specific dynamic action (SDA) is the cost of biochemically processing food. SDA includes both catabolic processes, deamination of proteins and breakdown of fats and carbohydrates (Beamish 1974), and anabolic processes, protein synthesis and conversion of fatty acids and carbohydrates into storage products (Jobling 1981, 1983, Kiørboe et al. 1987, Torres et al. 1996). The costs of mechanical digestion and absorption are separate but not easily isolated from SDA; the term apparent SDA is used to reflect this (Beamish 1974).

The specific dynamic action was found by comparing the metabolic rates of freshly fed larvae to larvae held in the absence of food for 12 hours (fig. 2.12). For fish 5 to 19 days old the cost of SDA is $0.021 \mathrm{~J} \cdot \mathrm{mg}^{-1} \cdot \mathrm{h}^{-1}$. This value is useful as an index of the relative magnitude of SDA in the total bioenergetic budget. A limitation of this study is that the actual gut fullness of the fasted and fed larvae is unknown. The larvae may not be fed to satiation, however the amount of food within their gut should be typical of a larvae feeding freely for 12 hours in a prey-rich environment. Additionally, this value is based upon a diet of rotifers, which are not their prey in the ocean. In juvenile cod, SDA can raise the metabolic rate of a resting individual substantially above the basal rate and leave little aerobic scope to accommodate activity (Soofiani \& Hawkins 1982). The data here shows that SDA at this level of feeding in larval cod does not raise metabolism greatly 
above the basal rate (SDA $\approx 60 \%$ basal) and no decline in activity level was seen in the fed larvae compared to the unfed. 
Figure 2.8. The relationship between total metabolism $\left(\mathrm{M}_{\text {total }}\right)$ and dry weight for cod larvae 4 to 45 days old. Larvae were fasted $12 \mathrm{~h}$ to reduce the contribution of specific dynamic action to total metabolism. Data is divided into two swimming speed classes: 0 to $2.0 \mathrm{~m} \cdot \mathrm{h}^{-1}$ and 2.0 to $9.0 \mathrm{~m} \cdot \mathrm{h}^{-1}$. Allometric models were fit to $\log$-transformed data. (Regression parameters are presented in table 2.4.)

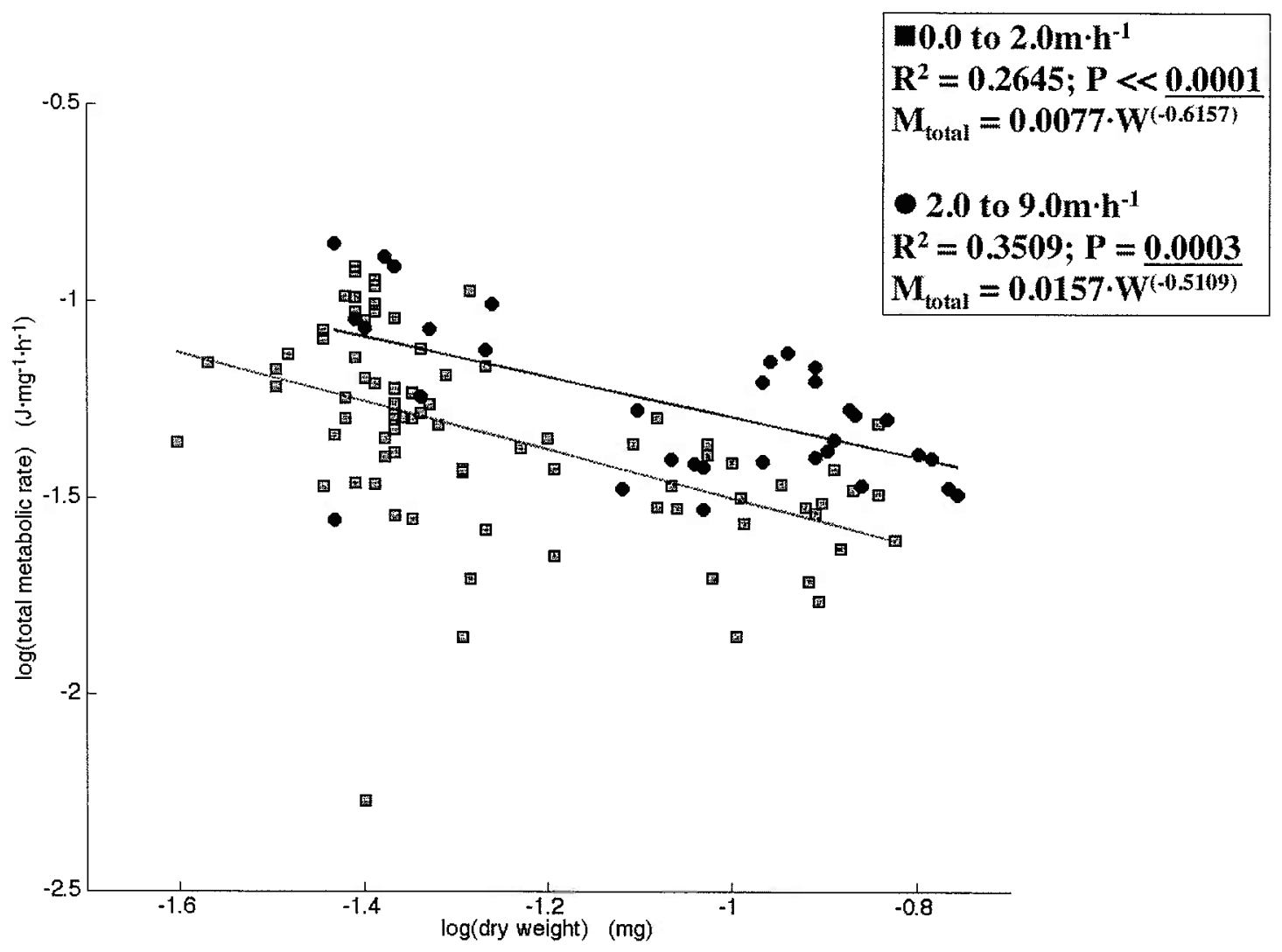


Figure 2.9. The basal metabolic rate $\left(\mathrm{M}_{\text {basal }}\right)$ as estimated from the oxygen consumption rates measured in the darkened experiment set. Larvae were 5 to 45 days old and fasted $12 \mathrm{~h}$ to reduce the contribution of specific dynamic action to total metabolism. An allometric model was fit to log-transformed data. Also shown is the basal metabolic rate estimated from interpolating the multi-parameter power-performance relationship (table 2.2 middle) at swimming speed $(\mathrm{S})=0$.

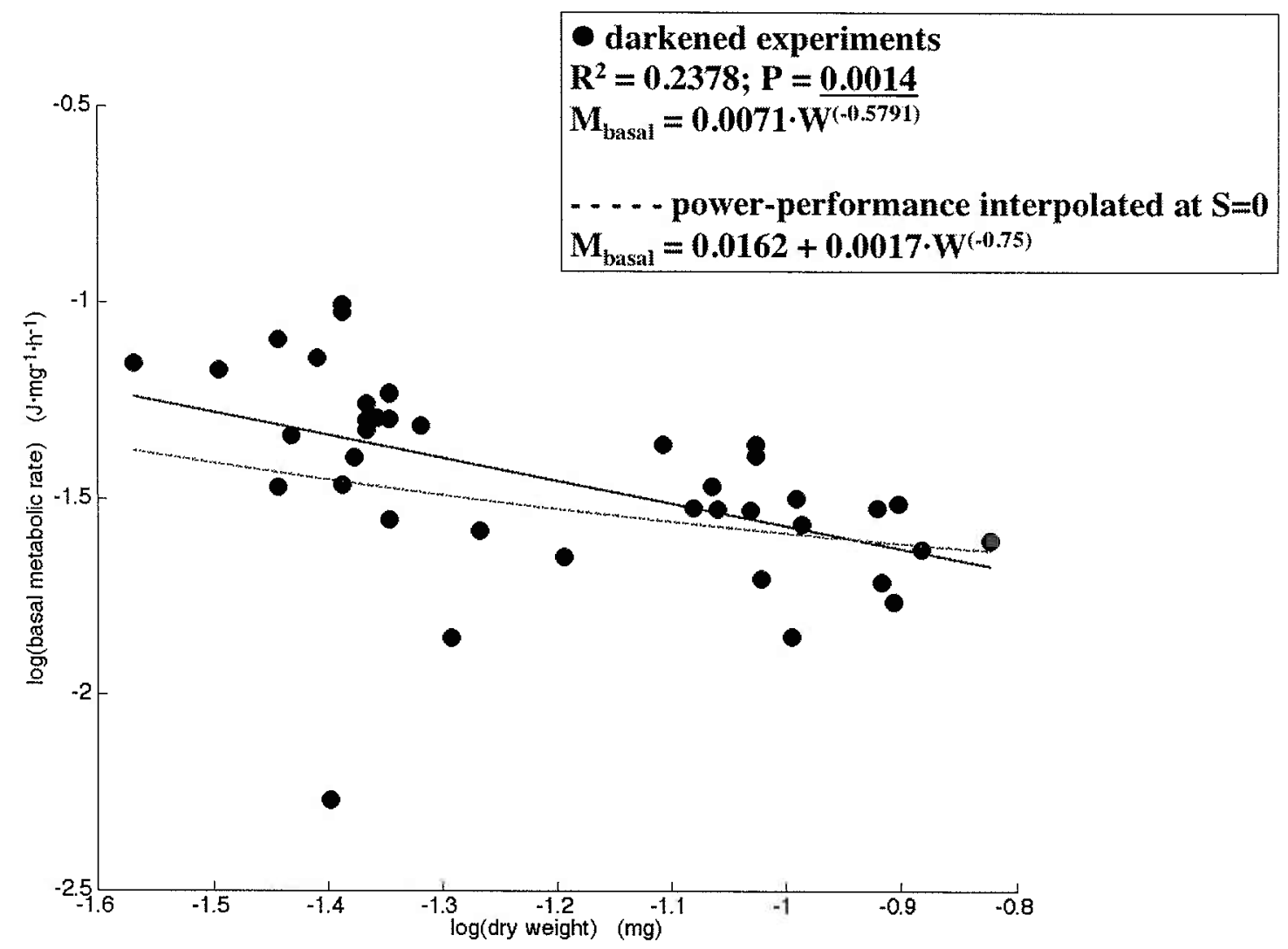


Figure 2.10. The net cost of swimming activity $\left(\mathrm{M}_{\text {activity }}\right)$ for larvae 5 to 45 days old divided into two speed classes: 0 to $2.0 \mathrm{~m} \cdot \mathrm{h}^{-1}$ and 2.0 to $9.0 \mathrm{~m} \cdot \mathrm{h}^{-1}$. Larvae were fasted $12 \mathrm{~h}$ to reduce the contribution of specific dynamic action to total metabolism. The net cost of activity was calculated from the total metabolic rate (figure 2.8 , table 2.4 ) minus the basal metabolic rate as estimated from the darkened experiments (figure 2.9, table 2.4). An allometric model was fit to log-transformed data.

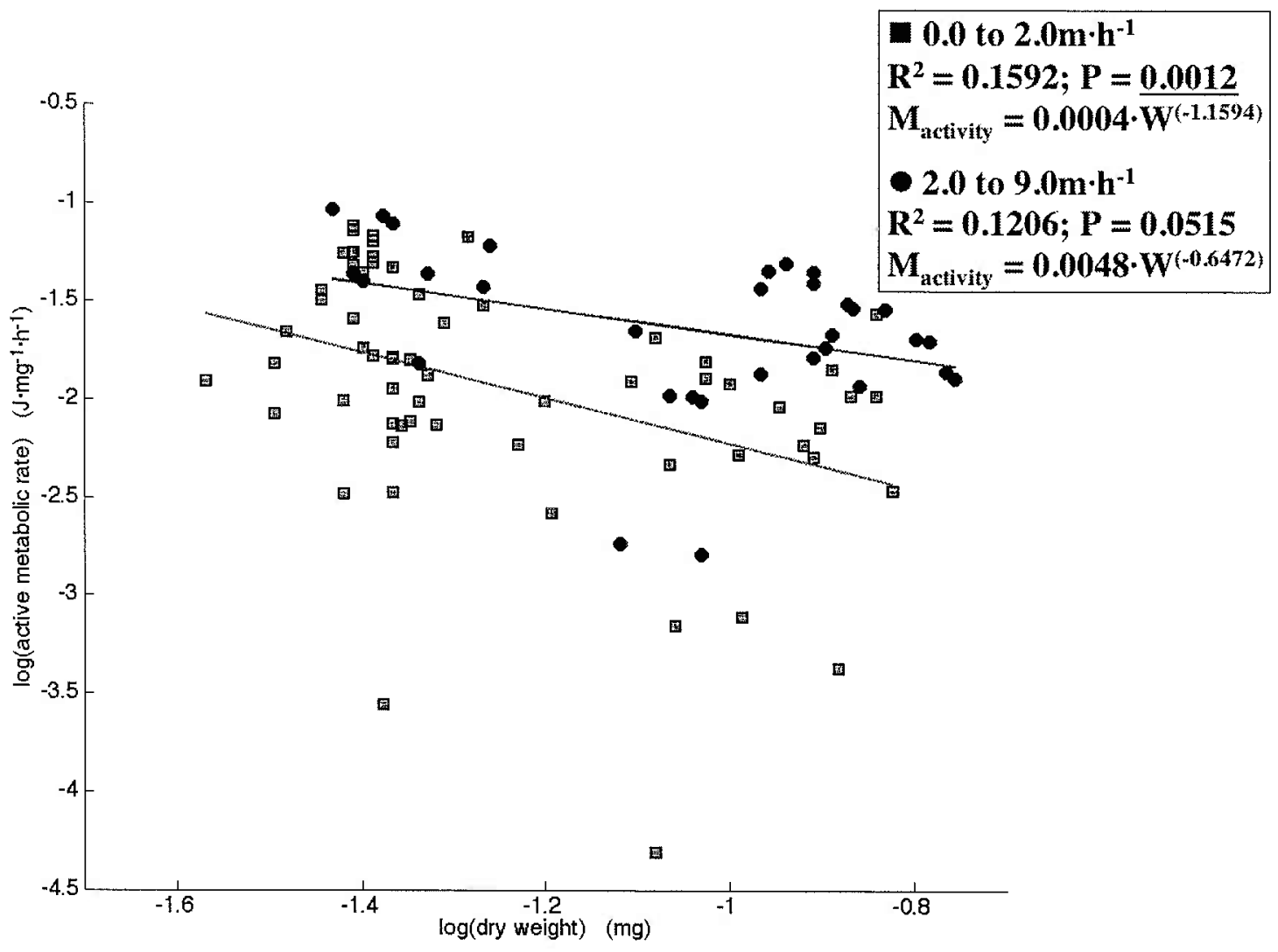


The cost of swimming activity may be expressed as a power-performance relation (total energy spent as a function of swimming speed), the cost of transport (net energy spent to travel a particular distance), or as its contribution to the bioenergetic budget (activity metabolism and routine metabolism). In the present study, power-performance relationships were measured for spontaneously swimming cod larvae and fitted to linear models (fig. 2.7, table 2.2).

Kaufmann (1990) and Dabrowski (1986a, 1986b) use non-linear models to describe the power-performance relationships of larval coregonids and cyprinids showing everincreasing energy expenditure at higher velocities. A non-linear model does not provide a better fit to the data in the present study, and an underlying curvilinear signal may be lost in the noise. There is much less noise in the Kaufmann and Dabrowski studies because they use much larger larvae that are induced to swim at a wide range of selected velocities. A more precise power-performance model for larval cod must await more sensitive and more rapidly responsive oxygen-measurement technology.

Hunt von Herbing and Boutilier (1996) developed linear power-performance models for two genetically discrete populations of larval cod from hatching to 40 days old (reared at $5^{\circ} \mathrm{C}$, measured at $10^{\circ} \mathrm{C}$ ):

(3) Gross activity cost $\left(\mathrm{J} \cdot \mathrm{mg}^{-1} \cdot \mathrm{h}^{-1}\right)=0.0290+0.0232 \cdot \mathrm{speed}\left(\mathrm{m} \cdot \mathrm{h}^{-1}\right)$ Scotian Shelf

(4) Gross activity cost $\left(\mathrm{J} \cdot \mathrm{mg}^{-1} \cdot \mathrm{h}^{-1}\right)=0.0169+0.0119 \cdot$ speed $\left(\mathrm{m} \cdot \mathrm{h}^{-1}\right)$ Newfoundland

The gross activity cost is basal metabolism plus the added net cost of transport (COT). These power-performance models were converted to the same units as the models developed in the present study (presented below) so that they may be directly compared:

(5) Gross activity cost $\left(\mathrm{J} \cdot \mathrm{mg}^{-1} \cdot \mathrm{h}^{-1}\right)=0.0335+0.0209 \cdot$ speed $\left(\mathrm{m} \cdot \mathrm{h}^{-1}\right) 5$ to 19 days old

(6) Gross activity cost $\left(\mathrm{J} \cdot \mathrm{mg}^{-1} \cdot \mathrm{h}^{-1}\right)=0.0288+0.0043 \cdot$ speed $\left(\mathrm{m} \cdot \mathrm{h}^{-1}\right) 35$ to 45 days old 
The slope of the power-performance relation is an index of the cost of activity. The cost of activity measured in the present study for larvae 5 to 19 days old is comparable to that measured by Hunt von Herbing and Boutilier for larvae 0 to 40 days old. However, the cost of activity measured in the present study for older larvae ( 35 to 45 days old) is much less than measured by Hunt von Herbing and Boutilier for either of their stocks. Several factors could account for this difference: oxygen diffusion into the respirometry chambers used in the present study, errors in dry weight measurement, differences in the method of measuring swimming speed, or bias in oxygen measurements in either study. The oxygen diffusion rate is linearly related to the concentration gradient across the chamber walls (Fick's Law). Higher respiration rates (i.e., those of the more active individuals) would be more underestimated relative to lower respiration rates; this would lower the apparent cost of activity, especially for larger, more active larvae. However, oxygen diffusion into the respirometry chambers was too small to be detectable. Biased measurement of swimming activity in either study is unlikely to be the cause of the different power-performance models; the mean swimming speed ranges are the same in both studies for similarly sized larvae. Errors in dry weight measurements would have a large effect on weight-specific respiration rates. Hunt von Herbing and Boutilier do not report the weight range of the larvae they used. In the present study, repetition of the lyophilization process confirmed that larvae were completely dried before weighing. Also, use of Laurence's length-weight regression for larval cod (Laurence 1979) in place of the measured weights does not substantially change the gross cost of activity. Low sensitivity to small changes in oxygen concentration could bias the Hunt von Herbing and Boutilier model to overestimate the cost of activity. Circumstantial evidence for such a bias are the low estimates of basal metabolism that are derived when interpolating their model to zero activity and their inability to detect a relation between activity and metabolism among larvae younger than 14 days old.

The net cost of transport (COT), the net energy spent to swim a particular distance $\left(\mathrm{J} \cdot \mathrm{m}^{-1} \cdot \mathrm{mg}^{-1}\right)$, was calculated for every individual from its active metabolic rate (total 
minus basal metabolic rate) normalized by its mean swimming speed. COT was then modeled as a function of larval size in two swimming speed classes: slow $\left(0.0-2.0 \mathrm{~m} \cdot \mathrm{h}^{-1}\right)$ and fast $\left(2.0-9.0 \mathrm{~m} \cdot \mathrm{h}^{-1}\right)$ (fig. 2.11 , table 2.4 bottom). COT clearly decreases allometrically as larval cod grow larger, but no change in COT could be detected with respect to swimming speed.

Larvae live in a different hydrodynamic regime than juveniles and adults; frictional forces acting against motion are more important and have a large effect on the cost of transport. The Reynolds number (Re) is the ratio of inertial forces to frictional (viscous) forces in a flow moving past a larva's body. Frictional forces are dominant when $\operatorname{Re}<20$, and inertial forces dominate when Re>200 (Webb \& Weihs 1986). The flow field around small swimming larvae (Danio rerio) was observed in detail by Müller et al. (2000), clearly showing the effect of viscous forces on larval swimming. During propulsion, vortices shed at the tail gather in a vortex ring that contains the momentum added to the water during a tail thrust. The vortex ring is quickly consumed by viscous diffusion, increasing drag and adding to the cost of swimming. During a coasting phase vorticity remains high adjacent to the body so that a large volume of water is pulled along with the larva thereby increasing drag.

The smallest larvae spend most of their time in a viscous flow regime (low $\mathrm{Re}$ ). In this environment viscous forces stop forward motion once larvae stop swimming; highspeed bursts of anguiliform motion is the most efficient swimming strategy (Hunter 1972, Weihs 1980, reviewed by Hunter 1981, Batty 1984). These young larvae are living upon yolk-sac energy reserves and easily captured protozoan prey (Gallager et al. 1996b). They are not yet dependent upon their swimming and foraging abilities to acquire food, but burst swimming is important for predator escape and may dissipate an oxygendepleted boundary layer and act as an aid to cutaneous respiration (Hunter 1972).

The flow field around a larva is a function of both swimming speed and larval length. Allometric growth along the longitudinal axis over which thrust is generated allows post yolk-sac larvae to forage in the intermediate and inertial Reynolds regimes without having to swim ever harder to overcome increasingly resistive drag (Webb \& Weihs 
1986, Fuiman \& Webb 1988, Re=70 to 100 for foraging cod larvae Hunt von Herbing \& Gallager 2000). Dabrowski et al. (1986) estimated swimming efficiency in freshwater larvae (Coregonus schinzi palea) as the ratio of theoretical drag power and measured aerobic effort. Theoretical swimming efficiency increases as larvae grow larger and as they swim faster. Results from the present study with larval cod show the same trend with respect to size; COT decreases as larvae grow larger (fig. 2.11). In this intermediate Reynolds number regime, a quick tail beat allows larvae to benefit from inertial forces during the ensuing glide. This style of beat-and-glide swimming is the most efficient and dominant swimming strategy for feeding larvae (Vlymen 1974, Weihs 1980, Videler \& Weihs 1982, Webb \& Weihs 1986). In adults, beat-and-glide swimming can save more than $50 \%$ of the energy that would be spent during continuous swimming (Weihs 1974). However, no change in COT was observed for larval cod swimming at different speeds (fig. 2.11, table 2.5). This result is consistent with a linear power-performance model; the COT must be the same at all swimming speeds for an individual of a given size.

The cost of transport for adult fish of a diverse array of species and swimming styles fall tightly along the same allometric relationship (Schmidt-Nielsen 1972). The COT curves for three larval fish species can be compared directly to the adult curve (fig. 2.13). The significance of swimming within different hydrodynamic regimes is readily apparent. If extrapolated down to larval sizes, the adult model would seriously underestimate COT. Compared to Rutilus (Kaufmann 1990) and Coregonus (Dabrowski 1986b), COT is very high for larval cod. It is interesting to note that the curve for slowly swimming cod larvae falls along the same general line as the curve for the larger, slowly swimming Coregonus larvae.

Without knowledge of the level of swimming activity performed, transport costs tell little about the amount of energy larval fish expend on activity. In many studies, activity metabolism is reported as routine metabolism: the sum of basal metabolism and the metabolic cost of normal levels of spontaneous swimming activity (Beamish \& Mookherjii 1964). The overall importance of activity may then be expressed as the 
routine scope for aerobic activity (the net energy expenditure above basal metabolism) or the routine factorial scope (the ratio of routine metabolism to basal metabolism). The routine scope for aerobic activity is best defined by the net metabolic rate of the individuals in the highest speed class (fig. 2.14) because they define the upper limit of routine activity observed in this study. The routine scope for activity declines as larvae grow from $\approx 0.04$ to $0.02 \mathrm{~J} \cdot \mathrm{mg}^{-1} \cdot \mathrm{h}^{-1}$ ). The routine factorial scope tends to vary from 1.5 to 2.5 in temperate and sub-arctic larval fish (review by Rombough 1988). In the present study, the routine factorial scope of larval cod is seen to depend on the mean swimming speed of the individual. Observed routine factorial scopes are 1.4 (swimming at 0.0 $2.0 \mathrm{~m} \cdot \mathrm{h}^{-1}$ ) and 2.0 (swimming at $2.0-9.0 \mathrm{~m} \cdot \mathrm{h}^{-1}$ ) (fig. 2.14). Therefore, from $29 \%$ to $50 \%$ of the total routine metabolism in larval cod is due to activity, depending upon the routine swimming speed. This points to the need to better define 'routine' activity or precisely define the activity level that is called 'routine' on a study-by-study basis. Also, these activity data obtained from larvae in very unnatural conditions should not be construed to be reflective of the activity levels of larvae in the ocean. They do, however provide a range of activity intensities that along with the concurrent metabolic data can be used to determine the cost of swimming activity in the natural environment.

The importance of activity to the total bioenergetic budget varies greatly between studies. Solberg and Tilseth (1984) calculate a routine factorial scope for cod larvae within the range found here; factorial scope $=1.6$ or $37 \%$ of total routine metabolism is due to activity. Hunt von Herbing and Boutilier's (1996) empirical power-performance model and behavior data show that activity can account for 60 to $67 \%$ of the total routine aerobic metabolism, but this could be an overestimate based on an overly high estimate of the cost of transport. In contrast to the large activity-related expenditures in larval cod, Kaufmann's (1990) study of cyprinid larvae concludes that activity does not play an important role in the energy budget, accounting for only 10-15\% of the total energy budget. Much of this range may be due to temperature effects on muscle efficiency and on the viscosity of water itself, both of which affect the cost of swimming (Hunt von 
Herbing 2002). The relative importance of swimming activity in larval bioenergetic budgets may be latitudinal, and care must be taken when generalizing between studies.

The combined costs of all metabolic demands above basal metabolism (i.e., activity and SDA) must be accommodated within the limits of an individual's aerobic scope. Aerobic scope is the range between the basal metabolic rate and the maximum metabolic rate obtained when swimming at the greatest aerobically sustainable speed (Brett \& Groves 1979, Soofiani \& Priede 1985). The aerobic scope in larval fish is limited by the rate that oxygen is delivered by diffusion to oxidizing tissues and the low mitochondrial capacity of fish in general (Kaufmann 1990, Wieser 1995). The gills and capillary system are not yet formed in most small fish larvae so oxygen reaches the tissues entirely by diffusion across the skin (Rombough 1988). Some larvae have a thin layer of embryonic red muscle immediately under the skin that may act as a respiratory organ (ElFiky et al. 1987). Yet, larval metabolism appears fully aerobic (El-Fiky et al. 1987, Hinterleitner et al. 1989); even at high activity levels, little oxygen debt is incurred (Kaufmann 1990). The mass-specific activities of aerobic metabolism enzymes (e.g., cytochrome oxidase, citrate synthase, and fatty acid catabolism enzymes) are high after hatching and peak around the period of first feeding; the activities of anaerobic metabolism enzymes (e.g., phosphofructokinase and lactate dehydrogenase) are low immediately after hatching and increase slowly as larvae grow (Forstner et al. 1983, ElFiky et al. 1987, Hinterleitner et al. 1989). Larval muscle may differ from adult muscle; the white fibers that make up most of the muscle mass may be powered by aerobic metabolism rather than anaerobic metabolism as in adults (Hinterleitner et al. 1989).

This study was not sufficient to determine the aerobic scope of larval cod because the larvae were not forced to swim up to intensity at which added activity is anaerobic. However, oxygen consumption did not level off at high swimming velocities indicating that the activity observed was still within the aerobic scope for activity (fig. 2.7). The broad routine aerobic scope observed for the smaller larvae and the relatively small cost 
of specific dynamic action (SDA $=0.021 \mathrm{~J} \cdot \mathrm{mg}^{-1} \cdot \mathrm{h}^{-1}$ ) are evidence that behavioral plasticity is not limited by the overall aerobic scope.

\section{Conclusions}

Respirometry methods in the lab such as those used here can successfully measure the energetic cost of swimming activity for small larvae. The results are consistent with hydrodynamic theory; larval cod swim more efficiently as they grow larger. This is the result of larvae being better able to overcome forces of drag as they grow and swim out of a low Reynolds regime. The evidence presented above shows that among larval cod, the cost of transport is high and that activity can use a significant but variable proportion of the routine aerobic scope. The results also show that voluntary 'routine' activity is variable for a given size of larva and that the activity level defined as routine should be explicitly described in metabolic studies. More importantly, in order to know the true cost of activity metabolism to larval cod, activity levels must be measured in natural (or near natural) foraging conditions. Activity within small respirometry chambers or laboratory observation tanks cannot be taken as realistic measures of normal behavior. 
Figure 2.11. The net cost of transport (COT) for larvae 5 to 45 days old divided into two speed classes: 0 to $2.0 \mathrm{~m} \cdot \mathrm{h}^{-1}$ and 2.0 to $9.0 \mathrm{~m} \cdot \mathrm{h}^{-1}$. Larvae were fasted $12 \mathrm{~h}$ to reduce the contribution of specific dynamic action to total metabolism. The cost of transport $\left(\mathrm{J} \cdot \mathrm{m}^{-}\right.$ ${ }^{1} \cdot \mathrm{mg}^{-1}$ ) was calculated from the estimated active metabolic rate (figure 2.10 ) divided by the mean swimming speed observed in each speed class. Allometric models were fit to log-transformed data (table 2.4).

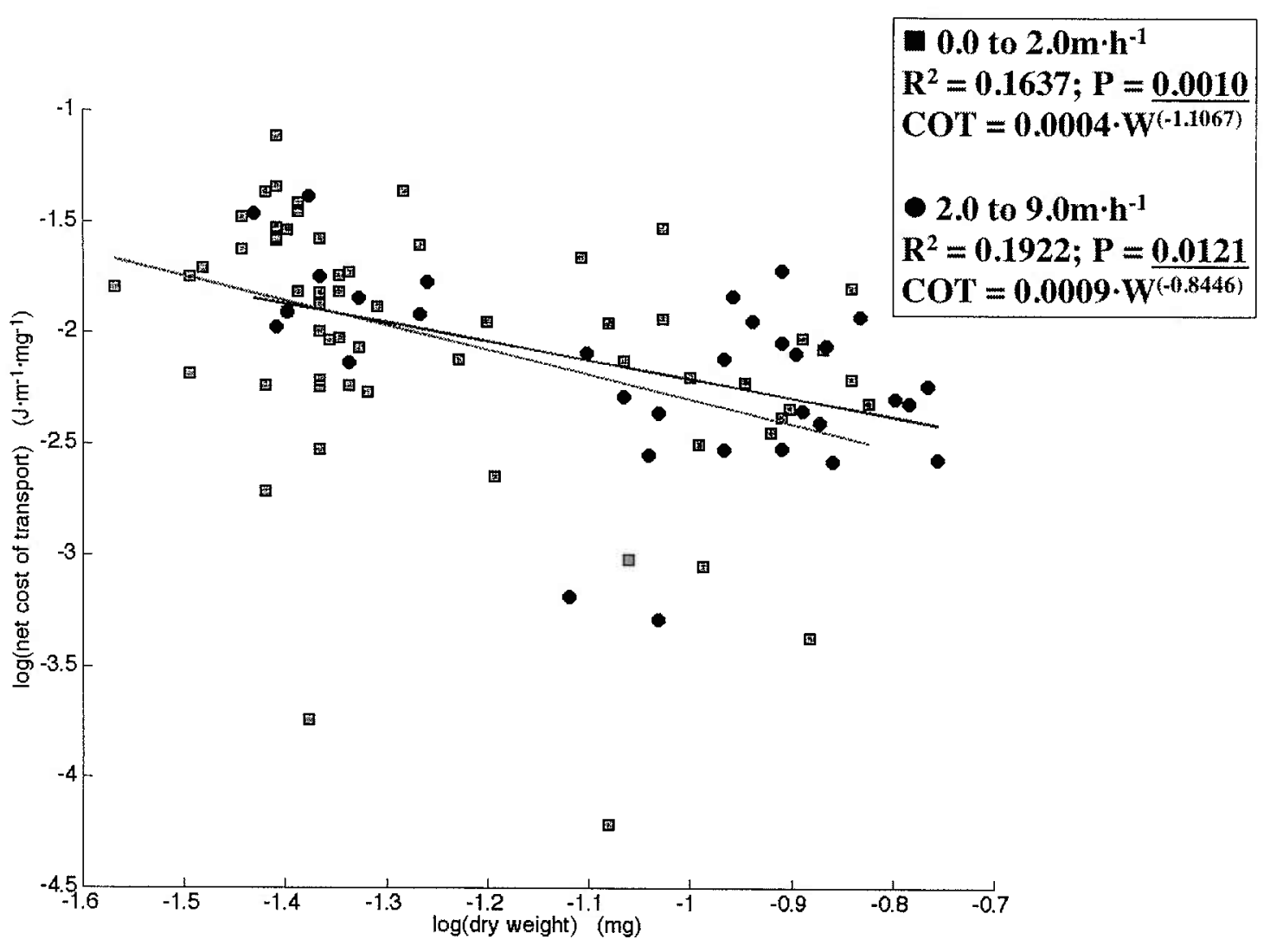




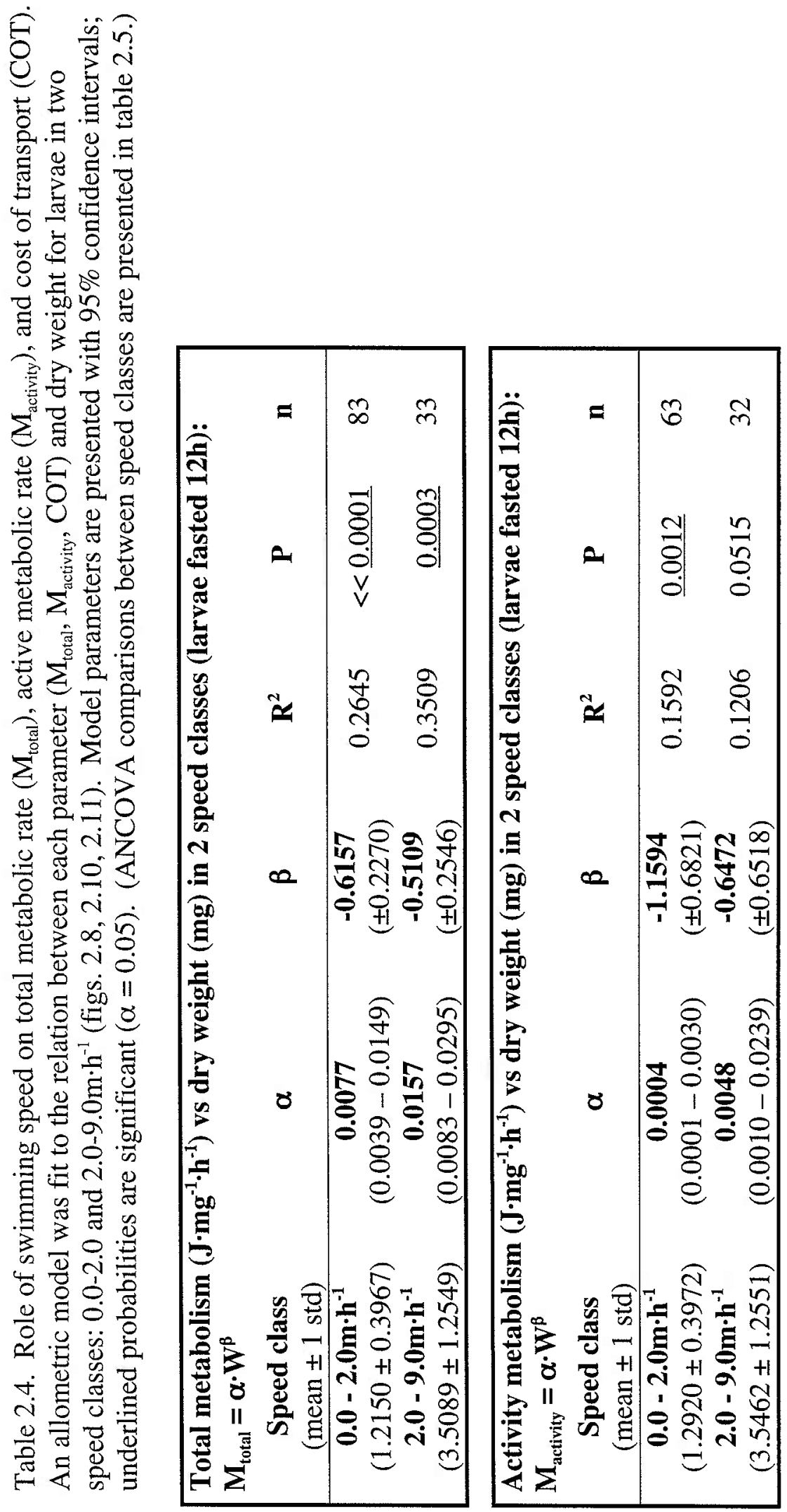




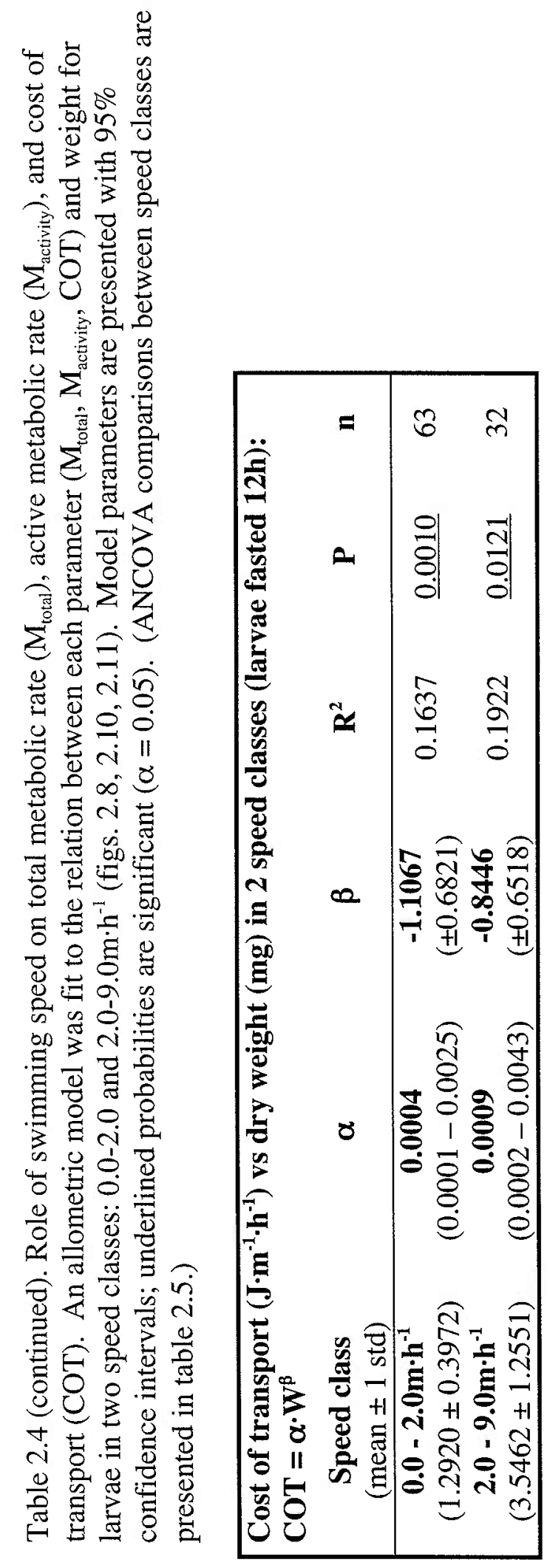




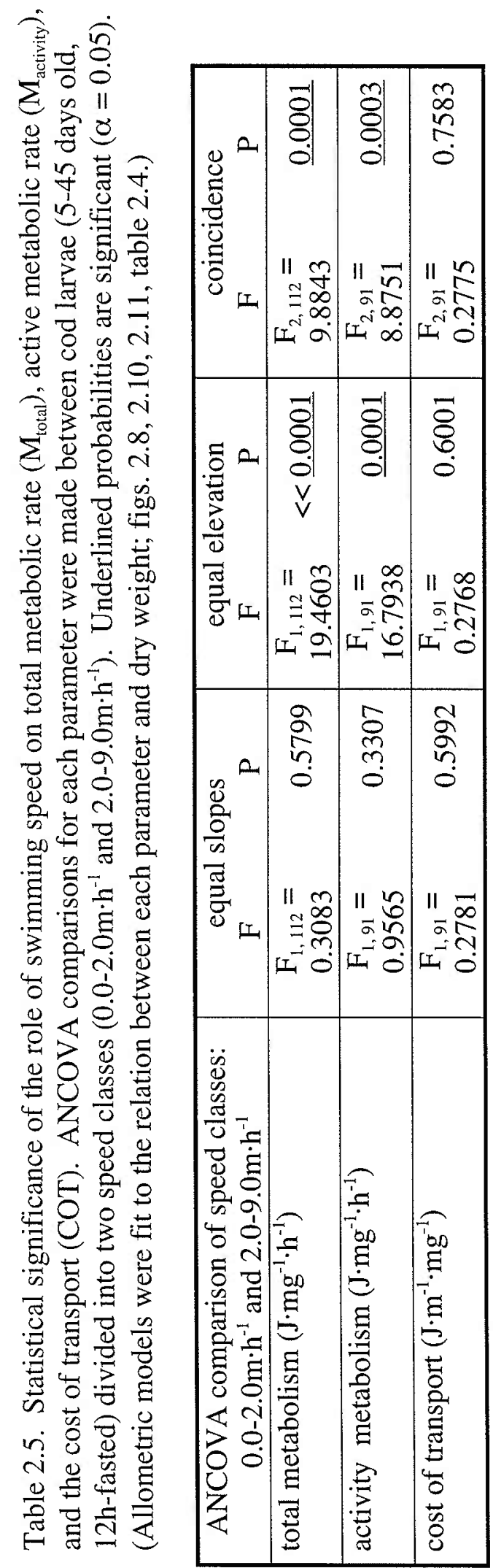


Figure 2.12. The power-performance relationship between total metabolic rate and individual mean swimming speed for fed and 12h fasted larvae 5-19 days old. Regressions are shown with their 95\% confidence intervals.

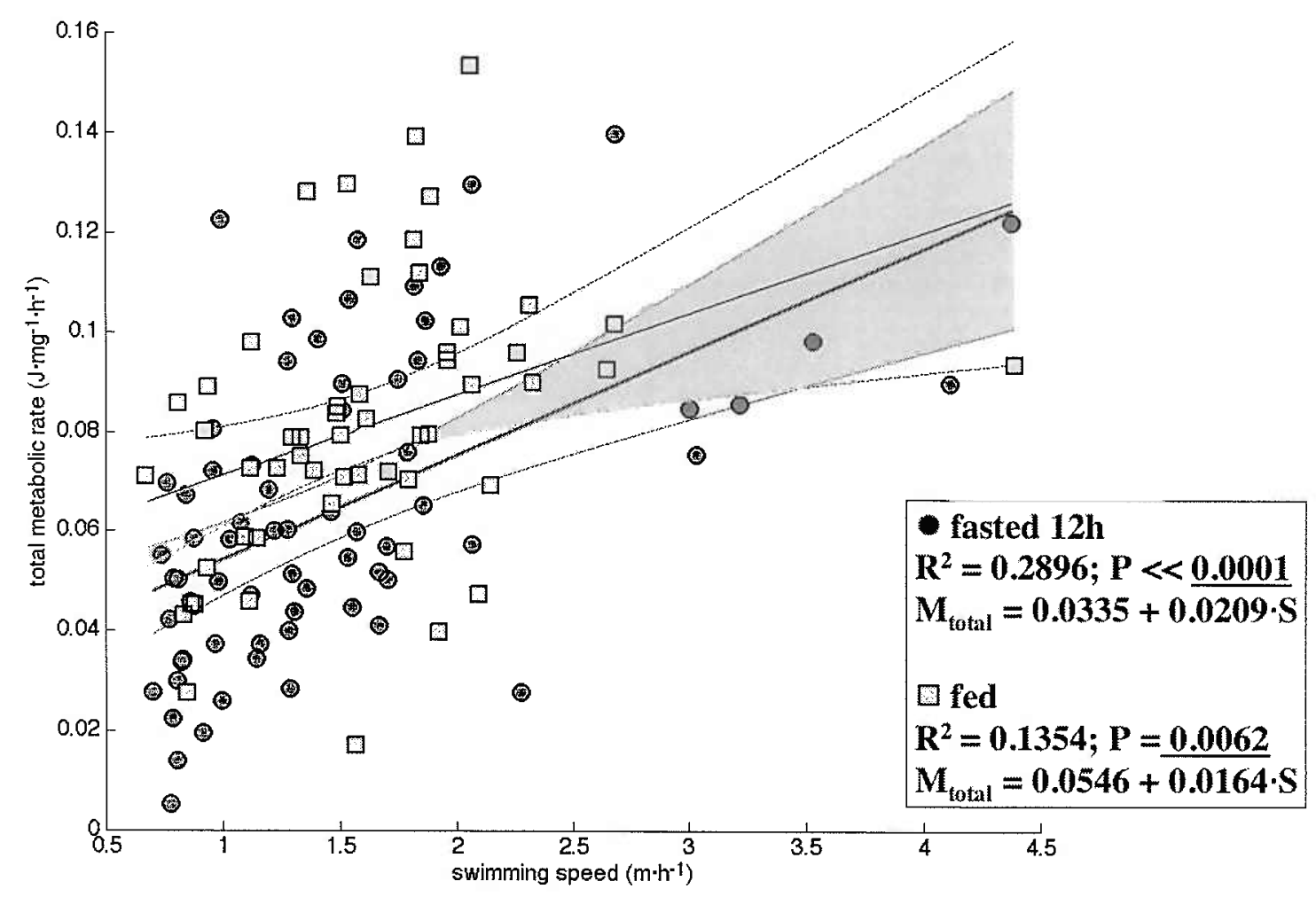


Figure 2.13. The net cost of transport (COT) for larval cod measured in the present study plotted with COT for larval Coregonus measured by Dabrowski (1986b), COT for larval Rutilus measured by Kaufmann (1990), and COT for adult fish in general (compiled by Schmidt-Nielsen 1972). The cod curve was calculated for a typical cruising speed of $12 \mathrm{~m} \cdot \mathrm{h}^{-1}$ and assumes the dry weight is $17 \%$ wet weight. The Coregonus curve was measured for fish swimming $10.8 \mathrm{~m} \cdot \mathrm{h}^{-1}$. The Rutilus curve was measured for fish forced to swim at a sustainable $216 \mathrm{~m} \cdot \mathrm{h}^{-1}$.

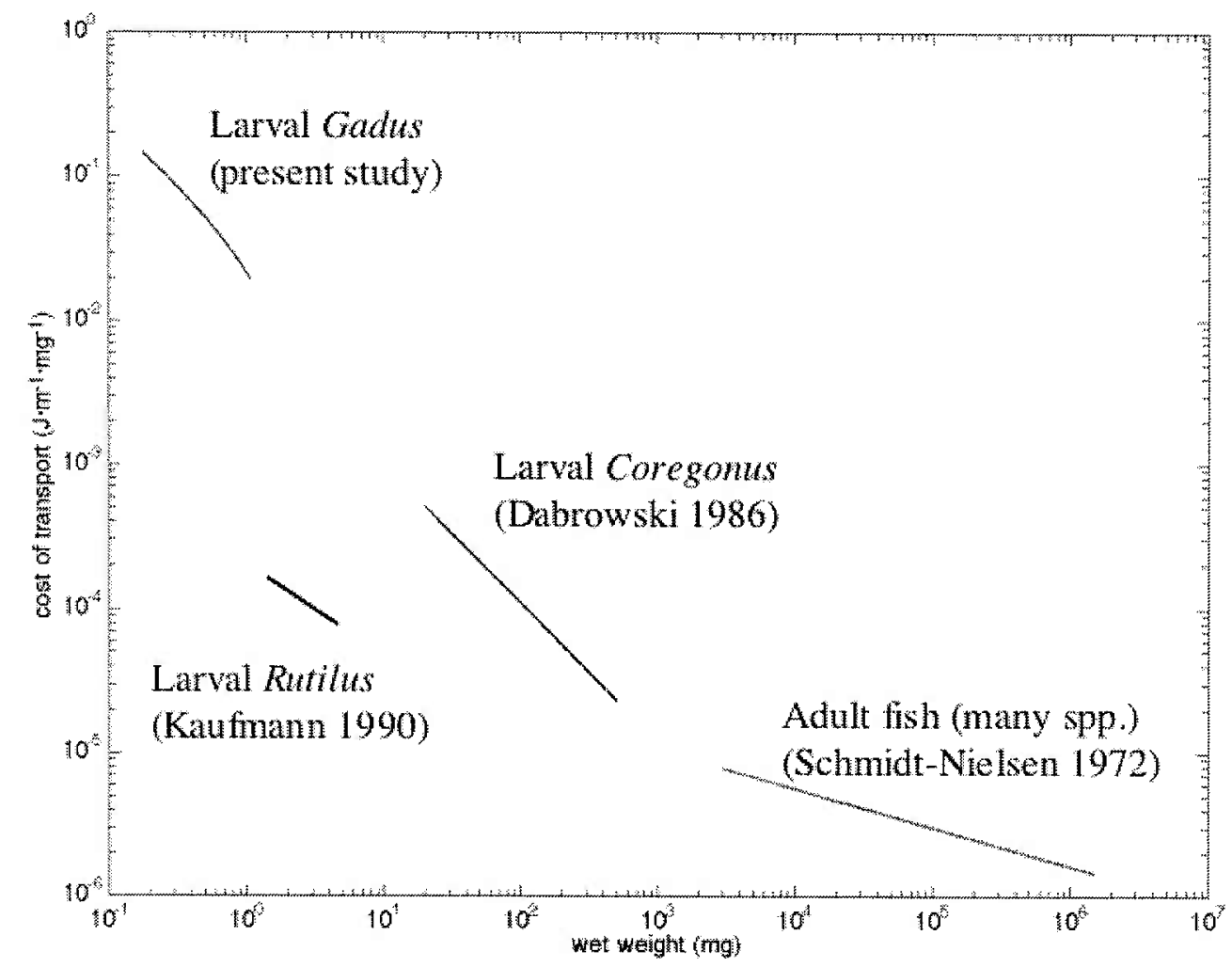


Figure 2.14. The routine factorial scope for activity (RFS) for larval cod 5 to 45 days old as measured within sealed respirometry chambers. The routine factorial scope is the ratio of the total routine metabolic rate to the basal metabolic rate $\left(\mathrm{M}_{\text {routine }} \div \mathrm{M}_{\mathrm{basa}}\right)$. The larvae, 5 to 45 days old, were divided into two speed classes: 0 to $2.0 \mathrm{~m} \cdot \mathrm{h}^{-1}$ and 2.0 to $9.0 \mathrm{~m} \cdot \mathrm{h}^{-1}$. These larvae were fasted $12 \mathrm{~h}$; this RFS does not include $\mathrm{M}_{\mathrm{SDA}}$.

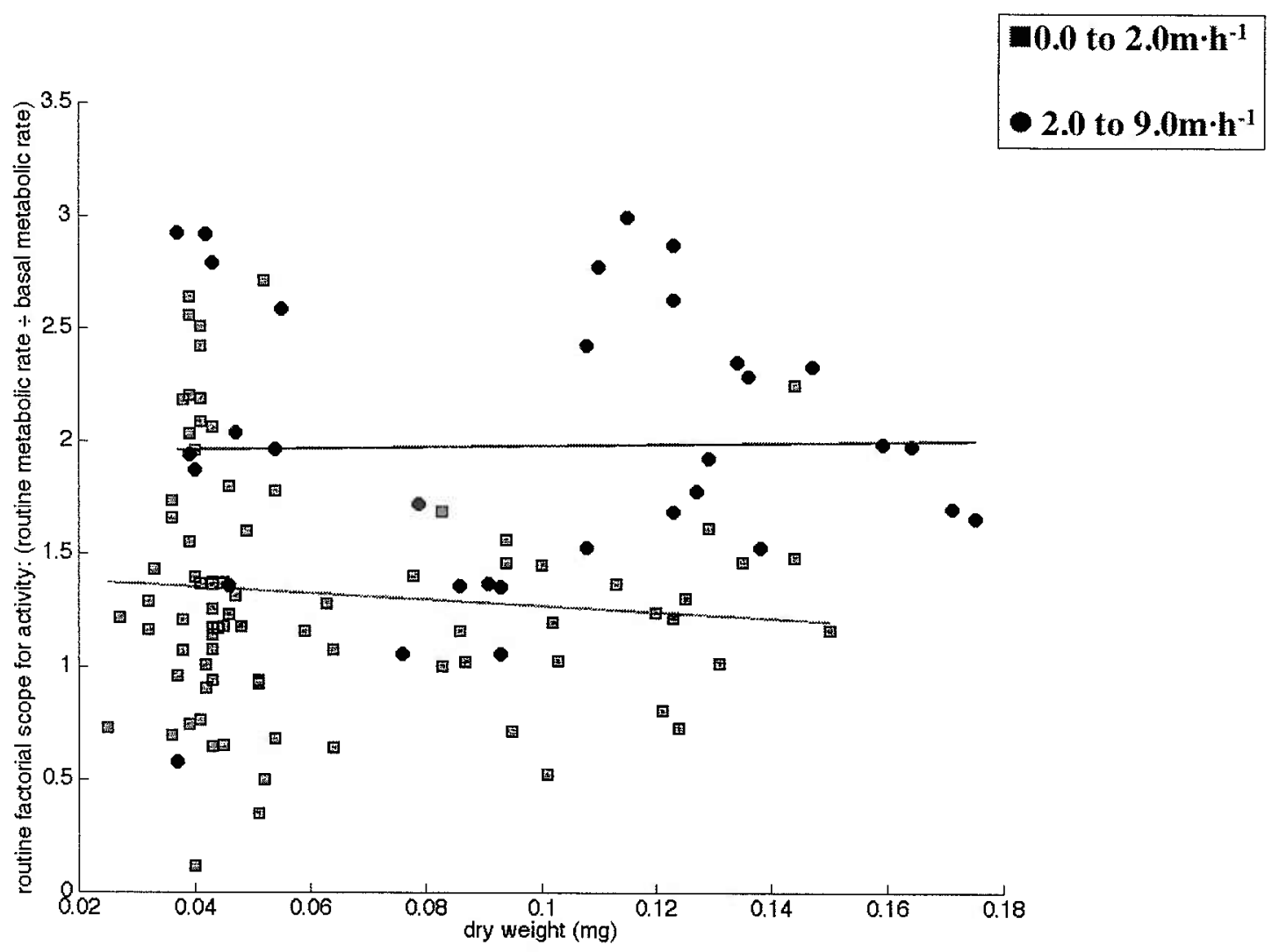




\section{References}

Batty RS (1984) Development of swimming movements and musculature of larval herring (Clupea harengus). Journal of Experimental Biology 110:217-229

Beamish FWH (1974) Apparent specific dynamic action of largemouth bass, Micropterus salmoides. J. Fish. Res. Board Can. 31:1763-1769

Beamish FWH, Mookherjii PS (1964) Respiration of fishes with special emphasis on standard oxygen consumption. Can. J. Zool. 42:161-175

Brett JR (1972) The metabolic demand for oxygen in fish, particularly salmonids, and a comparison with other vertebrates. Respiration Physiology 14:151-170

Brett JR, Groves TDD (1979) Physiological energetics. In: Hoar WS, Randall DJ, Brett JR (eds) Fish Physiology, Vol 8. Academic Press, New York, p 279-352

Dabrowski KR (1986a) Active metabolism in larval and juvenile fish: ontogenetic changes, effect of water temperature and fasting. Fish Physiol. and Biochem. $1: 125-144$

Dabrowski KR (1986b) Energy utilization during swimming and cost of locomotion in larval and juvenile fish. J. Appl. Ichthyol. 3:110-117

Dabrowski KR, Kok LY, Takashima F (1986) How efficiently do fish larvae and juveniles swim? Comparative Biochemistry and Physiology, A 85A:657-661

El-Fiky N, Hinterleitner S, Wieser W (1987) Differentiation of swimming muscles and gills, and development of anaerobic power in the larvae of cyprinid fish (Pisces, Teleostei). Zoomorphology 107:126-132

Finn RN, Fyhn HJ, Evjen MS (1995) Physiological energetics of developing embryos and yolk-sac larvae of Atlantic cod (Gadus morhua). I. Respiration and nitrogen metabolism. Marine Biology 124:355-369

Forstner H, Gnaiger E (1983) Appendix A: Calculation of equilibrium oxygen concentration. In: Gnaiger E, Forstner H (eds) Polarographic Oxygen Sensors. Springer-Verlag, New York, p 321-333

Forstner H, Hinterleitner S, Mähr K, Wieser W (1983) Towards a better definition of "metamorphosis" in Coregonus sp.: Biochemical, histological, and physiological data. Canadian Journal of Fisheries and Aquatic Sciences 40:1224-1232

Fry FEJ (1971) The effect of environmental factors on the physiology of fish. In: Fish Physiology, Vol VI. Academic Press, New York, p 1-98

Fuiman LA, Webb PW (1988) Ontogeny of routine swimming activity and performance in zebra danios (Teleostei: Cyprinidae). Animal Behaviour 36:250-261 
Gallager SM, Hunt von Herbing I, Davis L, Alatalo P (1996) First-feeding cod larvae ingest microzooplankton exclusively from natural plankton assemblages on Georges Bank AGU/ASLO

Gnaiger E (1983) Appendix C: Calculation of energetic and biochemical equivalents of respiratory oxygen consumption. In: Gnaiger E, Forstner H (eds) Polarographic oxygen sensors. Springer-Verlag, New York, p 337-345

Hinterleitner S, Thurner-Flür J, Wieser W, El-Fiky N (1989) Profiles of enzyme activity in larvae of two cyprinid species with contrasting life styles (Cyprinidae;

Teleostei). Journal of Fish Biology 35:709-718

Hunt von Herbing I (2002) Effects of temperature on larval fish swimming performance: the importance of physics to physiology. Journal of Fish Biology [J. Fish Biol.]. $61: 865-876$

Hunt von Herbing I, Boutilier RG (1996) Activity and metabolism of larval Atlantic cod (Gadus morhua) from Scotian Shelf and Newfoundland source populations. Mar. Biol. 124:607-617

Hunt von Herbing I, Gallager SM (2000) Foraging behavior in early Atlantic cod larvae (Gadus morhua) feeding on a protozoan (Balanion sp.) and a copepod nauplius (Pseudodiaptomus sp.). Marine Biology [Mar. Biol.]. 136:591-602

Hunter JR (1972) Swimming and feeding behavior of larval anchovy Engraulis mordax. Fish. Bull. 70:821-838

Hunter JR (1981) Feeding ecology and predation of marine fish larvae. In: Lasker R (ed) Marine fish larvae. Washington Sea Grant Program, Seattle, p 32-77

Jobling M (1981) The influences of feeding on the metabolic rate of fishes: a short review. J. Fish. Biol. 18:385-400

Jobling M (1983) Towards an explanation of specific dynamic action (SDA). J. Fish. Biol. 23:549-555

Kaufmann R (1990) Respiratory cost of swimming in larval and juvenile cyprinids. J. Exp. Biol. 150:343-366

Kaufmann R, Wieser W (1992) Influence of temperature and ambient oxygen on the swimming energetics of cyprinid larvae and juveniles. Environmental Biology of Fishes 33:87-95

Kiørboe T, Munk P, Richardson K (1987) Respiration and growth of larval herring Clupea harengus: relation between specific dynamic action and growth efficiency. Mar. Ecol. Prog. Ser. 40:1-10

Kleinbaum DG, Kupper LL, Muller KE, Nizam A (1998) Applied regression analysis and other multivariable methods, Vol. Duxbury Press, Pacific Grove

Laurence GC (1979) Larval length-weight relations for seven species of Northwest Atlantic fishes reared in the laboratory. Fishery Bulletin 76:890-895 
Müller UK, Stamhuis EJ, Videler JJ (2000) Hydrodynamics of unsteady fish swimming and the effects of body size: comparing the flow fields of fish larvae and adults. Journal of Experimental Biology [J. Exp. Biol.] 203:193-206

Rombough PJ (1988) Respiratory gas exchange, aerobic metabolism and effects of hypoxia during early life. In: Hoar WS, Randall DJ (eds) Fish Physiology, Vol 11 The physiology of developing fish. part A Eggs and larvae. Academic Press, New York, p 59-161

Schmidt-Nielsen K (1972) Locomotion: energy cost of swimming, flying, and running. Science 177:222-228

Solberg T, Tilseth S (eds) (1984) Growth, energy consumption and prey density requirements in first feeding larvae of cod (Gadus morhua L.), Vol 1. Flødevigen rapportser.

Soofiani NM, Hawkins AD (1982) Energetic costs at different levels of feeding in juvenile cod, Gadus morhua L. J. Fish. Biol. 21:577-592

Soofiani NM, Priede IG (1985) Aerobic metabolic scope and swimming performance in juvenile cod, Gadus morhua L. J. Fish. Biol. 26:127-138

The MathWorks I (1998) Matlab, Natick, Ma

Torres JJ, Brightman RI, Donnelly J, Harvey J (1996) Energetics of larval red drum, Sciaenops ocellatus. Part 1: oxygen consumption, specific dynamic action, and nitrogen excretion. Fish. Bull. 94:756-765

Videler JJ, Weihs D (1982) Energetic advantages of burst-and-coast swimming of fish at high speeds. J. Exp. Biol. 97:169-178

Vlymen WJ, III (1974) Swimming energetics of the larval anchovy, Engraulis mordax. Fish. Bull. 72:885-899

Wang W, Reimers CE, Wainright SC, Shahriari M, Morris MJ (1999) Applying FiberOptic Sensors for Monitoring Dissolved Oxygen. Sea Technology [Sea Technol.]. no. 3:69-77

Webb PW (1988) Simple physical principles and vertebrate aquatic locomotion. Amer. Zool. 28:709-725

Webb PW, Weihs D (1986) Functional locomotor morphology of early life history stages of fishes. Trans. Am. Fish. Soc. 115:115-127

Weihs D (1974) Energetic advantages of burst swimming of fish. Journal of Theoretical Biology 48:215-229

Weihs D (1980) Energetic significance of changes in swimming modes during growth of larval anchovy, Engraulis mordax. Fish. Bull. 77:597-604

Wieser W (1995) Energetics of fish larvae, the smallest vertebrates. Acta Physiol. Scand. $154: 279-290$ 


\section{Chapter 3: The Foraging Behavior of Larval Cod}

\section{Introduction}

Unlike the larvae of coral reef fish, which have impressive swimming abilities (Stobutzki \& Bellwood 1994), the larvae of temperate marine fish like cod (Gadus morhua) are weak swimmers. Are their foraging abilities also weak? Early laboratory observations of larval cod foraging behavior suggest that their foraging capacity is very limited, and their survival depends upon encountering high-density prey patches (Solberg \& Tilseth 1984, Skiftesvik \& Huse 1987) or taking advantage of turbulence to enhance prey-contact rates (Dower et al. 1997). However, data from the field and later laboratory observations suggest that they are capable foragers under a variety of conditions (MacKenzie et al. 1990, Munk 1995).

Accurate descriptions of foraging behavior are necessary for modeling potential energy gain through prey encounter rates (e.g., MacKenzie \& Kiørboe 1995) as well as foraging-related energy expenditures. Larval cod use a saltatory foraging strategy (unpub. data cited in Browman \& O'Brien 1992, MacKenzie \& Kiørboe 1995, Munk 1995). The components of the saltatory foraging cycle are a forward swimming burst, a glide, and a pause during which the larva searches for prey (Evans \& O'Brien 1988). Since beat-and-glide swimming is the most efficient swimming mode for post-yolk-sac larvae (Vlymen 1974, Weihs 1980, Videler \& Weihs 1982, Webb \& Weihs 1986), saltatory foraging may be the optimum search strategy for small larvae.

The components of the saltatory foraging cycle can be varied to suit environmental conditions. The prey field (the size, relative visibility, and density of prey) has a significant effect on the behavior of a range of saltatory foraging taxa from fish to birds (O'Brien et al. 1990). As prey become more difficult to find, the search effort should increase. The distance between search-volumes, the duration of the search period, the frequency at which new water parcels are searched, selectivity of prey, swimming speed, 
and the time spent swimming could all be varied to adjust foraging effort. There have been few studies that have looked at how different components of a larval fish's foraging cycle change in response to changing conditions, and the results are not consistent. Munk \& Kiørboe (1985) and Munk (1995) have shown that swimming intensity and search capacity (the volumetric rate of foraging) increase at lower prey concentrations in cod and herring larvae. However, MacKenzie \& Kiørboe (1995) did not see a change in foraging effort under different prey concentrations.

The goals of this research were: first, to observe the behavior of larval cod in large volumes to reduce confinement effects; second, to observe behavior throughout early development (from 5 to 50 days post-hatch); third, to measure the foraging capacity of larval cod (volume searched per unit time); and fourth, to observe if and how larval cod adjust their foraging effort in response to different foraging conditions, in this case prey density. Foraging behavior was observed in a large, cylindrical tank $1.5 \mathrm{~m}$ tall by $0.5 \mathrm{~m}$ across (300L). Although still an artificial system, use of such large volumes should greatly reduce confinement effects on behavior. The tank has a plate glass bottom, and stereo-paired video cameras were positioned to look into the tank from below and observe larvae silhouetted against the lit surface. The positions of individual cod larvae throughout the water-column were recorded in a three-dimensional coordinate system. Stereo video systems have been successfully employed to study the swimming patterns of larger fish in three-dimensions (Boisclair 1992, Krohn \& Boisclair 1994). An automated system was developed to interpret the swimming behavior of each individual from its position trace. Because this study sought to measure how larvae respond to changing conditions, all larvae were reared under the same conditions before being observed foraging under two different prey treatments (no prey and rotifers at $100 \mathrm{~L}^{-1}$ ). An additional set of experiments observed the behavior of larval cod foraging upon wild zooplankton. Several cohorts of eggs from different adults were studied to reduce any potential bias from studying the behavior of a single cohort; however, there is evidence that maternal condition has little effect on the behavior of larvae (Browman et al. 2003). 


\section{Materials and Methods}

\section{Rearing of larvae}

For this experiment, eleven separate batches of cod embryos were reared (table 3.1). Eight batches were obtained from the cod broodstock maintained by the National Marine Fisheries Service in Narrragansett, RI. One batch was obtained from the cod broodstock maintained by the Marine Biological Laboratory (Woods Hole, MA). The Narrragansett and the Woods Hole broodstocks were both made up of fish caught off of Cape Cod. Two additional batches of embryos were obtained from Canadian broodstocks: one from the Ocean Sciences Centre, Memorial University of Newfoundland (Newfoundland, Canada) and one from the St. Andrews Biological Station (New Brunswick, Canada). Fertilized embryos were transported in insulated containers back to the Woods Hole Oceanographic Institution for rearing. Embryos were held in black, $120 \mathrm{~L}$ barrels. An airstone was suspended in the center of the barrel $\approx 2.5 \mathrm{~cm}$ off the bottom. One-third of the water was changed daily with filtered $(1 \mu \mathrm{m})$, natural seawater (salinity $=32.5 \%$ ) and the bottom siphoned for debris. Lighting was from fluorescent lamps directly above the barrels on an $11 \mathrm{~h}$-on $/ 13 \mathrm{~h}$-off cycle. The light intensity within the rearing barrels was 13.3 $\mu$ Einsteins $\cdot \mathrm{m}^{-2} \cdot \mathrm{s}^{-1}$ at the surface to $5.2 \mu$ Einsteins $\cdot \mathrm{m}^{-2} \cdot \mathrm{s}^{-1}$ at the bottom (Biospherical Instruments, Inc. model QSP200L4S, San Diego, CA). Embryos were held at approximately $6.25^{\circ} \mathrm{C}$ and hatched about 3 weeks after spawning. Most hatching occurred within 1 day. At the time of hatching, extra care was taken to remove egg debris and several additional water changes were made. Larvae were retained in the same barrels in which they hatched. Beginning on the third day after hatching, larvae were fed rotifers (Brachionus plicatilis) daily. After three weeks, the larval diet was supplemented with wild caught zooplankton containing copepod nauplii (predominately Acartia sp.). Larvae were maintained for up to 60 days before use in experiments or termination.

Stock growth rates with respect to total length (mm, fig. 3.1) and dry weight (mg) are summarized in table 3.2. Stock growth rates were modeled exponentially and forced through a standardized size at hatch, $4.9 \mathrm{~mm}$ and $0.035 \mathrm{mg}$. The standardized hatch size 
was selected from the approximate intercept of the non-forced growth curves. These growth rates are typical of larval cod reared in the laboratory (e.g., MacKenzie \& Kiørboe 1995, Munk 1995) but lower than inferred from the otoliths of wild-caught larvae on Georges Bank (Bolz \& Lough 1988).

\section{Observation tank system}

The observation tank system is shown in figure 3.2. A custom fiberglass cylinder ( $3 \mathrm{~m}$ tall $\times 0.5 \mathrm{~m}$ diameter) with flanged ends (Solar Components Corp., Manchester, $\mathrm{NH}$ ) was fitted with a 1/4" glass bottom, adhered with RTV-157 (General Electric). The tank was positioned on a wooden frame with a 3/4" plate glass top; a thin sheet of mineral oil was spread between the glass panes. For observation into the tank from below, a mirror was oriented at a $45^{\circ}$ angle beneath the wooden frame.

The tank was lit from above by a collimated light source consisting of a quartzhalogen bulb and large fresnel lens $(500 \mathrm{~mm}$ diameter, $500 \mathrm{~mm}$ focal length, AWI Industries, Corona, CA). The photoperiod was an 11h-on/13h-off cycle. Black plastic sheet was hung around the entire observation tank system to prevent ambient light from entering. Light intensity levels within the observation tank were measured in $30.5 \mathrm{~cm}$ intervals with a Biospherical Instruments, Inc. 4 $\pi$ PAR sensor (model QSP200L4S, San Diego, CA) (table 3.3, fig. 3.3). The light intensity throughout the tank was within the range found to be optimal for larval cod feeding (Ellertsen et al. 1980).

The tank was filled with filtered seawater $(1 \mu \mathrm{m})$ to a depth of $1.5 \mathrm{~m}$. Temperature was maintained within the tank at $7^{\circ} \mathrm{C}\left( \pm 1^{\circ} \mathrm{C}\right)$. A garden hose perforated with $3 \mathrm{~mm}$ holes every $30.5 \mathrm{~cm}$ was coiled around the outside of the tank from top to bottom. Chilled water was run through the hose and cascaded down the outside of the tank. The chilled water was collected in a skirt at the bottom of the tank, returned to the chiller, and pumped back through the cooling hose. The entire tank and cooling system was insulated with bubble-wrap.

Larval behavior was monitored from below with paired video cameras (PULNiX, Sunnyvale, CA, model TM-7EX) with 35-70mm zoom lenses (Minolta, set to 70mm). 
The cameras were mounted on a stand $12 \mathrm{~cm}$ apart (center-to-center), $38 \mathrm{~cm}$ off of the floor, and $1.9 \mathrm{~m}$ from the base of the tank stand. The optical axes of the two cameras were aligned in parallel by centering the image of each on a distant light beacon $(6.4 \mathrm{~km}$ distant). The video signal from each camera was recorded on separate SVHS tapes. A time-code was stamped on each frame with a time-code generator (Horita) so that the record from each camera could be synchronized. 


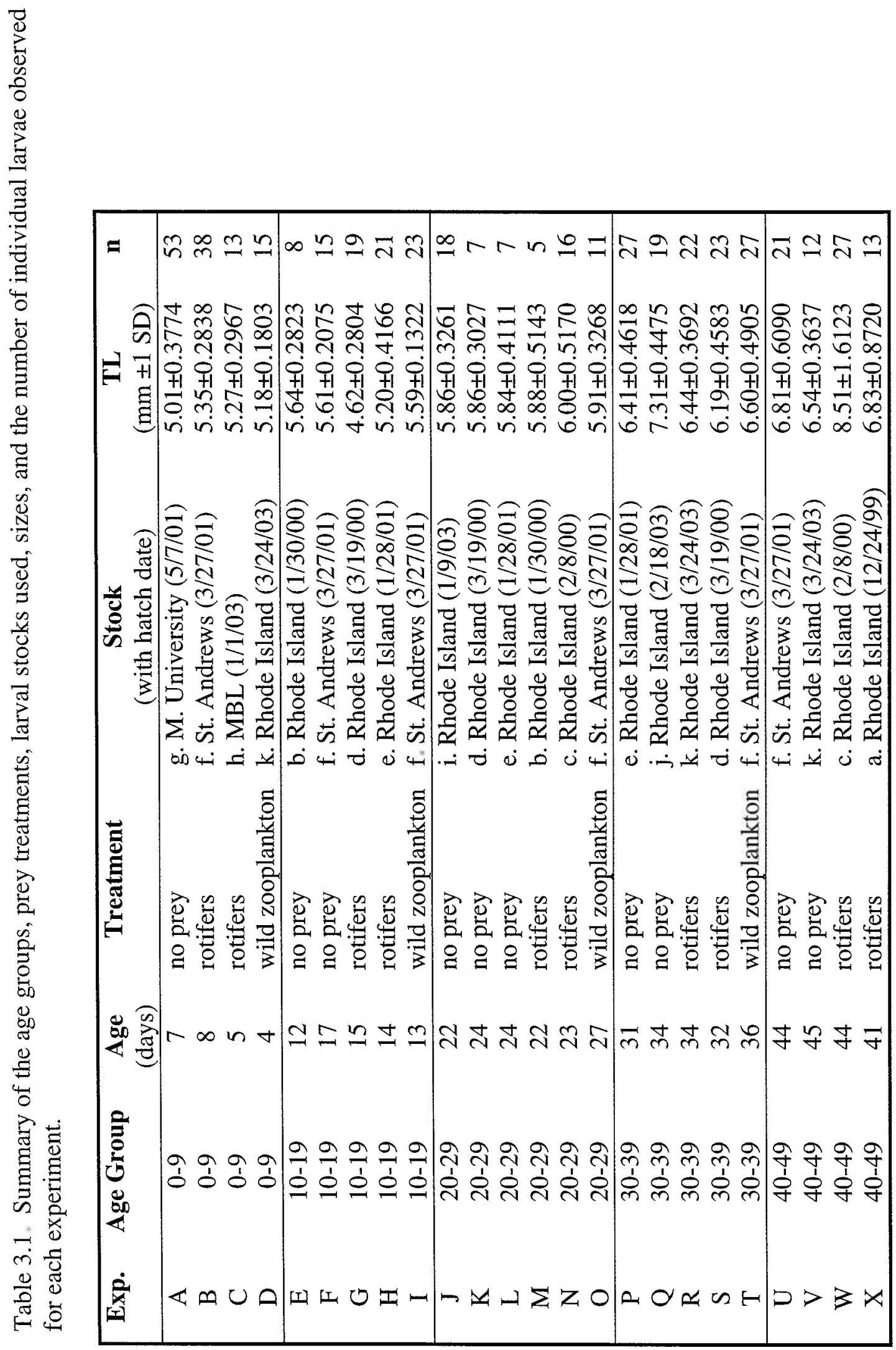


Figure 3.1. Total length of each larval fish stock used in this study as a function of age. Error bars represent \pm 1 standard deviation. Stock code letters are as defined in table 3.1.

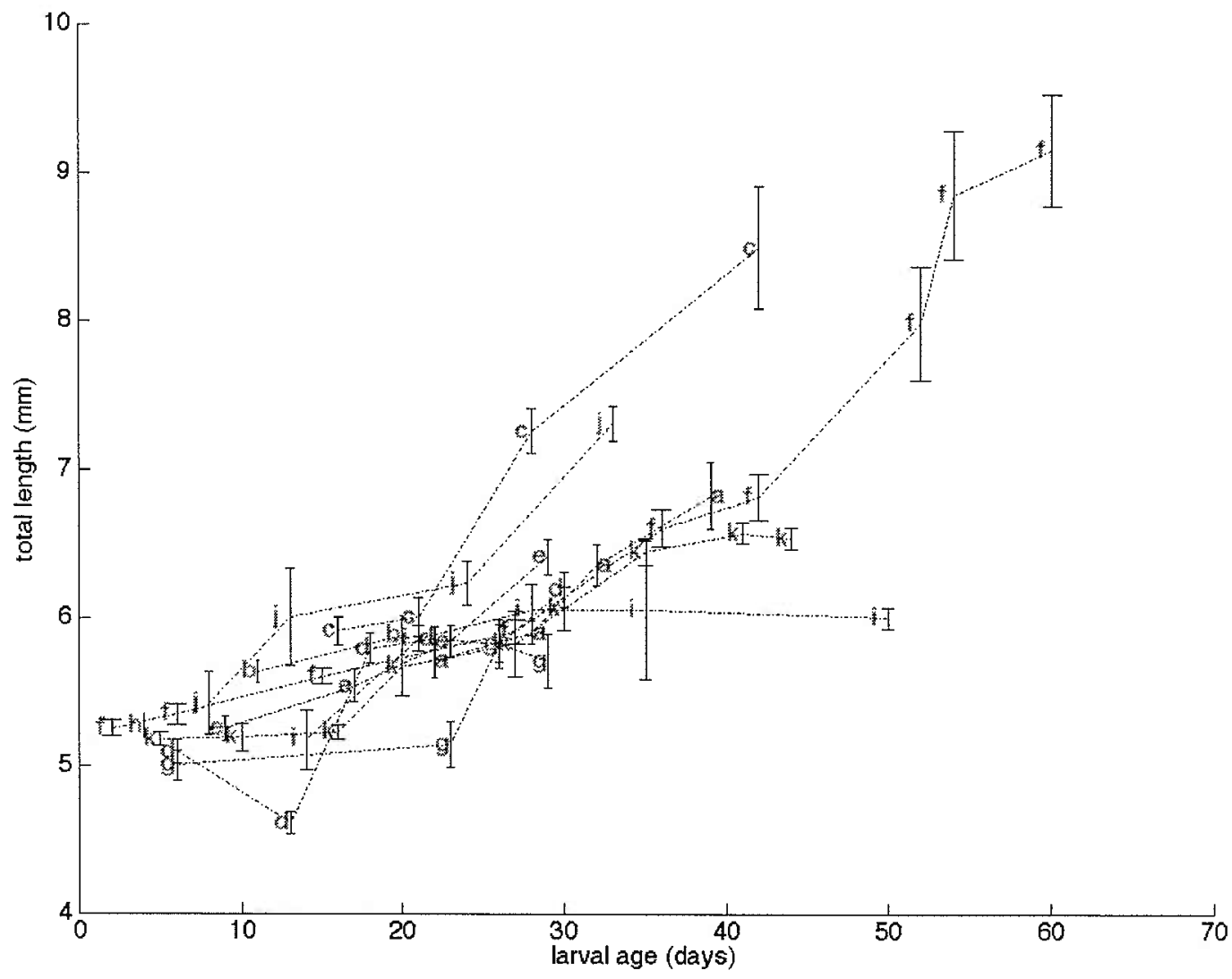


Table 3.2. Larval cod stock growth rates with respect to total length (mm, fig. 3.1) and dry weight $(\mathrm{mg})$. Stock growth rates were modeled exponentially and forced through a standardized size at hatch selected from the approximate average intercept of non-forced growth curves $(4.9 \mathrm{~mm}$ and $0.035 \mathrm{mg})$. Stock names are given as identifier code letter, brood-stock source, and hatch date.

\begin{tabular}{|c|c|c|c|}
\hline & stock & $\begin{array}{c}\text { growth in length } \\
\mathrm{l}_{\mathrm{age}}=4.9 \cdot \mathrm{e}^{\mathrm{r}(\mathrm{age})} \\
\mathrm{r}\end{array}$ & $\begin{array}{c}\text { growth in weight } \\
\mathrm{W}_{\mathrm{age}}=0.035 \cdot \mathrm{e}^{\mathrm{r(age})} \\
\mathrm{r}\end{array}$ \\
\hline a & Rhode Island (12/24/99) & 0.0068 & - \\
\hline $\mathrm{b}$ & Rhode Island (1/30/00) & 0.0070 & 0.0619 \\
\hline $\mathrm{c}$ & Rhode Island (2/8/00) & 0.0075 & 0.0613 \\
\hline $\mathrm{d}$ & Rhode Island $(3 / 19 / 00)$ & 0.0070 & 0.0619 \\
\hline e & Rhode Island (1/28/01) & 0.0071 & 0.0619 \\
\hline $\mathrm{f}$ & St. Andrews (3/27/01) & 0.0099 & 0.1172 \\
\hline $\mathrm{g}$ & Memorial University $(5 / 7 / 01)$ & 0.0049 & 0.1396 \\
\hline $\mathrm{h}$ & MBL $(1 / 1 / 03)$ & 0.0099 & 0.1173 \\
\hline i & Rhode Island (1/9/03) & 0.0067 & 0.0614 \\
\hline $\mathrm{j}$ & Rhode Island (2/18/03) & 0.0071 & 0.0607 \\
\hline $\mathrm{k}$ & Rhode Island (3/24/03) & 0.0069 & 0.0612 \\
\hline
\end{tabular}


Figure 3.2. The observation tank developed for this study. Overall dimensions are $3 \mathrm{~m}$ tall $\times 0.5 \mathrm{~m}$ diameter. Filled half-full, it provides $250 \mathrm{~L}$ for larval foraging. Stereopaired video cameras positioned to observe the silhouettes of swimming larvae from below record behavior throughout the tank in three dimensions.

\section{Tall Tank System}

a.

b.
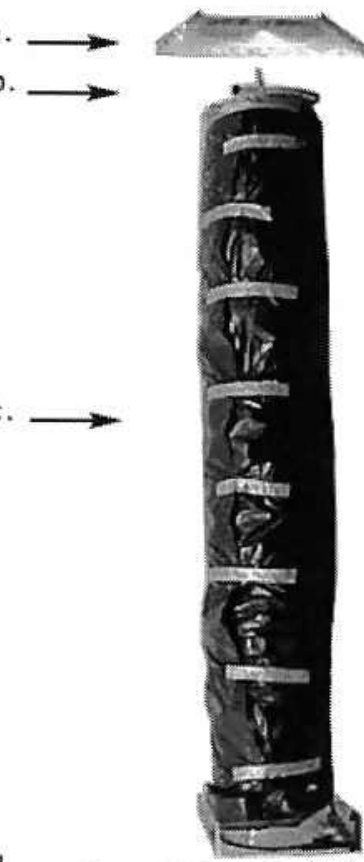

f. stereo cameras

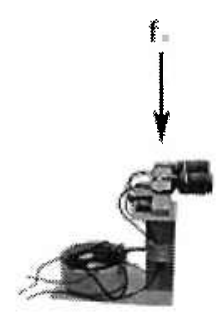

d.

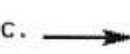

c. $\operatorname{tank}(3 \mathrm{~m} \times \mathbf{0 . 5 m})$

d. 3/4" glass plate

e. mirror 


\section{Processing the video record}

The analog SVHS record was digitized with a frame-grabber card mounted in a standard desktop computer (MV-1000 frame-grabber card and accompanying 'Wseq' software, MuTech Corp., Billerica, MA). Video frames were sampled at a rate of 3.75 frames per second and saved as gray-scale TIFF files at a resolution of $640 \times 480$ pixels.

Original Matlab routines (The MathWorks 1998) were written to produce swimming tracks (frame-by-frame series of pixel coordinates) of individual larvae from a series of TIFF frames. The procedure was semi-automated; all computer-constructed swimming tracks were checked by eye and errors were manually corrected.

Step 1 (observation system calibration): A plexiglass calibration placard was constructed upon which were 23 points; the distance from each point to every other point was pre-measured to the nearest $0.5 \mathrm{~mm}$. The calibration placard was lowered into the observation tank in discrete intervals $(30.5 \mathrm{~cm})$ from the surface to the bottom, and the video image of the placard was recorded with both cameras. The pixel coordinates of every point on the placard was recorded manually for each depth interval. From these data, three calibration parameters calculated: 1 . the exponential relation between depth and the $\mathrm{x}$-axis offset between the left and right cameras (fig. 3.4), 2. the linear relation between depth and spatial resolution (mm/pixel ${ }^{-1}$; fig. 3.5), and 3. the angle of rotation about the optical axis of the left camera relative to the right camera (always $<0.5^{\circ}$ ).

Step 2 (each TIFF frame is reduced to a set of pixel coordinates representing potential larvae): An average image from a 1-minute set of frames (225) was calculated (averageIMAGE). A scaled average image (f-averageIMAGE) was subtracted from each consecutive image to remove the unchanging background. The resulting image was binarized; all pixels with intensity values greater than an adjustable threshold value were set to ' 1 ', all others to ' 0 ', and the coordinates for each identified object were recorded. System sensitivity was adjusted automatically if too many or too few potential larvae were located by adjusting the average image multiplier (f-averageIMAGE) to strengthen or weaken the intensity of the average image. 
Step 3 (swimming tracks of individual larvae are constructed): Pixel coordinates of potential larvae are arranged by time but cannot yet be grouped into sets that represent individual larvae. Each time-step $(0.2667 \mathrm{~s})$ was processed sequentially. The coordinates of each potential larva in the current time-step was paired with the nearest neighbor in the previous time-step.

Step 4 (manual inspection and correction): A movie was constructed from the raw TIFF image sets upon which the computer-generated larval swimming tracks were overlain. Errors were corrected by manually re-entering larval coordinates and deleting noise points as necessary.

Step 5: Swimming tracks from consecutive minutes were linked together manually.

Step 6: Matching swimming tracks from each camera, left and right, were paired together manually.

Step 7: (calculate depth and convert pixel coordinates to millimeter coordinates): Tracks from the cameras were synchronized using the time-code stamp from each image frame. The optical axis of the left camera was mathematically de-rotated relative to the right camera. The $\mathrm{x}$-axis offset between the left and right cameras and corresponding depth was calculated for each larva at each time step. Pixel coordinates were converted to millimeter coordinates using the depth-specific conversion parameter.

\section{Experimental treatments and protocol}

Behavior of larvae 4 to 45 days old was observed in 10-day intervals. Three feeding treatments were used: no prey ( 2 repetitions for each age group), rotifer prey stocked at $100 \mathrm{~L}^{-1}$ ( 2 repetitions for each age group), wild zooplankton prey (predominately Acartia sp.) stocked at $100 \mathrm{~L}^{-1}$ ( 1 repetition for each age group). Table 3.1 summarizes the age groups, prey treatments, larval stock used, and number of individual larvae observed for each experiment.

All experiments were run at $7^{\circ} \mathrm{C}\left( \pm 1^{\circ} \mathrm{C}\right)$. Each experiment was run over two days. Larvae (50 to 100) were added to the surface of the observation tank the evening before the experiment began. The first day was an acclimation period, no prey was added to the 
tank. In prey treatments, prey were added at 8:00am on the second day, and the tank was bubbled for one-half hour to mix the prey throughout the tank. A video record was taken at 1:00pm on the second day. Five to ten minutes of the record were analyzed depending upon the number of larvae visible. A temperature profile from the surface to the bottom of the observation tank was taken at 1-foot intervals in the evenings of day 1 and day 2 . A prey-density profile was taken in the evening of day 2 by siphoning $1 \mathrm{~L}$ of water in 1 foot depth intervals and counting the number of prey items recovered at each depth.

Length and weight data was collected from a sub-sample of 15 larvae the evening before each experiment. A video camera with a macro-lens provided focused images of a larva within a field of view $20 \mathrm{~mm}$ in diameter. Video images were saved as TIFF files, and the total length of each larva was measured using NIH Image (vers. 1.62, The National Institutes of Health). Larvae were living when imaged. Larvae were then placed in TRIS buffer, frozen in liquid nitrogen, and stored at $-70^{\circ} \mathrm{C}$. To obtain dry weights, larvae were thawed, rinsed in chilled distilled water, refrozen, and freeze-dried for 8 to 12 hours (Labconco Freeze Dryer 5). Dry weights were measured to the nearest $\mu \mathrm{g}$ on the same day larvae were removed from the freeze-dryer (Cahn microbalance, model C-33). Re-weighing of a sub-sample showed that the freeze-drying process was complete.

\section{Classification of behavioral modes}

Distance and speed traveled over each time interval were calculated from position data for each individual larva as was acceleration/deceleration between successive intervals. With this information, each interval was then classified as either a pause or as a swimming burst using a pre-defined set of rules. A pause was a period of no active swimming. Because larvae seldom come to a full stop, being carried along by momentum until the next burst, pauses were allowed a speed ceiling of $<4 \mathrm{~mm} \cdot \mathrm{s}^{-1}$. Bursts were defined as intervals of positive acceleration greater than $4 \mathrm{~mm} \cdot \mathrm{s}^{-2}$ and a speed greater than $3 \mathrm{~mm} \cdot \mathrm{s}^{-1}$ (fig. 3.6). A larva was still considered to be in burst mode until its speed had fallen to less than $110 \%$ of its pre-burst speed. 
Figure 3.3. Light intensity profile within the tall observation tank $\left(\mu\right.$ Einsteins $\cdot \mathrm{m}^{-2} \cdot \mathrm{s}^{-1} \mathrm{vs}$. depth from water surface). Values are summarized in table 3.3.

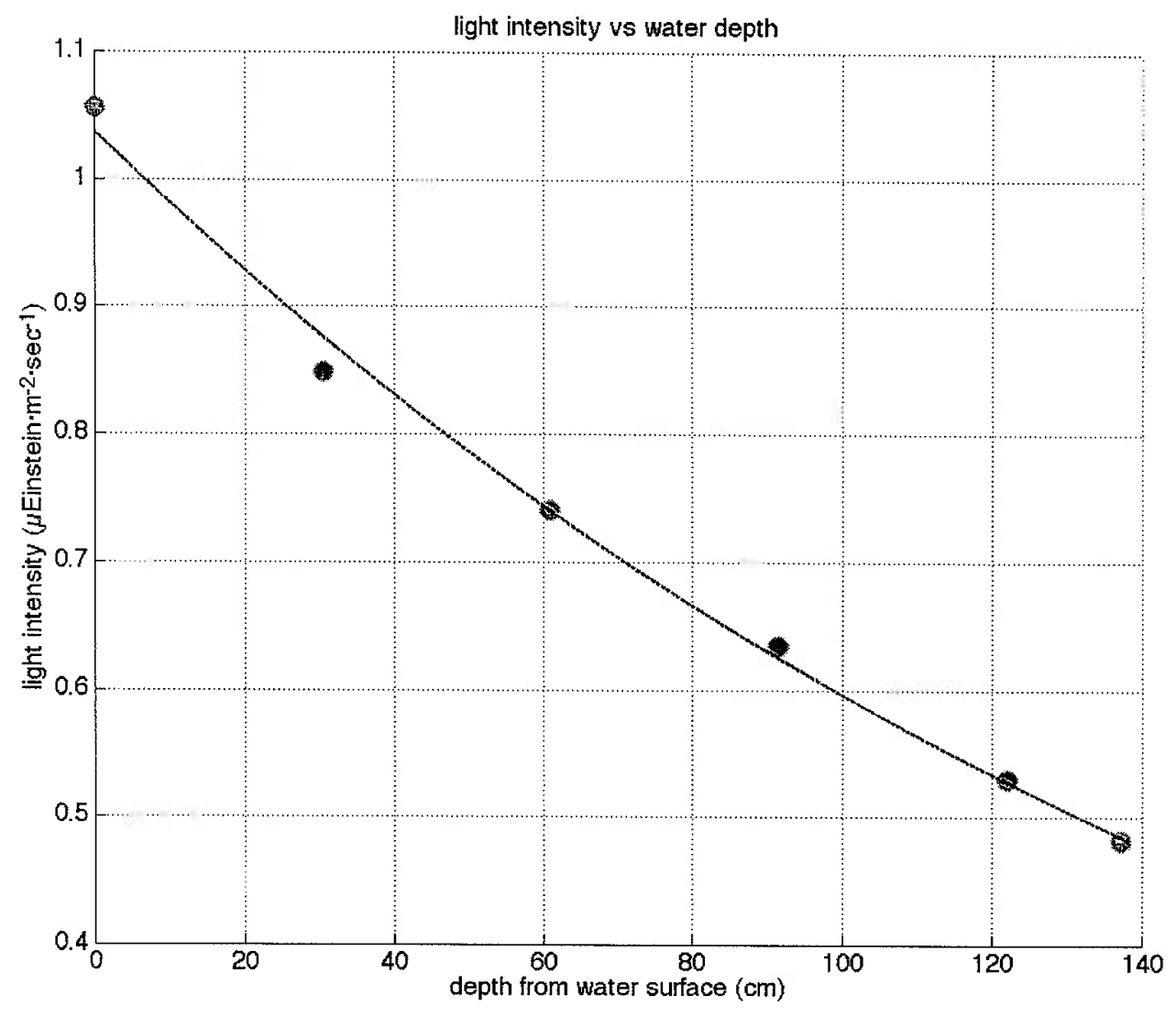


Table 3.3. Light intensity profile within the observation tank. The light decay curve is shown in figure 3.3 .

\begin{tabular}{|cc|}
\hline Depth from surface $(\mathrm{cm})$ & Irradiance $\left(\mu\right.$ Einsteins $\left.\cdot \mathrm{m}^{-2} \cdot \mathrm{s}^{-1}\right)$ \\
\hline 0.0 & 1.056 \\
30.5 & 0.849 \\
61.0 & 0.741 \\
91.4 & 0.634 \\
121.9 & 0.529 \\
137.2 & 0.481 \\
\hline
\end{tabular}


Figure 3.4. Depth calibration curve showing the exponential relation between depth within the observation tank and the $\mathrm{x}$-axis offset (in pixels) between the left and right cameras (experiment $\mathrm{K}$ ). Error bars represent \pm 1 standard deviation.

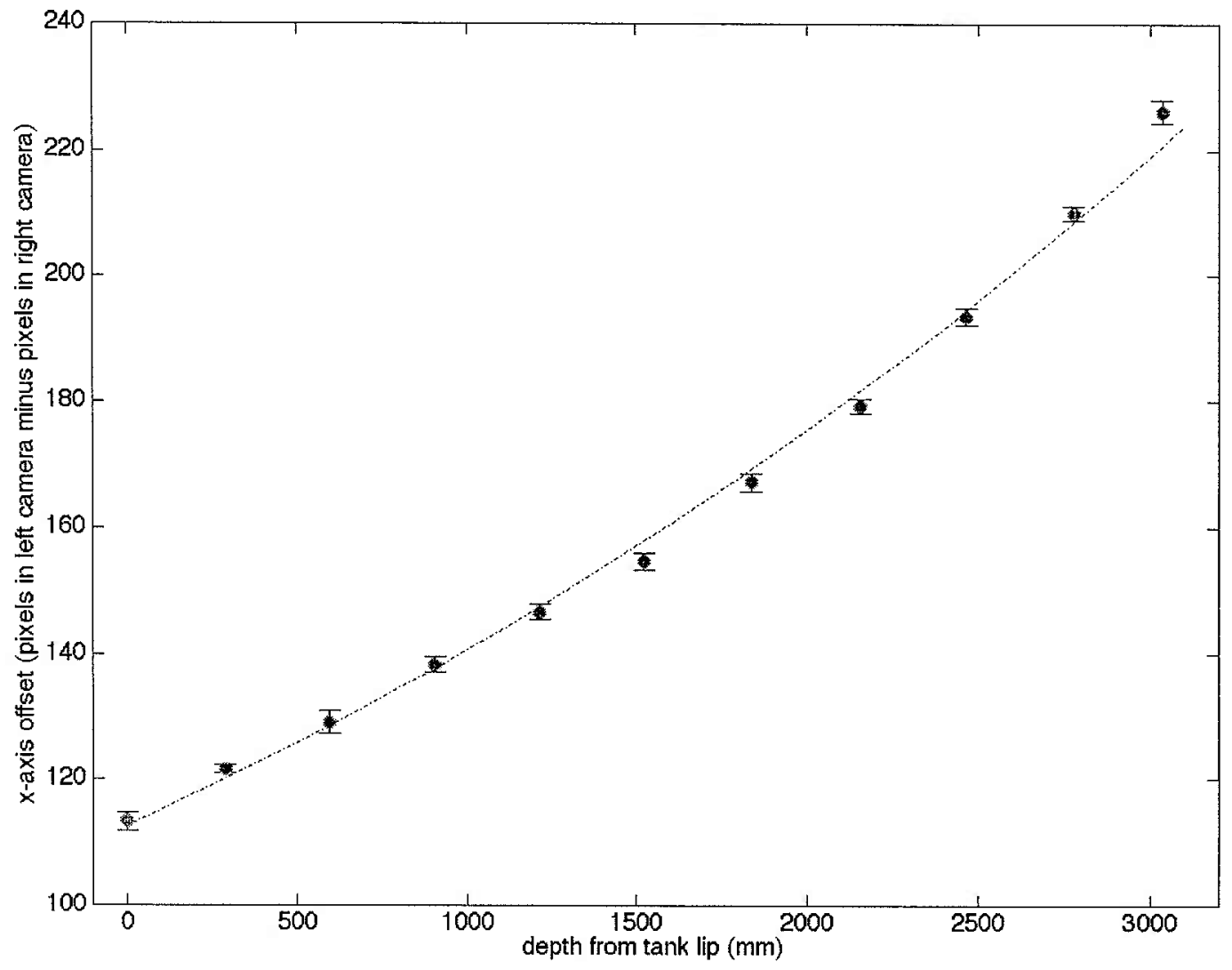


Figure 3.5. Length calibration curve showing the linear relation between depth and the $\mathrm{mm}$ per pixel conversion factor for the right camera (experiment K). Error bars represent \pm 1 standard deviation.

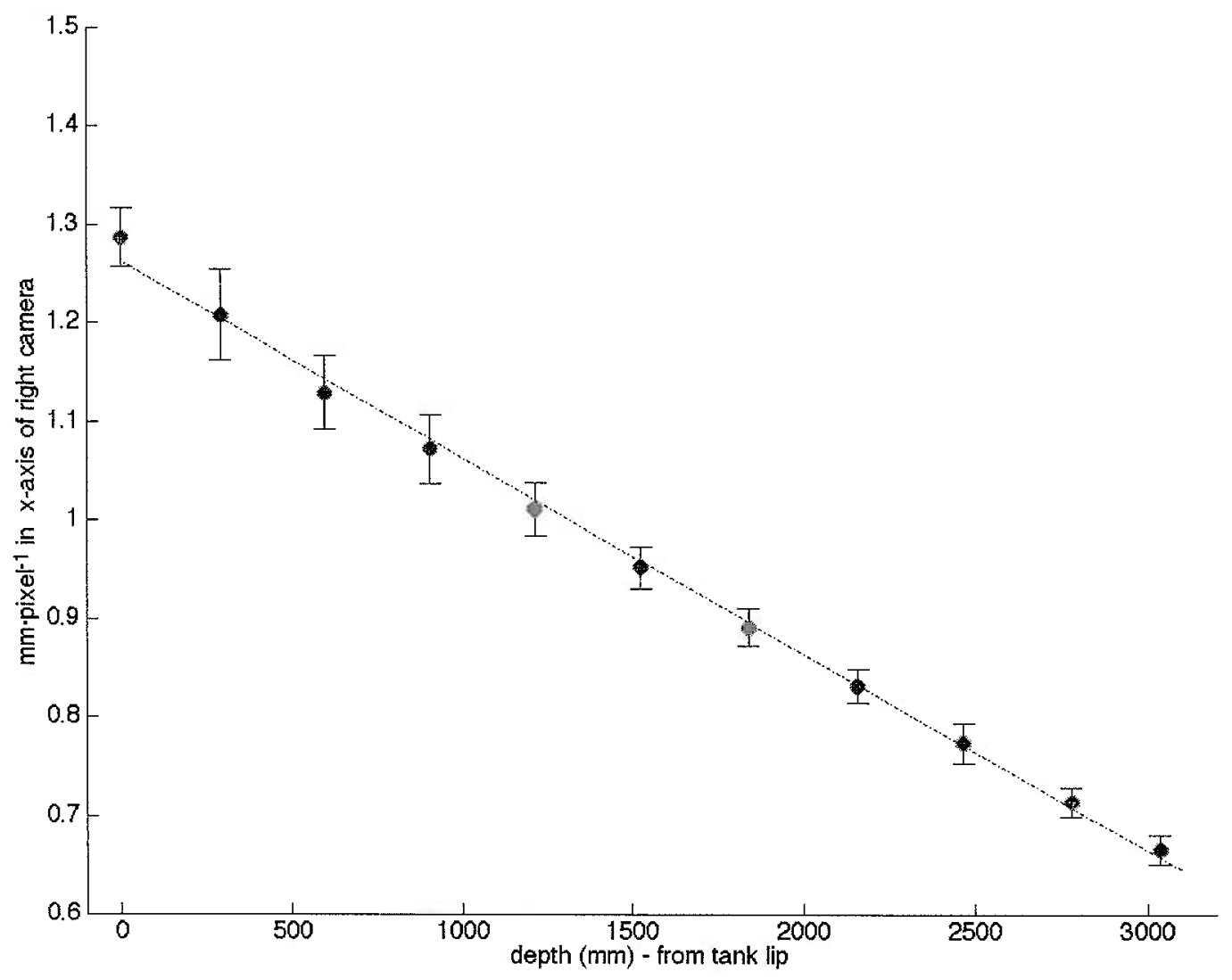


Figure 3.6. A 1-minute velocity profile for an individual larva (experiment K). Circles have been classed as pause events, and triangles have been classed as burst events. The time resolution is $0.2667 \mathrm{~s}$.

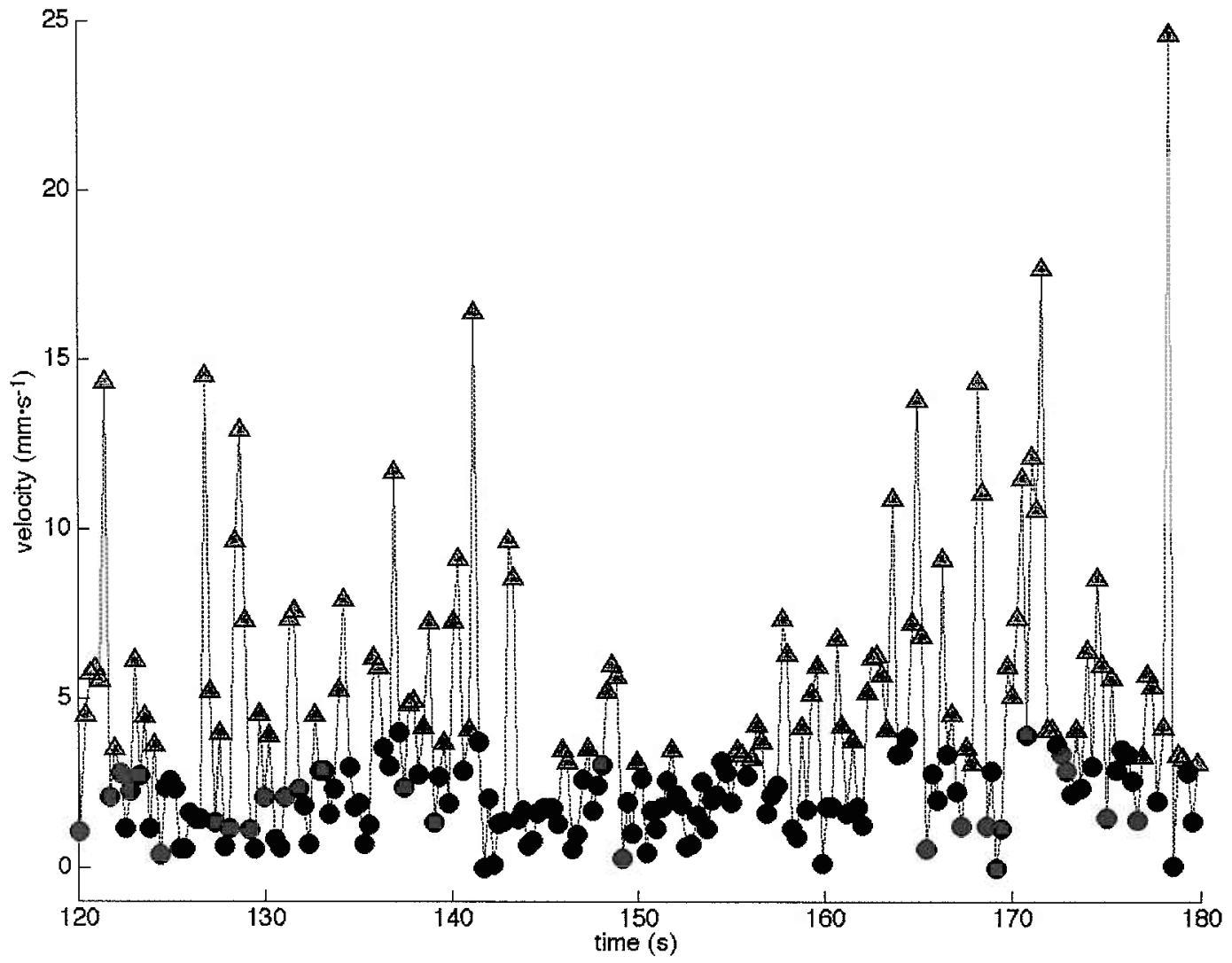




\section{$\underline{\text { Results }}$}

The swimming tracks of all larvae visible to both cameras were recorded. Six key behavioral parameters were measured: pause duration, pause frequency, distance traveled between pauses, burst swimming speed, burst duration, and the fraction of time spent swimming.

\section{Behavior of the individual}

For the purpose of comparing the behavioral response of cod larvae to the three different foraging conditions studied in the current work, behavior was described at the level of the individual. The behavior of each individual was summarized as a single value for each parameter, the mean parameter value of the entire observation period (table 3.4).

Examination of each burst and each pause event shows the behavioral variability of an individual within, presumably, constant foraging conditions. Figure 3.7 shows the frequency distribution of the duration of each pause event as well as the mean burst swimming speed and distance traveled between each pause event for one individual larva. Pause durations and the distances traveled between pauses followed an exponential distribution. Burst velocities were log-normally distributed. Probability plots verified that the parameter-value distributions for every individual conformed to this pattern. The mean and variance of pause durations and the distances traveled between pauses were determined by maximum likelihood estimation for each individual (The MathWorks 1998). The mean and variance of burst velocities were calculated from log-transformed data.

Because individuals demonstrated behavioral variability, an accurate and unbiased description of an individual's behavior requires an adequate observation period. For each experiment, larval swimming tracks were sub-sampled and analyzed in increasingly greater time intervals from 10 seconds to 3 minutes in 10-second intervals. For every individual, the mean and variance of each behavior parameter value was calculated, and the median of all individuals observed within each experiment was plotted against 
sampling time (fig. 3.8). The determination of adequate sampling time was made by examining the plotted data. For each behavior parameter a 40 -second sampling interval was usually sufficient for an accurate measurement. Only individuals that were observed continuously for 1 minute or more were analyzed. 


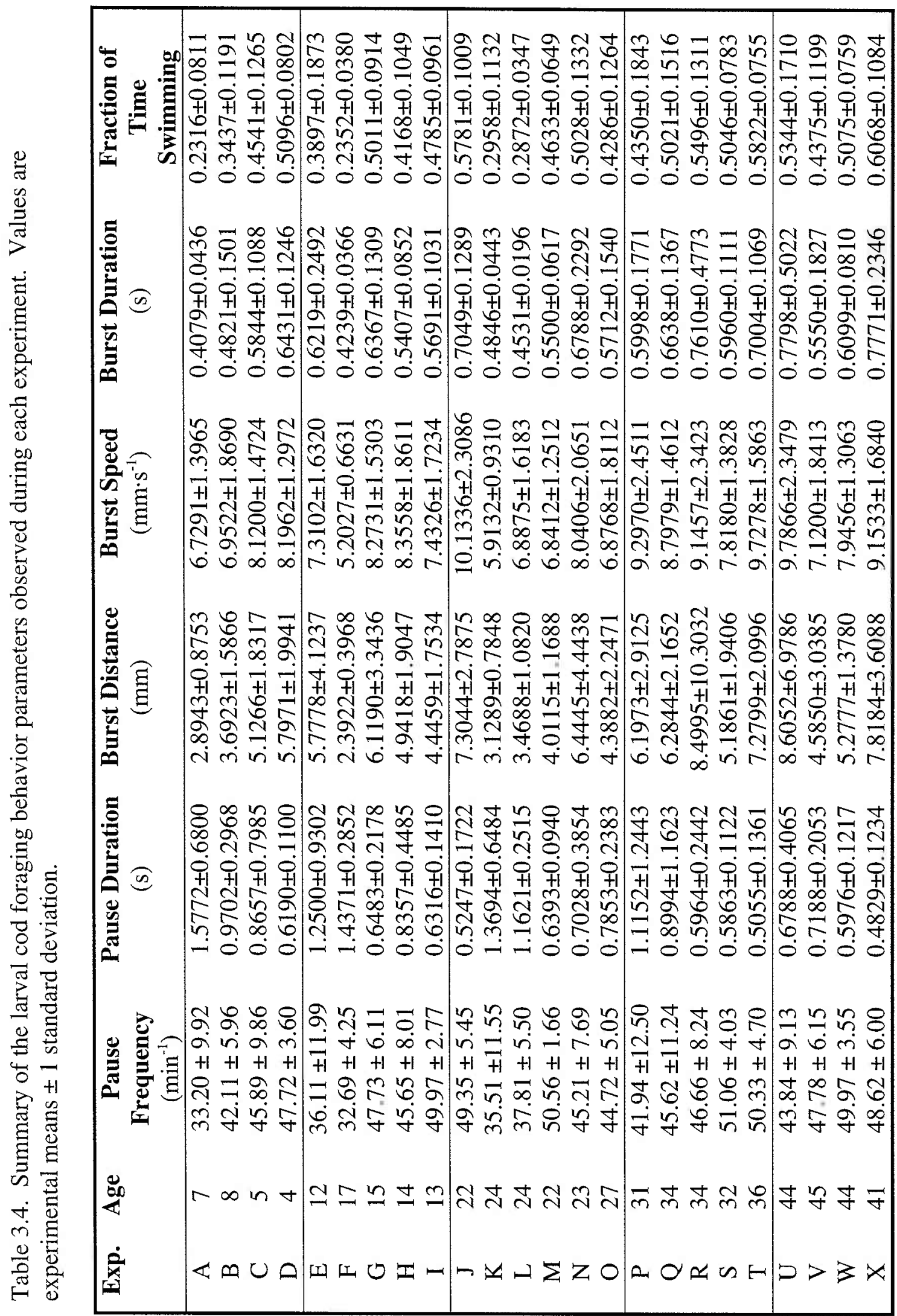


Figure 3.7. Frequency distributions of pause event durations, burst event durations, distances traveled between each pause event, and the mean burst swimming speeds for the same individual larva shown in figure 3.6 (experiment $\mathrm{K}$ ). Pause and burst durations and the distances traveled between pauses followed an exponential distribution. Burst velocities were log-normally distributed.
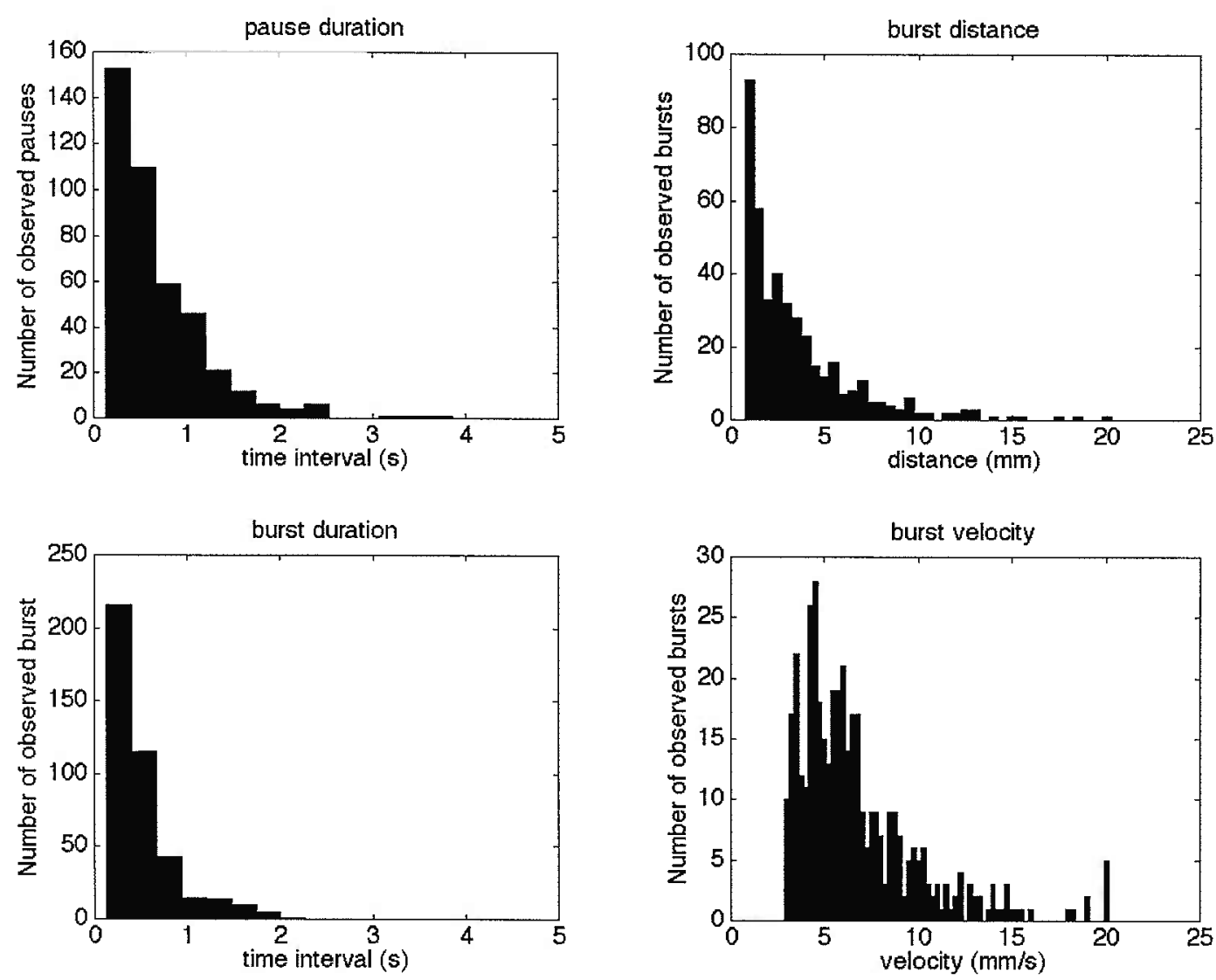
Figure 3.8. Example of the effect of observation time on the apparent behavior. This graph shows the effect of observation time on the estimation of pause duration for all larva in the 40 to 49 day-old age group. From plots such as these made for every behavioral parameter, $60 \mathrm{~s}$ was considered to be the minimum length for a reliable observation period of a single individual. The upper two traces represent no prey treatments, and the lower two traces represent rotifer treatments.

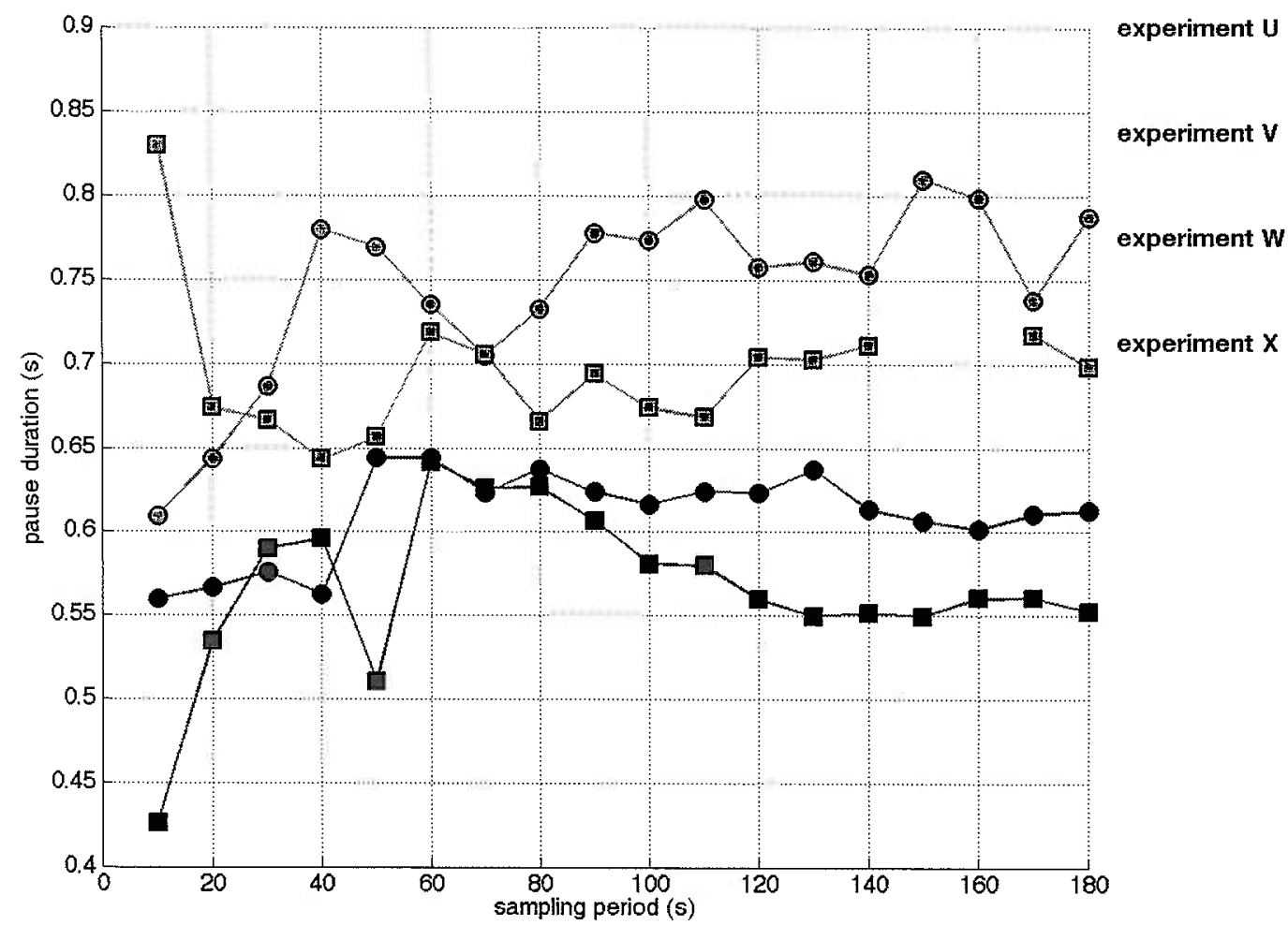




\section{Effect of the presence or absence of prey}

The frequency distribution of the values of each behavior parameter within each experiment was analyzed. Within each experiment, burst speed and pause frequency were normally distributed, while burst distance and pause duration were normally distributed after log-transformation.

To see the effect of prey treatment and age upon the foraging behavior of larval cod, the mean response of each experiment in each treatment group was plotted against age (figs. 3.9a-3.9f). In each case, graphical analyses of standardized residuals were used to evaluate how well the data met the assumptions of a linear regression. Normalprobability plots showed that the residuals were either normally (burst speed and pause frequency) or log-normally distributed (burst distance and pause duration), and plots of residuals against the expected response to age showed that the variance was reasonably homogeneous across the full range of ages studied. The relationship between each behavior parameter and age for each treatment group were described with linear leastsquares regressions (table 3.5 ).

The behavioral response to the presence or absence of prey (rotifers) was tested by ANCOVA (Kleinbaum et al. 1998) (table 3.6). Testing the mean response of each experiment gives each an equal weight in the analysis without regard to the number of individual larvae that could be tracked. The mean burst speed and the distance traveled during swimming bursts did not change significantly with larval age (table 3.5 , figs. $3.9 \mathrm{c}$ and $3.9 \mathrm{~d}$ ), nor were these characteristics of swimming bursts significantly different whether rotifer prey were present or absent (table 3.6).

Pause duration and the frequency that larvae pause (pauses per minute) were both significantly related to larval age (table 3.5). Pause duration was significantly longer in the absence of prey than when rotifers were present (table 3.6). When prey were not present, pause duration was $\approx 70 \%$ longer at 5 days old; this difference declined to $\approx 20 \%$ longer pauses at 45 days old. Pause frequency is the inverse of the total search-cycle duration, the sum of pause duration and burst duration. As pause duration decreased with age, burst duration increased but to a lesser amount (significant only in the presence of 
prey); therefore pause frequency increased as larvae grew older. Larvae in an environment without prey paused less frequently, making $\approx 26 \%$ fewer pauses per unit time at 5 days old but only $\approx 6 \%$ fewer pauses at 45 days old.

No formal statistical comparison was made between the zooplankton and rotifer treatments nor between the zooplankton and zero prey treatments because only four experiments were run. However, the behavior of larvae preying upon wild zooplankton was much the same as larvae preying upon rotifers (figs. 3.9a-3.9f). In every measured parameter (pause duration, pause frequency, burst distance, burst speed, burst duration, and the fraction of time spent swimming) the behavioral response of larvae to zooplankton was similar to the response to rotifers. 
Figure 3.9a. Pause duration vs age for no prey, rotifer prey $\left(100 \mathrm{~L}^{-1}\right)$, and zooplankton prey $\left(100 \mathrm{~L}^{-1}\right)$ treatments. Error bars are $\pm 95 \%$ confidence intervals. Pause duration has been log-transformed.

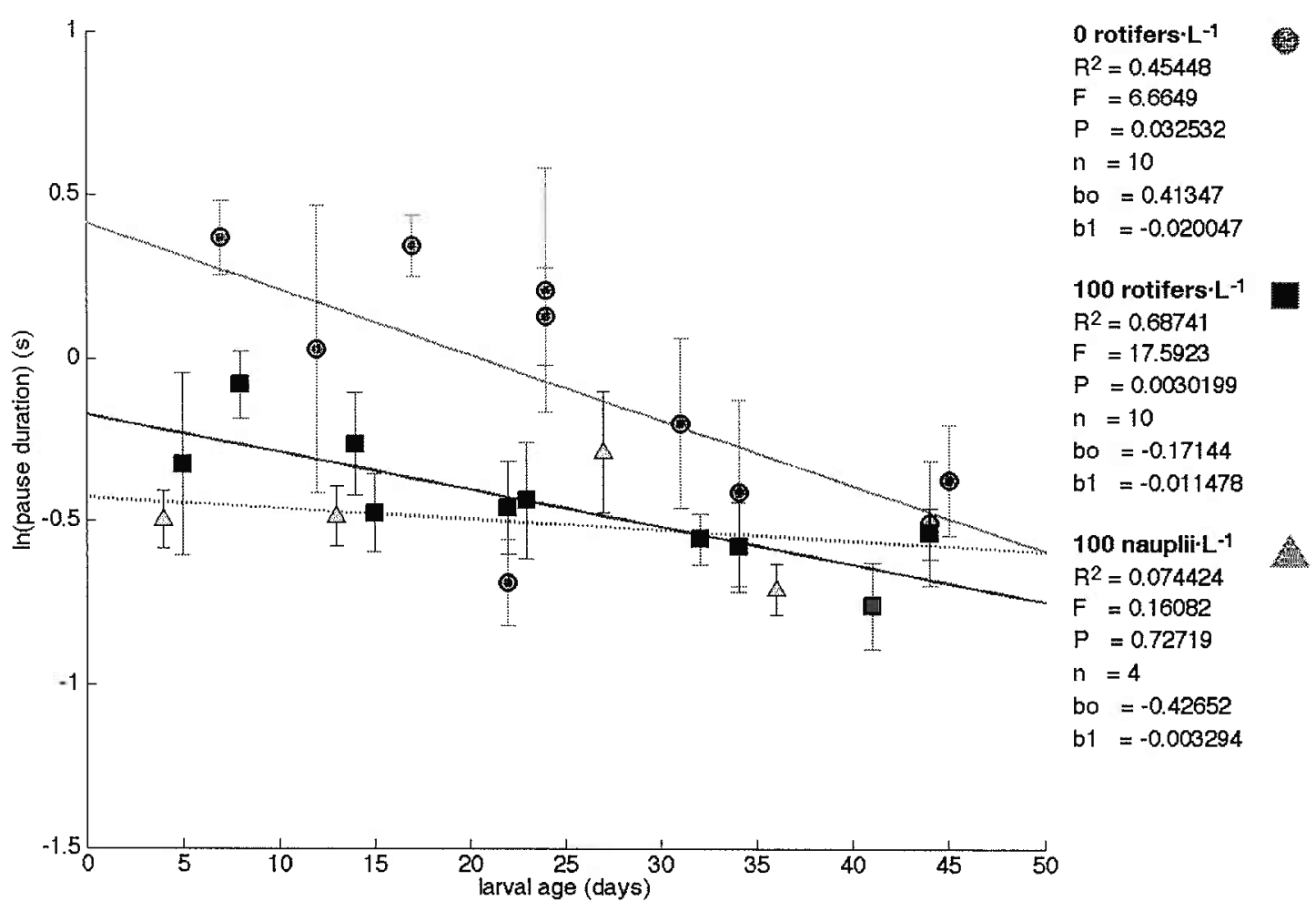


Figure 3.9b. Pause frequency plotted against age for no prey, rotifer prey $\left(100 \mathrm{~L}^{-1}\right)$, and zooplankton prey $\left(100 \mathrm{~L}^{-1}\right)$ treatments. Error bars are $\pm 95 \%$ confidence intervals.

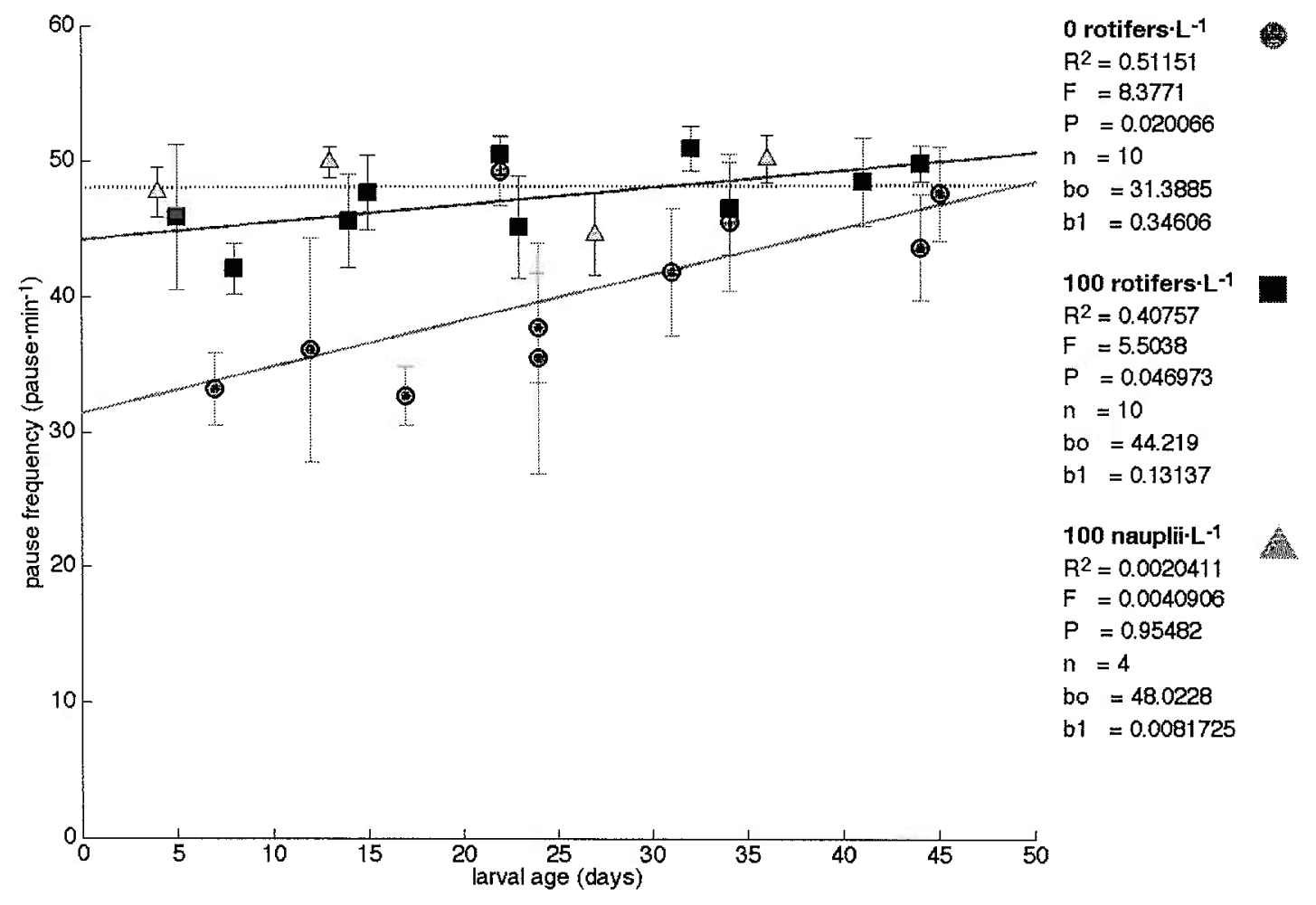


Figure 3.9c. Burst distance plotted against age for no prey, rotifer prey $\left(100 \mathrm{~L}^{-1}\right)$, and zooplankton prey $\left(100 \mathrm{~L}^{-1}\right)$ treatments. Error bars are $\pm 95 \%$ confidence intervals. Burst distance has been log-transformed.

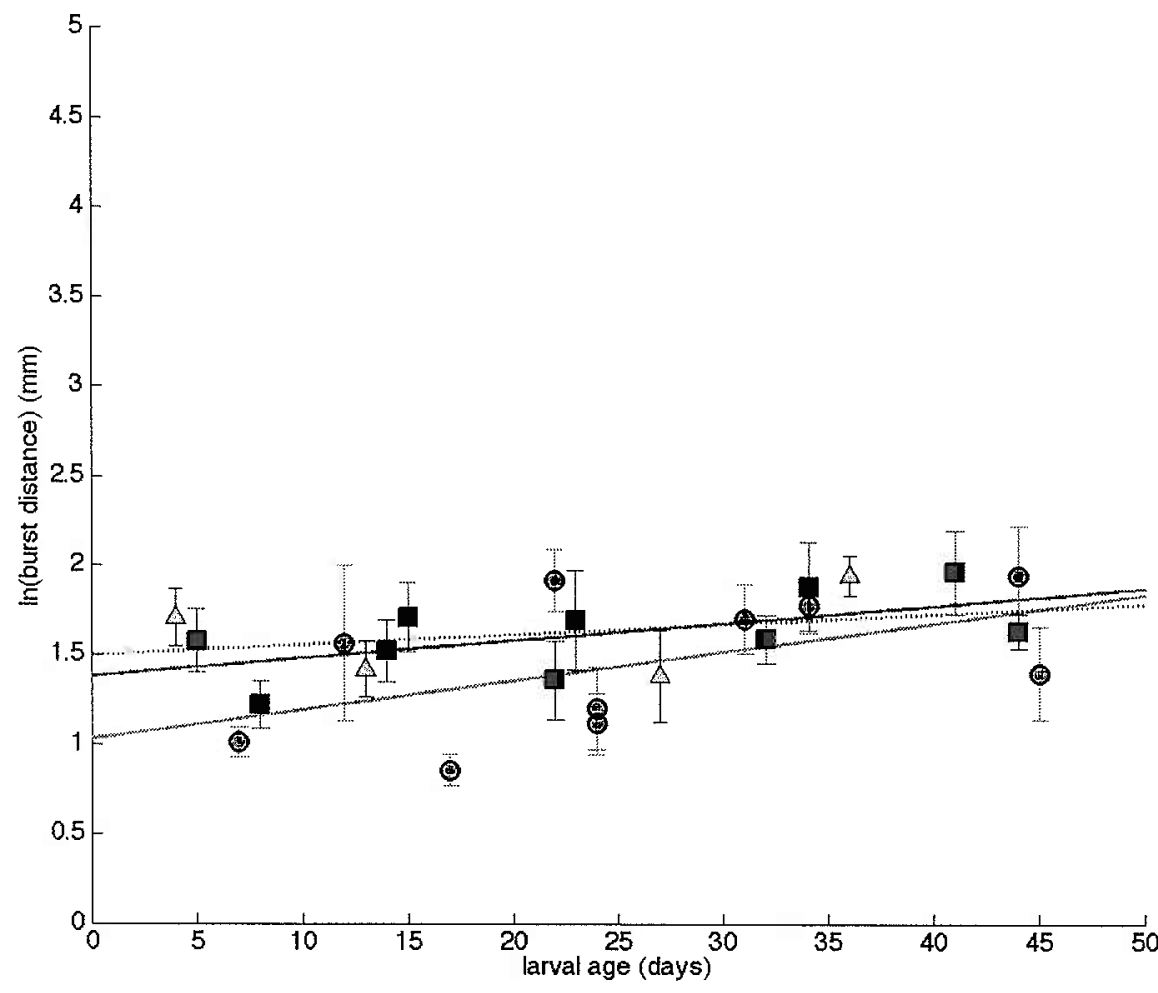


Figure 3.9d. Burst speed vs age for no prey, rotifer prey $\left(100 \mathrm{~L}^{-1}\right)$, and zooplankton prey $\left(100 \mathrm{~L}^{-1}\right)$ treatments. Error bars are $\pm 95 \%$ confidence intervals.

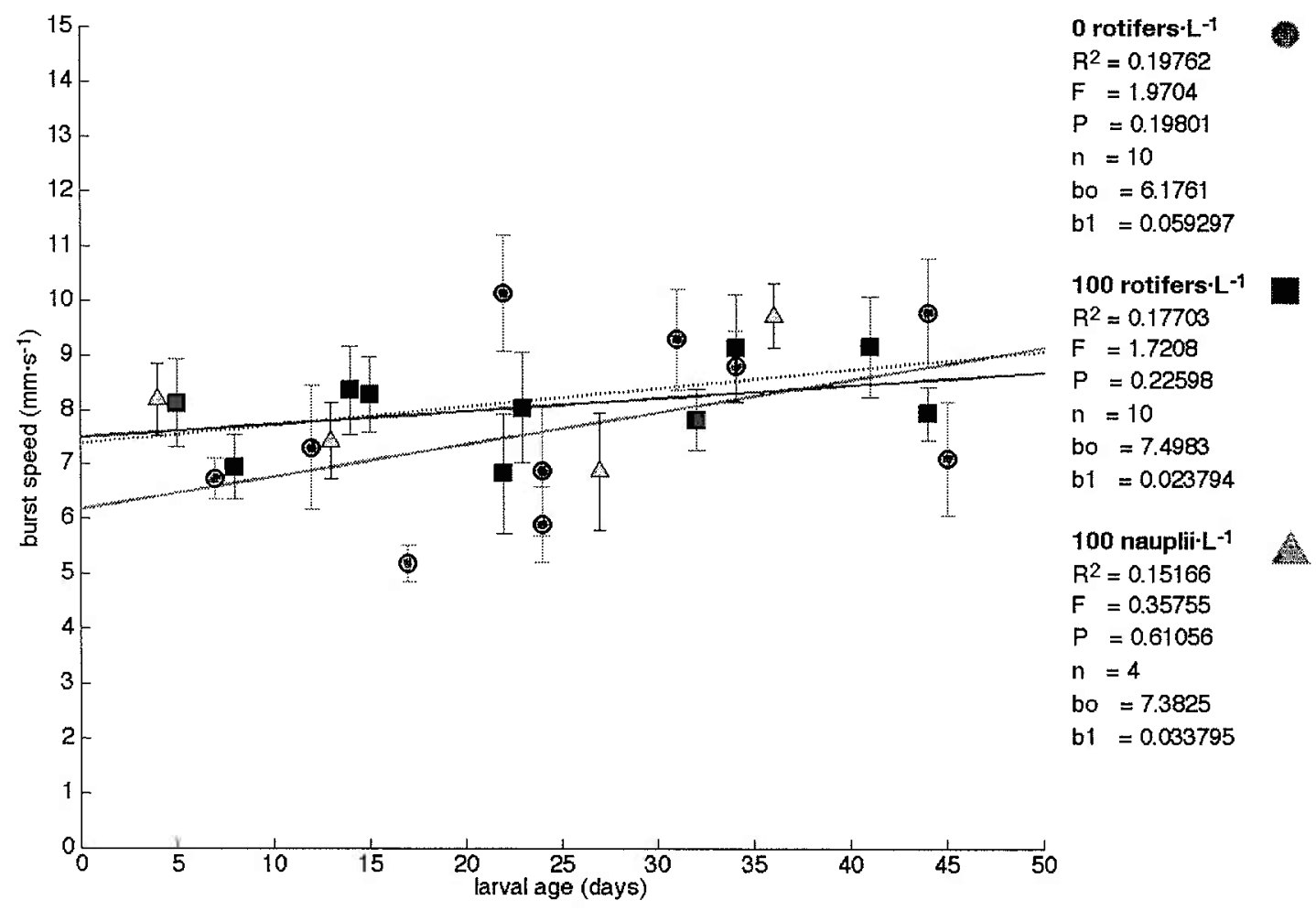


Figure 3.9e. Burst duration vs age for no prey, rotifer prey $\left(100 \mathrm{~L}^{-1}\right)$, and zooplankton prey $\left(100 \mathrm{~L}^{-1}\right)$ treatments. Error bars are $\pm 95 \%$ confidence intervals. Burst duration has been log-transformed.

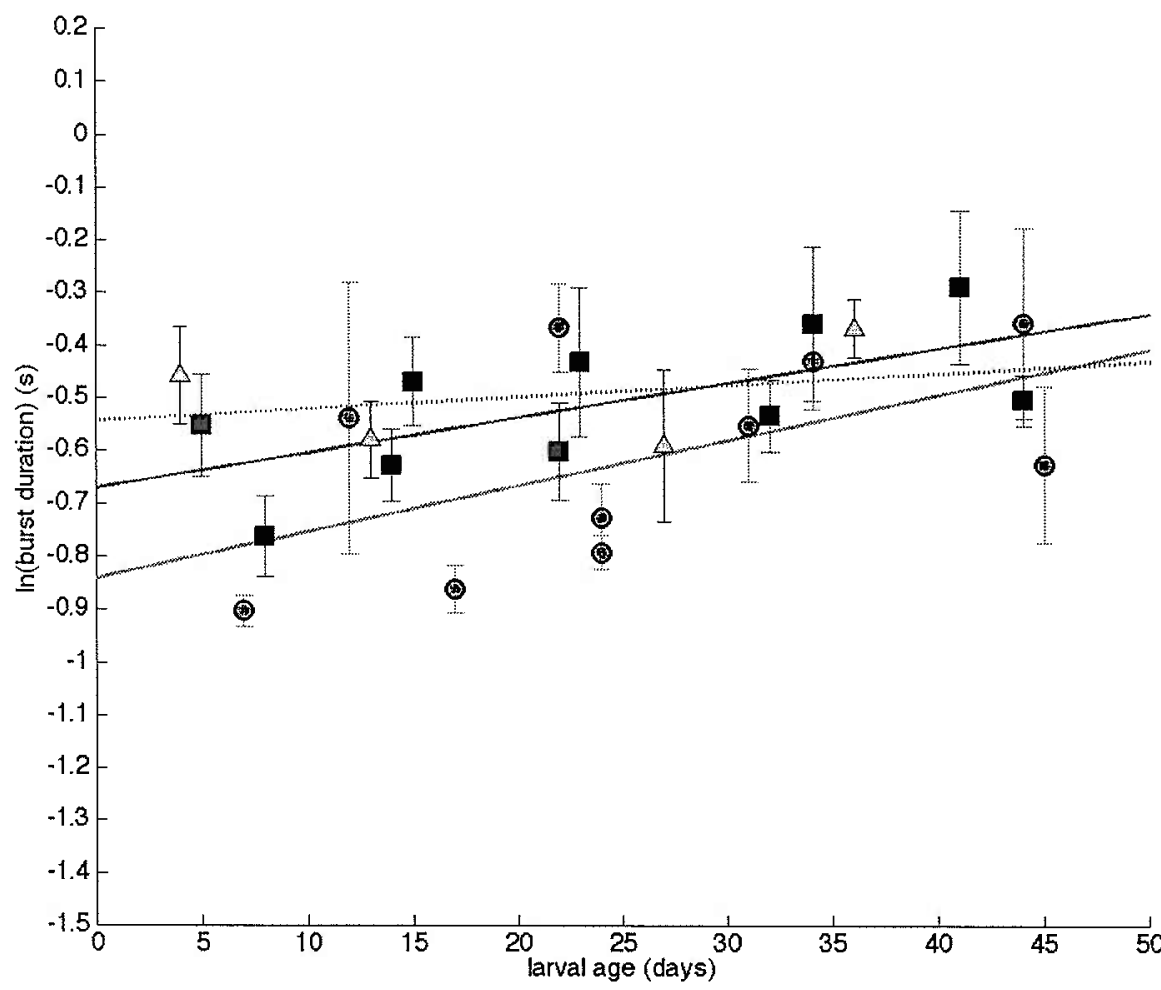

0 rotifers $\cdot \mathrm{L}^{-1}$

$\mathrm{R}^{2}=0.29837$

$\mathrm{F}=3.402$

$P=0.10235$

$\mathrm{n}=10$

bo $=-0.84041$

b1 $=0.0086667$

100 rotifers $L^{-1}$

$R^{2}=0.43451$

$F=6.1471$

$P=0.038152$

$\mathrm{n}=10$

bo $=-0.67049$

b1 $=0.0066414$

100 nauplii $L^{-1}$

$R^{2}=0.093229$

$F=0.20563$

$P=0.69467$

$n=4$

bo $=-0.5434$

b1 $=0.0022668$ 
Figure 3.9f. Fraction of time spent swimming vs age for no prey, rotifer prey $\left(100 \mathrm{~L}^{-1}\right)$, and zooplankton prey $\left(100 \mathrm{~L}^{-1}\right)$ treatments. Error bars are $\pm 95 \%$ confidence intervals.

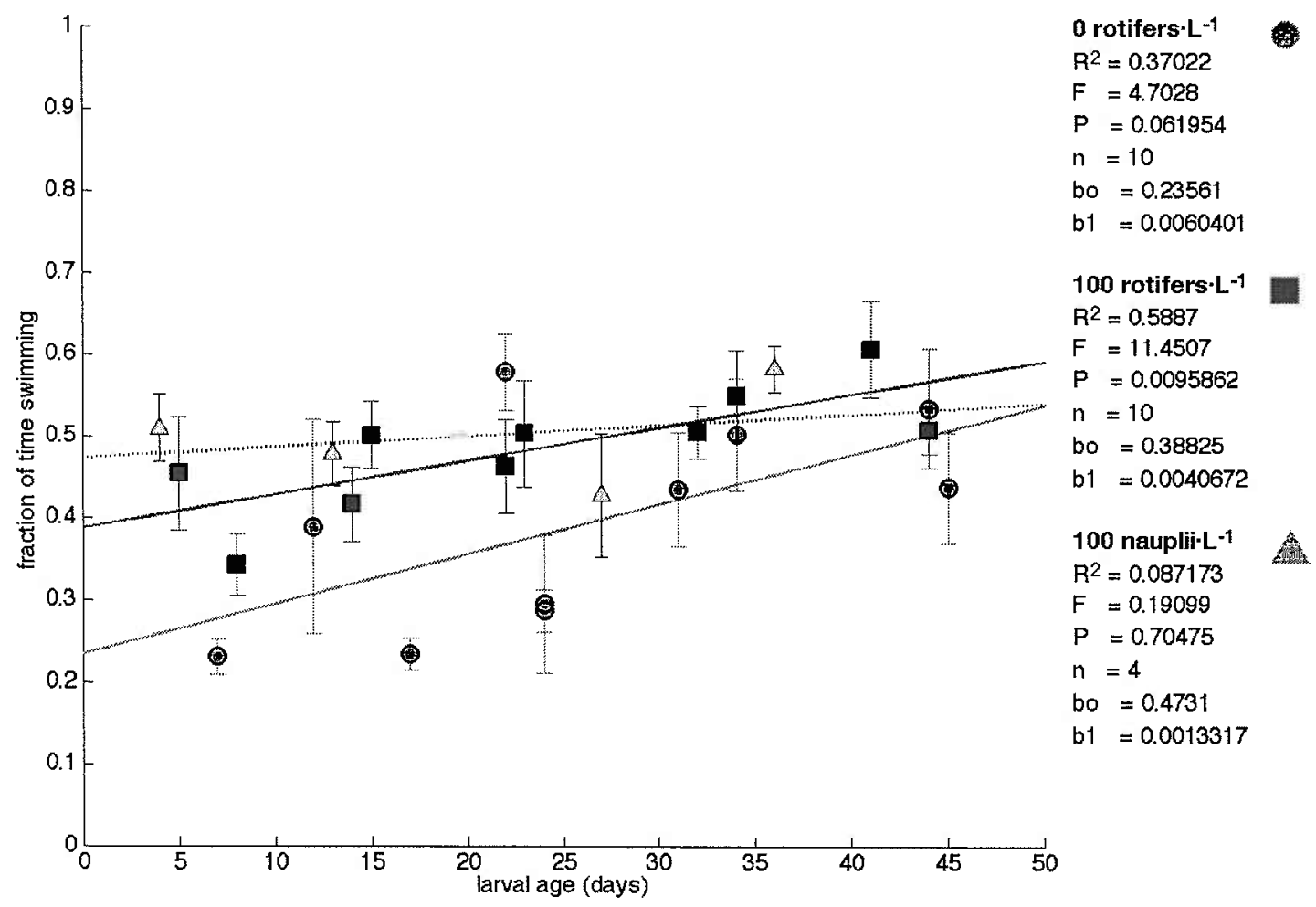




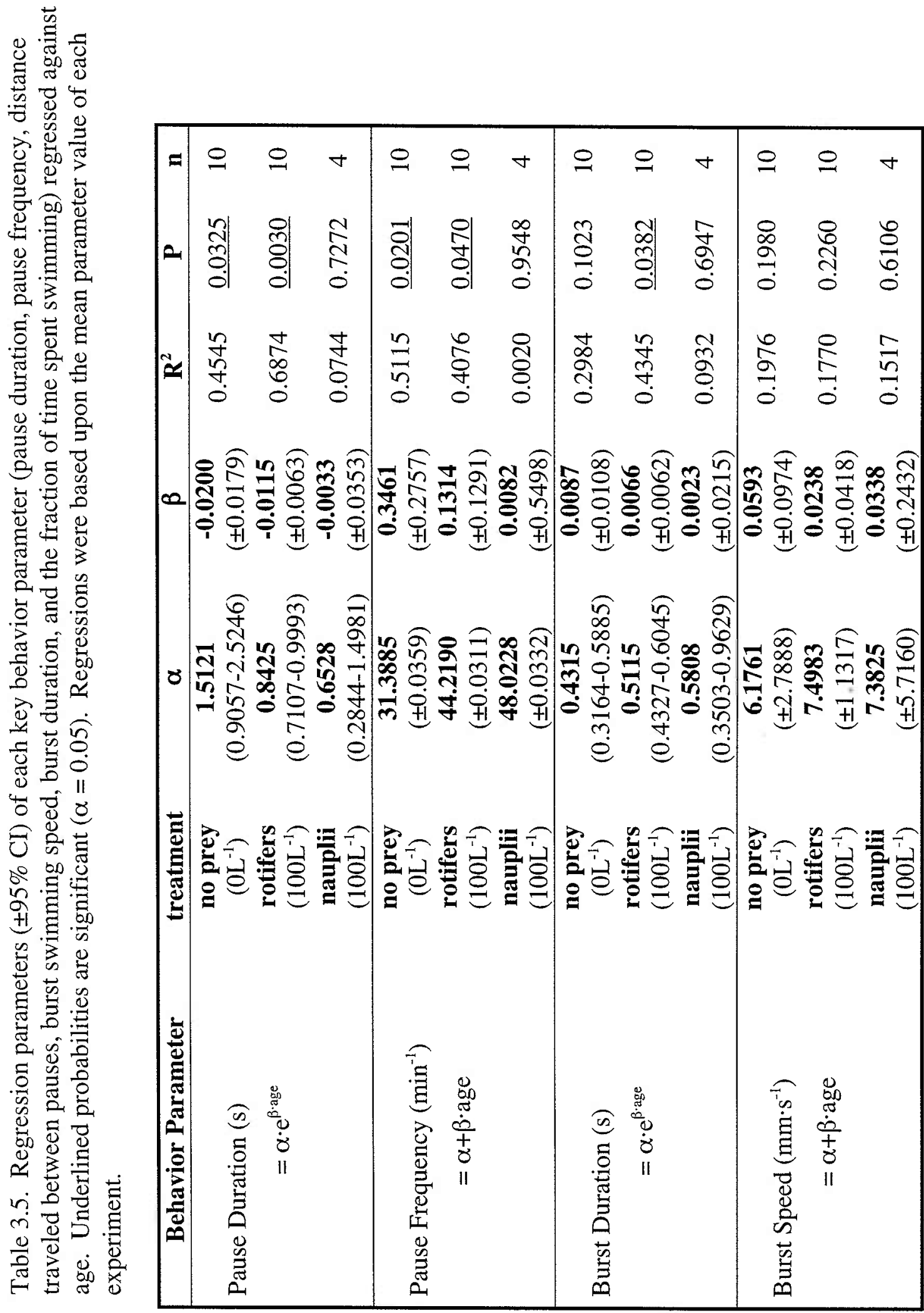




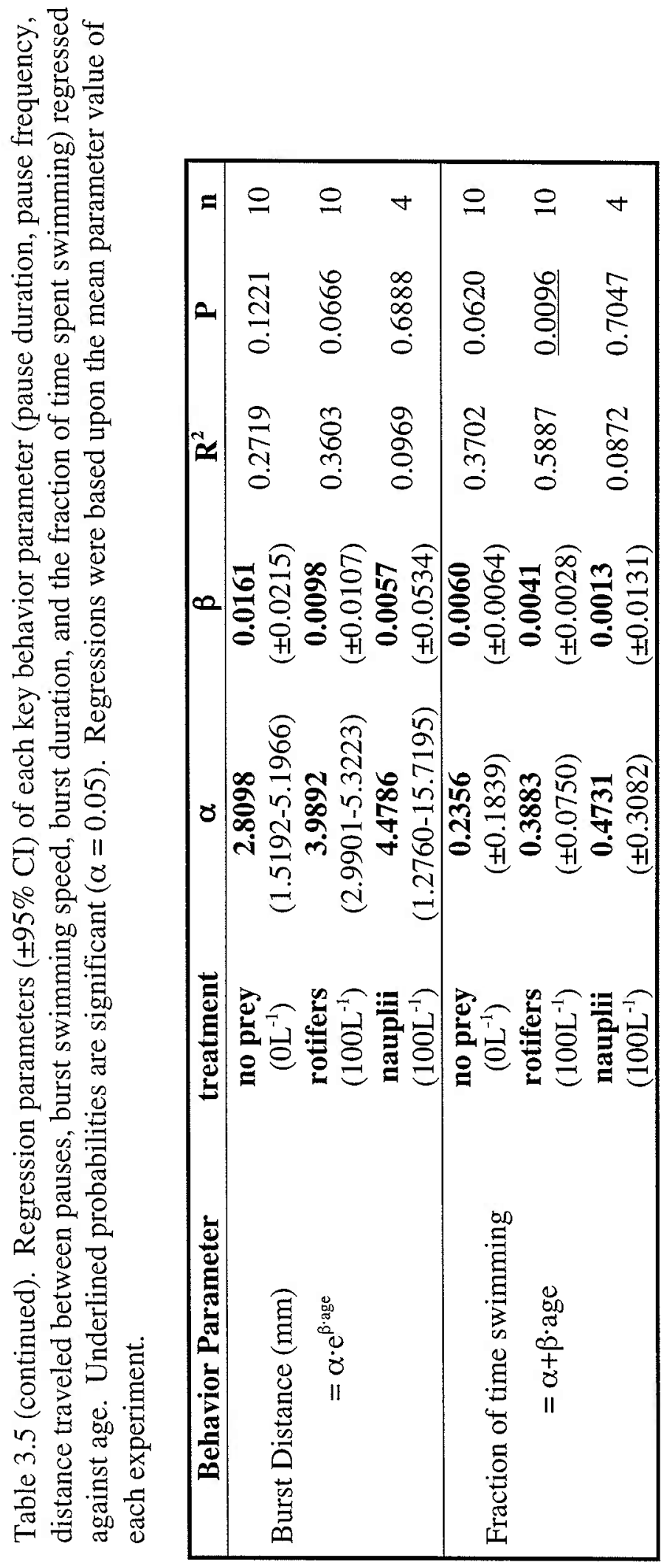




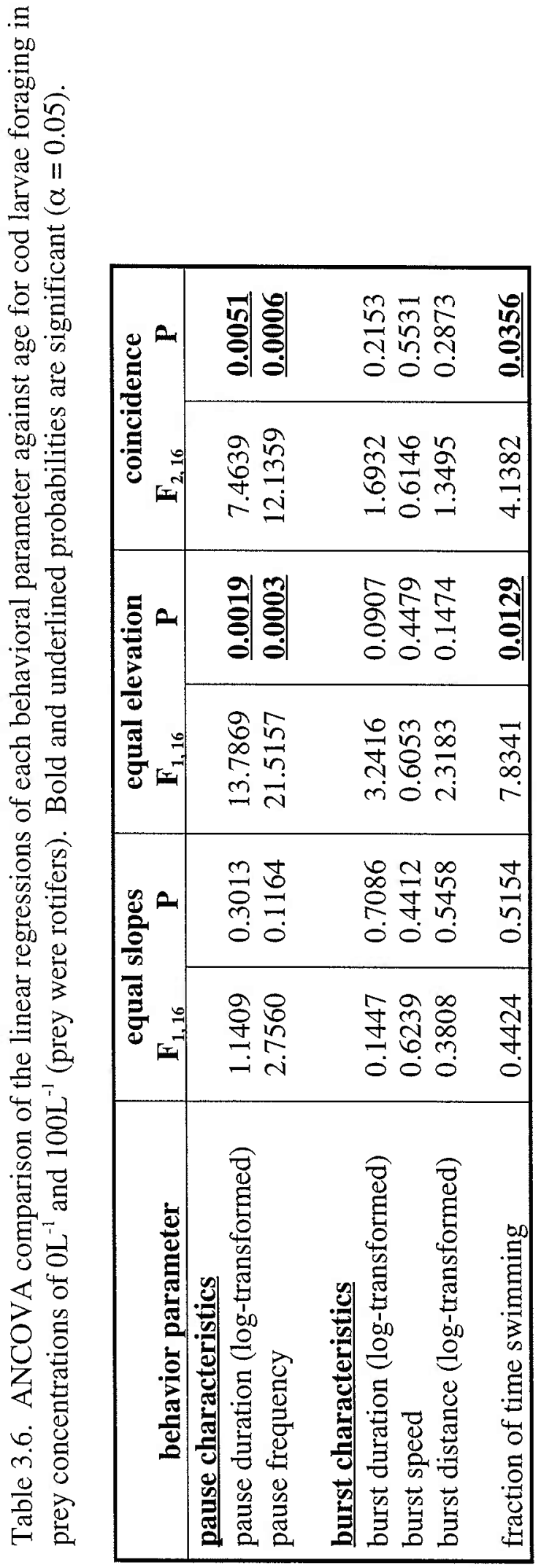




\section{Discussion}

The goals of this research were 1) to observe the foraging behavior of larval cod in large volumes in an attempt to reduce confinement and crowding effects; 2) to observe behavior throughout early development; 3) to measure the foraging capacity; and 4) to observe if and how larval cod adjust their foraging behavior in response to foraging conditions, in this case, the presence or absence of prey.

The main reason for developing the tall-tank observation system was to be able to observe larval behavior in large volumes. Previously, observations of larval foraging behavior have been conducted in small volumes (usually under $80 \mathrm{~L}$ ) which may have introduced unknown confinement and crowding effects on behavior. The current system allowed observation throughout a $250 \mathrm{~L}$ column of water. Observing larvae in large volumes does, however limit the type of data that can be collected. Prey organisms could not be observed, therefore direct measurement of search-volume geometry and reactive distance could not be collected. Also, the body orientation of larvae could not be well resolved so no attempt was made to collect data on the rate of attack posturing. Stereo video cameras allowed recording larval position in three-dimensions. However, since larval swimming activity was predominately in the horizontal plane, the depth-position data of a larva was used to calibrate horizontal distances. Tracking larval positions on a series of video images provides not only measurements of the frequency and duration of different behavioral events but also accurate measurements of the distances and swimming speeds involved. Collecting data from a video record also provides data with a high time resolution $(0.2667 \mathrm{~s})$ and eliminates any error and bias of human response time that could be introduced when quantifying larval behavior by eye in real time. The automated tracking protocol that was developed for this study was an aid but could not replace human observation. All larval swimming tracks had to be error-checked and corrected by eye in both cameras, a very labor-intensive effort. Future improvements in automated tracking algorithms should allow more rapid collection of behavioral data at even higher temporal and spatial resolutions. 


\section{Larval cod as saltatory predators}

Larval cod are saltatory predators. Saltatory predators travel in short, discrete episodes, and search for prey only during the motionless periods between swimming bursts (Evans \& O'Brien 1988, Hunt von Herbing \& Gallager 2000). Cruise predators, on the other hand, swim continuously while scanning for prey at the periphery of their search space (Rosenthal \& Hempel 1970). A saltatory foraging strategy conveys several potential advantages to larval fish over a cruise foraging strategy. First, there is an energetic advantage, and it fits well with the burst-and-glide pattern of larval cod noted by many previous studies (Solberg \& Tilseth 1984, MacKenzie \& Kiørboe 1995, Munk 1995, Puvanendran \& Brown 1999, Hunt von Herbing \& Gallager 2000). Burst-andglide swimming is the most efficient and dominant swimming strategy for foraging larvae (Vlymen 1974, Weihs 1980, Videler \& Weihs 1982, Webb \& Weihs 1986). Second, saltatory foraging provides stabilization of the visual field. Visual acuity may be reduced as swimming speed increases (Gendron \& Staddon 1983, Anderson et al. 1997) but among saltatory foragers which search at rest, this problem is avoided. Third, saltatory foraging may offer a better opportunity to practice prey choice because prey can be located throughout the search space, and there is greater chance of encountering multiple prey items simultaneously. And fourth, saltatory foraging is a potentially more flexible search strategy. There are just two phases of the saltatory search cycle before prey are encountered, the burst that serves to position larvae within a new search-volume and the pause when larvae search for prey. The burst phase may be described by its speed, duration, and distance traveled. The pause phase can be described by its duration and frequency (or search frequency). Both burst and pause characteristics can be changed with foraging conditions (O'Brien et al. 1989, O'Brien et al. 1990).

This study looked at how larval cod search behavior changes in response to the presence and absence of prey. Because saltatory foragers only search for prey during pauses when speed is very low or zero, variation in burst speed and the distance traveled during swimming bursts should have no effect on foraging success under conditions of different prey density (O'Brien et al. 1986). In the present study, larval cod swimming 
bursts did not change in response to prey treatment with respect to speed, duration, or distance traveled (table 3.6); and only in the rotifer prey treatment was there a significant correlation between burst duration and age (table 3.5).

In many genera that practice saltatory foraging from fish to birds, the pause duration increases under more difficult foraging conditions such as when searching for smaller prey or when searching in more visually complex environments (review by O'Brien et al. 1990). Anderson et al. (1997) developed a general predictive model of saltatory search patterns when pause-travel motion is more economical than continuous motion and predict that as prey density increases, pause duration should decrease and pause frequency increase to maximize net energy gain. The present study shows that the presence or absence of prey has a significant effect upon larval cod pause duration and pause frequency, and this effect is consistent with these earlier observations and predictions (table 3.6, figs. 3.9a-3.9b). When prey are absent, presumably difficult foraging conditions, pause duration is longer $(\approx 70 \%$ longer at 5 days old and $\approx 20 \%$ longer at 45 days). Pause frequency must decrease if pause duration increases because pause frequency is the inverse of the total search cycle duration (search cycle duration = pause duration + burst duration). Pause frequency is lower when prey are absent (27\% lower at 5 and $6 \%$ lower at 45 days old).

The results of this study are unlike those of Munk (1995) who found that foraging activity was greater (pause duration was lower and pause frequency greater) at lower prey densities when prey were harder to find. There may be several explanations for this difference. First, there were methodological differences in the way in which data were recorded; in Munk's study larval behavior was recorded and interpreted by eye in realtime, in this study behavior was recorded on video-tape and interpreted by computer algorithm. There may be a large behavioral difference between larvae foraging in an environment with no prey (the present study) and larvae foraging in an environment in which prey are rare (Munk's study). The feeding history of the larvae used in the two studies was different (hunger as a factor is discussed below). Finally, Munk's observations were made under conditions of turbulence and larval response to different 
prey concentrations may change with turbulence. MacKenzie and Kiørboe (1995) measured the separate components of the larval cod foraging cycle in conditions of calm and turbulence for two size classes. For the smaller larvae $(5.2 \mathrm{~mm})$, the larvae responded to prey density as they did in Munk's study while for the larger larvae $(6.1 \mathrm{~mm})$, larvae responded to prey density as they did in the present study. For both size classes, the response to prey density remained consistent in calm and turbulent conditions (turbulence is further discussed below).

\section{Foraging capacity}

What effect does the observed modification of foraging behavior with prey treatment have upon overall foraging capacity? The foraging capacity $\left(\mathrm{ml} \cdot \mathrm{min}^{-1}\right)$ was estimated for every individual larva. Larval cod respond to prey only when they are not actively swimming (MacKenzie \& Kiørboe 1995, Hunt von Herbing \& Gallager 2000), therefore their foraging capacity $\left(\mathrm{ml} \cdot \mathrm{min}^{-1}\right)$ is a function of pause frequency (PF) rather than of swimming speed. Cod larvae perceive prey $30^{\circ}$ to $90^{\circ}$ off of the longitudinal axis of the body in both the horizontal and vertical axes (Hunt von Herbing \& Gallager 2000). The search-volume can therefore realistically be modeled as a half-sphere in front of the larva extending as far as the reactive distance $(R$, the distance at which larvae react to perceived prey). The search rate can be modeled as:

$$
\text { Foraging capacity }=(2 / 3) \cdot \pi \cdot R^{3} \cdot \mathrm{PF} \text {. }
$$

The reactive distance could not be measured in the present study; however, it may be estimated as the distance traveled between search-volumes if consecutive volumes are assumed to neither overlap nor leave unsearched water in between. This strategy should be the energetically most efficient, minimizing the distance traveled to search a given volume of water (O'Brien et al. 1990).

Estimated foraging capacities of each age group are shown in figure 3.10 and table 3.7. These estimates are based upon the measured pause frequencies for each individual and the mean burst distances predicted at each age (ie., from burst distance regressed 
against age, table 3.5). Estimated foraging capacity was significantly higher among larvae foraging under high prey densities (ANCOVA comparison of mean experimental response: equal slopes, $\mathrm{F}_{1,16}=58.8236, \mathrm{P}<<\underline{0.0001}$; equal intercepts, $\mathrm{F}_{1,16}=377.0445, \mathrm{P}<<$ 0.0001). The value of this statistical comparison is limited because the variability between experiments has been reduced to the variability in the pause frequency alone. The size of the search-volume is very sensitive to the perceptive radius, and measurement error of burst distance is magnified to the third power. Ninety-five percent prediction intervals around foraging capacities estimated using individual measurements of burst distance span more than two orders of magnitude and estimated values are not significantly different between prey treatments.

Unfortunately, there are still no accurate, direct measurements of reactive distance and the size of larval cod search-volumes. The most precise measurements of reactive distance in larval cod (Hunt von Herbing \& Gallager 2000) show that as larvae grow, their visual acuity increases, and reactive distance increases from about 1 body length (at $5 \mathrm{~mm}$ ) to 2.5 body lengths (at $8 \mathrm{~mm}$ ) (table 3.7 ). These values are considerably higher than the estimates used in the present study and higher than the 0.8 body lengths estimated by MacKenzie and Kiørboe (1995) which have been used in subsequent trophodynamic models (e.g., Werner et al. 2001, Lough et al. in press). The laboratory measurements made by Hunt von Herbing \& Gallager (2000) may be greater than reactive distance under natural conditions. In their experimental set-up, the foraging environment was illuminated laterally with bright prey standing out against a black background, and prey items may have been visible at a greater distance than they would have been otherwise. Munk's (1995) estimates of reactive distance may also be too high as they were calculated from prey encounter rates (as estimated from attack posture rate) which may have been enhanced by turbulence introduced by water-jets in the observation tank.

Larval cod clearly demonstrated lowered pause frequency when prey were absent (fig. 3.9b) and therefore a lower foraging capacity because fewer search-volumes can be searched in a given period of time. An increased foraging capacity when prey were 
scarce would seem to be more beneficial for growth and survival. This could be an energy-conservation strategy; hungry larvae reduce their swimming activity until foraging conditions improve. Alternatively, pause frequency may be lower because the pause duration becomes longer as larvae spend more time visually processing each search-volume. These two hypotheses are not mutually exclusive. 
Figure 3.10. The estimated foraging capacity of larvae in the presence and absence of prey (rotifers, $100 \mathrm{~L}^{-1}$ ). Foraging capacity $=(2 / 3) \cdot \pi \cdot \mathrm{R}^{3} \cdot$ (pause frequency). Points represent the mean estimated value of all individual larvae observed in each experiment \pm $95 \%$ confidence intervals. Reactive distance was taken as the burst distance at each age as calculated from the burst distance vs age regression (table 3.3).

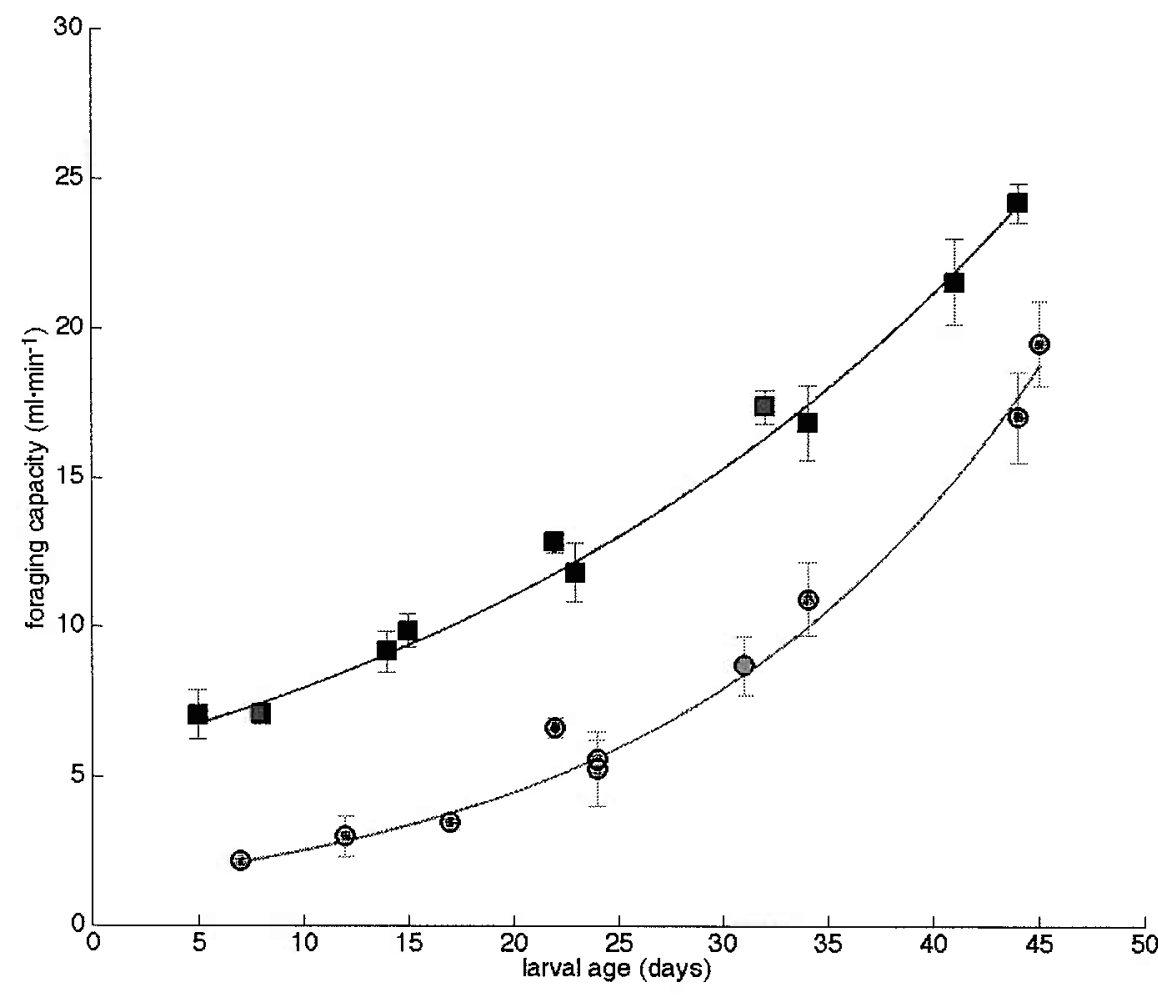

$$
\begin{aligned}
& \text { O rotifers } \cdot \mathrm{L}^{-1} \\
& \mathrm{R}^{2}=0.97812 \\
& F=357.675 \\
& P=6.3194 \mathrm{e}-08 \\
& \mathrm{n}=10 \\
& \text { bo }=0.34879 \\
& b 1=0.057417 \\
& 100 \text { rotifers } \cdot \mathrm{L}-1 \\
& \mathrm{R}^{2}=0.98749 \\
& F=631.456 \\
& P=6.7322 \mathrm{e}-09 \\
& \mathrm{n}=10 \\
& \text { bo }=1.7478 \\
& b 1=0.032655
\end{aligned}
$$




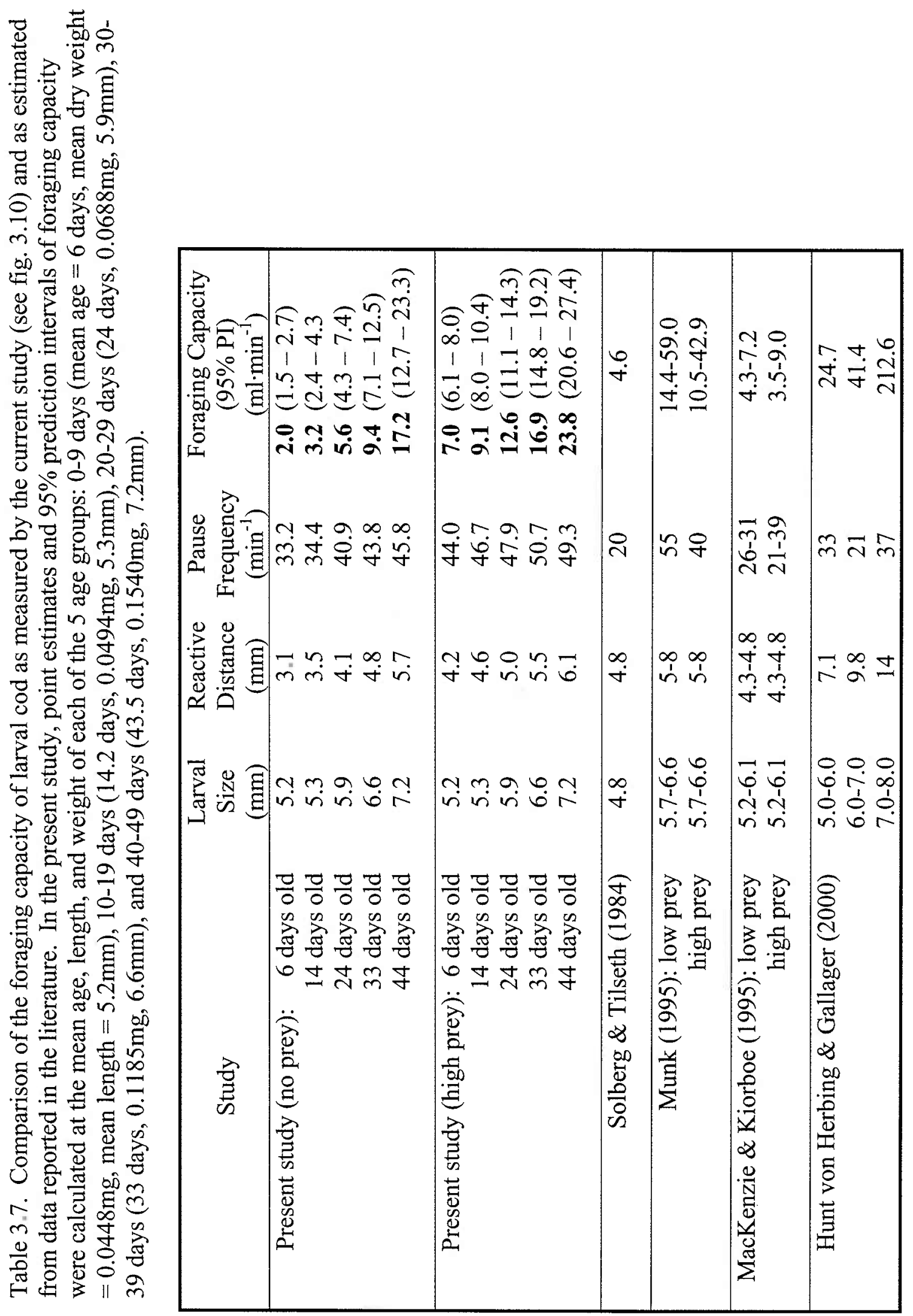




\section{Other factors that may affect foraging behavior}

In the ocean environment larval cod must, of course, contend with more than just variation in prey density. Turbulence, hunger, and ambient light intensity are some of the other important factors that can affect foraging success.

Larvae in the ocean have been observed feeding near their maximum rate independent of prey concentration, and field ingestion rates are generally higher than observed in the laboratory (MacKenzie et al. 1990). Moderate small-scale turbulence can enhance preyencounter rates by increasing the relative motion between predator and prey and carrying prey into the larval search-volume (Rothschild \& Osborn 1988). The prey encounter rate for saltatory foragers in a moderately turbulent environment has been modeled and measured in laboratory studies (MacKenzie \& Kiørboe 1995):

$$
\mathrm{E}=(2 / 3) \cdot \pi \cdot \mathrm{R}^{3} \cdot \mathrm{N} \cdot \mathrm{PF}+\pi \cdot \mathrm{R}^{2} \cdot \mathrm{N} \cdot \mathrm{PF} \cdot \mathrm{PD} \cdot\left(v^{2}+2 w^{2}\right)^{0.5}
$$

where, $\mathrm{E}=$ encounter rate $\left(\mathrm{s}^{-1}\right), \mathrm{R}=$ reactive distance $(\mathrm{m}), \mathrm{N}=$ prey density $\left(\mathrm{m}^{-3}\right), \mathrm{PF}=$ pause frequency $\left(\mathrm{s}^{-1}\right), \mathrm{PD}=$ pause duration $(\mathrm{s}), \mathrm{v}=$ larval velocity $\left(\mathrm{m} \cdot \mathrm{s}^{-1}\right)$, and $\mathrm{w}^{2}=$ turbulent velocity $=3.615 \cdot(\varepsilon \cdot \mathrm{R})^{0.667} ;\left(\varepsilon\right.$ is the turbulent energy dissipation rate, $7.4 \cdot 10^{-8} \mathrm{~m}^{2} \cdot \mathrm{s}^{-3}$ in the MacKenzie \& Kiørboe 1995 study).

The observations in the present study were made under non-turbulent conditions but the implications of the observed behavior in a moderately turbulent environment can be illustrated with the MacKenzie \& Kiørboe (1995) model. In a calm environment with a theoretical prey density of $100 \mathrm{~L}^{-1}$, a 25 day-old larva behaving as observed in the absence of prey $\left(\mathrm{R}=4.6 \mathrm{~mm}, \mathrm{PF}=40 \mathrm{~min}^{-1}\right.$, and $\left.\mathrm{PD}=0.92 \mathrm{~s}\right)$, would encounter $0.62 \mathrm{prey} \cdot \mathrm{min}^{-1} . \mathrm{A}$ larva behaving as observed in the presence of prey $\left(\mathrm{R}=4.6 \mathrm{~mm}, \mathrm{PF}=48 \mathrm{~min}^{-1}\right.$, and $\mathrm{PD}=0.63 \mathrm{~s}$ ) would encounter $0.74 \mathrm{prey} \cdot \mathrm{min}^{-1}$. This is a $17 \%$ difference between the two observed foraging modes. Using the same turbulence level as MacKenzie \& Kiørboe (1995), the theoretical encounter rates of the same two larvae would be 1.14 prey $\cdot \mathrm{min}^{-1}$ and 1.19 prey $\mathrm{min}^{-1}$, respectively (a $4 \%$ difference). In a turbulent environment, not only would the prey encounter rates would be enhanced but the difference between the estimated foraging capacities of larvae in the two prey treatments would be reduced. 
Are there behavioral adaptations that allow larval cod to further increase the derived benefit from turbulent conditions? MacKenzie \& Kiørboe (1995) is the only study that has compared the searching behavior of larval fish under both calm and turbulent conditions. Turbulent conditions appear to stimulate swimming activity in larval cod; pause duration is shorter (by 15 to $30 \%$ ), pause and swim burst frequency is greater (by 15 to $35 \%$ ), while the duration of individual swimming bursts remains unchanged. The expected increase in prey encounter rates in turbulent compared to calm conditions as a function of turbulent velocity and behavior can be expressed as:

$$
\left.\mathrm{E}_{\text {turbulent }} / \mathrm{E}_{\text {calm }}=\mathrm{PF}_{\text {turbulent }} \cdot(2 / 3) \cdot \mathrm{R}+\mathrm{PD}_{\text {turbulent }} \cdot\left(v^{2}+2 w^{2}\right)^{0.5}\right] \div[(2 / 3) \cdot \mathrm{R} \cdot \mathrm{PF} \text { calm }]
$$

Equation 3 suggests that a greater pause frequency in turbulent conditions allows turbulence to have an even greater effect on prey encounter rates. However, because pause duration must decrease as pause frequency increases (burst duration remained constant regardless of turbulence in the MacKenzie \& Kiørboe study), equation 3 predicts that adjusting behavior to turbulent conditions provides only a small increase to the benefit derived from turbulent conditions.

Hunger may be a powerful force that both limits and motivates changes in foraging strategy. On short time scales, as with healthy growing larvae with empty guts, hunger may act as a signal to adjust behavior to better fit local conditions. On long time scales, as with chronically starved larvae in weak condition, larvae may have fewer energy resources to draw upon to support vigorous swimming activity. The goal of the present study was to observe behavioral plasticity in the face of changing conditions (i.e., prey density) and reduce any confounding effect of larval condition on behavior. Therefore, all larvae had a similar rearing history before experiments were begun but only recently different feeding histories. In the no-prey treatment, larvae were fasted for 36 hours before observations were made. In both of the prey treatments (rotifers and nauplii), larvae were fasted for 32 hours before prey were introduced and allowed to feed for 4 additional hours before observations were made. In the no-prey treatment, pause duration was longer, pause frequency lower, and overall swimming activity lower than either of 
the two prey treatments. In contrast, Munk (1995) found that hunger stimulated activity in larval cod. The feeding histories of the present study and Munk's hunger study were similar (fasted $24 \mathrm{~h}$ vs. fasted for $36 \mathrm{~h}$ in the present study), but other differences between these two studies were discussed above. The role of short-term hunger in shaping larval behavior remains unclear.

Skiftesvik \& Huse (1987) and Skiftesvik (1992) studied the effect of long-term hunger and the presence of prey on larval cod activity. Among post-yolk-sac larvae, those monitored in the presence of prey were more active than those held without prey from hatching to starvation. This observation would indicate either an energyconservation strategy or an inability to maintain high activity levels on the part of the starved larvae. However, the presence of prey also stimulated activity among pre-feeding larvae (jaw not yet functional), elevating activity by $15 \%$ over those observed in the absence of prey indicating that visual cues can stimulate activity.

Cod larvae are primarily visual predators, and light intensity can have a large effect upon foraging success by directly affecting the distance at which prey can be perceived, R. Foraging capacity and the prey encounter rate model for saltatory foragers (equation 2) are very sensitive to the value of $R$. Reactive distance will be reduced with depth as light intensity decays exponentially and under conditions of increasing turbidity (Fiksen et al. 1998). Vertical swimming behavior of larvae will therefore also have a large effect on reactive distance. Larval cod show diurnal migration by the time they reach $9 \mathrm{~mm}$, moving deeper by day and shallower by night (Lough \& Potter 1993). Huse (1994) showed that early larval cod feeding was inhibited at high light intensity, but the available data from the field does not make clear whether cod larvae migrate to follow an isolume and avoid light inhibition. Light intensity also has a synergistic effect with turbulence. Low light levels make turbulence less beneficial because there is a greater probability of prey being advected out of the larva's reduced search-volume before it has time to react (Fiksen et al. 1998).

Puvanendran and Brown (2002) and Batty (1987) show that cod and herring larvae become more active under higher light levels. But, there has been no study of how the 
various components of the foraging cycle or reactive distance change with ambient light intensity. The behavioral response to ambient light levels low enough to degrade reactive distance may be predicted with a hypothesis based upon saltatory foraging theory. If foraging in low light levels is analogous to foraging in a visually complex habitat or analogous to foraging for small, cryptic prey, then net energy gain will be maximized when pause duration decreases, pause frequency increases, and the distance traveled between consecutive search-volumes decreases (O'Brien et al. 1989).

\section{Conclusions}

This research allows the following conclusions to be made about larval cod foraging behavior: 1) all observations were consistent with larval cod being saltatory foragers; 2) as larvae grow older and larger their foraging capacity increases; 3) swimming bursts (speed, duration, and distance traveled) remain the same regardless of foraging conditions; 4) the duration of each search event is longer when no prey are present, perhaps reflecting a greater time investment to process each search-volume more thoroughly; 5) the pause frequency, and therefore foraging capacity, is lower when prey are absent, but this could be mitigated under conditions of moderate turbulence. To better understand larval foraging capacity in a dynamic environment, future research should refine measurements of reactive distance, study the role and impact of turbulence on foraging behavior, and study how the cost of swimming may limit behavior.

The foraging capacity of larval cod is linearly related to pause frequency but is exponentially related to the reactive distance. Therefore, small changes in reactive distance will have a much larger impact upon the volume of water searched for prey than a change in pause frequency. For example, a 1-mm increase in the reactive distance from 4.5 to $5.5 \mathrm{~mm}$ will have about the same impact on foraging capacity as a doubling of pause frequency from $30 \mathrm{~min}^{-1}$ to $60 \mathrm{~min}^{-1}$. The greatest advance in understanding the foraging capacity of larval fish will come from accurate measurements of the reactive distance and how it changes with light intensity, prey size, and prey motion. 
How much does the cost of swimming limit the behavioral repertoire of larval cod? Small fish larvae live in a hydrodynamic environment where the frictional forces acting against motion are substantial, and the cost of swimming is much higher than it is for adult fish (Dabrowski 1986a, b, Kaufmann 1990, Kaufmann \& Wieser 1992, Hunt von Herbing \& Boutilier 1996, Müller et al. 2000). Activity is a significant part of the total bioenergetic budget of larval cod. Activity can account for roughly 30 to $60 \%$ of the total routine aerobic scope as measured by respirometry experiments (Solberg \& Tilseth 1984, Hunt von Herbing \& Boutilier 1996). However, these measurements were made on nonfeeding larvae in small sealed chambers. The importance of activity costs to freely foraging larvae and their foraging strategy will be addressed in the next chapter of this dissertation. 


\section{References}

Anderson JP, Stephens DW, Dunbar SR (1997) Saltatory search: a theoretical analysis. Behavioral Ecology 8:307-317

Batty RS (1987) Effect of light intensity on activity and food searching of larval herring Clupea harengus: a laboratory study. Marine Biology 93:323-327

Boisclair D (1992) An evaluation of the stereocinematographic method to estimate fish swimming speed. Canadian Journal of Fisheries and Aquatic Science 49:523-531

Bolz GR, Lough RG (1988) Growth through the first six months of Atlantic cod, Gadus morhua, and haddock, Melanogrammus aeglefinus, based on daily otolith increments. Fishery Bulletin 86:223-235

Browman HI, O'Brien WJ (1992) Foraging and prey search behaviour of Golden Shiner (Notemigonus crysoleucas) larvae. Canadian Journal of Fisheries and Aquatic Science 49:813-819

Browman HI, St. Pierre J-F, Skiftesvik AB, Racca RG (2003) Behaviour of Atlantic cod (Gadus morhua) larvae: an attemp to link maternal condition with larval quality. In: Browman HI, Skiftesvik AB (eds) The Big Fish Bang. Proceedings of the 26th Annual Larval Fish Conference. the Institue of Marine Research, Bergen, Norway, p 71-95

Dabrowski KR (1986a) Active metabolism in larval and juvenile fish: ontogenetic changes, effect of water temperature and fasting. Fish Physiology and Biochemistry 1:125-144

Dabrowski KR (1986b) Energy utilization during swimming and cost of locomotion in larval and juvenile fish. Journal of Applied Ichthyology 3:110-117

Dower JF, Miller TJ, Leggett WC (1997) The role of microscale turbulence in the feeding ecology of larval fish. Advances in Marine Biology 31:169-220

Ellertsen B, Solemdal P, Strømme T, Tilseth S, Westgård T, Moksness E, Øiestad V (1980) Some biological aspects of cod larvae (Gadus morhua L.). Fisk.Dir. Skr. Ser. HavUnders. 17:29-47

Evans BI, O'Brien WJ (1988) A reevaluation of the search cycle of planktivorous Arctic Grayling, Thamallus arcticus. Canadian Journal of Fisheries and Aquatic Science 45:187-192

Fiksen $\varnothing$, Utne ACW, Aksnes DL, Eiane K, Helvik JV, Sundby S (1998) Modelling the influence of light, turbulence and ontogeny on ingestion rates in larval cod and herring. Fisheries Oceanography 7:355-363

Gendron RP, Staddon JER (1983) Searching for cryptic prey: the effect of search rate. American Naturalist 121:172-186 
Hunt von Herbing I, Boutilier RG (1996) Activity and metabolism of larval Atlantic cod (Gadus morhua) from Scotian Shelf and Newfoundland source populations. Marine Biology 124:607-617

Hunt von Herbing I, Gallager SM (2000) Foraging behavior in early Atlantic cod larvae (Gadus morhua) feeding on a protozoan (Balanion sp.) and a copepod nauplius (Pseudodiaptomus sp.). Marine Biology 136:591-602

Huse I (1994) Feeding at different illumination levels in larvae of three marine teleost species: cod, Gadus morhua L., plaice, Pleuronectes platessa L., and turbot, Scophthalmus maximus (L.). Aquaculture and Fisheries Management 25:687-695

Kaufmann R (1990) Respiratory cost of swimming in larval and juvenile cyprinids. Journal of Experimental Biology 150:343-366

Kaufmann R, Wieser W (1992) Influence of temperature and ambient oxygen on the swimming energetics of cyprinid larvae and juveniles. Environmental Biology of Fishes 33:87-95

Kleinbaum DG, Kupper LL, Muller KE, Nizam A (1998) Applied regression analysis and other multivariable methods, Vol. Duxbury Press, Pacific Grove

Krohn MM, Boisclair D (1994) Use of a stereo-video system to estimate the energy expenditure of free-swimming fish. Canadian Journal of Fisheries and Aquatic Science 51:1119-1127

Lough RG, Buckley LJ, Werner FE, Quinlin JA, Edwards KP (in press) A general biophysical model of larval cod growth applied to populations on Georges Bank. Fisheries Oceanography

Lough RG, Potter DC (1993) Vertical distribution patterns and diel migrations of larval and juvenile haddock Melanogrammus aeglefinus and Atlantic cod Gadus morhua on Georges Bank. Fishery Bulletin 91:281-303

MacKenzie BR, Kiørboe T (1995) Encounter rates and swimming behavior of pausetravel and cruise larval fish predators in calm and turbulent laboratory environments. Limnology and Oceanography 40:1278-1289

MacKenzie BR, Leggett WC, Peters RH (1990) Estimating larval fish ingestion rates: can laboratory derived values be reliably extrapolated to the wild? Marine Ecology Progress Series 67:209-225

Müller UK, Stamhuis EJ, Videler JJ (2000) Hydrodynamics of unsteady fish swimming and the effects of body size: comparing the flow fields of fish larvae and adults. Journal of Experimental Biology 203:193-206

Munk P (1995) Foraging behaviour of larval cod (Gadus morhua) influenced by prey density and hunger. Marine Biology 122:205-212 
Munk P, Kiørboe T (1985) Feeding behaviour and swimming activity of larval herring (Clupea harengus) in relation to density of copepod nauplii. Marine Ecology Progress Series 24:15-21

O'Brien WJ, Browman HI, Evans BI (1990) Search strategies of foraging animals. American Scientist 78:152-160

O'Brien WJ, Evans BI, Browman HI (1989) Flexible search tactics and efficient foraging in saltatory searching animals. Oecologia 80:100-110

O'Brien WJ, Evans BI, Howick GL (1986) A new view of the predation cycle of a planktivorous fish, white crappie (Pomoxis annularis). Canadian Journal of Fisheries and Aquatic Science 43:1894-1899

Puvanendran V, Brown JA (1999) Foraging, growth and survival of Atlantic cod larvae reared in different prey concentrations. Aquaculture 175:77-92

Puvanendran V, Brown JA (2002) Foraging, growth and survival of Atlantic cod larvae reared in different light intensities and photoperiods. Aquaculture 214:1-4

Rosenthal H, Hempel G (1970) Experimental studies in feeding and food requirements of herring larvae (Clupea harengus L.). In: Steele JH (ed) Marine food webs. University of California Press, Berkeley, p 344-364

Rothschild BJ, Osborn TR (1988) Small-scale turbulence and plankton contact rates. Journal of Plankton Research 10:465-474

Skiftesvik AB (1992) Changes in behaviour at onset of exogenous feeding in marine fish larvae. Canadian Journal of Fisheries and Aquatic Science 49:1570-1572

Skiftesvik AB, Huse I (1987) Behaviour studies of cod larvae, Gadus morhua L. Sarsia 72:367-368

Solberg T, Tilseth S (eds) (1984) Growth, energy consumption and prey density requirements in first feeding larvae of cod (Gadus morhua L.), Vol 1. Flødevigen rapportser.

Stobutzki IC, Bellwood DR (1994) An analysis of the sustained swimming abilities of pre- and post-settlement coral reef fishes. Journal of Experimental Marine Biology and Ecology 175:275-286

The MathWorks I (1998) Matlab, Natick, Ma

Videler JJ, Weihs D (1982) Energetic advantages of burst-and-coast swimming of fish at high speeds. Journal of Experimental Biology 97:169-178

Vlymen WJ, III (1974) Swimming energetics of the larval anchovy, Engraulis mordax. Fishery Bulletin 72:885-899

Webb PW, Weihs D (1986) Functional locomotor morphology of early life history stages of fishes. Transactions of the American Fisheries Society 115:115-127 
Weihs D (1980) Energetic significance of changes in swimming modes during growth of larval anchovy, Engraulis mordax. Fishery Bulletin 77:597-604

Werner FE, MacKenzie BR, Perry RI, Lough RG, Naimie CE, Blanton BO, Quinlan JA (2001) Larval trophodynamics, turbulence, and drift on Georges Bank: a sensitivity analysis of cod and haddock. Scientia Marina 65:99-115 


\section{Chapter 4: The Importance of the Cost of Swimming to the Foraging Behavior and Ecology of Larval Cod}

\section{Introduction}

Annual recruitment into marine fish populations is notoriously variable, but the available evidence supports the general conclusion that year-class strength is determined by survival through the larval and pelagic postlarval period (Leggett \& DeBlois 1994, Serchuk et al. 1994). The chances for survival to recruitment into the adult population are improved when larvae can maximize their growth rate. Field data from marine environments show that mortality and larval size are inversely correlated (Pepin 1991). A larva's realized growth rate depends upon environmental conditions and its intrinsic foraging abilities. However, swimming is energetically expensive in small fish larvae compared to adults and juveniles because they must move in a hydrodynamic environment where frictional forces acting against motion are much more important than for large fish (Müller et al. 2000). The energetic cost of swimming may limit a larva's foraging capacity, the volume it can search for prey in a given period of time.

The importance of activity in the bioenergetic budget of larval fish is unknown. Trophodynamic models generally rely upon measurements made within small respirometry chambers to estimate the contribution of activity to the total bioenergetic budget (eg., Laurence 1977, Letcher et al. 1996, Werner et al. 1996, Huuskonen et al. 1998). Swimming intensity within a small, sealed respirometry chamber is unlikely to resemble swimming intensity in the open ocean, and these respirometry measurements are not accompanied by measurements of swimming activity that would allow extrapolation to estimate the energy spent on swimming in nature. Nor are there direct observations of larval foraging behavior in nature because of the logistical problems involved in locating and observing individual larvae for any extended period of time. However, many laboratory-based studies have observed larval behavior under controlled 
conditions (eg., Rosenthal \& Hempel 1970, Hunter 1972, Munk 1995, Hunt von Herbing \& Gallager 2000, MacKenzie \& Kiørboe 2000).

This research employed both behavioral and physiological laboratory studies to understand how important the cost of swimming is within the total bioenergetic budget of larval cod (Gadus morhua) and how this cost may limit foraging strategy. Behavioral studies describe quantitatively how key components of larval foraging behavior and swimming effort change with age and under different foraging conditions, while physiological studies measure the metabolic cost of activity as a function of swimming intensity and larval size. An observation system was developed for this study to observe and record the behavior of individual larvae in a three-dimensional coordinate system. The use of large cylindrical tanks (250L) allows the unprecedented acquisition of detailed behavioral data that has been impossible to collect from much smaller volumes used in previous larval fish behavior studies. Large volumes are necessary to reduce the confinement effects on behavior. Observation over long periods of time minimizes handling effects on behavior.

To measure the cost of swimming, a respirometry system was developed that allowed the simultaneous measurement of swimming activity and metabolism of individual cod larvae. The cost of swimming was modeled as a power-performance relationship (energy expenditure as a function of swimming speed, $\mathrm{J} \cdot \mathrm{mg}^{-1} \cdot \mathrm{h}^{-1}$ ).

This research addresses three questions concerning the role of activity costs in limiting foraging behavior and in the overall ecology of larval cod: 1) Is swimming cost an important component of the total bioenergetic budget? 2) What is the required prey density to support larval growth and survival? 3) How do larvae adjust their foraging behavior in different prey density conditions; when foraging conditions are poor, how do they compromise between increasing foraging activity to maximize prey encounter rates and reducing activity to conserve energy? 


\section{Materials and Methods}

\section{Rearing of larvae}

For the cost of activity measurements, three separate batches of cod embryos were reared: one batch was obtained from the cod broodstock maintained by the National Marine Fisheries Service in Narrragansett, RI, one batch was obtained from wild Gulf of Maine cod, stripped and fertilized in the lab, and one batch was obtained from the cod broodstock maintained by Memorial University of Newfoundland.

For the behavioral observations, eleven separate batches of cod embryos were reared. Eight batches were obtained from the cod broodstock maintained by the National Marine Fisheries Service in Narrragansett, RI. One batch was obtained from the cod broodstock maintained by the Marine Biological Laboratory (Woods Hole, MA). The Narrragansett and the Woods Hole broodstocks were both made up of fish caught off of Cape Cod. Two additional batches of embryos were obtained from Canadian broodstocks: one from the Ocean Sciences Centre, Memorial University of Newfoundland (Newfoundland, Canada) and one from the St. Andrews Biological Station (New Brunswick, Canada).

Fertilized embryos were transported in insulated containers back to the Woods Hole Oceanographic Institution for rearing in black-walled, $120 \mathrm{~L}$ barrels. An airstone was suspended in the center of the barrel $\approx 2.5 \mathrm{~cm}$ off the bottom. One-third of the water was changed daily with filtered $(1 \mu \mathrm{m})$, natural seawater (salinity $=32.5 \%$ ) and the bottom siphoned for debris. Lighting was from fluorescent lamps directly above the barrels on an $11 \mathrm{~h}$-on/13h-off cycle. The light intensity within the rearing barrels was 13.3 $\mu$ Einsteins $\cdot \mathrm{m}^{-2} \cdot \mathrm{s}^{-1}$ at the surface to $5.2 \mu$ Einsteins $\cdot \mathrm{m}^{-2} \cdot \mathrm{s}^{-1}$ at the bottom (Biospherical Instruments, Inc. model QSP200L4S, San Diego, CA). Embryos were held at approximately $6.25^{\circ} \mathrm{C}$ and hatched about 3 weeks after spawning. Most hatching occurred within 1 day. At the time of hatching, extra care was taken to remove egg debris and several additional water changes were made. Larvae were retained in the same barrels in which they hatched. Beginning on the third day after hatching, larvae were fed rotifers (Brachionus plicatilis) daily. After three weeks, the larval diet was supplemented with wild caught zooplankton containing copepod nauplii (predominately 
Acartia sp.). Larvae were maintained for up to 60 days before use in experiments or termination.

\section{Respirometry}

A respirometry system was developed that allowed the simultaneous measurement of swimming activity and metabolism of individual cod larvae. The cost of swimming was modeled as a power-performance relationship (energy expenditure as a function of swimming speed, $\left.\mathrm{J} \cdot \mathrm{mg}^{-1} \cdot \mathrm{h}^{-1}\right)$.

Seven respirometry chambers (described below) were used simultaneously; five with individual larvae and two blanks without larvae. Larvae were placed in vessels without prey 12 hours prior to each experiment. Twelve-hour fasting allows sufficient time for food to be cleared from the gut (Tilseth \& Ellertsen 1984) and eliminates the contribution of specific dynamic action from the total metabolism. In order to ensure observations over a wide range of activity levels, experiments were conducted in a completely darkened lab overnight when activity levels are minimal as well as in a lighted lab during the day. Darkened experiments also provide an estimate of basal metabolism because swimming activity is minimal and activity metabolism approaches zero (e.g., Yamashita \& Bailey 1989). Thirty-nine separate experiments were run at $7.0^{\circ} \mathrm{C}: 26$ illuminated experiments and 13 darkened experiments. Experiments were conducted on larvae from each cohort between the ages of 5 to 45 days.

The oxygen depletion within each chamber was measured as the change in end-point oxygen concentration from the start to the end of a 6-hour incubation period minus the oxygen change in the blank chambers. Respiration rates were calculated by normalizing oxygen depletion rates by dry weight to determine the weight-specific metabolic rate $\left(\mu\right.$ mole $\mathrm{O}_{2} \cdot \mathrm{ml}^{-1} \cdot \mathrm{mg}^{-1}$ ). The metabolic rate of each larva was then converted to its energy equivalent in Joules using a generalized oxycaloric equivalent of $1 \mu$ mole $\mathrm{O}_{2}=0.450 \mathrm{~J}$ (Gnaiger 1983).

Sealed respirometry chambers were constructed specifically for this research. A $10 \mathrm{~cm}$ long, $1 \mathrm{~cm}$ inner-diameter glass tube allowed observation of the swimming activity 
within the chamber. The observation tube was threaded at both ends; one end was sealed with a Teflon backed, silicone septa held tightly with a phenolic compression cap, the other was sealed with a luer adapter assembly. The total chamber volume was approximately $6.5 \mathrm{ml}$ for all chambers.

Oxygen was measured with the FOXY oxygen optode system (Ocean Optics Inc., Dunedin, FL; www.oceanoptics.com). Light emitted by an LED (475nm) increases the energy-state of a ruthenium complex coating the optode tip causing it to fluoresce at $600 \mathrm{~nm}$. The presence of oxygen quenches the fluorescence via a non-radiative transfer of energy to the oxygen molecule (Wang et al. 1999). The fluorescence intensity is inversely proportional to the oxygen concentration. At the end of the incubation period, respirometry chambers were unsealed and attached directly to the oxygen measurement assembly via luer adapters. The oxygen measurement assembly was constructed by mounting the FOXY optode tip within a standard 3-way HPLC tee fitting. The optode tip extends into the center of the flow path of the other two ports. A syringe was attached to one port to draw the sample from the respirometry chamber attached directly to the other port. Two such assemblies are mounted in parallel to return replicate readings for each sample.

The activity of each larva was quantified in five minutes blocks throughout the 6-hour incubation period for a total of fifteen minutes per larva. A video camera was oriented two feet above the respirometry chambers, which were lit from below by an infra-red diode array. The use of an infra-red light source allowed observation in dark conditions without stimulating swimming activity. Swimming activity over the duration of each experiment was recorded on videotape and digitized via a video frame-grabber card installed in a desktop computer to produce a series of bitmap files. Matlab (The MathWorks 1998) routines were written to process the bitmap files. The position of each larva at the point on the head between the eyes was recorded manually every 2 seconds of each five minute observation block. From data on larval position over time, swimming speed $\left(\mathrm{mm} \cdot \mathrm{s}^{-1}\right)$ was measured. The mean activity level of all 5-minute observation blocks was used to infer the overall mean activity level of the entire 6-hour experimental period. 


\section{Behavior}

Larval cod use a saltatory foraging strategy ( unpub. data cited in Browman \& O'Brien 1992, MacKenzie \& Kiørboe 1995, Munk 1995). The components of the saltatory foraging cycle are a forward swimming burst, a glide, and a pause during which the larva searches for prey (Evans \& O'Brien 1988). Six key saltatory foraging parameters were measured: pause duration, pause frequency, distance traveled between pauses, burst swimming speed, burst duration, and the fraction of time spent swimming.

The behavior of larvae 5 to 50 days old was observed at an interval of 10 days. Three feeding treatments were used: I. no prey ( 2 repetitions for each age group), II. rotifer prey stocked at $100 \mathrm{~L}^{-1}$ (2 repetitions for each age group), and III. wild zooplankton prey (predominately Acartia sp.) stocked at $100 \mathrm{~L}^{-1}$ ( 1 replicate for each age group). For each prey treatment, 10 experiments were conducted. All experiments were run at $7^{\circ} \mathrm{C}( \pm$ $1^{\circ} \mathrm{C}$ ). Each experiment was run over two days. The evening before the experiment began, larvae (50 to 100) were added to the surface of the observation tank (described below). The first day was an acclimation period, no prey were added to the tank. On the second day, in prey treatments, prey were added at 8:00am and the tank was bubbled for one-half hour to mix the prey throughout the tank. A video record was taken at 1:00pm on the second day. Depending on the number of larvae visible, five to ten minutes of the record were analyzed. Only larvae that were observed for at least 1 minute were analyzed. At least five larvae were analyzed in each experiment.

An observation tank system was developed to record larval swimming activity in large volumes. A fiberglass cylinder ( $3 \mathrm{~m}$ tall $\mathrm{x} 0.5 \mathrm{~m}$ diameter), fitted with a $1 / 4$ " glass bottom, was positioned on a wooden frame with a 3/4" plate glass top. For observation into the tank from below, a mirror was oriented at a $45^{\circ}$ angle beneath the wooden frame. The tank was filled to a depth of $1.5 \mathrm{~m}$ with filtered seawater $(1 \mu \mathrm{m})$ and maintained at $7.0^{\circ} \mathrm{C}$ by running chilled water down the exterior. The tank was lit from above by a collimated light source consisting of a quartz-halogen bulb and large fresnel lens on an $11 \mathrm{~h}$-on/13h-off photoperiod. The entire tank was wrapped in black plastic to prevent 
ambient light from entering. Larval behavior was monitored from below with paired video cameras with optical axes aligned in parallel. The video signal from each camera was recorded on SVHS tape and synchronized via a time-code stamp on each video field. The observation system was calibrated using a plexiglass calibration grid lowered into the tank in discrete $30.5 \mathrm{~cm}$ intervals. Three calibration parameters were calculated: 1) the exponential relation between depth and the x-axis offset between the left and right cameras, 2) the linear relation between depth and spatial resolution (mm.pixel $\left.\left.{ }^{-1}\right) 3\right)$ the angle of rotation about the optical axis of the left camera relative to the right camera.

The analog SVHS record was digitized with a frame-grabber card mounted in a standard desktop computer. Video fields were sampled at a rate of 3.75 fields per second and saved as gray-scale TIFF files at a resolution of 640x480 pixels. Original Matlab routines were written to produce swimming tracks of individual larvae (time-dependent centroid positions). The procedure was semi-automated; all computer-constructed swimming tracks were checked by eye and errors were manually corrected.

Corresponding swimming tracks from each camera, left and right, were paired together manually. Larval depth within the tank was calculated from the $\mathrm{x}$-axis offset between the paired tracks recorded from each camera. Horizontal centroid coordinates were converted to millimeter coordinates using the depth-specific spatial resolution. Distance and speed during each time interval $(0.2667 \mathrm{~s})$ were calculated for each larva as was acceleration/deceleration calculated between successive time intervals. Each interval was then classified as either a pause or as a swimming burst using predefined rules. Bursts were defined as intervals of acceleration $>4 \mathrm{~mm} \cdot \mathrm{s}^{-2}$ and speed $>3 \mathrm{~mm} \cdot \mathrm{s}^{-1}$ lasting until speed fell to $<110 \%$ pre-burst speed. The maximum allowed pause speed was $<4 \mathrm{~mm} \cdot \mathrm{s}^{-1}$.

\section{Trophodynamic model}

A simple trophodynamic model was constructed in order to study the significance of new measurements of the cost of swimming upon the overall bioenergetic budget. The model also allowed an investigation of the sensitivity of potential net energy gain of 
individual cod larvae to foraging behavior. The basic model is a simple energy-balance equation (net energy gain = gross energy gain - metabolic expenses):

$$
\mathrm{G}=[\mathrm{C} \cdot \mathrm{p} \cdot \mathrm{a}]-\left[\mathrm{M}_{\text {basal }}+\mathrm{M}_{\mathrm{SDA}}+\mathrm{M}_{\text {activity }}\right]
$$

where,

$$
\mathrm{G}=\text { net energy gain rate }\left(\mathrm{J} \cdot \mathrm{h}^{-1}\right)
$$

$\mathrm{C}=$ prey capture rate $\left(\right.$ prey $\left.\cdot \mathrm{h}^{-1}\right)$

$\mathrm{p}=$ prey energy value $(\mathrm{J})$

$\mathrm{a}=$ assimilation efficiency $(0$ to 1$)$

$\mathrm{M}_{\text {basal }}=$ basal metabolic rate $\left(\mathrm{J} \cdot \mathrm{h}^{-1}\right)$

$\mathrm{M}_{\text {activity }}=$ metabolic rate due to activity $\left(\mathrm{J} \cdot \mathrm{h}^{-1}\right)$

$\mathrm{M}_{\mathrm{SDA}}=$ apparent specific dynamic action; metabolic rate due to biochemical processing of assimilated prey $\left(\mathrm{J} \cdot \mathrm{h}^{-1}\right)$.

The prey capture rate $\left(\mathrm{s}^{-1}\right)$ is a function of the prey encounter rate and the probability of capturing a prey item that is within the search volume:

$$
\mathrm{C}=\mathrm{E} \cdot \mathrm{s}
$$

where,

$\mathrm{E}=$ encounter rate $\left(\mathrm{s}^{-1}\right)$

$\mathrm{s}=$ probability of capturing a prey item that is within the search volume.

The prey encounter rate for saltatory foragers in a moderately turbulent environment has been modeled and measured in laboratory studies (MacKenzie \& Kiørboe 1995):

$$
\mathrm{E}=(2 / 3) \cdot \pi \cdot \mathrm{R}^{3} \cdot \mathrm{N} \cdot \mathrm{PF}+\pi \cdot \mathrm{R}^{2} \cdot \mathrm{N} \cdot \mathrm{PF} \cdot \mathrm{PD} \cdot\left(u^{2}+v^{2}+2 w^{2}\right)^{0.5}
$$

where,

$$
\begin{aligned}
& \mathrm{R}=\text { reactive distance }(\mathrm{m}) \\
& \mathrm{N}=\text { prey density }\left(\mathrm{m}^{-3}\right) \\
& \mathrm{PF}=\text { pause frequency }\left(\mathrm{s}^{-1}\right) \\
& \mathrm{PD}=\text { pause duration }(\mathrm{s})
\end{aligned}
$$




$$
\begin{aligned}
& u=\text { larval velocity }\left(\mathrm{m} \cdot \mathrm{s}^{-1}\right) \\
& v=\text { prey velocity }\left(\mathrm{m} \cdot \mathrm{s}^{-1}\right) \\
& w^{2}=\text { turbulent velocity }=3.615 \cdot(\varepsilon \cdot \mathrm{R})^{0.667} \\
& \varepsilon=\text { turbulent energy dissipation rate }\left(\mathrm{m}^{2} \cdot \mathrm{s}^{-3}\right)
\end{aligned}
$$

The first term, $(2 / 3) \cdot \pi \cdot R^{3} \cdot N \cdot P F$, assumes that the shape of the search volume is a halfsphere. This has been shown to be approximately the case for larval cod (Hunt von Herbing \& Gallager 2000) which respond to prey positioned 30 to $90^{\circ}$ vertically and horizontally relative to the larva's lateral axis. The second term in this model, $\pi \cdot \mathrm{R}^{2} \cdot \mathrm{N} \cdot \mathrm{PF} \cdot \mathrm{PD} \cdot\left(v^{2}+2 w^{2}\right)^{0.5}$, is omitted if the effects of turbulence are not considered. The reactive distance, $R$, is estimated as the distance traveled between search-volumes if consecutive volumes are assumed to neither overlap nor leave un-searched water in between. This strategy should be the energetically most efficient, minimizing the distance traveled to search a given volume of water (O'Brien et al. 1990).

Larval velocity, $u$, is the coasting speed during the pause periods and is set to the mean speed observed for each behavioral experiment (typically 1 to $2 \mathrm{~mm} \cdot \mathrm{s}^{-1}$ ). Larval cod on Georges Bank eat a diet of nauplius and copepodite of four key species: Calanus finmarchicus, Pseudocalanus spp., Oithona similis, and Centropages typicus (Kane 1984, Lough et al. in press). Copepod nauplii appear to practice two general swimming patterns specific to species and development stage: continuous swimming (e.g., Centropages typicus) and jump-sink swimming (e.g., Oithona similis) (Titelman \& Kiørboe 2003). Swimming speed, absolute or relative to body speed, also depends upon species and developmental stage (Paffenhöfer et al. 1996, Titelman \& Kiørboe 2003). As a simplifying assumption, for all model prey items swimming is assumed to be continuous and speed, $v$, is set to the average relative speed measured by Titleman $\&$ Kiørboe for Centropages typicus nauplii, $3 \mathrm{BL} \cdot \mathrm{s}^{-1}$.

Turbulence levels on Georges Bank range from $\varepsilon=10^{-8}$ to $10^{-5} \mathrm{~m}^{2} \cdot \mathrm{s}^{-3}$ (Horne et al. 1996). In well mixed waters as found over the central cap or during winter, turbulence is high throughout the water-column, $\varepsilon=10^{-6}$ to $10^{-5}$ (Horne et al. 1996, Burgett et al. 2001). The seasonal pycnocline forms in mid-May, and turbulence is 1 to 2 orders of magnitude 
lower within the pycnocline $\left(\varepsilon=10^{-9}-10^{-8} \mathrm{~m}^{2} \cdot \mathrm{s}^{-3}\right)$ than it is at the surface or near the bottom where wind and tidally generated turbulence originates, $\varepsilon=10^{-6} \mathrm{~m}^{2} \cdot \mathrm{s}^{-3}$ (Burgett et al. 2001). In calculations of net energy gain and prey density requirements, three alternative turbulence scenarios are used representing no turbulence, low turbulence found within the pycnocline, and high turbulence found in mixed waters $\left(\varepsilon=0,1 \cdot 10^{-8}\right.$, and $\left.1 \cdot 10^{-5} \mathrm{~m}^{2} \cdot \mathrm{s}^{-3}\right)$.

The probability of a successful capture, $\mathrm{s}$, is a function of larval size, prey type (and prey size and swimming ability), and turbulence. There are few measurements of larval capture proficiency. The probability of successful attack of first-feeding larval cod (4.6mm) foraging upon nauplii in non-turbulent water is $\mathrm{s}=0.22$ (Solberg \& Tilseth 1984), while among older larvae (5.7 to $6.6 \mathrm{~mm}$ ) foraging in turbulent water, $\mathrm{s}=0.22$ (Munk 1995, $\varepsilon$ was not reported). When foraging upon slowly swimming prey, the capture success probability is much greater than when foraging upon rapidly swimming prey such as nauplii; $\mathrm{s}=0.68$ for larvae $(5$ to $8 \mathrm{~mm}$ ) preying on protozoa in non-turbulent water (Hunt von Herbing \& Gallager 2000). Turbulence may reduce capture success by knocking prey out of a larva's search-volume before it has a chance to react (MacKenzie et al. 1994). MacKenzie and Kiørboe (2000) observed the capture success probability of larval cod upon nauplii and early-stage copepodites at different turbulence levels.

Capture success was substantially reduced at turbulence levels frequently experienced by larval cod in the ocean. For an $8.7 \mathrm{~mm}$ larva at $\varepsilon=0$ to $2 \cdot 10^{-9}, \mathrm{~s}=0.8$; at $\varepsilon=1 \cdot 10^{-6}, \mathrm{~s}=$ 0.5 ; at $\varepsilon=1.3 \cdot 10^{-5}, \mathrm{~s}=0.1$. Turbulence should have a greater effect upon smaller larvae because of their shorter reactive distances (ibid.). However, the capture success rate of larvae smaller than $8.7 \mathrm{~mm}$ has not been measured at different turbulence levels. In this model, $\mathrm{s}$ is set for each larval size class and turbulence level consistent with the published observations of capture proficiency ( $\mathrm{s}$ is assumed to not change with prey type):

(4) $\mathrm{s}=($ see table 4.1$)$.

This trophodynamic model is based on larvae feeding within a spatially uniform prey field. The preferred diet of three size classes of larval cod $(5,6$, and $7 \mathrm{~mm})$ on Georges Bank is provided by Kane (1984) and Lough et al. (in press) based upon gut-content 
analyses of wild-caught larvae (table 4.2). Sizes for the different development stages of the four main prey species (Calanus, Pseudocalanus, Oithona, and Centropages) are compiled in table 4.3 from Lynch et al. (2001) and Lough et al. (in press). The estimated energy content of an individual prey item is taken as $0.02356 \mathrm{~J} \cdot \mu \mathrm{g}^{-1}$ dry weight (Laurence 1976):

$$
\left.\mathrm{p}=\text { energy content of prey item }=(\text { dry weight, } \mu \mathrm{g}) \cdot 0.02356 \mathrm{~J}^{\prime} \mu \mathrm{g}^{-1} \text { (see table } 4.3\right)
$$

The assimilation efficiency of larval fish measured from several marine and freshwater species in the laboratory ranges from 0.67 to 0.99 (review by Govoni et al. 1986). Assimilation efficiency decreases with higher ration (Boehlert \& Yoklavich 1984, Wieser \& Medgyesy 1990b); but it is unclear how assimilation efficiency changes as larvae grow, either increasing (Buckley \& Dillman 1982) or decreasing (Keckeis et al. 2001) with age. Assimilation efficiency is estimated here as a constant:

$$
\mathrm{a}=0.7,
$$

the value measured for herring, Clupea harengus, (Boehlert \& Yoklavich 1984) and typical for marine larval fish in general (Houde 1989).

The three metabolic cost terms are basal metabolism, activity metabolism, and specific dynamic action. Basal (or maintenance or standard) metabolism is the minimum observable metabolic rate; it is the energy spent by a non-feeding, resting individual (Fry 1971, Brett 1972). Basal metabolic costs include protein turnover for maintenance and repair, maintaining hydrostatic balance, and active ion transport to maintain transmembrane ionic gradients. The weight-specific basal metabolic rate is assumed to be the metabolic rate measured in this study of fasted larvae (contribution of $\mathrm{M}_{\mathrm{SDA}} \approx 0$ ) measured in darkness when activity levels are minimal $\left(\mathbf{M}_{\text {activity }} \approx 0\right)$ :

$$
\mathrm{M}_{\text {basal }}\left(\mathrm{J} \cdot \mathrm{mg}^{-1} \cdot \mathrm{h}^{-1}\right)=0.007085 \cdot(\text { dry weight })^{-0.5791} \text {. }
$$

Specific dynamic action (SDA) is the cost of biochemically processing food. SDA includes both catabolic processes, deamination of proteins and breakdown of fats and 
carbohydrates (Beamish 1974), and anabolic processes, protein synthesis and conversion of fatty acids and carbohydrates into storage products (Jobling 1981, 1983, Kiørboe et al. 1987, Torres et al. 1996). SDA is here estimated as the fraction of assimilated energy that is used to pay for these anabolic and catabolic processes. Kiørboe et al. (1987) estimated the SDA factor as 0.11. However, this value is low compared to measurements made by Wieser \& Medgyesy $(1990 \mathrm{a}, 1990 \mathrm{~b})$ (SDA factor $=0.36$ to 0.49 ). The discrepancy between the two sets of studies may be due to the use of anaesthetized larvae and non-simultaneous measurements of ingestion, growth, and metabolism in the Kiørboe et al. study (Wieser \& Medgyesy 1990a). This model uses a factor of 0.4, the value used by Werner et al. (1996) in their trophodynamic model and consistent with Wieser \& Medgyesy (1990a, 1990b):

$$
\mathrm{M}_{\mathrm{SDA}}=0.4 \cdot(\text { assimilated energy }) \text {. }
$$

The activity metabolism $\left(\mathrm{M}_{\text {activity }}\right)$ of a larval fish is a function of the cost of swimming and swimming intensity (swimming speed and the fraction of time spent swimming). Often, activity metabolism is included in the bioenergetic model as 'routine metabolism' because of the difficulty isolating the components of total metabolism. Routine metabolism is the sum of basal metabolism and the metabolic cost of swimming activity (Beamish \& Mookherjii 1964):

$$
M_{\text {routine }}=M_{\text {basal }}+M_{\text {activity }}
$$

The activity levels involved in 'routine metabolism' are seldom quantified. One of the goals of the present study was to quantify spontaneous swimming activity under different foraging conditions, the costs incurred, and elucidate any variation embedded within the 'routine' term. The energy spent on activity is estimated from the multiple-regression model for larval cod 5 to 45 days old as a function of swimming speed, dry weight, and basal metabolic rate (see results):

$$
\mathrm{M}_{\text {activity }}\left(\mathrm{J} \cdot \mathrm{mg}^{-1} \cdot \mathrm{h}^{-1}\right)=\alpha+\beta_{1} \cdot \mathrm{S}+\beta_{2} \cdot \mathrm{W}^{(-0.75)}+\beta_{3} \cdot \mathrm{S} \cdot \mathrm{W}^{(-0.75)}-\mathrm{M}_{\text {basal }}
$$


where,

$$
\begin{aligned}
& \alpha=0.01619 \\
& \beta_{1}=-0.006111 \\
& \beta_{2}=0.001708 \\
& \beta_{3}=0.002433 \\
& S=\text { mean swimming speed }\left(\mathrm{m} \cdot \mathrm{h}^{-1}\right) \\
& W=\text { dry weight }(\mathrm{mg}) .
\end{aligned}
$$

The minimum daily energy requirement $\left(\mathrm{J} \cdot \mathrm{day}^{-1}\right)$ for an individual larva can be estimated from the daily gross energy gain required to balance all daily metabolic demands and achieve zero net energy gain:

$$
\text { (gross energy gain) }-\left(\mathrm{M}_{\text {total }}+\mathrm{M}_{\text {actvity }}+\mathrm{M}_{\mathrm{SDA}}\right)=0
$$

where,

$($ gross energy gain $)=($ required energy input $) \cdot($ assimilation efficiency $)$,

$($ required energy input $)=($ number of prey captured $) \cdot($ energy content per prey $)$,

$\mathrm{M}_{\mathrm{SDA}}=($ gross energy gain $) \cdot 0.4$.

Rearranging gives,

$$
(\text { required energy input })=\left[\left(\mathrm{M}_{\text {total }} \cdot 24\right)+\left(\mathrm{M}_{\text {activity }} \cdot \mathrm{fh}\right)\right] \div[\mathrm{a} \cdot(1-0.4)]
$$

where,

$$
\begin{aligned}
& \mathrm{a}=\text { assimilation efficiency } \\
& \mathrm{fh}=\text { foraging hours }=14 \text { hours between sunrise and sunset on Georges Bank in early }
\end{aligned}
$$
May. 
Table 4.1. Capture success probabilities, $\mathrm{s}$, used in the trophodynamic model for three size classes of larval cod foraging upon copepod prey within three different turbulence regimes. Capture success probabilities are chosen based upon the few direct measurements available (Solberg \& Tilseth 1984, Munk 1994, MacKenzie \& Kiørboe 2000 ) and the general observations that 1) $\mathrm{s}$ is high for larger larvae in conditions of mild turbulence, decreasing as turbulence intensifies ( $\mathrm{s}=0.8$ for $8.7 \mathrm{~mm}$ larvae at $\varepsilon=0$ to $2 \cdot 10^{-}$ ${ }^{9}$ ), and 2) s is lower for smaller larvae (MacKenzie \& Kiørboe 2000).

\begin{tabular}{|r|c|c|c|}
\hline & \multicolumn{3}{|c|}{ larval size class } \\
turbulence level, $\boldsymbol{\varepsilon}$ & $\mathbf{5 m m}$ & $\mathbf{6} \mathbf{m m}$ & $\mathbf{7 m m}$ \\
\hline $0 \mathrm{~m}^{2} \cdot \mathrm{s}^{-3}$ & $0.22^{\mathrm{a}}$ & 0.50 & 0.75 \\
$1 \cdot 10^{-8} \mathrm{~m}^{2} \cdot \mathrm{s}^{-3}$ & 0.10 & 0.50 & 0.75 \\
$1 \cdot 10^{-5} \mathrm{~m}^{2} \cdot \mathrm{s}^{-3}$ & 0.05 & $0.22^{\mathrm{b}}$ & 0.38 \\
\hline
\end{tabular}

${ }^{a}$ Solberg \& Tilseth (1984), observations of larvae $4.6 \mathrm{~mm}$ foraging in calm conditions ${ }^{b}$ Munk (1995), observations of larvae 5.7 and $6.6 \mathrm{~mm}$ foraging in unknown turbulence levels. 
Table 4.2. Nauplius and copepodite stages available as prey for each of three size classes of larval cod on Georges Bank (Kane 1984, Lough et al. in press).

\begin{tabular}{|l|l|l|l|}
\hline & \multicolumn{3}{c|}{ larval size class } \\
prey species & $\mathbf{5 m m}$ & $\mathbf{6 m m}$ & $\mathbf{7 m m}$ \\
\hline Calanus finmarchicus & $\mathrm{N} 1-\mathrm{N} 3$ & $\mathrm{~N} 1-\mathrm{N} 4$ & $\mathrm{~N} 1-\mathrm{C} 3$ \\
Pseudocalanus spp. & $\mathrm{N} 1-\mathrm{C} 4$ & $\mathrm{~N} 1-\mathrm{C} 5$ & $\mathrm{~N} 1-$ Adult \\
Oithona similis & $\mathrm{N} 1-\mathrm{C} 4$ & $\mathrm{~N} 1-\mathrm{C} 5$ & $\mathrm{~N} 1-$ Adult \\
Centropages typicus & $\mathrm{N} 1-\mathrm{C} 2$ & $\mathrm{~N} 1-\mathrm{C} 3$ & $\mathrm{~N} 1-$ Adult \\
\hline
\end{tabular}


Table 4.3. Available length and dry weight data for the major copepod prey of larval cod: Calanus finmarchicus, Pseudocalanus spp., Oithona similis, and Centropages typicus. Calanus finmarchicus and Pseudocalanus spp. data are taken from the compilation of Lynch et al. (2001) and are sub-divided into six naupliar stages, five copepodite stages, and adult females. Oithona similis and Centropages typicus data are from Lough et al. (in press) and Lough (pers. comm. 2004).

\begin{tabular}{|c|cc|cc|cc|cc|}
\hline & \multicolumn{2}{|c|}{ C. finmarchicus } & \multicolumn{2}{c|}{ Pseudocalanus spp. } & \multicolumn{2}{c|}{ O. similis } & \multicolumn{2}{c|}{ C. typicus } \\
\hline stage & $\begin{array}{c}\text { length } \\
(\mathrm{mm})\end{array}$ & $\begin{array}{c}\text { weight } \\
(\mu \mathrm{g})\end{array}$ & $\begin{array}{c}\text { length } \\
(\mathrm{mm})\end{array}$ & $\begin{array}{c}\text { weight } \\
(\mu \mathrm{g})\end{array}$ & $\begin{array}{c}\text { length } \\
(\mathrm{mm})\end{array}$ & $\begin{array}{c}\text { weight } \\
(\mu \mathrm{g})\end{array}$ & $\begin{array}{c}\text { length } \\
(\mathrm{mm})\end{array}$ & $\begin{array}{c}\text { weight } \\
(\mu \mathrm{g})\end{array}$ \\
\hline N1 & 0.22 & 0.33 & 0.18 & 0.22 & 0.13 & 0.12 & 0.11 & 0.09 \\
N2 & 0.27 & 0.49 & 0.20 & 0.29 & 0.15 & 0.16 & 0.15 & 0.16 \\
N3 & 0.40 & 1.00 & 0.26 & 0.47 & 0.17 & 0.20 & 0.18 & 0.22 \\
N4 & 0.48 & 1.51 & 0.31 & 0.64 & 0.20 & 0.26 & 0.22 & 0.31 \\
N5 & 0.55 & 2.09 & 0.36 & 0.84 & 0.23 & 0.34 & 0.27 & 0.45 \\
N6 & 0.61 & 2.76 & 0.40 & 1.00 & 0.27 & 0.45 & 0.31 & 0.58 \\
C1 & 0.79 & 4.18 & 0.42 & 1.11 & 0.28 & 0.48 & 0.33 & 0.65 \\
C2 & 1.08 & 13.24 & 0.52 & 1.82 & 0.32 & 0.61 & 0.38 & 0.83 \\
C3 & 1.38 & 21.13 & 0.62 & 2.89 & 0.36 & 0.75 & 0.50 & 1.51 \\
C4 & 1.80 & 63.64 & 0.73 & 4.80 & 0.41 & 0.95 & 0.65 & 3.01 \\
C5 & 2.43 & 169.58 & 0.88 & 9.58 & 0.47 & 1.31 & 0.85 & 7.56 \\
adult & 3.11 & 276.29 & 1.00 & $19.33^{\mathrm{a}}$ & 0.52 & 1.65 & 1.13 & 18.84 \\
\hline
\end{tabular}

adult female with eggs 


\section{$\underline{\text { Results }}$}

\section{Cost of Swimming}

The larvae studied in the respirometry experiments were in two size-classes, 5-19 days old (median weight $=0.043 \mathrm{mg})$ and $34-45$ days old $($ median weight $=0.120 \mathrm{mg})$. The measured weight-specific total metabolic rate increased linearly and significantly with larval swimming speed within each separate size class (fig. 2.7, table 2.2). In each case, graphical analyses of standardized residuals show that the assumptions of a linearregression were met (i.e., homogeneous variance and normal distribution of the dependent variable). The relation between the total metabolic rate and activity level did not remain constant as larvae grew. The power-performance relations of the large and small larvae were compared using ANCOVA (Kleinbaum et al. 1998); the relation for the larger larva had a significantly lower slope $\left(\mathrm{F}_{1,112}=18.9779, \mathrm{P}<<\underline{0.0001}\right)$ and lower intercept $\left(\mathrm{F}_{1,112}=59.4978, \mathrm{P}<<\underline{0.0001}\right)$ than the relation for the small larva. This implies that both the weight-specific basal metabolic rate and the cost of swimming activity are lower for larger larvae.

A multiple regression model was fit to the data with total metabolic rate as the dependent variable and dry weight and swimming speed as the independent variables. The best fit to the data was established with a 4-term model; a linear relationship between metabolism and swimming speed and a power-relationship between metabolism and dry weight (table 2.2 center). The basal metabolic rate was estimated as the metabolism of fasted larvae with empty guts measured in darkness to eliminate the contribution of specific dynamic action and when activity levels were minimal to eliminate the contribution of activity (table 2.2 bottom).

\section{Foraging Behavior}

The behavior of each individual was summarized as a single value for each parameter, the mean parameter value of the entire observation period. Within each 
experiment, burst speed and pause frequency were normally distributed, while burst distance and pause duration were normally distributed after log-transformation.

The relationship between each behavior parameter and age for the no prey $\left(0 \mathrm{~L}^{-1}\right)$ and rotifer prey $\left(100 \mathrm{~L}^{-1}\right)$ treatment groups were described with linear least-squares regressions (table 3.5). In each case, graphical analyses of standardized residuals were used to evaluate how well the data met the assumptions of a linear regression. Normalprobability plots showed that the residuals were either normally (burst speed and pause frequency) or log-normally distributed (burst distance and pause duration), and plots of residuals against the expected response to age showed that the variance was reasonably homogeneous across the full range of ages studied.

The behavioral response to the presence or absence of prey was tested by ANCOVA (Kleinbaum et al. 1998) (table 3.6). Testing the mean response of each experiment gives each an equal weight in the analysis without regard to the variable number of individual larvae analyzed from each experiment. The mean burst speed and the distance traveled during swimming bursts did not change significantly with larval age, nor were these characteristics of swimming bursts significantly different whether or not prey were present (figs. 3.9c and 3.9d). Pause duration and pause frequency (pauses per minute) were both significantly related to larval age (figs. 3.9a and 3.9b). Pause duration was significantly longer in the absence of prey (table 3.6). When prey were not present, pause duration was $\approx 70 \%$ longer at 5 days old; this difference declined to $\approx 20 \%$ longer pauses at 45 days old. Pause frequency is the inverse of the total search-cycle duration, the sum of pause duration and burst duration. As pause duration decreased with age, burst duration increased but to a lesser amount (significant only in the presence of prey); therefore pause frequency increased as larvae grew older. Larvae in an environment without prey paused less frequently, making $\approx 26 \%$ fewer pauses per unit time at 5 days old but only $\approx 6 \%$ fewer pauses at 45 days old. Because the pause duration was significantly longer in the absence of prey, the median swimming speed was lower when prey were absent (fig. 4.1). 


\section{Energy use during foraging activity}

The amount of energy spent on activity (fig. 4.2) was calculated for every larva observed in the foraging behavior experiments using the power-performance relationship (equation 10), the individual median swimming speed (fig. 4.1), and the group (experiment) median dry weight.

Median swimming speed increased with larval age; this trend was significant among the rotifer treatments but not among the absent prey and zooplankton prey treatments (table 4.4). Activity metabolism decreased as larvae grew; this trend was significant for the fed larvae (both rotifers and zooplankton prey) but not among the absent prey treatment (table 4.4). ANCOVA analyses of the individual median swimming speed and energy spent on swimming $\left(\mathrm{M}_{\text {activity }}\right)$ shows no significance difference between the highprey rotifer treatment and no prey treatment (table 4.5).

In most behavioral parameters the zero prey treatment shows much higher variability than both of the rotifer and zooplankton prey treatments. Much of this variability is due to a single experiment (experiment $J$, table 3.1) in which larvae behave much like larvae in the presence of prey. It is possible, but not confirmed, that prey from the rearing barrels were inadvertently introduced into the observation tank along with the larvae. If this group were to be omitted from ANCOVA analyses, larvae in the absence of prey would be found to spend significantly less energy on activity than larvae foraging in high-prey density conditions (test of equal slopes: $F_{1,15}=3.7978, P=0.0703$; test of equal intercepts: $F_{1,15}=12.3861, P=\underline{0.0031}$ ).

The power-performance relationship was established from the respirometry experiment, however, swimming speeds observed within the large observation tank were roughly five times greater than the speeds observed within the small respirometry chambers. The estimation of the energy spent by an individual swimming within the observation tank is an extrapolation beyond the respirometry data from which the powerperformance model was calculated. The mean swimming speed over a period of time is a function of both burst speed and the fraction time actively swimming, while the cost of swimming at any given instant is a function of swimming speed alone. Therefore, the 
proper comparison of the data range between the respirometry and the behavioral experiments is of the burst swimming speeds. Respirometry activity measurements have a resolution of 2 seconds while behavioral activity measurements have a resolution of 0.2667 seconds. To compare burst speeds, behavioral position data was sub-sampled at a rate of once every 2 seconds. The median individual burst speeds were greater in the large observation tank than they were in the respirometry chambers (fig. 4.3).

The estimation of the energy spent by individuals swimming within the observation tank assumes that the power-performance relationships for all size classes remain linear over the entire observed swimming speed range. How the cost of swimming changes with swimming speed depends upon how hydrodynamic drag changes with swimming speed. There is no simple rule for predicting drag on even simple-shaped objects (Vogel 1994). Drag, D, can be expressed as:

$$
D=(1 / 2) \cdot \rho \cdot S^{2} \cdot A \cdot C_{d},
$$

where, $S=$ swimming speed, $\rho=$ water density, $A=$ wetted surface area (alternatively the area perpendicular to the flow), and $\mathrm{C}_{\mathrm{d}}=$ drag coefficient. $\mathrm{C}_{\mathrm{d}}$ is a function of the Reynolds number, Re, and its relationship to Re changes depending upon the hydrodynamic regime of interest. In the viscous regime $(\mathrm{Re}<20), \mathrm{C}_{\mathrm{d}}$ is approximately inversely proportional to $\operatorname{Re}\left(C_{d} \propto \operatorname{Re}^{-1}\right)$; while in the inertial regime ( $\left.\operatorname{Re}>200\right), C_{d}$ is lower and approximately constant (Vogel 1994). The Reynolds number is a dimensionless ratio of inertial forces to viscous forces and is itself a function of swimming speed:

$$
\operatorname{Re}=L \cdot S \div \nu
$$

where, $L=$ length and $v=$ kinematic viscosity of the seawater medium.

For fish larvae, the viscous forces of drag are gradually supplanted by inertial forces over the transitional regime $(20<\operatorname{Re}<200$, Weihs 1980$)$, but, there is evidence from larval herring that the viscous regime may extend as high as $\mathrm{Re}=450$ (Fuiman \& Batty 1997). Within the viscous $(\operatorname{Re}<20)$ and lower transitional hydrodynamic regimes where small cod larvae forage, greater swimming speed has two opposing effects upon drag. First, at 
faster swimming speeds $R e$ increases and drag decreases because $C_{d} \propto \operatorname{Re}^{-1}$. Second, in this low Reynolds number regime, drag is proportional to speed (D $\propto S \cdot L)$ (Fuiman \& Batty 1997) and any increase in speed would tend to increase drag. In the present behavioral study, the top speed attained by larvae within the large observation tank during swimming bursts did not carry them out of the low Reynolds number regime. The highest Reynolds number attained during the peak of swimming bursts was $\operatorname{Re}<65$ for even the largest larvae (fig. 4.4). The power-performance relation established in the respirometry study should remain approximately linear over the greater swimming speed range observed within the large observation tank because viscous forces still dominate inertial forces and drag remains linearly proportional to speed.

\section{Trophodynamic model}

An individual larva's minimum daily energy requirement $\left(\mathrm{J} \cdot \mathrm{day}^{-1}\right)$ is the total energy value of captured prey that is required to balance all daily metabolic demands $\left(\mathrm{M}_{\text {basal }}+\right.$ $\left.\mathrm{M}_{\text {activity }}+\mathrm{M}_{\mathrm{SDA}}\right)$ and achieve zero net energy gain. Daily energy demands were calculated for the activity levels observed under each prey treatment (high rotifer concentration and no prey) using equation 12 . Point estimates were calculated at the mean age and weight of each of the 5 age groups used in the behavioral observations: 0-9 days (mean age $=6$ days, mean dry weight $=0.0448 \mathrm{mg}), 10-19$ days $(14.2$ days, $0.0494 \mathrm{mg}), 20-29$ days $(24$ days, $0.0688 \mathrm{mg}$ ), $30-39$ days ( 33 days, $0.1185 \mathrm{mg}$ ), and $40-49$ days (43.5 days, $0.1540 \mathrm{mg})$.

The higher activity levels observed in the high prey treatment must be supported by a greater daily gross energy intake than is required by the larvae foraging at the lower activity levels observed in the no prey treatment (fig. 4.5). This difference amounts to a $30 \%$ greater energy demand for young larvae ( $<2$ weeks old) actively foraging in high prey conditions, but the difference between prey treatments declines rapidly with age due to the lower cost of swimming for larger larvae (fig. 2.7).

These estimated daily energy requirements are used to estimate the prey density required to support larvae in three size classes: $5 \mathrm{~mm}, 6 \mathrm{~mm}$, and $7 \mathrm{~mm}$ (see discussion). 
Figure 4.1. Median individual swimming speeds of each behavioral experiment plotted against age for no prey, rotifer prey $\left(100 \mathrm{~L}^{-1}\right)$, and zooplankton prey $\left(100 \mathrm{~L}^{-1}\right)$ treatments. Each point represents the mean value for each experiment. Error bars are $95 \%$ confidence intervals.

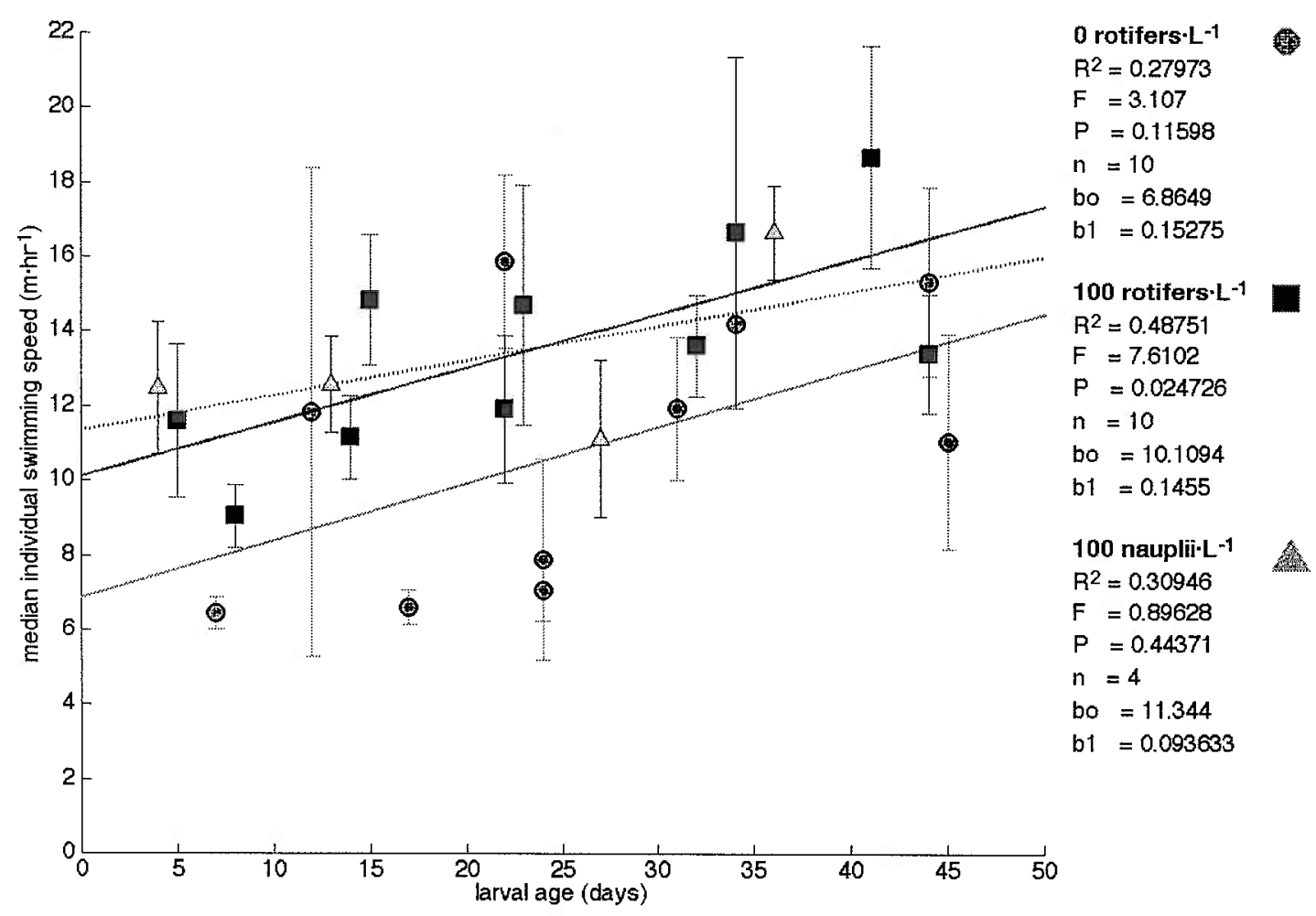


Figure 4.2. The isolated cost of swimming activity (active metabolism, not including basal metabolism) calculated from the observed median individual swimming speed. Each point represents the mean value for each experiment. Error bars are $95 \%$ confidence intervals

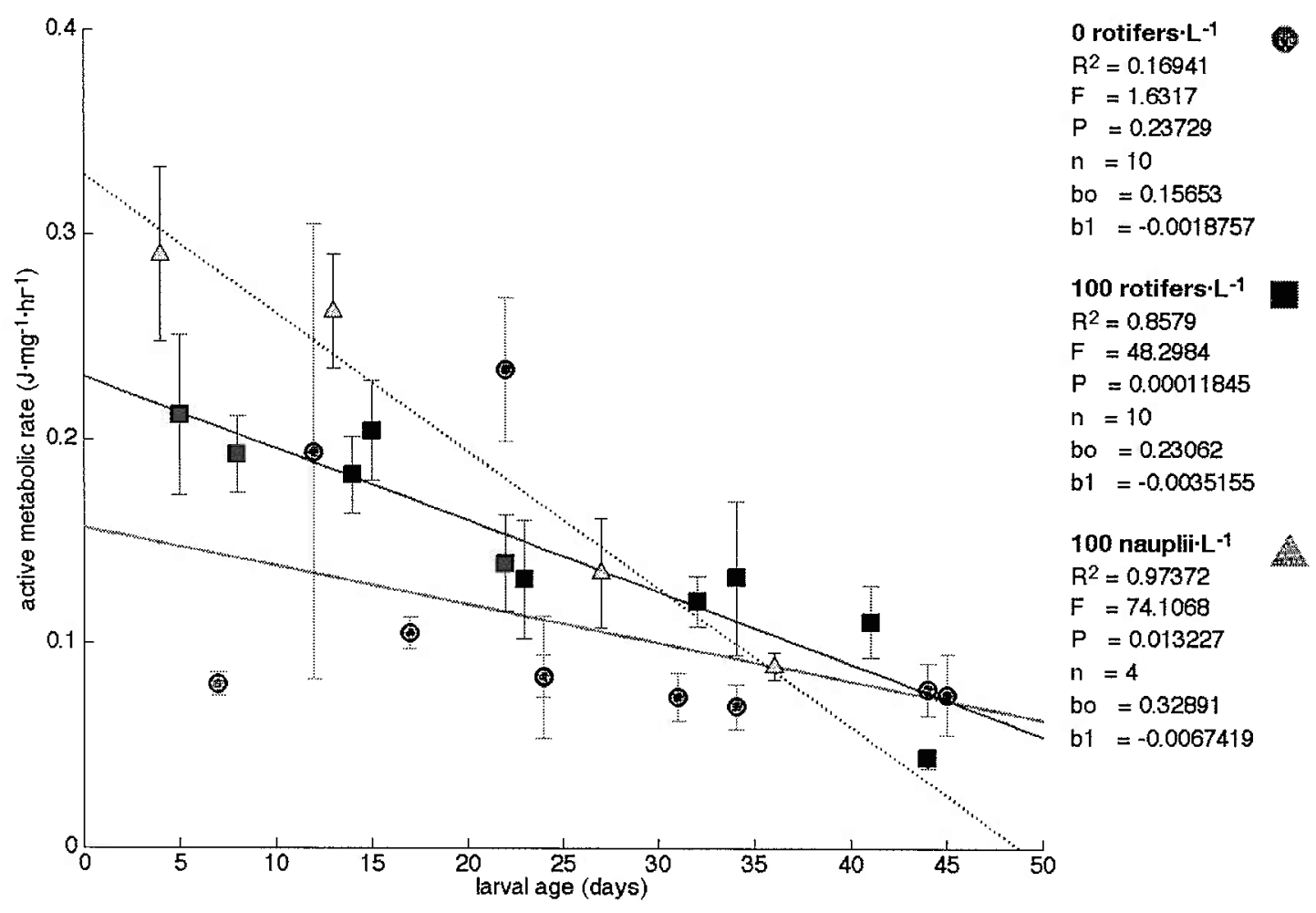


Figure 4.3. Comparison of the median burst swimming speeds of individual larvae in the large observation tank and the small respirometry chambers. ' + ' symbols denote outliers more extreme than 1.5 times the inter-quartile range. (The time resolution for measuring speed was 2s.)

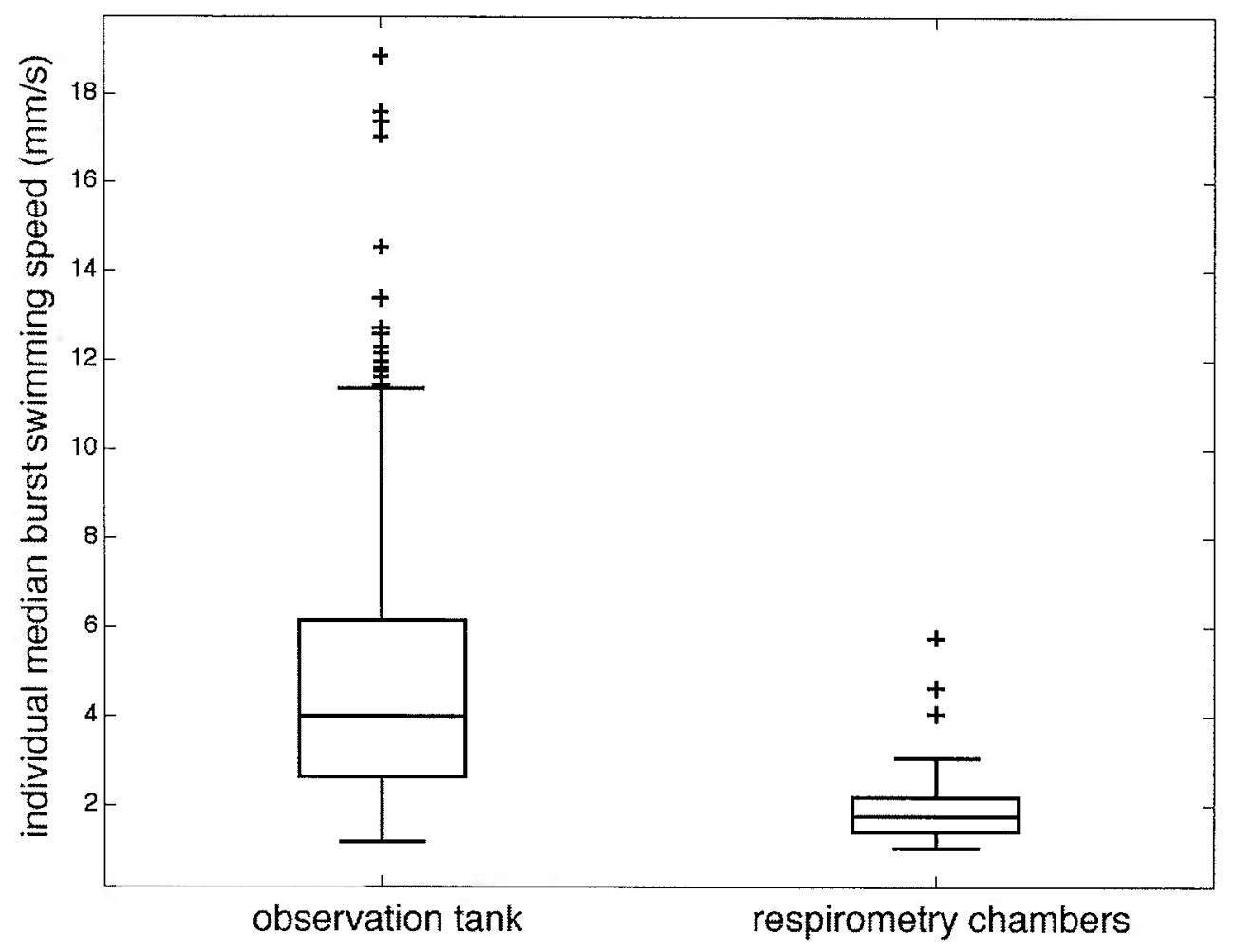


Figure 4.4. The top Reynolds numbers obtained during the height of swimming bursts by larvae foraging within the large observation tank. These values are the mean $R e$ calculated from the median peak burst speeds of individual larvae in each high prey treatment experiment. Error bars are $\pm 95 \%$ confidence intervals. (The time resolution for measuring speed was $0.2667 \mathrm{~s}$.)

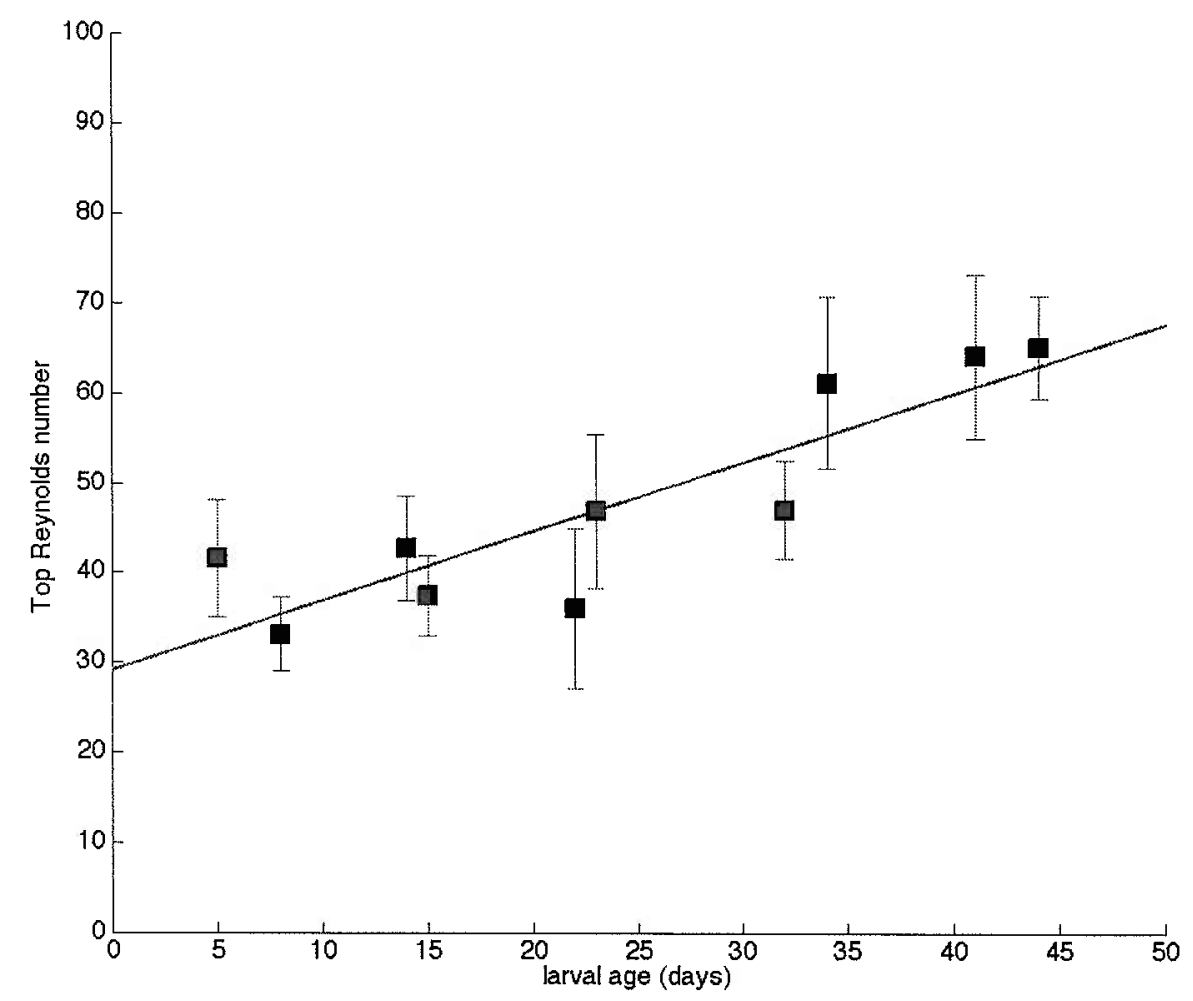




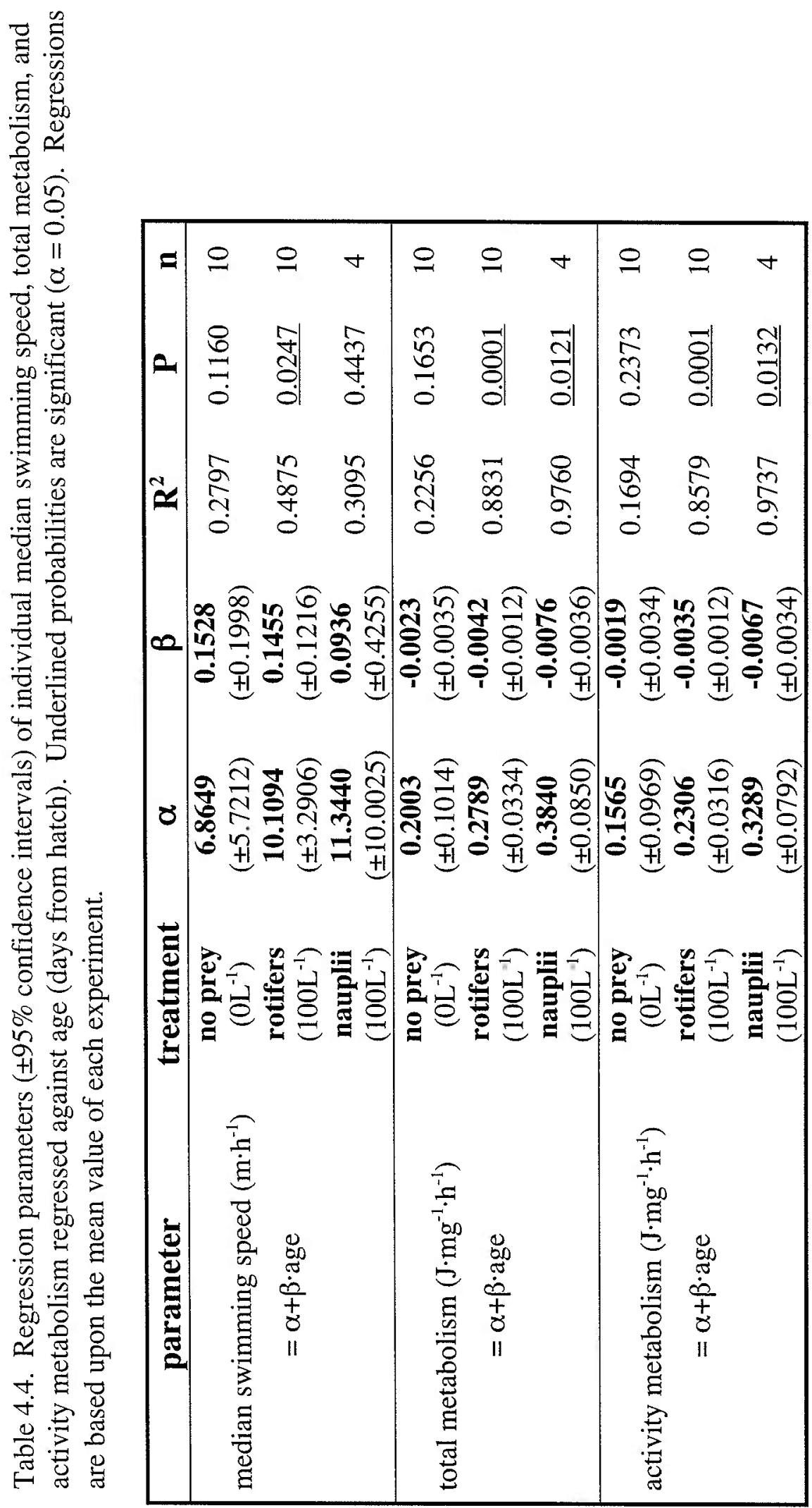




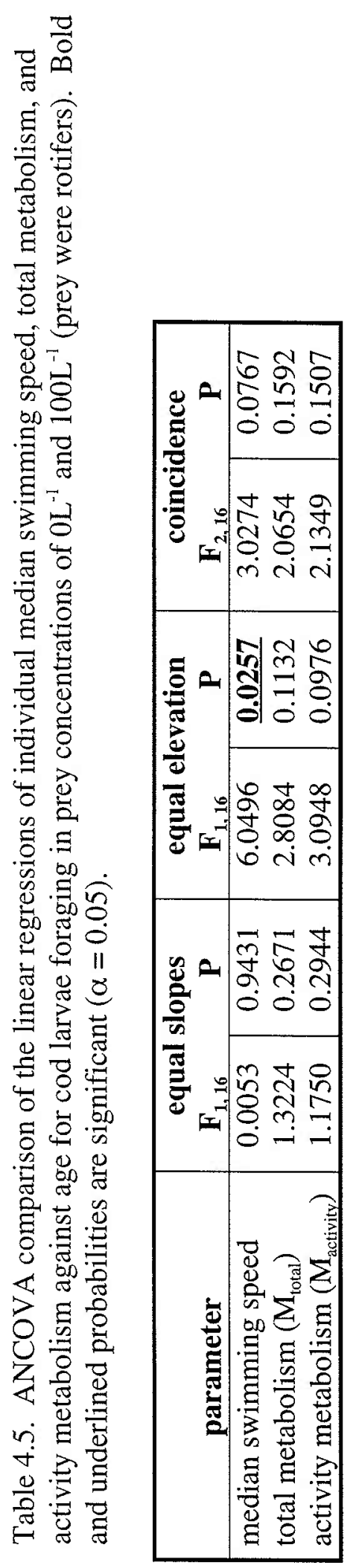


Figure 4.5. The estimated total daily energy demand (Joules.individual ${ }^{-1}$ ) of larvae foraging in $11 \mathrm{~h}$ daylight $/ 13 \mathrm{~h}$ night. This is the minimum energy demand required to achieve zero net energy gain. Energy demands were calculated for the activity levels observed under each prey treatment (high rotifer concentration and no prey). Point estimates were calculated at the mean age and weight of each of the 5 age groups used in the behavioral observations: $0-9$ days (mean age $=6$ days, mean dry weight $=0.0448 \mathrm{mg}$ ), 10 - 19 days ( 14.2 days, $0.0494 \mathrm{mg}$ ), 20-29 days ( 24 days, $0.0688 \mathrm{mg}$ ), $30-39$ days (33 days, $0.1185 \mathrm{mg}$ ), and $40-49$ days ( 43.5 days, $0.1540 \mathrm{mg}$ ).

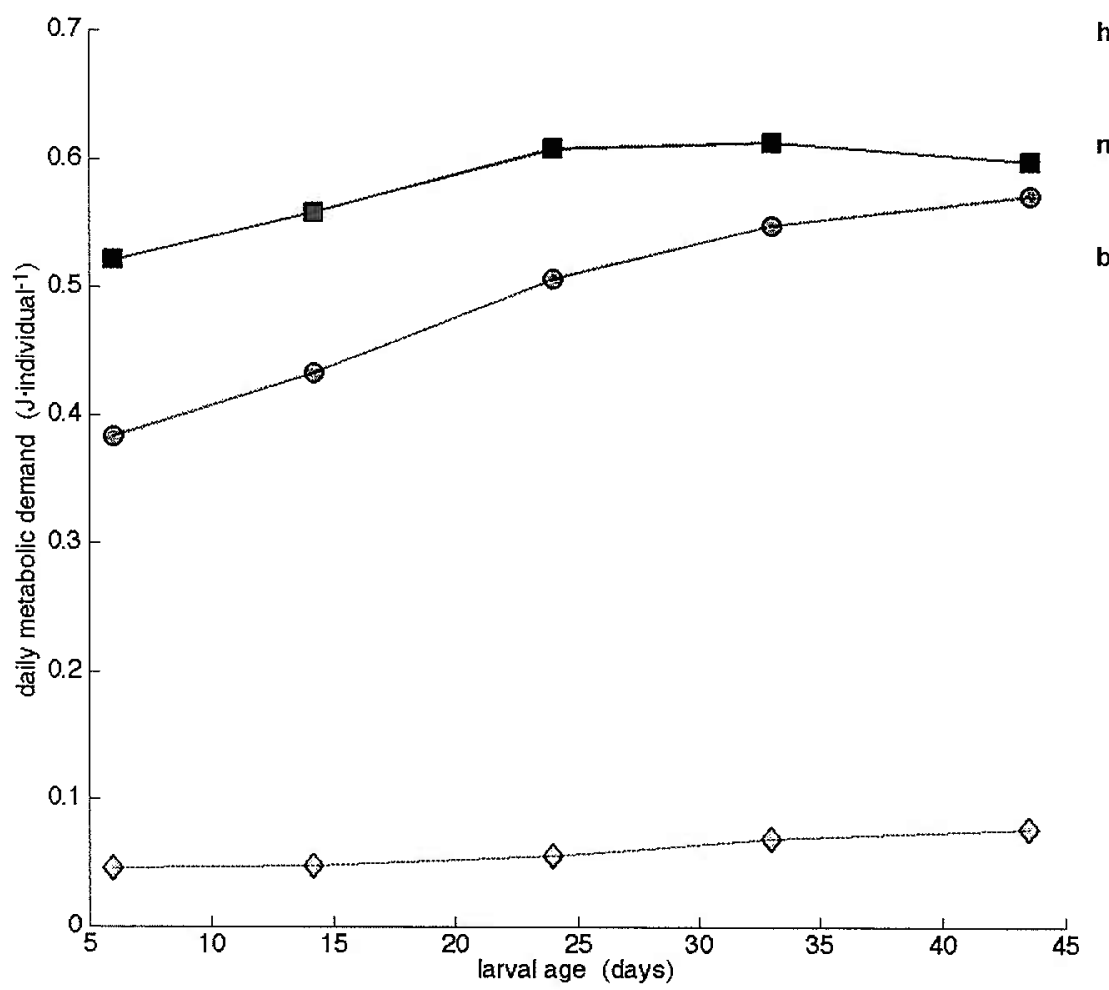

high prey treatment

no prey treatment

basal demand

(1)

$\diamond$ 


\section{Discussion}

The importance of activity in the overall bioenergetic budget and ecology of larval fish is not well known. A bioenergetic strategy favoring rapid growth should be of great value for fish larvae. Foraging capacity and ability to successfully escape predators improve as sensory acuity and swimming ability increase with larval size (Peterson \& Wroblewski 1984, Folkvord \& Hunter 1986, Miller et al. 1988, Bailey \& Houde 1989, Hunt von Herbing \& Gallager 2000). However, the total amount of energy available to a larva is limited by the amount of prey it can capture which requires an investment of energy for foraging activity. Foraging activity is expensive. The weight specific cost of swimming is much higher for larvae than it is for juveniles and adults (Dabrowski 1986b, Kaufmann 1990) while the overall aerobic scope, or metabolic capacity, is narrow in larval fish (Wieser et al. 1988). The energy demanding processes of growth and activity may be in conflict, and the foraging behavior of larval fish may be limited by the cost of activity.

Is the cost of activity a substantial and variable component of a larva's total bioenergetic budget?

Many studies have measured the activity costs of juvenile and adult fish (e.g., Boisclair \& Leggett 1989, Forstner \& Wieser 1990, Krohn \& Boisclair 1994, Tang et al. 1994), but isolating activity metabolism from all other metabolic demands is difficult in larval fish. Also difficult is observing larval swimming intensity in natural or near natural conditions. Trophodynamic models for larval fish have been restricted to very crude estimates about the importance of activity that are based upon the metabolic range observed within small respirometry chambers such as those used within the present respirometry study. By applying the power-performance model established in the present respirometry study to the swimming intensities of freely foraging larvae observed within the large tank of the behavioral study, the present study aims to make an accurate estimate of the importance of activity metabolism in the overall bioenergetic budget of larval cod. 
Routine metabolism is the sum of basal metabolism and the activity metabolism of spontaneously swimming fish (Beamish \& Mookherjii 1964, Fry 1971). The ratio of routine metabolism to basal metabolism $\left(\mathrm{M}_{\text {routine }} \div \mathrm{M}_{\text {basal }}\right)$ is referred to as the routine factorial scope (Rombough 1988) or $k$. The routine factorial scope has been used in all trophodynamic models developed for larval cod to date to estimate the cost of activity as: $\mathrm{M}_{\text {activity }}=k \cdot \mathrm{M}_{\text {basal }}-\mathrm{M}_{\text {basal }}$ (Laurence 1985, Werner et al. 1996, Leising \& Franks 1999, Buckley et al. 2000, Leising \& Franks 2000, Werner et al. 2001). Some models (eg., Laurence 1985) specify that routine metabolism is applied when light levels are too low for foraging and $k \cdot \mathrm{M}_{\text {routine }}$ is applied when larvae are active. In these cases the term basal metabolism is more appropriate than the term routine metabolism. Among temperate and sub-arctic larval fish in general, the routine factorial scope tends to vary from 1.5 to 2.5 (reviews by Rombough 1988 and Kamler 1992). Laurence (1985), Werner et al. (1996), Leising and Franks (1999), Buckley et al. (2000), Leising and Franks (2000), and Werner et al. (2001) all use a value of 2.5 which was originally derived from Ware (1975) as the average value for juvenile and adult fish and not on data specific to larval cod. Solberg and Tilseth (1984) and Davenport and Lønning (1980) each calculate a routine factorial scope for first-feeding cod larvae (5 days-old) that is substantially lower than 2.5 ; routine factorial scope $=1.4$ to 1.6 or $29 \%$ to $38 \%$ of total routine metabolism is due to activity, respectively.

There are three major limitations with using the routine factorial scope to estimate the cost of swimming. First, it does not allow for variation of swimming activity under changing conditions. Though many bioenergetic models have included the cost of activity as a non-varying scalar of basal or routine metabolism (e.g., Laurence 1977, Yamashita \& Bailey 1989, Post 1990, Huuskonen et al. 1998), other studies have established that activity costs are not only significant but also highly variable (Ware 1975, Boisclair \& Leggett 1989, Boisclair \& Sirois 1993, for juveniles and adults, Madon \& Culver 1993, for larvae). In the present study, the routine factorial scope of larval cod measured within respirometry chambers depended on the swimming speed of the individual (fig. 2.14). Observed routine factorial scopes are 1.4 (swimming at 0.0- 
$2.0 \mathrm{~m} \cdot \mathrm{h}^{-1}$ ) and 2.0 (swimming at $2.0-9.0 \mathrm{~m} \cdot \mathrm{h}^{-1}$ ) (fig. 2.14). This points to the need to better define 'routine' activity or precisely define the activity level that is called 'routine' on a study-by-study basis.

Second, very few of the respirometry experiments that have measured routine metabolism provide any index of the larval swimming intensity within the respirometry chamber to allow comparisons between studies. The best way to accurately measure the role of activity in the overall bioenergetic budget is to measure the cost of swimming as a function of intensity and apply that knowledge to observed swimming intensity. Studies of freshwater larval corregonids and cyprinids by Dabrowski (1986a, 1986b), Kaufmann (1990), Kaufmann and Wieser (1992), and studies of larval cod by Hunt von Herbing and Boutilier (1996) as well as the current work are the only studies to date that have established specific power-performance relations of energy demand as a function of swimming intensity. Hunt von Herbing and Boutilier's (1996) empirical powerperformance model and behavior data show that activity can account for 69 to $72 \%$ of the total routine aerobic metabolism of larval cod (routine factorial scope 3.2 to 3.5 for larvae 0 to 40 days old). In contrast to the large activity-related expenditures in larval cod, Kaufmann's (1990) study of cyprinid larvae concludes that activity does not play an important role in the energy budget (routine factorial scope between 1.0 and 1.5), accounting for only $10-15 \%$ of the total energy budget. The difference between the two sets of studies may be due to temperature effects on muscle efficiency and on the viscosity of water itself, both of which affect the cost of swimming (Hunt von Herbing 2002). Kaufmann's study on larval cyprinids was conducted at $20^{\circ} \mathrm{C}$ while Hunt von Herbing and Boutilier's study on larval cod was conducted at $10^{\circ} \mathrm{C}$. The relative importance of swimming activity in larval bioenergetic budgets may be latitudinal, and care must be taken when generalizing between species.

Third, the activity levels within small, sealed, possibly crowded respirometry chambers for extended periods of time are very unlikely to resemble activity levels in the sea. The purpose of using a large observation tank in this study to observe larval swimming behavior was to more closely match foraging conditions in the ocean by 
reducing confinement and crowding effects. The activity levels of larvae swimming in the large observation tank (250L) were approximately 5 times the levels observed within the small respirometry cells $(6.5 \mathrm{ml})$ (fig. 4.6$)$.

Applying the empirically derived power-performance relation (equation 10) to the swimming intensity measured within the large observation tank allowed the energy investment in swimming activity to be calculated for each of the prey treatments and larval age classes investigated. Expressed as routine factorial scope, the amount of energy that larval cod spent on swimming activity within the observation tank was greater than was spent on activity in the small respirometry chambers (fig. 4.7, table 4.6). These values were also greater than the range previously reported in the literature for larval fish in general (1.4-3.5, reviews by Rombough 1988, and Kamler 1992).

The energy spent on activity also varied with foraging conditions. Over the longterm, the search for prey may reasonably be assumed to be more significant than prey capture and handling in terms of both the energy spent (Drost \& van den Boogaart 1986) and time. Of the larvae studied here, 45 day old larvae have the greatest foraging capacity. Even at a very high prey density of 50 prey $\cdot \mathrm{L}^{-1}$ only $3.3 \%$ of the pause searches by a 45 day old larva will encounter a prey item (equation 3). Conservatively, searching represents more than $95 \%$ of the foraging-related activity energy expenditure. When searching in the absence of prey, larvae spent less energy than they did when foraging in the presence of prey (fig. 4.2). The difference between the prey treatments decreased as larvae grew from a roughly $30 \%$ difference at 5 days to no difference at 35 days because the cost of swimming declined with size.

Accurate trophodynamic models must also include behavior and the environmental conditions that affect foraging effort. Activity costs that are highly variable and substantially larger than previously assumed can be interpreted as evidence that the existing trophodynamic models for cod larvae underestimate metabolic demands. These trophodynamic models (e.g., Leising \& Franks 1999, Werner et al. 2001) fairly accurately predict growth rates despite underestimating metabolic demand; compensating errors in the models may account for this (Buckley et al. 2000). Sensitivity analyses of 
trophodynamic models developed for fish larvae show that errors in assimilation efficiency and reactive distance have a large impact on predicted growth rate (Letcher et al. 1996, Lough et al. in press). These parameters, in particular, are not well known, and underestimating either assimilation efficiency or reactive distance could offset the error of underestimating activity metabolism. 
Figure 4.6. Swimming speeds in tall tanks and in respirometry chambers showing the depressed activity levels in the respirometry chambers relative to the much larger tall tank. Tall tank data points represent mean values for each experiment run. Respirometry data represents individual larvae.

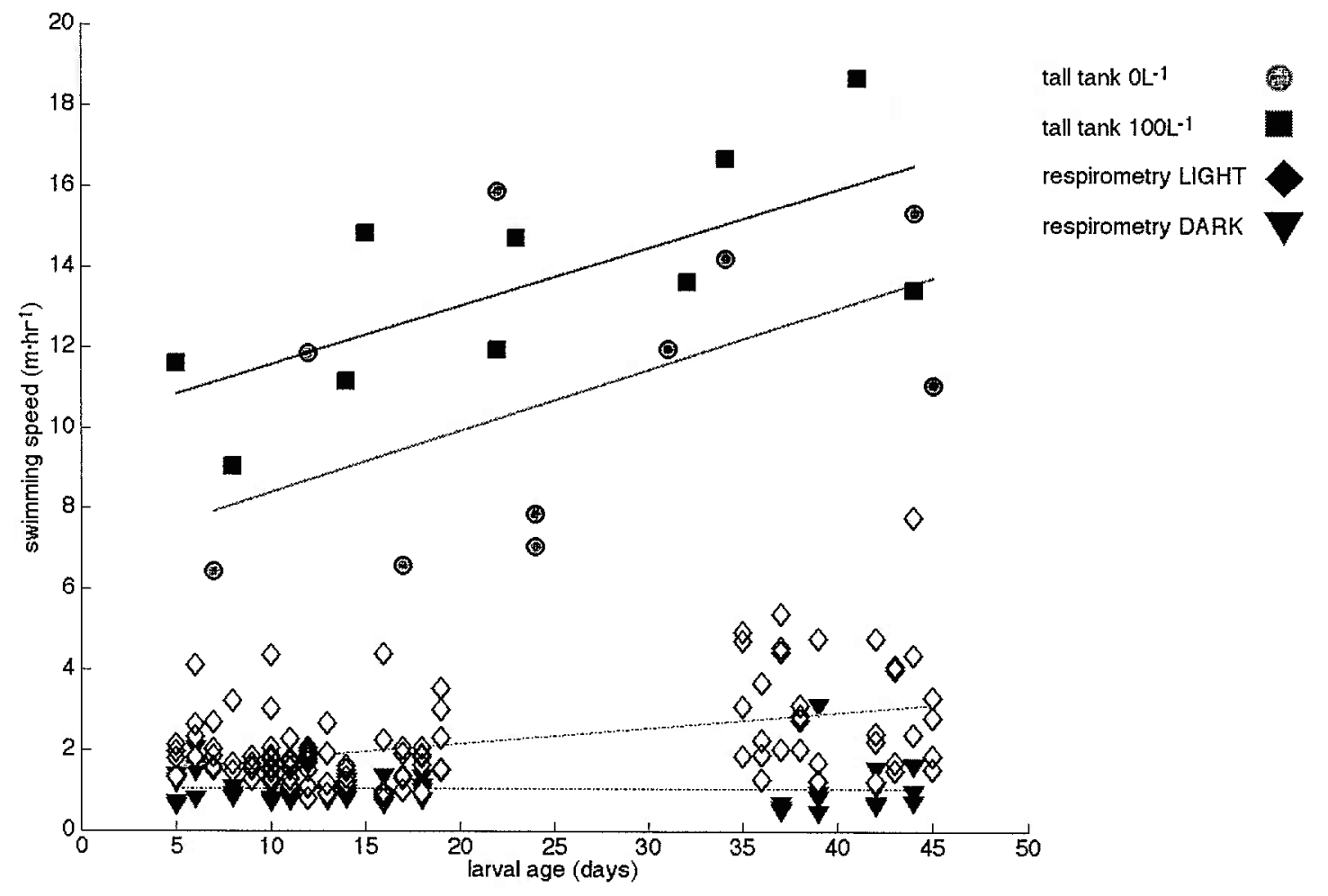


Figure 4.7. Box plot distributions of the individual routine factorial scopes $\left(\mathrm{M}_{\text {routine }} \div\right.$ $\mathrm{M}_{\text {basal }}$ ) of actively foraging cod larvae observed in the large (250L) observation tank (no prey treatment $n=187$; rotifer prey treatment $n=197$, and zooplankton prey treatment $\mathrm{n}=76$ ). Data represent individual larvae in each prey treatment. (Six outliers $>10$ are not shown; 2 in each prey treatment).

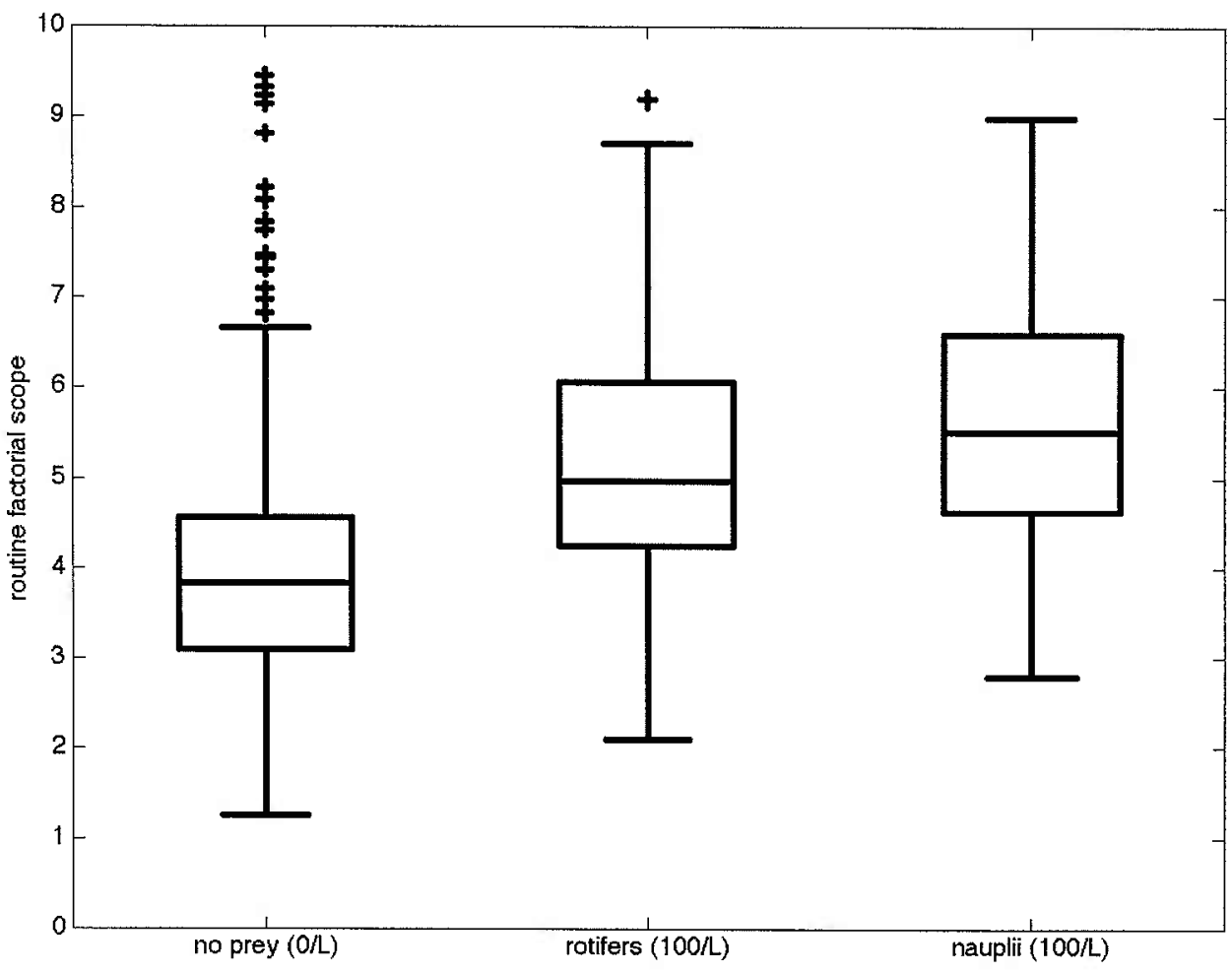


Table 4.6. Routine factorial scope estimated from observed swimming behavior within the large observation tank and the empirically derived power-performance relation that relates energy expenditure to swimming intensity. Data are shown in figure 4.6.

\begin{tabular}{|rcc|}
\hline Prey treatment & $\begin{array}{c}\text { Routine Factorial Scope } \\
\left(\mathbf{M}_{\text {routine }} \div \mathbf{M}_{\text {basal }}\right)( \pm 1 \mathrm{std})\end{array}$ & $\mathbf{n}$ \\
\hline no prey $0 \cdot \mathrm{L}^{-1}$ & $3.80( \pm 1.58)$ & 187 \\
rotifers $100 \cdot \mathrm{L}^{-1}$ & $4.91( \pm 1.89)$ & 197 \\
nauplii $100 \cdot \mathrm{L}^{-1}$ & $5.24( \pm 1.20)$ & 76 \\
\hline
\end{tabular}


What is the required prey density to support larval growth and survival?

A full trophodynamic model incorporates larval foraging capacity, all components of metabolism ( $\left.\mathrm{M}_{\text {basal }}, \mathrm{M}_{\text {activity }}, \mathrm{M}_{\mathrm{SDA}}\right)$, the physical parameters that directly effect foraging (e.g., prey field characteristics, light intensity, turbulence), and the behavioral response to the entire range of foraging conditions that larvae are expected to experience. The goal of the simplified trophodynamic model presented in this study is to demonstrate the balance between foraging capacity and the cost of foraging activity. The prey treatments used in the behavioral studies $\left(0 \mathrm{~L}^{-1}\right.$ and $\left.100 \mathrm{~L}^{-1}\right)$ encompass the full range of prey concentrations larvae are ever likely to experience in the ocean. Prey concentration is likely to be the single most important factor controlling the difficulty of finding prey. As a simplifying assumption, the responses to these prey treatments are assumed to show the full behavioral range of larvae in nature.

On Georges Bank, larval cod prey upon Calanus finmarchicus, Pseudocalanus spp., Centropages typicus, and Oithona similis as their main prey species (Kane 1984, Lough et al. in press). Prey densities for each of the prey species required to achieve zero net energy gain were calculated for three size classes of larvae $(5,6$, and $7 \mathrm{~mm})$ at three turbulence levels spanning the range typically found on Georges Bank; $\varepsilon=0,110^{-7}$, and $1 \cdot 10^{-5} \mathrm{~m}^{2} \mathrm{~s}^{-3}$ (Horne et al. 1996). These values represent the prey densities required to cover all metabolic demands if larvae were preying exclusively upon a particular copepod species and development stage (table 4.7). They have been calculated based upon an 14h foraging day found on Georges Bank in early May and assume that larvae forage at a constant rate throughout the entire period and cease foraging activity after sunset. Because the goal of this exercise was to calculate the minimum prey density needed for survival, gut capacity and gut clearance rates were ignored by assuming that gut capacity is greater than can be filled at these low prey densities.

Spring prey concentrations on the eastern and southern flanks and over the central cap of Georges Bank reach up to 12 nauplii $\cdot \mathrm{L}^{-1}$ and 2.5 copepodites $\cdot \mathrm{L}^{-1}$ averaging out all horizontal and vertical variability and grouping all species and stages together (Werner et al. 1996, Lough et al. in press). Concentrations are considerably lower on the northern 
flank, reaching 1 nauplius $\cdot \mathrm{L}^{-1}$ and 0.2 copepodite $\cdot \mathrm{L}^{-1}$ (Werner et al. 1996); Georges Bank regions are as defined by Davis (1984).

The model shows that theoretically, all size classes of larvae $(5,6$, and $7 \mathrm{~mm})$ could survive on the mean springtime prey concentrations over most of Georges Bank (table 4.7). Small larvae $(5 \mathrm{~mm})$ have the lowest foraging capacity (see table 3.7 ) and require high prey densities, but they can meet their energy demands when turbulence is low and mean prey concentrations approach the high-end of the range observed on Georges Bank. Larger larvae are more effective predators and can survive in much lower prey densities.

While turbulence enhances predator-prey contact rates (Rothschild \& Osborn 1988), it can interfere with the successful pursuit and capture of encountered prey (MacKenzie $\&$ Kiørboe 2000). Even at modest turbulence levels $\left(\varepsilon=1 \cdot 10^{-7} \mathrm{~m}^{2} \mathrm{~s}^{-3}\right)$, larval cod require higher prey densities relative to calm conditions to overcome lower capture success probabilities. The model predicts that small larval cod $(5 \mathrm{~mm})$ can only survive on the mean Georges Bank prey densities in calm or very mildly turbulent conditions. Larger larvae $(6$ and $7 \mathrm{~mm})$ can survive even at high turbulence levels $\left(\varepsilon=1 \cdot 10^{-5} \mathrm{~m}^{2} \mathrm{~s}^{-3}\right)($ table 4.7).

Werner et al. (1996) calculated that larval cod could not survive on the mean prey concentrations observed on Georges Bank without the action of turbulence to enhance predator-prey contact rates. Their revised model (Werner et al. 2001) incorporated the negative effect of turbulence on the ability of larvae to capture prey once encountered. They conclude that larvae could not survive on the mean (spatially homogenous) springtime prey concentrations of any of the regions of Georges Bank. They hypothesize that larval survival and growth requires the exploitation of prey patches. The present model predicts that larval cod can better cope with conditions on Georges Bank because it is based upon higher measurements of larval foraging capacity. Werner et al. (2001) use the somewhat lower measurements of MacKenzie and Kiørboe (1995); foraging capacity was $7-12 \mathrm{ml} \cdot \mathrm{min}^{-1}$ in the present model vs. $4-9 \mathrm{ml} \cdot \mathrm{min}^{-1}$ in the Werner et al. model for similarly sized 5-6mm larvae (see table 3.7). However, to survive in the Georges Bank prey-field, small larvae must forage at the intensities observed in the high-prey 
treatment while larger larvae can survive under the full range of foraging behaviors observed in this laboratory study.

Even using the higher foraging capacities measured in the present study, smaller larvae will be hard pressed to acquire enough food; their survival may depend upon encountering patches of high prey density or feeding upon protozoans. Small larval cod are efficient predators of protozoans (Gallager et al. 1996b, Hunt von Herbing \& Gallager 2000), but protozoan abundance and energy value are not well known. Larval growth is enhanced when they can forage in higher-than-background prey aggregations (Buckley \& Lough 1987, Davis et al. 1991). One process for aggregating prey is the springtime formation of the seasonal thermocline in the waters surrounding the central cap of Georges Bank (Buckley \& Lough 1987). Prey species such as Calanus are concentrated in and above the thermocline and the formation of fine-scale patches can occur in such regions of vertical stability (Gallager et al. 1996a). Behavioral mechanisms may retain larvae within a prey patch once it has been encountered. Herring larvae alter their swimming behavior in response to different prey densities. At high prey density, herring cross their own swimming paths more frequently, reducing the overall displacement away from the high prey region (Gallego 1994). Non-directed swimming can also retain larvae within prey patches if swimming speed and handling time is lower at higher prey densities (Davis et al. 1991).

This model makes several assumptions and simplifications. With respect to foraging capacity, the reactive distance was not measured directly but was set to the mean burst distance. The justification for this assumption is that for greatest efficiency larvae will move only as far as necessary to search a new volume of water leaving no un-searched water between consecutive search-volumes, and larvae will move far enough to avoid searching portions of a search-volume more than once (O'Brien et al. 1990). This estimate of reactive distance is close to the 0.8 body lengths estimated by MacKenzie and Kiørboe (1995) (see table 3.7). The reactive distance is also a function of light intensity and prey characteristics (size, contrast against the background, motion). As light 
intensity declines with depth or turbidity, reactive distance (and foraging capacity) should theoretically decrease (Fiksen et al. 1998). As a simplifying assumption, reactive distance was held constant in the present model.

Capture efficiency (or capture success probability) is a function of larval size, turbulence levels, and prey type. There are few measurements of capture efficiency in marine fish larvae (Solberg \& Tilseth 1984, Munk 1995, Hunt von Herbing \& Gallager 2000, MacKenzie \& Kiørboe 2000) and no observations of the capture efficiency of small larvae $(<8 \mathrm{~mm})$ under variable conditions. The current model conservatively (lower than assumed in the Werner et al. 2001 model) sets the values of capture efficiency consistent with the few available measurements, the observation of MacKenzie and Kiørboe (2000) that moderate to high turbulence interferes with the capture process, and the theory that turbulence has a stronger negative effect upon small larvae. Variability with prey size and type was ignored.

With respect to metabolic processes, bioenergetic models are very sensitive to variation in assimilation efficiency (Letcher et al. 1996, Lough et al. in press). Assimilation efficiency was set at a constant 0.7 for all size classes. This is the value measured for larval herring (Boehlert \& Yoklavich 1984) and is typical for marine fish larvae in general (at $10^{\circ} \mathrm{C}$, Houde 1989). Assimilation efficiency may be a function of larval size and development but studies conflict over whether it increases as larvae grow (e.g., Buckley \& Dillman 1982) or decreases as larvae grow (e.g., Keckeis et al. 2001).

Finally, the cost of growth (specific dynamic action, SDA) is not constant at all growth rates. The high cost of growth may be offset by increasing the efficiency of protein synthesis at high growth rates (Wieser \& Medgyesy 1990a). Generally for all animals, oxygen consumption increases with growth rate (Jobling 1985); this rule does not apply to larval fish. Several studies show no close link between growth and metabolism during the early life stages of fish (Wieser \& Medgyesy 1990a, b, Rombough 1994, Houlihan et al. 1995, reviewed by Pedersen 1997). The highest rates of protein synthesis are accompanied by the lowest aerobic costs in vitro (Pannevis \& Houlihan 1992, Smith \& Houlihan 1995). Houlihan et al. (1995) suggest that there are two costs 
associated with protein synthesis. At low growth rates, a high proportion of the cost of growth is the cost of producing the machinery of protein biosynthesis (i.e., ribosomes and mRNA). At higher growth rates, this machinery is already in place and further protein synthesis approaches the theoretical minimum cost. Because the purpose of this exercise was to estimate the minimum prey densities necessary for food-limited larvae to survive, growth rates under such conditions should be low and SDA increase linearly with growth (Wieser \& Medgyesy 1990b). The SDA factor was therefore set to a constant value. 
Table 4.7. Prey densities required for each of four prey species required to meet all metabolic demands ( 0 net energy gain) for three size classes of larval cod and at three turbulence levels. Values represent the required prey concentration if larvae were feeding exclusively upon a particular species and development stage. Values are presented as a range based upon the foraging intensities observed within the behavior study (first value given is the high-prey treatment, second value given is the absent prey treatment). Highlighted values are within the (spatially homogenous) spring-time prey concentrations observed over much of Georges Bank: up to 12 nauplii $\cdot \mathrm{L}^{-1}$ and 2.5 copepodites $\cdot L^{-1}$ (Werner et al. 1996, Lough et al. 2004). For each species, density requirements were calculated for the largest nauplius and copepodite stage that larvae could prey upon. (see table 4.3 for prey sizes used in the model.)

\begin{tabular}{|c|c|c|c|c|}
\hline \multirow{2}{*}{ Larval size: $\mathbf{5 m m}$} & & \multicolumn{3}{|c|}{ Turbulent energy dissipation rate $(\varepsilon)$} \\
\hline & & $0 \mathrm{~m}^{2} \mathrm{~s}^{-3}$ & $1 \cdot 10^{-8} \mathrm{~m}^{2} \mathrm{~s}^{-3}$ & $1 \cdot 10^{-5} \mathrm{~m}^{2} \mathrm{~s}^{-3}$ \\
\hline Calanus & nauplii (N3) & $\underline{11.1}-20.9$ & $23.4-43.1$ & $20.2-28.4$ \\
\hline \multirow[t]{2}{*}{ Pseudocalanus } & nauplii (N6) & $\underline{11.1}-20.9$ & $23.4-43.1$ & $20.2-28.4$ \\
\hline & copepodites (C4) & $\underline{\underline{\mathbf{2 . 3}}}-4.4$ & $4.9-9.0$ & $4.2-5.9$ \\
\hline \multirow[t]{2}{*}{ Centropages } & nauplii (N6) & $19.1-36.1$ & $40.3-74.4$ & $34.8-49.0$ \\
\hline & copepodites (C2) & $13.3-25.2$ & $28.2-52.0$ & $24.3-34.2$ \\
\hline \multirow[t]{2}{*}{ Oithona } & nauplii (N6) & $24.6-46.5$ & $51.9-95.9$ & $44.9-63.1$ \\
\hline & copepodites (C4) & $11.6-22.0$ & $24.6-45.4$ & $21.3-29.9$ \\
\hline
\end{tabular}

\begin{tabular}{|c|c|c|c|c|}
\hline \multicolumn{2}{|c|}{ Larval size: $\mathbf{6 m m}$} & $0 m^{2} s^{-3}$ & $1 \cdot 10^{-8} \mathrm{~m}^{2} \mathrm{~s}^{-3}$ & $1 \cdot 10^{-5} \mathrm{~m}^{2} \mathrm{~s}^{-3}$ \\
\hline Calanus & nauplii (N4) & $\underline{2.3}-\underline{3.6}$ & $\underline{2.3}-\underline{3.4}$ & $\underline{2.5}-\underline{3.1}$ \\
\hline Pseudocalanus & nauplii (N6) & $\underline{3.5}-\underline{5.4}$ & $\underline{3.4}-\underline{5.2}$ & $\underline{3.8}-\underline{4.7}$ \\
\hline & copepodites (C5) & $\underline{0.4}-\underline{0.6}$ & $\underline{0.4}-\underline{0.5}$ & $\overline{0.4}-\overline{0.5}$ \\
\hline Centropages & $\begin{array}{l}\text { nauplii (N6) } \\
\text { copepodites (C3) }\end{array}$ & $\frac{6.1}{2.3}-\frac{9.3}{3.6}$ & $\begin{array}{l}\mathbf{5 . 9}-8.9 \\
\mathbf{2 . 3}-3.4\end{array}$ & $\frac{6.5}{2.5}-\frac{8.1}{3.1}$ \\
\hline Oithona & $\begin{array}{l}\text { nauplii (N6) } \\
\text { copepodites (C5) }\end{array}$ & $\frac{\mathbf{7 . 8}}{2.7}-\frac{\mathbf{1 2 . 0}}{-4.1}$ & $\frac{7.6}{2.6}-\frac{11.5}{3.9}$ & $\frac{\mathbf{8 . 3}}{2.9}-\frac{\mathbf{1 0 . 5}}{3.6}$ \\
\hline
\end{tabular}

\begin{tabular}{|c|c|c|c|c|}
\hline Larval size: $7 \mathrm{mn}$ & & $0 \mathrm{~m}^{2} \mathrm{~s}^{-3}$ & $1 \cdot 10^{-8} \mathrm{~m}^{2} \mathrm{~s}^{-3}$ & $1 \cdot 10^{-5} \mathrm{~m}^{2} \mathrm{~s}^{-3}$ \\
\hline Calanus & nauplii (N6) & $0.7-\underline{0.9}$ & $\underline{0.5}-\underline{0.6}$ & $\underline{0.5}-\underline{0.6}$ \\
\hline & copepodites (C3) & $\underline{0.1}-\underline{0.1}$ & $\underline{0.1}-\underline{0.1}$ & $\underline{0.1}-\underline{0.1}$ \\
\hline Pseudocalanus & nauplii (N6) & $\underline{2.0}-\underline{2.4}$ & $1.3-\underline{1.6}$ & $1.4-1.6$ \\
\hline & copepodites (C5) & $\underline{0.2}-\underline{0.3}$ & $\underline{0.1}-\underline{0.2}$ & $\underline{0.1}-\underline{0.2}$ \\
\hline & adults & $\underline{0.1}-\underline{0.1}$ & $\underline{0.1}-\underline{0.1}$ & $\overline{0.1}-\underline{0.1}$ \\
\hline Centropages & nauplii (N6) & $\underline{3.5}-\underline{4.2}$ & $\underline{2.3}-\underline{2.7}$ & $2.5-2.7$ \\
\hline & copepodites (C5) & $\underline{0.3}-\underline{0.3}$ & $0.2-0.2$ & $\underline{0.2}-\underline{0.2}$ \\
\hline & adults & $\underline{0.1}-\underline{0.1}$ & $\underline{0.1}-\underline{0.1}$ & $\underline{0.1}-\underline{0.1}$ \\
\hline Oithona & nauplii (N6) & $\underline{4.5}-\underline{5.4}$ & $\underline{2.9}-\underline{3.5}$ & $\underline{3.2}-\underline{3.5}$ \\
\hline & copepodites (C5) & $1.5-\underline{1.9}$ & $1.0-1.2$ & $\underline{1.1}-\underline{1.2}$ \\
\hline & adults & $\underline{1.2}-\underline{1.5}$ & $\underline{0.8}-\underline{1.0}$ & $\underline{0.1}-\underline{0.9}$ \\
\hline
\end{tabular}


When foraging conditions are poor, how do larvae compromise between increasing foraging activity to maximize prey encounter rates and reducing activity to conserve energy?

Because of their small size, fish larvae live in a hydrodynamic regime where frictional (viscous) forces acting against motion are substantial and low-speed motion is energetically inefficient (Weihs 1980). A single, powerful tail beat allows larvae to benefit from inertial forces during the ensuing glide. This style of beat-and-glide swimming is the most efficient and dominant swimming strategy for post yolk-sac larvae (Vlymen 1974, Weihs 1980, Videler \& Weihs 1982, Webb \& Weihs 1986). Within the beat-and-glide framework, a larva could adjust the components of its saltatory foraging cycle to best suit current conditions (O'Brien et al. 1990). Alternative pause duration and burst distance strategies were run through the trophodynamic model to investigate the effect of foraging behavior on prey encounter rate and net energy gain. These simulations were run for the same age classes $(6,24$, and 33 days) and turbulence levels ( $\varepsilon=0,1 \cdot 10^{-8}, 1 \cdot 10^{-5} \mathrm{~m}^{2} \mathrm{~s}^{-3}$ ) used previously to estimate required prey density. The prey field was N3 Pseudocalanus spp. nauplii.

To model the effect of alternative pause duration strategies on prey capture rate and net energy gain rate, burst characteristics (distance, speed, duration) and reactive distances were held constant at the values observed in the behavioral experiments (table 3.5). Pause frequency was adjusted as appropriate:

$$
\text { pause frequency }=1 \div \text { (burst duration }+ \text { pause duration) }
$$

In calm and moderate turbulence conditions $\left(\varepsilon=0\right.$ and $\left.1 \cdot 10^{-8} \mathrm{~m}^{2} \cdot \mathrm{s}^{-3}\right)$ the highest capture rates were always realized with the shortest pause durations (for all age classes). This reflects greater foraging capacity as pause frequency (i.e., saltatory search frequency) increases. At lower prey densities, the capture rate is lower and the relative benefit of a shorter pause duration is less, i.e., the relation between capture rate and pause duration flattens out at lower prey densities (fig. 4.8). In high turbulence conditions ( $\varepsilon=$ $1 \cdot 10^{-5} \mathrm{~m}^{2} \cdot \mathrm{s}^{-3}$ ), longer pause durations should be favored. High turbulence interferes with 
the pursuit and capture of prey (MacKenzie \& Kiørboe 2000) and the overall prey capture rate is lower. However, turbulence increases predator-prey contact rates in proportion to pause duration (equation 3) so at high turbulence prey encounter rates increase as pause duration increases even though the larva is searching fewer new water parcels.

Short pause durations provide the greatest net energy gains when prey capture rates are high. This is the case as prey density increases, for larger larvae with greater foraging capacities and capture success probabilities, and under conditions when turbulence is not so high as to substantially interfere with the pursuit and capture of encountered prey . As the capture rate declines for any reason, the relative advantage of shorter pause durations is reduced (the relation between net energy gain and pause duration flattens) until extended pause durations are favored (fig. 4.9). However, under these conditions net energy gain even at long pause durations is much lower than realized under the conditions that favor short pause durations.

This simulation model incorporates several assumptions and simplifications. A saltatory predator is unlikely to instantaneously evaluate the contents of a new water parcel it has just entered after pausing from a burst. The probability of discovering prey within the search volume must increase with time from 0 at the start of a pause. The search-space evaluation process is evident in many genera that practice saltatory foraging from fish to birds; the pause duration increases under more difficult foraging conditions such as when searching for smaller prey or when searching in visually complex environments (O'Brien et al. 1990). For larval cod, the pause duration significantly decreased as they grew (fig. 3.9a) possibly reflecting the improved visual acuity that comes with growth (Hunt von Herbing \& Gallager 2000) and more rapid prey recognition. The evaluation period is an unknown function of pause duration and prey characteristics and is not included in this simulation model. Capture rates and net energy gain rates at shorter pause durations than observed in the laboratory are shown as dashed lines (figs. 4.8 and 4.9).

While the simulation model predicts that larvae would achieve greater net energy gains by remaining at rest for extended periods (several seconds) under conditions of low 
prey density, the observed increase in pause duration between the high-prey density and no prey treatments was much less. Twenty-five day old larvae only increased pause duration from $\approx 0.6 \mathrm{~s}$ when prey were abundant to $\approx 0.9 \mathrm{~s}$ when prey were absent (figs. 4.8 and 4.9). The larvae appear to use a prey encounter maximization strategy rather than an energy conservation strategy. Except under conditions of high turbulence $(\varepsilon=$ $1 \cdot 10^{-5} \mathrm{~m}^{2} \cdot \mathrm{s}^{-3}$ ), simulated prey capture rates are highest at short pause duration at all prey densities. The observed strategy makes sense for animals foraging in a dynamic and patchy environment where chances of encountering high-density prey patches improve as the volume searched increases.

The swimming effort needed to search a given volume of water is minimized if consecutive search-volumes neither overlap nor leave unsearched water in between. The distance traveled during each burst should be similar to the distance at which prey are perceived (O'Brien et al. 1990). The effect of alternative burst distances on the prey capture rate and net energy gain was simulated in figures 4.10 and 4.11. Burst speed, pause duration, and reactive distance were held constant. Burst duration and search frequency are both functions of burst distance and were adjusted as appropriate, equation 15 and:

$$
\text { (burst duration })=(\text { burst distance }) \div(\text { burst speed })
$$

The volume $\left(\mathrm{m}^{3}\right)$ of unsearched water added during each search-cycle when search volumes overlap is modeled as:

$$
V=(1 / 3) \cdot \pi \cdot B \cdot\left(3 \cdot R^{2}-B^{2}\right)
$$

where $B$ is the burst distance $(m)$ and $R$ is the reactive distance (m).

Neither turbulence nor prey density have any effect upon the optimum burst distance for greatest prey capture rate. However, as capture rate declines, whether from the negative effects of high turbulence or from low prey density, the greatest net energy gain rate is achieved at shorter burst distances (fig. 4.11). The simulated net energy gain was 
greatest when each burst carried the larva a distance slightly less than the observed reactive distance. At greater burst distances, the net energy gain declines off rapidly because of the added cost of swimming an additional distance with no improvement to prey encounter rate. At burst distances below the optimum, net energy gain declined because search volumes overlapped and less new water was searched each cycle.

The burst distances observed in the behavioral studies were longer than the modeled optimal burst distances. Perhaps there is a hydrodynamic explanation. To take advantage of the energy savings that is offered by beat-and-glide swimming, the acceleration during the beat must be great enough to bring the larvae into the inertial Reynolds number regime (Webb \& Weihs 1986). The glide distance following a tail beat reflects the magnitude of the thrust, and that distance may be close to the observed burst distance. 
Figure 4.8. Simulation model showing the effect of alternative pause duration upon prey capture rate for a 25 day old larva foraging in different prey density environments. Burst characteristics (distance, speed, and duration) and perceptive distances were held constant using the values observed for a 25 day old larvae in the high prey treatment (table 3.5). Pause frequency was adjusted as appropriate: pause frequency $=1 \div$ (burst duration + pause duration). In this example, $\varepsilon=0 \mathrm{~m}^{2} \cdot \mathrm{s}^{-3}$. The prey field was N3 Pseudocalanus spp. nauplii.

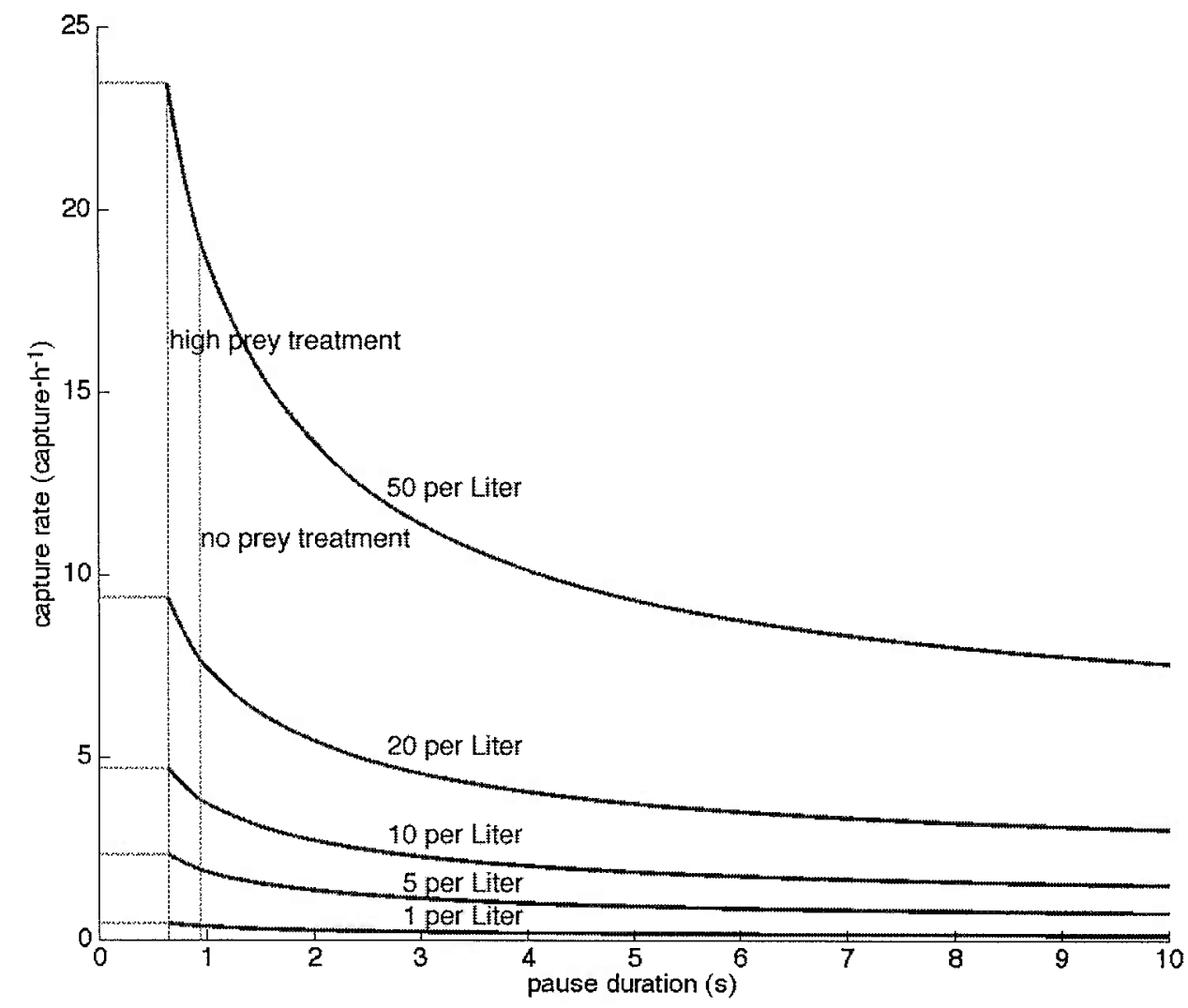


Figure 4.9. Simulation model showing the effect of alternative pause duration upon net energy gain for a 25 day old larva foraging in different prey density environments. Burst characteristics (distance, speed, and duration) and perceptive distances were held constant using the values observed for a 25 day old larvae in the high prey treatment (table 3.5). Pause frequency was adjusted as appropriate: pause frequency $=1 \div$ (burst duration + pause duration). In this example, $\varepsilon=0 \mathrm{~m}^{2} \cdot \mathrm{s}^{-3}$. The prey field was $\mathrm{N} 3$ Pseudocalanus spp. nauplii.

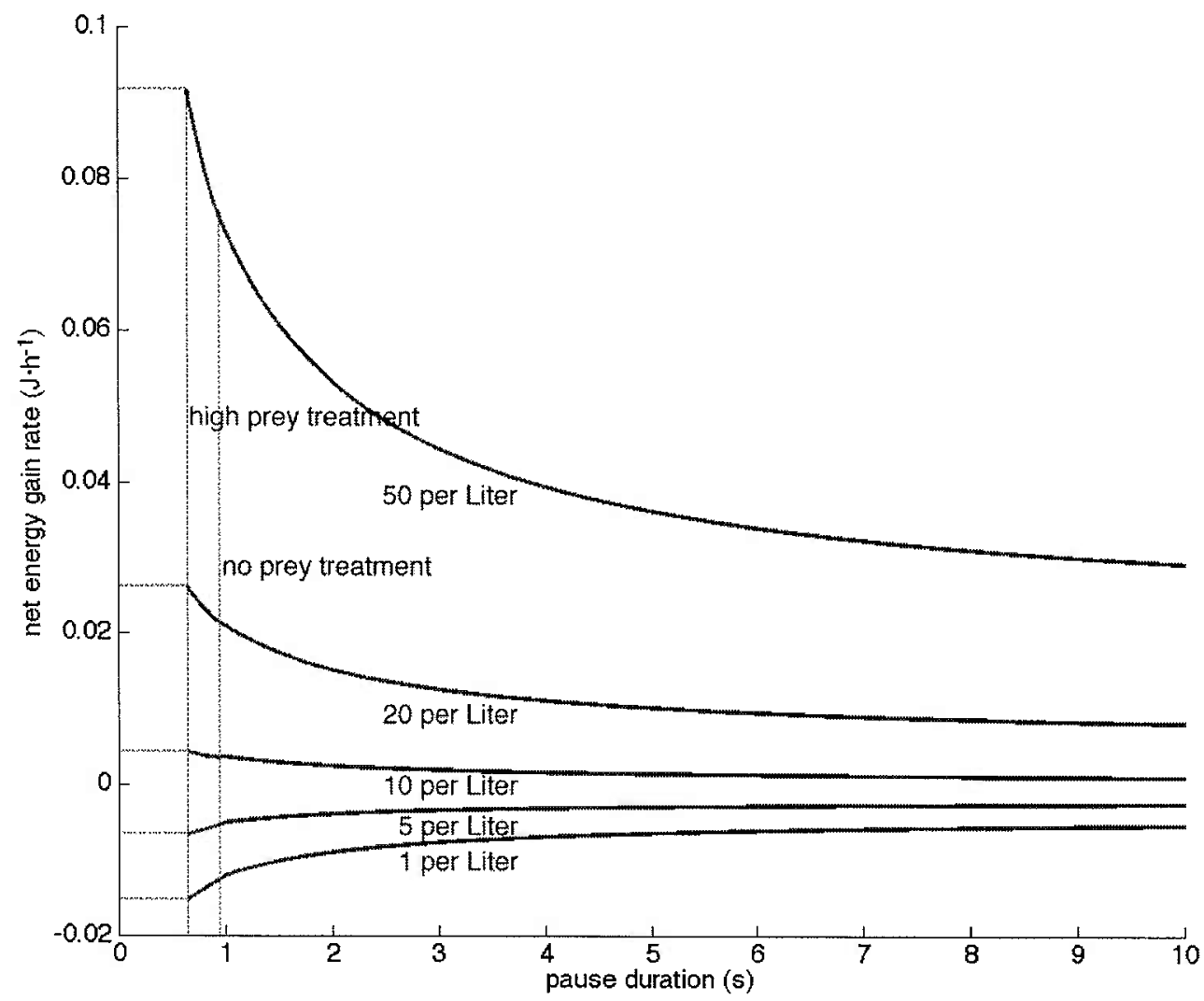


Figure 4.10. Simulation model showing the effect of alternative burst distance upon prey capture rate for a 25 day old larva foraging in different prey density environments. Burst speed, pause duration, and perceptive distance were held constant. Burst duration and search frequency are both functions of burst distance and were adjusted as appropriate: (burst duration) $=$ (burst distance) $\div$ (burst speed), pause frequency $=1 \div$ (burst duration + pause duration). In this example, $\varepsilon=0 \mathrm{~m}^{2} \cdot \mathrm{s}^{-3}$. The prey field was N3 Pseudocalanus spp. nauplii.

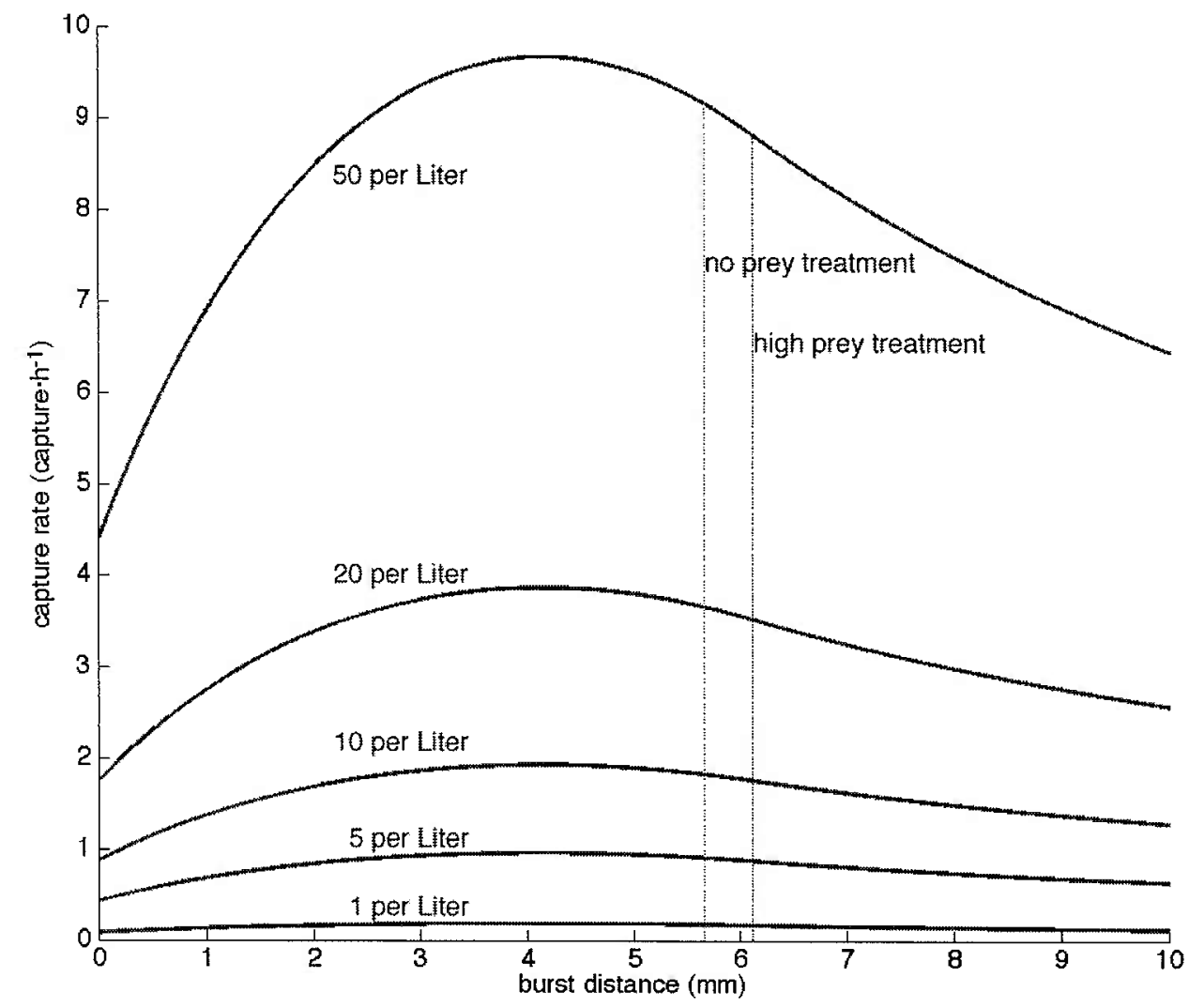


Figure 4.11. Simulation model showing the effect of alternative burst distance upon net energy gain for a 25 day old larva foraging in different prey density environments. Burst speed, pause duration, and perceptive distance were held constant. Burst duration and search frequency are both functions of burst distance and were adjusted as appropriate: (burst duration) $=($ burst distance $) \div($ burst speed $)$, pause frequency $=1 \div$ (burst duration + pause duration). In this example, $\varepsilon=0 \mathrm{~m}^{2} \cdot \mathrm{s}^{-3}$. The prey field was $\mathrm{N} 3$ Pseudocalanus spp. nauplii.

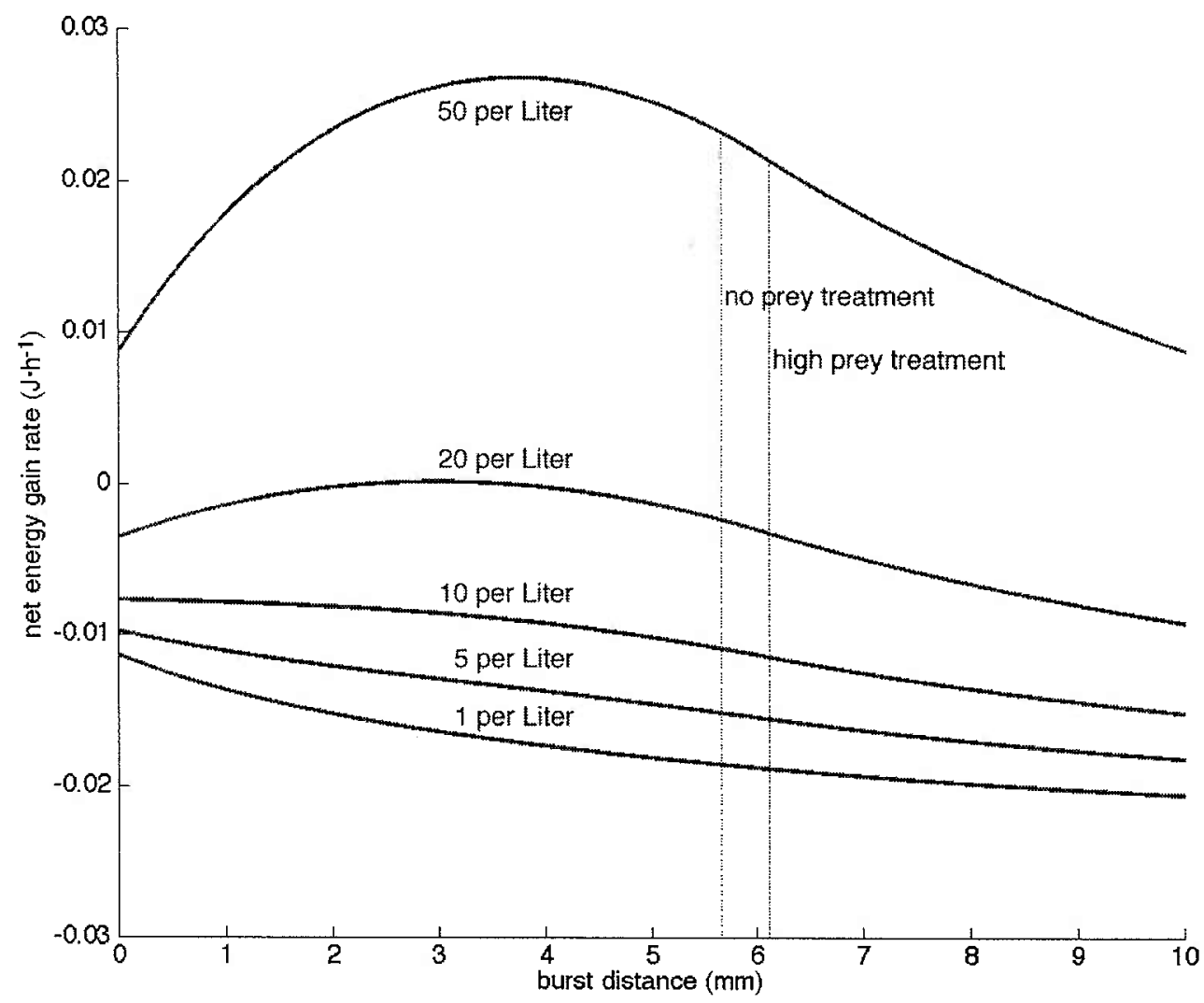




\section{Conclusions}

1. The cost of swimming is both a substantial and variable component of a larval cod's bioenergetic budget. Activity levels of larvae foraging freely within the large observation tank were five times greater than observed within small, sealed respirometry chambers. Existing trophodynamic models for larval cod underestimate the magnitude of activity metabolism when scaling basal metabolism by a factor of 2.5. Applying the empirically derived relation between swimming intensity and metabolism to the activity levels observed within the large observation tank suggests that a more correct scaling factor would vary between 3.8 when prey are scarce and 5 when prey are abundant.

2. The estimated nauplius and copepodite concentrations required for the survival of small larvae is within the concentrations found on Georges Bank. However, the smallest larvae may only capture sufficient prey to meet their metabolic demands under nonturbulent conditions. Their survival may depend upon encountering patches of higher prey density or exploiting alternative prey sources such as protozoans (Gallager et al. 1996b). Alternatively, larval foraging capacity may be underestimated. Reactive distance in the ocean may be greater than measured in the laboratory, or larvae in the ocean may be more adept at capturing prey once spotted than has been measured in laboratory studies.

3. Larvae live in a hydrodynamic regime where the viscous forces resisting motion are important. Burst characteristics (speed, duration, and distance) did not vary significantly between prey treatments and may be fixed in order to take advantage of the energy savings provided by the beat-and-glide swimming style. Longer pause durations observed at low prey densities convey energy savings to smaller larvae, diminishing as larvae grow. Simulation modeling suggests that even longer pause durations than observed would provide a slightly better net energy return. The fact that pause duration changes by a much lesser amount suggests that maximizing prey encounter rates is more important than maximizing energy conservation. This strategy should increase the chances of encountering patches of higher prey density. 


\section{References}

Bailey KM, Houde ED (1989) Predation on eggs and larvae of marine fishes and the recruitment problem. Advances in Marine Biology 25:1-83

Beamish FWH (1974) Apparent specific dynamic action of largemouth bass, Micropterus salmoides. Journal of the Fisheries Research Board of Canada 31:1763-1769

Beamish FWH, Mookherjii PS (1964) Respiration of fishes with special emphasis on standard oxygen consumption. Canadian Journal of Zoolology 42:161-175

Boehlert GW, Yoklavich MM (1984) Carbon assimilation as a function of ingestion rate in Pacific herring, Clupea harengus pallasi Valenciennes. Journal of Experimental Marine Biology and Ecology 79:251-262

Boisclair D, Leggett WC (1989) The importance of activity in bioenergetics models applied to actively foraging fishes. Canadian Journal of Fisheries and Aquatic Science 46:1859-1867

Boisclair D, Sirois P (1993) Testing assumptions of fish bioenergetics models by direct estimation of growth, consumption, and activity rates. Transactions of the American Fisheries Society 122:784-796

Brett JR (1972) The metabolic demand for oxygen in fish, particularly salmonids, and a comparison with other vertebrates. Respiration Physiology 14:151-170

Browman HI, O'Brien WJ (1992) Foraging and prey search behaviour of Golden Shiner (Notemigonus crysoleucas) larvae. Canadian Journal of Fisheries and Aquatic Science 49:813-819

Buckley LJ, Dillman DW (1982) Nitrogen utilization by larval summer flounder, Paralichthys dentatus (Linnaeus). Journal of Experimental Marine Biology and Ecology 59:243-256

Buckley LJ, Lough RG (1987) Recent growth, biochemical composition, and prey field of larval Haddock (Melanogrammus aeglefinus) and Atlantic cod (Gadus morhua) on Georges Bank. Canadian Journal of Fisheries and Aquatic Science 44:14-25

Buckley LJ, Lough RG, Peck MA, Werner FE (2000) Comment: Larval Atlantic cod and haddock growth models, metabolism, ingestion, and temperature effects. Canadian Journal of Fisheries and Aquatic Science 57:1957-1960

Burgett RL, Hebert D, Oakey NS (2001) Vertical structure of turbulence on the southern flank of Georges Bank. Journal of Geophysical Research 106:22545-22558

Dabrowski KR (1986a) Active metabolism in larval and juvenile fish: ontogenetic changes, effect of water temperature and fasting. Fish Physiology and Biochemistry 1:125-144 
Dabrowski KR (1986b) Energy utilization during swimming and cost of locomotion in larval and juvenile fish. Journal of Applied Ichthyology 3:110-117

Davenport J, Lønning S (1980) Oxygen uptake in developing eggs and larvae of the cod Gadus morhua L. J. Fish. Biol. 16:249-256

Davis CS (1984) Interaction of a copepod population with the mean circulation on Georges Bank. Journal of Marine Research 42:573-590

Davis CS, Flierl GR, Wiebe PH, Franks PJS (1991) Micropatchiness, turbulence and recruitment in plankton. Journal of Marine Research 49:109-151

Drost MR, van den Boogaart JGM (1986) The energetics of feeding strikes in larval carp, Cyprinus carpio. Journal of Fish Biology 29:371-379

Evans BI, O'Brien WJ (1988) A reevaluation of the search cycle of planktivorous Arctic Grayling, Thamallus arcticus. Canadian Journal of Fisheries and Aquatic Science 45:187-192

Fiksen $\varnothing$, Utne ACW, Aksnes DL, Eiane K, Helvik JV, Sundby S (1998) Modelling the influence of light, turbulence and ontogeny on ingestion rates in larval cod and herring. Fisheries Oceanography 7:355-363

Folkvord A, Hunter JR (1986) Size-specific vulnerability of Northern Anchovy, Engraulis mordax, larvae to predation by fishes. Fishery Bulletin 84:859-869

Forstner H, Wieser W (1990) Patterns of routine swimming and metabolic rate in juvenile cyprinids at three temperatures: analysis with a respirometer-activity-monitoring system. Journal of Comparative Physiology B 160:71-76

Fry FEJ (1971) The effect of environmental factors on the physiology of fish. In: Fish Physiology, Vol VI. Academic Press, New York, p 1-98

Fuiman LA, Batty RS (1997) What a drag it is getting cold: partitioning the physical and physiological effects of temperature on fish swimming. The Journal of Experimental Biology 200:1745-1755

Gallager SM, Davis CS, Epstein AW, Solow A, Beardsley RC (1996a) High-resolution observations of plankton spatial distributions correlated with hydrography in the Great South Channel, Georges Bank. Deep-Sea Research II 43:1627-1663

Gallager SM, Hunt von Herbing I, Davis L, Alatalo P (1996b) First-feeding cod larvae ingest microzooplankton exclusively from natural plankton assemblages on Georges Bank AGU/ASLO

Gallego A (1994) Changes in the swimming behaviour of larval herring in response to two different prey densities. Journal of the Marine Biological Association of the United Kingdom 74:955-958

Gnaiger E (1983) Appendix C: Calculation of energetic and biochemical equivalents of respiratory oxygen consumption. In: Gnaiger E, Forstner H (eds) Polarographic oxygen sensors. Springer-Verlag, New York, p 337-345 
Govoni JJ, Boehlert GW, Watanabe Y (1986) The physiology of digestion in fish larvae. Environmental Biology of Fishes 16:59-77

Horne EPW, Loder JW, Naimie CE, Oakey NS (1996) Turbulence dissipation rates and nitrate supply in the upper water column on Georges Bank. Deep-Sea Research II $43: 1683-1712$

Houde ED (1989) Comparative growth, mortality, and energetics of marine fish larvae. Fisheries Bulletin 87:471-495

Houlihan DF, Pedersen BH, Steffensen JF, Brechin J (1995) Protein synthesis, growth and energetics in larval herring (Clupea harengus) at different feeding regimes. Fish Physiology and Biochemistry 14:195-208

Hunt von Herbing I (2002) Effects of temperature on larval fish swimming performance: the importance of physics to physiology. Journal of Fish Biology 61:865-876

Hunt von Herbing I, Boutilier RG (1996) Activity and metabolism of larval Atlantic cod (Gadus morhua) from Scotian Shelf and Newfoundland source populations. Marine Biology 124:607-617

Hunt von Herbing I, Gallager SM (2000) Foraging behavior in early Atlantic cod larvae (Gadus morhua) feeding on a protozoan (Balanion sp.) and a copepod nauplius (Pseudodiaptomus sp.). Marine Biology 136:591-602

Hunter JR (1972) Swimming and feeding behavior of larval anchovy Engraulis mordax. Fishery Bulletin 70:821-838

Huuskonen H, Karjalainen J, Medgyesy N, Wieser W (1998) Energy allocation in larval and juvenile Coregonus lavaretus: validation of a bioenergetics model. J. Fish. Biol. 52:962-972

Jobling M (1981) The influences of feeding on the metabolic rate of fishes: a short review. J. Fish. Biol. 18:385-400

Jobling M (1983) Towards an explanation of specific dynamic action (SDA). J. Fish. Biol. 23:549-555

Jobling M (1985) Growth. In: Tytler P, Calow P (eds) Fish energetics - new perspectives. Croom Helm, Beckenham, p 213-230

Kamler E (1992) Early life history of fish, Vol. Chapman and Hall, New York

Kane J (1984) The feeding habits of co-occurring cod and haddock larvae. Marine Ecology Progress Series 16:9-20

Kaufmann R (1990) Respiratory cost of swimming in larval and juvenile cyprinids. Journal of Experimental Biology 150:343-366

Kaufmann R, Wieser W (1992) Influence of temperature and ambient oxygen on the swimming energetics of cyprinid larvae and juveniles. Environmental Biology of Fishes 33:87-95 
Keckeis H, Kamler E, Bauer-Nemeschkal E, Schneeweiss K (2001) Survival, development and food energy partitioning of nase larvae and early juveniles at different temperatures. Journal of Fish Biology 59:45-61

Kiørboe T, Munk P, Richardson K (1987) Respiration and growth of larval herring Clupea harengus: relation between specific dynamic action and growth efficiency. Marine Ecology Progress Series 40:1-10

Kleinbaum DG, Kupper LL, Muller KE, Nizam A (1998) Applied regression analysis and other multivariable methods, Vol. Duxbury Press, Pacific Grove

Krohn MM, Boisclair D (1994) Use of a stereo-video system to estimate the energy expenditure of free-swimming fish. Canadian Journal of Fisheries and Aquatic Science 51:1119-1127

Laurence GC (1976) Caloric values of some North Atlantic calanoid copepods. Fisheries Bulletin 74:218-220

Laurence GC (1977) A bioenergetic model for the analysis of feeding and survival potential of Winter Flounder, Pseudopleuronectes americanus, larvae during the period from hatching to metamorphosis. Fishery Bulletin 75:529-546

Laurence GC (1985) A report on the development of stochastic models of food limited growth and survival of cod and haddock larvae on Georges Bank. In: Laurence GC, Lough RG (eds) Growth and survival of larval fishes in relation to the trophodynamics of Georges Bank cod and haddock, Vol NMFS-F/NEC-36. NOAA Technical Memo, p 83-150

Leggett WC, DeBlois E (1994) Recruitment in marine fishes: is it regulated by starvation and predation in the egg and larval stages? Netherlands Journal of Sea Research 32:119-134

Leising AW, Franks PJS (1999) Larval Atlantic cod (Gadus morhua) and haddock (Melanogrammus aeglefinus) growth on Georges Bank: a model with temperature, prey size, and turbulence forcing. Canadian Journal of Fisheries and Aquatic Science 56:25-36

Leising AW, Franks PJS (2000) Reply to Buckley et al.'s "Comment: Larval Atlantic cod and haddock growth models, metabolism, ingestion, and temperature effects". Canadian Journal of Fisheries and Aquatic Science 57:1961-1963

Letcher BH, Rice JA, Crowder LB, Rose KA (1996) Variability in survival of larval fish: disentangling components with a generalized individual-based model. Canadian Journal of Fisheries and Aquatic Science 53:787-801

Lough RG, Buckley LJ, Werner FE, Quinlin JA, Edwards KP (in press) A general biophysical model of larval cod growth applied to populations on Georges Bank. Fisheries Oceanography 
Lynch DR, Lewis CVW, Werner FE (2001) Can Georges Bank larval cod survive on a calanoid diet? Deep-Sea Research II 48:609-630

MacKenzie BR, Kiørboe T (1995) Encounter rates and swimming behavior of pausetravel and cruise larval fish predators in calm and turbulent laboratory environments. Limnology and Oceanography 40:1278-1289

MacKenzie BR, Kiørboe T (2000) Larval fish feeding in turbulence: a case for the downside. Limnology and Oceanography 45:1-10

MacKenzie BR, Miller TJ, Cyr S, Leggett WC (1994) Evidence for a dome-shaped relationship between turbulence and larval fish ingestion rates. Limnology and Oceanography 39:1790-1799

Madon SP, Culver DA (1993) Bioenergetics model for larval and juvenile Walleyes: an in situ approach with experimental ponds. Transactions of the American Fisheries Society 122:797-813

Miller TJ, Crowder LB, Rice JA, Marschall EA (1988) Larval size and recruitment mechanisms in fishes: toward a conceptual framework. Canadian Journal of Fisheries and Aquatic Science 45:1657-1670

Müller UK, Stamhuis EJ, Videler JJ (2000) Hydrodynamics of unsteady fish swimming and the effects of body size: comparing the flow fields of fish larvae and adults. Journal of Experimental Biology 203:193-206

Munk P (1995) Foraging behaviour of larval cod (Gadus morhua) influenced by prey density and hunger. Marine Biology 122:205-212

O'Brien WJ, Browman HI, Evans BI (1990) Search strategies of foraging animals. American Scientist 78:152-160

Paffenhöfer G-A, Strickler JR, Lewis KD, Richman S (1996) Motion behavior of nauplii and early copepodid stages of marine planktonic copepods. Journal of Plankton Research 118:1699-1715

Pannevis MC, Houlihan DF (1992) The energetic cost of protein synthesis in isolated hepatocytes of rainbow trout (Oncorhynchus mykiss). Journal of Comparative Physiology B 162:363-400

Pedersen BH (1997) The cost of growth in young fish larvae, a review of new hypotheses. Aquaculture 155:259-269

Pepin P (1991) Effect of temperature and size on development, mortality, and survival rates of the pelagic early life history stages of marine fish. Can. J. Aquat. Sci. 48:503-518

Peterson I, Wroblewski JS (1984) Mortality rate of fishes in the pelagic ecosystem. Canadian Journal of Fisheries and Aquatic Science 41:1117-1120 
Post JR (1990) Metabolic allometry of larval and juvenile yellow perch (Perca flavescens): in situ estimates and bioenergetic models. Canadian Journal of Fisheries and Aquatic Science 47:554-560

Rombough PJ (1988) Respiratory gas exchange, aerobic metabolism and effects of hypoxia during early life. In: Hoar WS, Randall DJ (eds) Fish Physiology, Vol 11 The physiology of developing fish. part A Eggs and larvae. Academic Press, New York, p 59-161

Rombough PJ (1994) Energy partitioning during fish development: additive or compensatory allocation of energy to support growth? Functional Ecology 8:178186

Rosenthal H, Hempel G (1970) Experimental studies in feeding and food requirements of herring larvae (Clupea harengus L.). In: Steele JH (ed) Marine food webs. University of California Press, Berkeley, p 344-364

Rothschild BJ, Osborn TR (1988) Small-scale turbulence and plankton contact rates. Journal of Plankton Research 10:465-474

Serchuk FM, Grosslein MD, Lough RG, Mountain DG, O'Brien L (1994) Fishery and environmental factors affecting trends and fluctuations in the Georges Bank and Gulf of Maine Atlantic cod stocks: an overview. ICES Marine Science Symposium 198:77-109

Smith RW, Houlihan DF (1995) Protein synthesis and oxygen consumption in fish cells. Journal of Comparative Physiology B 165:93-101

Solberg T, Tilseth S (eds) (1984) Growth, energy consumption and prey density requirements in first feeding larvae of cod (Gadus morhua L.), Vol 1. Flødevigen rapportser.

Tang Y, Nelson JA, Reidy SP, Kerr SR, Boutilier RG (1994) A reappraisal of activity metabolism in Atlantic cod (Gadus morhua). Journal of Fish Biology 44:1-10

The MathWorks I (1998) Matlab, Natick, Ma

Tilseth S, Ellertsen B (1984) Food consumption rate and gut evacuation processes of first feeding cod larvae (Gadus morhua L.). In. E. D, Danielssen DS, Moksness E, Solemdal P (eds) The Propagation of Cod Gadus morhua L., Vol 1. Flødevigen rapportser, p 167-182

Titelman J, Kiørboe T (2003) Motility of copepod nauplii and implications for food encounter Marine Ecology Progress Series 247:123-135

Torres JJ, Brightman RI, Donnelly J, Harvey J (1996) Energetics of larval red drum, Sciaenops acellatus. Part 1: oxygen consumption, specific dynamic action, and nitrogen excretion. Fishery Bulletin 94:756-765

Videler JJ, Weihs D (1982) Energetic advantages of burst-and-coast swimming of fish at high speeds. Journal of Experimental Biology 97:169-178 
Vlymen WJ, III (1974) Swimming energetics of the larval anchovy, Engraulis mordax. Fishery Bulletin 72:885-899

Vogel S (1994) Life in Moving Fluids, Vol. Princeton University Press, Princeton, N.J.

Wang W, Reimers CE, Wainright SC, Shahriari M, Morris MJ (1999) Applying FiberOptic Sensors for Monitoring Dissolved Oxygen. Sea Technology 3:69-77

Ware DM (1975) Growth, metabolism, and optimal swimming speed of a pelagic fish. Journal of the Fisheries Research Board of Canada 32:33-41

Webb PW, Weihs D (1986) Functional locomotor morphology of early life history stages of fishes. Transactions of the American Fisheries Society 115:115-127

Weihs D (1980) Energetic significance of changes in swimming modes during growth of larval anchovy, Engraulis mordax. Fishery Bulletin 77:597-604

Werner FE, MacKenzie BR, Perry RI, Lough RG, Naimie CE, Blanton BO, Quinlan JA (2001) Larval trophodynamics, turbulence, and drift on Georges Bank: a sensitivity analysis of cod and haddock. Scientia Marina 65:99-115

Werner FE, Perry RI, Lough RG, Naimie CE (1996) Trophodynamic and advective influences on Georges Bank larval cod and haddock. Deep-Sea Research II 43:1793-1822

Wieser W, Forstner H, Medgyesy N, Hinterleitner S (1988) To switch or not to switch: partitioning energy between growth and activity in larval cyprinids (Cyprinidae: Teleostei). Functional Ecology 2:499-507

Wieser W, Medgyesy N (1990a) Aerobic maximum for growth in the larvae and juveniles of a cyprinid fish, Rutilus rutilus (L.): implications for energy budgeting in small poikilotherms. Functional Ecology 4:233-242

Wieser W, Medgyesy N (1990b) Cost and efficiency of growth in the larvae of two species of fish with widely differing metabolic rates. Proceedings of the Royal Society of London, Series B: Biological Sciences 242:51-56

Yamashita Y, Bailey KM (1989) A laboratory study of the bioenergetics of larval Walleye Pollock, Theragra chalcogramma. Fishery Bulletin 87:525-536 


\section{Chapter 5: Integrating Bioenergetics and Foraging Behavior:}

\section{The Physiological Ecology of Larval Cod (Gadus morhua)}

\section{Conclusion}

Small cod larvae, Gadus morhua, seem to be frail and ill-suited planktonic predators. They are small at the time of hatching and quickly exhaust their yolk-sac reserves. Though they must rely on their own foraging abilities, they are weak swimmers; and they must also pay a high energetic cost for foraging activity (Dabrowski 1986b, Kaufmann 1990). They live in a hydrodynamic environment where frictional forces acting against motion are much more important than for juvenile or adult fish (Müller et al. 2000). There is also evidence that for larval fish in general, the overall aerobic scope to meet all energy demands is very narrow and that the energy demanding processes of growth and activity may be in conflict (Wieser et al. 1988). Most cod larvae cannot meet these challenges and die but a very few survive and eventually grow to $60-80 \mathrm{~mm}$ before gradually settling out of the pelagic environment within three months (Bolz \& Lough 1988).

How do larval cod, Gadus morhua, balance foraging effort against the high cost of swimming in a viscous hydrodynamic regime? This research measured the energetic cost of swimming activity and quantified the foraging behavior of larval cod under two prey density conditions. Here, the major conclusions of each chapter of this dissertation are summarized, brief comments on the major assumptions are made, and the significance of the current findings to larvae in the ocean is discussed.

\section{Conclusions from chapter 2: "The Cost of Swimming for Larval Cod."}

The sealed respirometry system used in this study allowed the measurement of the metabolism of individual larvae and their concurrent swimming activity. The two main questions of the respirometry study were: 1) What is the cost of swimming for larval cod, 
and how does it change as larvae grow? and 2) Is the cost of swimming a substantial part of the overall bioenergetic budget? The energetic cost of swimming activity for larval cod 5 to 45 days after hatching was measured and modeled as a linear powerperformance relationship (total metabolic rate as a function of swimming speed) that did not remain constant as larvae grew. These results are consistent with hydrodynamic theory; larval cod swim more efficiently as they grow larger. Larvae are better able to overcome forces of drag as they grow and swim out of the viscous Reynolds regime. This research also shows that the cost of transport is much higher for larval cod than for juvenile and adult fish and that activity can use a significant but variable proportion of the routine aerobic scope. However, the activity within small respirometry chambers cannot be taken as realistic measures of normal behavior in the ocean; therefore, this respirometry study was paired with observations of freely foraging larvae within a large tank to estimate the importance of activity in the overall bioenergetic budget.

\section{Conclusions from chapter 3: "The Foraging Behavior of Larval Cod."}

Larval cod use a saltatory foraging strategy (unpub. data cited in Browman \& O'Brien 1992, MacKenzie \& Kiørboe 1995, Munk 1995). They travel in short, discrete bursts that serve to position larvae within a new water-parcel, and they search for prey only when they are not actively swimming (Hunt von Herbing \& Gallager 2000). One of the main hypothetical advantages of saltatory foraging is its flexiblility; both the burst and the pause phases can be modified to suit foraging conditions (O'Brien et al. 1989, O'Brien et al. 1990). The goals of the present research were: first, to observe the behavior of larval cod in large volumes to reduce confinement effects; second, to observe behavior throughout early development (from 5 to 50 days post-hatch); third, to measure the foraging capacity of larval cod (volume searched per unit time); and fourth, to observe if and how larval cod adjust their foraging effort in response to different foraging conditions, in this case prey density.

All observations were consistent with larval cod being saltatory foragers in that they maintained their burst-glide swimming style throughout the developmental period 
observed. Swimming burst characteristics (speed, duration, and distance traveled) remained the same regardless of prey treatment (no prey, rotifer prey at $100 \mathrm{~L}^{-1}$, and nauplii prey at $100 \mathrm{~L}^{-1}$ ). This is consistent with saltatory foraging theory; if the role of the burst is to put the predator into an unsearched volume, then altering burst characteristics in different prey density conditions provides no advantage (O'Brien et al. 1990). On the other hand, there would be an advantage to increasing burst distance if prey characteristics change, i.e., prey if are larger or otherwise relatively more visible (ibid.). As larvae grew older and larger their foraging capacity increased. For larvae of each specific age group, the duration of each search event (pause duration) was longer when no prey were present, perhaps reflecting a greater time investment to process each searchvolume more thoroughly. In a broad range of genera that practice saltatory foraging, pause duration increases under more difficult foraging conditions such as when searching for smaller prey or when searching in more visually complex environments (e.g., starlings foraging in tall grass pause significantly longer than when foraging in short grass, Brownsmith 1977). The pause frequency, and therefore foraging capacity, was lower when prey were absent, perhaps reflecting an energy conservation strategy by hungry larvae that reduce their swimming activity until foraging conditions improve.

\section{Conclusions from chapter 4: "The Importance of the Cost of Swimming to the Foraging Behavior and Ecology of Larval Cod."}

Both sets of studies, respirometry and behavioral observations, provide information necessary to address the following questions concerning the role of activity costs in limiting foraging behavior and in the overall ecology of larval cod: 1) Is swimming cost an important component of the total bioenergetic budget? 2) What is the required prey density to support larval growth and survival? 3) If larvae do modify foraging behavior under different prey density conditions; when foraging conditions are poor, how do they compromise between increasing foraging activity to maximize prey encounter rates and reducing activity to conserve energy? 
The cost of swimming is both a substantial and variable component of a larval cod's bioenergetic budget. Activity levels of larvae foraging freely within the large observation tank were five times greater than observed within small, sealed respirometry chambers. Existing trophodynamic models for larval cod underestimate the magnitude of activity metabolism when scaling basal metabolism by a factor of 2.5. Applying the empirically derived power-performance relationship to the activity levels observed within the large observation tank suggests that a more correct scaling factor would vary between 3.8 when prey are scarce and 5 when prey are abundant.

Estimates of the daily energy demand and foraging capacity were used to predict prey concentrations required for survival of post-yolk-sac larvae. The estimated nauplius and copepodite concentrations required for the survival of small larvae are within the range of mean homogeneous springtime concentrations found on Georges Bank. However, for the smallest post-yolk-sac larvae, favorable low-turbulence foraging conditions, encountering patches of higher prey density, or exploiting alternative prey sources such as protozoans (Gallager et al. 1996b) may be necessary.

Alternative pause duration strategies were run through the trophodynamic model developed in chapter 4 to predict which strategy would provide the greatest prey encounter rate and which strategy would provide the greatest net energy gain under different prey density conditions. Because search frequency increases as pause duration decreases, short pauses always allow the highest prey encounter rates. However, simulation modeling suggests that when prey are scarce, long pause durations on the order of several seconds should provide the best net energy return. The fact that the observed pause duration of larvae foraging in the absence of prey was much shorter suggests that maximizing foraging capacity is more important than maximizing energy conservation. This strategy could increase the chances of encountering patches of higher prey density because a greater distance is traveled. 


\section{Comments on assumptions}

This research makes several important assumptions that point out areas necessary for future research.

While the power-performance relationship between swimming speed and total metabolism was modeled linearly, the scatter in the data could mask a true non-linear relationship. However, hydrodynamic theory suggests that the relationship should be linear, at least over the range of swimming speeds involved in the present respirometry studies. In the low Reynolds number regime $(\operatorname{Re}<20)$ viscous forces dominate inertial forces and drag is proportional to speed while in the inertial Reynolds number regime ( $\operatorname{Re}>200)$ drag is proportional to speed-squared (Weihs 1980). Assuming no change in muscle efficiency at different swimming speeds, the power-performance relation should remain approximately linear as long as larvae remain within the low Reynolds number regime. Larvae swimming within the respirometry chambers remained within the low Reynolds number regime even during burst events $(\operatorname{Re} \leq 20)$.

Activity levels of larvae within small respirometry chambers are much lower than those of freely foraging larvae. To estimate the importance of activity costs for freely foraging larvae, the power-performance relation was applied to the activity levels (median individual swimming speed) observed within the large observation tank. This requires extrapolation beyond the respirometry data from which the power-performance model was calculated because swimming-burst speeds in the observation tank were higher than burst speeds in the respirometry chambers ( 1 to $12 \mathrm{~mm} \cdot \mathrm{s}^{-1}$ vs. 1 to $3 \mathrm{~mm} \cdot \mathrm{s}^{-1}$, respectively). This extrapolation remains valid only as long as the larvae remain within the hydrodynamic regime in which viscous forces dominate inertial forces and drag is linearly proportional to speed. For larvae in the observation tank, Re remained less than 65 during swimming burst events (fig. 4.4). This places these cod larvae within the lower transitional zone $(20<\operatorname{Re}<200)$ where viscous forces of drag are supplanted by inertial forces (Weihs 1980). For now, this extrapolation remains an untested assumption but should be valid because even the fastest larvae do not experience a hydrodynamic regime change. Additionally, there is evidence from larval herring that the viscous regime may 
extend as high as $\operatorname{Re}=450$ (Fuiman \& Batty 1997). Future work to measure the cost of swimming in small marine fish larvae will require the development of new respirometry systems to force larvae to swim up to speeds typical of larvae in the wild.

Sensitivity analyses of trophodynamic models developed for fish larvae show that the most important parameters for predicting growth and survival are assimilation efficiency and perceptive distance (or reactive distance) (Letcher et al. 1996, Lough et al. in press).

Assimilation efficiency of larval fish in general has been measured between roughly 70 to $100 \%$ of the energy content of ingested prey (Govoni et al. 1986). How it varies with prey type and larval development stage still remains unclear. In the present research, assimilation efficiency was assumed to be a constant $70 \%$ based upon studies of larval herring (Boehlert \& Yoklavich 1984).

The accuracy of the estimates of larval foraging capacity is limited by our lack of sophisticated knowledge of reactive distance and capture proficiency once prey are perceived. The foraging capacity of larval cod is linearly related to pause frequency but is exponentially related to the reactive distance. Therefore, small changes in reactive distance will have a much larger impact upon the volume of water searched for prey than a change in pause frequency. Reactive distance can reasonably be expected to depend upon prey characteristics (i.e., size and contrast against the background) and light intensity (Fiksen et al. 1998). There are few direct measurements of the perceptive ability of larval cod (Solberg \& Tilseth 1984, MacKenzie \& Kiørboe 1995, Munk 1995, Hunt von Herbing \& Gallager 2000) and no direct measurements of how reactive distance changes with light level. In the present study, the reactive distance was assumed to be the same as the distance traveled between consecutive search-volumes if volumes neither overlap nor leave unsearched water in between.

Capture proficiency may also be an important factor limiting foraging capacity but there are few measurements available for larval cod (Solberg \& Tilseth 1984, Munk 1995, Hunt von Herbing \& Gallager 2000, MacKenzie \& Kiørboe 2000). Capture proficiency is a function of larval size, prey type, and turbulence level. MacKenzie and Kiørboe (2000) observed that capture proficiency declined with increasing turbulence but 
studied larvae larger than the present research $(>8.5 \mathrm{~mm})$. In this research, the assumed capture proficiency for different larval sizes and turbulence levels was set conservatively low relative to the trophodynamic model of Werner et al. (2001) and was assumed to not change with prey type.

\section{Significance of the findings of this laboratory study to larvae in the ocean}

This research predicts that small post-yolk-sac cod larvae will only be able to survive on the average prey densities found on Georges Bank in conditions of mild turbulence. Exploiting prey patches may be necessary for their survival. On Georges Bank, cod spawn through the winter and early spring with peak spawning in late February through early March (Lough \& Bolz 1989). Many post-yolk-sac larvae will begin feeding in winter conditions; the water-column is mixed so there is little variation in the vertical prey density profile (Incze et al. 1996) and intermediate levels of turbulence as generated by storms may also break up prey patches (Davis et al. 1991). Also, moderate levels of turbulence can directly interfere with larval foraging success (MacKenzie \& Kiørboe 2000).

In May, warming at the surface establishes the seasonal pycnocline at $\approx 20 \mathrm{~m}$ in the deeper water surrounding Georges Bank ( $>60 \mathrm{~m}$ isobath); while over the shallower central cap, tidal shear keeps the water-column mixed from the bottom to the surface. Formation of the pycnocline is associated with a higher overall prey abundance and concentration of prey within and above the pycnocline (Lough \& Potter 1993, Incze et al. 1996, Lough et al. 1996). Fine-scale prey patches can occur in regions of vertical stability (Gallager et al. 1996a). The pycnocline also provides a refuge from higher turbulence where larvae could escape the detrimental effect of turbulence on prey capture success. The turbulent energy dissipation rate is 1 to 2 orders of magnitude lower within the pycnocline $(\varepsilon=$ $10^{-9}-10^{-8} \mathrm{~m}^{2} \cdot \mathrm{s}^{-3}$ ) than it is at the surface or near the bottom where wind and tidally generated turbulence originates $\left(\varepsilon=10^{-6} \mathrm{~m}^{2} \cdot \mathrm{s}^{-3}\right)$ (Burgett et al. 2001). Larval cod are concentrated within the pycnocline (Lough \& Mountain 1996) and achieve higher growth rates than larvae in mixed waters (Buckley \& Lough 1987). Yet larval cod survive and 
grow in winter conditions (i.e., well mixed waters and low prey densities) and are better adapted to such conditions than haddock larvae which appear on Georges Bank later in the season (Buckley \& Lough 1987). In the trophodynamic model presented in chapter 4 , prey capture proficiency was set conservatively low relative to the model of Werner et al. (2001). There are few direct measurements of capture proficiency available for small cod larvae in either calm or turbulent conditions, but the estimates used here (table 4.1) could represent the lower range in turbulent conditions.

The present research shows that larvae adjust their foraging behavior under different prey density conditions. Whether as an energy conservation strategy or as a search strategy, larvae foraging in the absence of prey were observed to increase their pause durations over that observed of larvae foraging in high prey density conditions. This has the immediate effect of lowering foraging capacity $\left(\mathrm{ml}\right.$ searched $\left.\cdot \mathrm{min}^{-1}\right)$. What other effect may this behavior have in real ocean conditions? Davis et al. (1991) show how random swimming leads to the rapid, passive accumulation of predators into volumes of high prey density. Prey handling time prolongs the time predators spend at higher prey densities without invoking predator memory or knowledge of local prey patch conditions. Extended pause duration, as observed, would not necessarily retain a larva within a preydeplete area but would prolong its exposure to poor foraging conditions. This could be an unfortunate side-effect of an inability to maintain high activity levels in prolonged poor foraging conditions. If extended pause duration is a 'voluntary' foraging strategy rather than a metabolic limitation, it would seem to be ill-suited in light of the Davis et al. (1991) predator diffusion model. There may be other behavioral strategies that mitigate this effect. Their model assumes random swimming but they state that any form of directed swimming would lead to more rapid accumulation of predators into prey patches than by diffusion (random) swimming. Horizontally directed swimming is unlikely among larvae that are unable to detect prey conditions much more than a single bodylength away, but vertical swimming short distances may quickly put larvae into different foraging conditions within a stratified water-column. Cod larvae do not begin daily vertical migration until they are at least $9 \mathrm{~mm}$ long (Lough \& Potter 1993). But within a 
stratified water-column, larvae may not have to swim far to encounter improved foraging conditions (Lough \& Mountain 1996). 


\section{References}

Anderson JP, Stephens DW, Dunbar SR (1997) Saltatory search: a theoretical analysis. Behavioral Ecology 8:307-317

Bailey KM, Houde ED (1989) Predation on eggs and larvae of marine fishes and the recruitment problem. Advances in Marine Biology 25:1-83

Batty RS (1984) Development of swimming movements and musculature of larval herring (Clupea harengus). Journal of Experimental Biology 110:217-229

Batty RS (1987) Effect of light intensity on activity and food searching of larval herring Clupea harengus: a laboratory study. Marine Biology 93:323-327

Beamish FWH (1974) Apparent specific dynamic action of largemouth bass, Micropterus salmoides. Journal of the Fisheries Research Board of Canada 31:1763-1769

Beamish FWH, Mookherjii PS (1964) Respiration of fishes with special emphasis on standard oxygen consumption. Canadian Journal of Zoolology 42:161-175

Boehlert GW, Yoklavich MM (1984) Carbon assimilation as a function of ingestion rate in Pacific herring, Clupea harengus pallasi Valenciennes. Journal of Experimental Marine Biology and Ecology 79:251-262

Boisclair D (1992) An evaluation of the stereocinematographic method to estimate fish swimming speed. Canadian Journal of Fisheries and Aquatic Science 49:523-531

Boisclair D, Leggett WC (1989) The importance of activity in bioenergetics models applied to actively foraging fishes. Canadian Journal of Fisheries and Aquatic Science 46:1859-1867

Boisclair D, Sirois P (1993) Testing assumptions of fish bioenergetics models by direct estimation of growth, consumption, and activity rates. Transactions of the American Fisheries Society 122:784-796

Bolz GR, Lough RG (1988) Growth through the first six months of Atlantic cod, Gadus morhua, and haddock, Melanogrammus aeglefinus, based on daily otolith increments. Fishery Bulletin 86:223-235

Brett JR (1972) The metabolic demand for oxygen in fish, particularly salmonids, and a comparison with other vertebrates. Respiration Physiology 14:151-170

Brett JR, Groves TDD (1979) Physiological energetics. In: Hoar WS, Randall DJ, Brett JR (eds) Fish Physiology, Vol 8. Academic Press, New York, p 279-352

Browman HI, O'Brien WJ (1992) Foraging and prey search behaviour of Golden Shiner (Notemigonus crysoleucas) larvae. Canadian Journal of Fisheries and Aquatic Science 49:813-819

Browman HI, St. Pierre J-F, Skiftesvik AB, Racca RG (2003) Behaviour of Atlantic cod (Gadus morhua) larvae: an attemp to link maternal condition with larval quality. 
In: Browman HI, Skiftesvik AB (eds) The Big Fish Bang. Proceedings of the 26th Annual Larval Fish Conference. the Institue of Marine Research, Bergen, Norway, p 71-95

Brownsmith CB (1977) Foraging rates of starlings in two habitats. Condor 79:386-387

Buckley LJ, Dillman DW (1982) Nitrogen utilization by larval summer flounder, Paralichthys dentatus (Linnaeus). Journal of Experimental Marine Biology and Ecology 59:243-256

Buckley LJ, Lough RG (1987) Recent growth, biochemical composition, and prey field of larval Haddock (Melanogrammus aeglefinus) and Atlantic cod (Gadus morhua) on Georges Bank. Canadian Journal of Fisheries and Aquatic Science 44:14-25

Buckley LJ, Lough RG, Peck MA, Werner FE (2000) Comment: Larval Atlantic cod and haddock growth models, metabolism, ingestion, and temperature effects. Canadian Journal of Fisheries and Aquatic Science 57:1957-1960

Burgett RL, Hebert D, Oakey NS (2001) Vertical structure of turbulence on the southern flank of Georges Bank. Journal of Geophysical Research 106:22545-22558

Cushing DH (1990) Plankton production and year-class strength in fish populations: an update of the match/mismatch hypothesis. Advances in Marine Biology 26:249293

Dabrowski KR (1986a) Active metabolism in larval and juvenile fish: ontogenetic changes, effect of water temperature and fasting. Fish Physiology and Biochemistry 1:125-144

Dabrowski KR (1986b) Energy utilization during swimming and cost of locomotion in larval and juvenile fish. Journal of Applied Ichthyology 3:110-117

Dabrowski KR, Kok LY, Takashima F (1986) How efficiently do fish larvae and juveniles swim? Comparative Biochemistry and Physiology, A 85A:657-661

Davenport J, Lønning S (1980) Oxygen uptake in developing eggs and larvae of the cod Gadus morhua L. J. Fish. Biol. 16:249-256

Davis CS (1984) Interaction of a copepod population with the mean circulation on Georges Bank. Journal of Marine Research 42:573-590

Davis CS, Flierl GR, Wiebe PH, Franks PJS (1991) Micropatchiness, turbulence and recruitment in plankton. Journal of Marine Research 49:109-151

Dower JF, Miller TJ, Leggett WC (1997) The role of microscale turbulence in the feeding ecology of larval fish. Advances in Marine Biology 31:169-220

Drost MR, van den Boogaart JGM (1986) The energetics of feeding strikes in larval carp, Cyprinus carpio. Journal of Fish Biology 29:371-379 
El-Fiky N, Hinterleitner S, Wieser W (1987) Differentiation of swimming muscles and gills, and development of anaerobic power in the larvae of cyprinid fish (Pisces, Teleostei). Zoomorphology 107:126-132

Ellertsen B, Solemdal P, Strømme T, Tilseth S, Westgård T, Moksness E, Øiestad V (1980) Some biological aspects of cod larvae (Gadus morhua L.). Fiskeridirektoratets Skrifter Serie Havunders $\varnothing$ kelser 17:29-47

Evans BI, O'Brien WJ (1988) A reevaluation of the search cycle of planktivorous Arctic Grayling, Thamallus arcticus. Canadian Journal of Fisheries and Aquatic Science 45:187-192

Fiksen $\varnothing$, Utne ACW, Aksnes DL, Eiane K, Helvik JV, Sundby S (1998) Modelling the influence of light, turbulence and ontogeny on ingestion rates in larval cod and herring. Fisheries Oceanography 7:355-363

Finn RN, Fyhn HJ, Evjen MS (1995) Physiological energetics of developing embryos and yolk-sac larvae of Atlantic cod (Gadus morhua). I. Respiration and nitrogen metabolism. Marine Biology 124:355-369

Folkvord A, Hunter JR (1986) Size-specific vulnerability of Northern Anchovy, Engraulis mordax, larvae to predation by fishes. Fishery Bulletin 84:859-869

Forstner H, Gnaiger E (1983) Appendix A: Calculation of equilibrium oxygen concentration. In: Gnaiger E, Forstner H (eds) Polarographic Oxygen Sensors. Springer-Verlag, New York, p 321-333

Forstner H, Hinterleitner S, Mähr K, Wieser W (1983) Towards a better definition of "metamorphosis" in Coregonus sp.: Biochemical, histological, and physiological data. Canadian Journal of Fisheries and Aquatic Sciences 40:1224-1232

Forstner H, Wieser W (1990) Patterns of routine swimming and metabolic rate in juvenile cyprinids at three temperatures: analysis with a respirometer-activity-monitoring system. Journal of Comparative Physiology B 160:71-76

Fry FEJ (1971) The effect of environmental factors on the physiology of fish. In: Fish Physiology, Vol VI. Academic Press, New York, p 1-98

Fuiman LA, Batty RS (1997) What a drag it is getting cold: partitioning the physical and physiological effects of temperature on fish swimming. The Journal of Experimental Biology 200:1745-1755

Fuiman LA, Webb PW (1988) Ontogeny of routine swimming activity and performance in zebra danios (Teleostei: Cyprinidae). Animal Behaviour 36:250-261

Gallager SM, Davis CS, Epstein AW, Solow A, Beardsley RC (1996a) High-resolution observations of plankton spatial distributions correlated with hydrography in the Great South Channel, Georges Bank. Deep-Sea Research II 43:1627-1663 
Gallager SM, Hunt von Herbing I, Davis L, Alatalo P (1996b) First-feeding cod larvae ingest microzooplankton exclusively from natural plankton assemblages on Georges Bank AGU/ASLO

Gallego A (1994) Changes in the swimming behaviour of larval herring in response to two different prey densities. Journal of the Marine Biological Association of the United Kingdom 74:955-958

Gendron RP, Staddon JER (1983) Searching for cryptic prey: the effect of search rate. American Naturalist 121:172-186

Gnaiger E (1983) Appendix C: Calculation of energetic and biochemical equivalents of respiratory oxygen consumption. In: Gnaiger E, Forstner H (eds) Polarographic oxygen sensors. Springer-Verlag, New York, p 337-345

Govoni JJ, Boehlert GW, Watanabe Y (1986) The physiology of digestion in fish larvae. Environmental Biology of Fishes 16:59-77

Hinterleitner S, Thurner-Flür J, Wieser W, El-Fiky N (1989) Profiles of enzyme activity in larvae of two cyprinid species with contrasting life styles (Cyprinidae; Teleostei). Journal of Fish Biology 35:709-718

Hjort J (1914) Fluctuations in the great fisheries of northern Europe viewed in the light of biological research. Rapports et Procès Verbaux des Réunions, Internationale Conseil pour l'Exploration de la Mer 20:1-228

Horne EPW, Loder JW, Naimie CE, Oakey NS (1996) Turbulence dissipation rates and nitrate supply in the upper water column on Georges Bank. Deep-Sea Research II 43:1683-1712

Houde ED (1987) Fish early life dynamics and recruitment variability. In: Hoyt RD (ed) 10th Annual Larval Fish Conference, Miami FL (USA), p 17-29

Houde ED (1989) Comparative growth, mortality, and energetics of marine fish larvae. Fisheries Bulletin 87:471-495

Houlihan DF, Pedersen BH, Steffensen JF, Brechin J (1995) Protein synthesis, growth and energetics in larval herring (Clupea harengus) at different feeding regimes. Fish Physiology and Biochemistry 14:195-208

Hunt von Herbing I (2002) Effects of temperature on larval fish swimming performance: the importance of physics to physiology. Journal of Fish Biology 61:865-876

Hunt von Herbing I, Boutilier RG (1996) Activity and metabolism of larval Atlantic cod (Gadus morhua) from Scotian Shelf and Newfoundland source populations. Marine Biology 124:607-617

Hunt von Herbing I, Gallager SM (2000) Foraging behavior in early Atlantic cod larvae (Gadus morhua) feeding on a protozoan (Balanion sp.) and a copepod nauplius (Pseudodiaptomus sp.). Marine Biology 136:591-602 
Hunter JR (1972) Swimming and feeding behavior of larval anchovy Engraulis mordax. Fishery Bulletin 70:821-838

Hunter JR (1981) Feeding ecology and predation of marine fish larvae. In: Lasker R (ed) Marine fish larvae. Washington Sea Grant Program, Seattle, p 32-77

Huse I (1994) Feeding at different illumination levels in larvae of three marine teleost species: cod, Gadus morhua L., plaice, Pleuronectes platessa L., and turbot, Scophthalmus maximus (L.). Aquaculture and Fisheries Management 25:687-695

Huuskonen H, Karjalainen J, Medgyesy N, Wieser W (1998) Energy allocation in larval and juvenile Coregonus lavaretus: validation of a bioenergetics model. J. Fish. Biol. 52:962-972

Incze LS, Aas P, Ainaire T (1996) Distributions of copepod nauplii and turbulence on the southern flank of Georges Bank: implications for feeding by larval cod ( Gadus morhua). Deep-Sea Research II 42:1855-1873

Jobling M (1981) The influences of feeding on the metabolic rate of fishes: a short review. J. Fish. Biol. 18:385-400

Jobling M (1983) Towards an explanation of specific dynamic action (SDA). J. Fish. Biol. 23:549-555

Jobling M (1985) Growth. In: Tytler P, Calow P (eds) Fish energetics - new perspectives. Croom Helm, Beckenham, p 213-230

Kamler E (1992) Early life history of fish, Vol. Chapman and Hall, New York

Kane J (1984) The feeding habits of co-occurring cod and haddock larvae. Marine Ecology Progress Series 16:9-20

Kaufmann R (1990) Respiratory cost of swimming in larval and juvenile cyprinids. Journal of Experimental Biology 150:343-366

Kaufmann R, Wieser W (1992) Influence of temperature and ambient oxygen on the swimming energetics of cyprinid larvae and juveniles. Environmental Biology of Fishes 33:87-95

Keckeis H, Kamler E, Bauer-Nemeschkal E, Schneeweiss K (2001) Survival, development and food energy partitioning of nase larvae and early juveniles at different temperatures. Journal of Fish Biology 59:45-61

Kiørboe T, Munk P, Richardson K (1987) Respiration and growth of larval herring Clupea harengus: relation between specific dynamic action and growth efficiency. Marine Ecology Progress Series 40:1-10

Kleinbaum DG, Kupper LL, Muller KE, Nizam A (1998) Applied regression analysis and other multivariable methods, Vol. Duxbury Press, Pacific Grove 
Krohn MM, Boisclair D (1994) Use of a stereo-video system to estimate the energy expenditure of free-swimming fish. Canadian Journal of Fisheries and Aquatic Science 51:1119-1127

Laurence GC (1976) Caloric values of some North Atlantic calanoid copepods. Fisheries Bulletin 74:218-220

Laurence GC (1977) A bioenergetic model for the analysis of feeding and survival potential of Winter Flounder, Pseudopleuronectes americanus, larvae during the period from hatching to metamorphosis. Fishery Bulletin 75:529-546

Laurence GC (1979) Larval length-weight relations for seven species of Northwest Atlantic fishes reared in the laboratory. Fishery Bulletin 76:890-895

Laurence GC (1985) A report on the development of stochastic models of food limited growth and survival of cod and haddock larvae on Georges Bank. In: Laurence GC, Lough RG (eds) Growth and survival of larval fishes in relation to the trophodynamics of Georges Bank cod and haddock, Vol NMFS-F/NEC-36. NOAA Technical Memo, p 83-150

Leggett WC, DeBlois E (1994) Recruitment in marine fishes: is it regulated by starvation and predation in the egg and larval stages? Netherlands Journal of Sea Research 32:119-134

Leising AW, Franks PJS (1999) Larval Atlantic cod (Gadus morhua) and haddock (Melanogrammus aeglefinus) growth on Georges Bank: a model with temperature, prey size, and turbulence forcing. Canadian Journal of Fisheries and Aquatic Science 56:25-36

Leising AW, Franks PJS (2000) Reply to Buckley et al.'s "Comment: Larval Atlantic cod and haddock growth models, metabolism, ingestion, and temperature effects". Canadian Journal of Fisheries and Aquatic Science 57:1961-1963

Letcher BH, Rice JA, Crowder LB, Rose KA (1996) Variability in survival of larval fish: disentangling components with a generalized individual-based model. Canadian Journal of Fisheries and Aquatic Science 53:787-801

Lough RG, Bolz GR (1989) The movement of cod and haddock larvae onto the shoals of Georges Bank. Journal of Fish Biology 25 (supplement A):71-79

Lough RG, Buckley LJ, Werner FE, Quinlin JA, Edwards KP (in press) A general biophysical model of larval cod growth applied to populations on Georges Bank. Fisheries Oceanography

Lough RG, Caldarone EM, Rotunno TK, Broughton EA, Burns BR, Buckley LJ (1996) Vertical distribution of cod and haddock eggs and larvae, feeding and condition in stratified and mixed waters on southern Georges Bank, May 1992. Deep-Sea Research II 43:1875-1904 
Lough RG, Mountain DG (1996) Effect of small-scale turbulence on feeding rates of larval cod and haddock in stratified water on Georges Bank. Deep-Sea Research II 43:1745-1772

Lough RG, Potter DC (1993) Vertical distribution patterns and diel migrations of larval and juvenile haddock Melanogrammus aeglefinus and Atlantic cod Gadus morhua on Georges Bank. Fishery Bulletin 91:281-303

Lynch DR, Lewis CVW, Werner FE (2001) Can Georges Bank larval cod survive on a calanoid diet? Deep-Sea Research II 48:609-630

MacKenzie BR, Kiørboe T (1995) Encounter rates and swimming behavior of pausetravel and cruise larval fish predators in calm and turbulent laboratory environments. Limnology and Oceanography 40:1278-1289

MacKenzie BR, Kiørboe T (2000) Larval fish feeding in turbulence: a case for the downside. Limnology and Oceanography 45:1-10

MacKenzie BR, Leggett WC, Peters RH (1990) Estimating larval fish ingestion rates: can laboratory derived values be reliably extrapolated to the wild? Marine Ecology Progress Series 67:209-225

MacKenzie BR, Miller TJ, Cyr S, Leggett WC (1994) Evidence for a dome-shaped relationship between turbulence and larval fish ingestion rates. Limnology and Oceanography 39:1790-1799

Madon SP, Culver DA (1993) Bioenergetics model for larval and juvenile Walleyes: an in situ approach with experimental ponds. Transactions of the American Fisheries Society $122: 797-813$

Miller TJ, Crowder LB, Rice JA, Marschall EA (1988) Larval size and recruitment mechanisms in fishes: toward a conceptual framework. Canadian Journal of Fisheries and Aquatic Science 45:1657-1670

Müller UK, Stamhuis EJ, Videler JJ (2000) Hydrodynamics of unsteady fish swimming and the effects of body size: comparing the flow fields of fish larvae and adults. Journal of Experimental Biology 203:193-206

Munk P (1995) Foraging behaviour of larval cod (Gadus morhua) influenced by prey density and hunger. Marine Biology 122:205-212

Munk P, Kiørboe T (1985) Feeding behaviour and swimming activity of larval herring (Clupea harengus) in relation to density of copepod nauplii. Marine Ecology Progress Series 24:15-21

Nag AC, Nursall JR (1972) Histogenesis of white and red muscle fibers of trunk muscles of a fish Salmo gairdneri. Cytobios 6:227-246

O'Brien WJ, Browman HI, Evans BI (1990) Search strategies of foraging animals. American Scientist 78:152-160 
O'Brien WJ, Evans BI, Browman HI (1989) Flexible search tactics and efficient foraging in saltatory searching animals. Oecologia 80:100-110

O'Brien WJ, Evans BI, Howick GL (1986) A new view of the predation cycle of a planktivorous fish, white crappie (Pomoxis annularis). Canadian Journal of Fisheries and Aquatic Science 43:1894-1899

Paffenhöfer G-A, Strickler JR, Lewis KD, Richman S (1996) Motion behavior of nauplii and early copepodid stages of marine planktonic copepods. Journal of Plankton Research 118:1699-1715

Pannevis MC, Houlihan DF (1992) The energetic cost of protein synthesis in isolated hepatocytes of rainbow trout (Oncorhynchus mykiss). Journal of Comparative Physiology B 162:363-400

Pedersen BH (1997) The cost of growth in young fish larvae, a review of new hypotheses. Aquaculture 155:259-269

Pepin P (1991) Effect of temperature and size on development, mortality, and survival rates of the pelagic early life history stages of marine fish. Can. J. Aquat. Sci. 48:503-518

Peterson I, Wroblewski JS (1984) Mortality rate of fishes in the pelagic ecosystem. Canadian Journal of Fisheries and Aquatic Science 41:1117-1120

Post JR (1990) Metabolic allometry of larval and juvenile yellow perch (Perca flavescens): in situ estimates and bioenergetic models. Canadian Journal of Fisheries and Aquatic Science 47:554-560

Puvanendran V, Brown JA (1999) Foraging, growth and survival of Atlantic cod larvae reared in different prey concentrations. Aquaculture 175:77-92

Puvanendran V, Brown JA (2002) Foraging, growth and survival of Atlantic cod larvae reared in different light intensities and photoperiods. Aquaculture 214:1-4

Rombough PJ (1988) Respiratory gas exchange, aerobic metabolism and effects of hypoxia during early life. In: Hoar WS, Randall DJ (eds) Fish Physiology, Vol 11 The physiology of developing fish. part A Eggs and larvae. Academic Press, New York, p 59-161

Rombough PJ (1994) Energy partitioning during fish development: additive or compensatory allocation of energy to support growth? Functional Ecology 8:178186

Rosenthal H, Hempel G (1970) Experimental studies in feeding and food requirements of herring larvae (Clupea harengus L.). In: Steele JH (ed) Marine food webs. University of California Press, Berkeley, p 344-364

Rothschild BJ, Osborn TR (1988) Small-scale turbulence and plankton contact rates. Journal of Plankton Research 10:465-474 
Serchuk FM, Grosslein MD, Lough RG, Mountain DG, O'Brien L (1994) Fishery and environmental factors affecting trends and fluctuations in the Georges Bank and Gulf of Maine Atlantic cod stocks: an overview. ICES Marine Science Symposium 198:77-109

Skiftesvik AB (1992) Changes in behaviour at onset of exogenous feeding in marine fish larvae. Canadian Journal of Fisheries and Aquatic Science 49:1570-1572

Skiftesvik AB, Huse I (1987) Behaviour studies of cod larvae, Gadus morhua L. Sarsia $72: 367-368$

Smith RW, Houlihan DF (1995) Protein synthesis and oxygen consumption in fish cells. Journal of Comparative Physiology B 165:93-101

Solberg T, Tilseth S (eds) (1984) Growth, energy consumption and prey density requirements in first feeding larvae of cod (Gadus morhua L.), Vol 1. Flødevigen rapportser.

Soofiani NM, Hawkins AD (1982) Energetic costs at different levels of feeding in juvenile cod, Gadus morhua L. J. Fish. Biol. 21:577-592

Soofiani NM, Priede IG (1985) Aerobic metabolic scope and swimming performance in juvenile cod, Gadus morhua L. J. Fish. Biol. 26:127-138

Stobutzki IC, Bellwood DR (1994) An analysis of the sustained swimming abilities of pre- and post-settlement coral reef fishes. Journal of Experimental Marine Biology and Ecology 175:275-286

Tang Y, Nelson JA, Reidy SP, Kerr SR, Boutilier RG (1994) A reappraisal of activity metabolism in Atlantic cod (Gadus morhua). Journal of Fish Biology 44:1-10

The MathWorks I (1998) Matlab, Natick, Ma

Tilseth S, Ellertsen B (1984) Food consumption rate and gut evacuation processes of first feeding cod larvae (Gadus morhua L.). In: E. D, Danielssen DS, Moksness E, Solemdal P (eds) The Propagation of Cod Gadus morhua L., Vol 1. Flødevigen rapportser, p 167-182

Titelman J, Kiørboe T (2003) Motility of copepod nauplii and implications for food encounter. Marine Ecology Progress Series 247:123-135

Torres JJ, Brightman RI, Donnelly J, Harvey J (1996) Energetics of larval red drum, Sciaenops ocellatus. Part 1: oxygen consumption, specific dynamic action, and nitrogen excretion. Fishery Bulletin 94:756-765

Videler JJ, Weihs D (1982) Energetic advantages of burst-and-coast swimming of fish at high speeds. Journal of Experimental Biology 97:169-178

Vlymen WJ, III (1974) Swimming energetics of the larval anchovy, Engraulis mordax. Fishery Bulletin 72:885-899

Vogel S (1994) Life in Moving Fluids, Vol. Princeton University Press, Princeton, N.J 
Wang W, Reimers CE, Wainright SC, Shahriari M, Morris MJ (1999) Applying FiberOptic Sensors for Monitoring Dissolved Oxygen. Sea Technology 3:69-77

Ware DM (1975) Growth, metabolism, and optimal swimming speed of a pelagic fish. Journal of the Fisheries Research Board of Canada 32:33-41

Webb PW (1988) Simple physical principles and vertebrate aquatic locomotion. American Zoologist 28:709-725

Webb PW, Weihs D (1986) Functional locomotor morphology of early life history stages of fishes. Transactions of the American Fisheries Society 115:115-127

Weihs D (1974) Energetic advantages of burst swimming of fish. Journal of Theoretical Biology 48:215-229

Weihs D (1980) Energetic significance of changes in swimming modes during growth of larval anchovy, Engraulis mordax. Fishery Bulletin 77:597-604

Werner EE, Gilliam JF (1984) The ontogenetic niche and species interactions in sizestructured populations. Annual Review of Ecology and Systematics 15:393-425

Werner FE, MacKenzie BR, Perry RI, Lough RG, Naimie CE, Blanton BO, Quinlan JA (2001) Larval trophodynamics, turbulence, and drift on Georges Bank: a sensitivity analysis of cod and haddock. Scientia Marina 65:99-115

Werner FE, Perry RI, Lough RG, Naimie CE (1996) Trophodynamic and advective influences on Georges Bank larval cod and haddock. Deep-Sea Research II 43:1793-1822

Wieser W (1995) Energetics of fish larvae, the smallest vertebrates. Acta Physiologica Scandinavica 154:279-290

Wieser W, Forstner H, Medgyesy N, Hinterleitner S (1988) To switch or not to switch: partitioning energy between growth and activity in larval cyprinids (Cyprinidae: Teleostei). Functional Ecology 2:499-507

Wieser W, Medgyesy N (1990a) Aerobic maximum for growth in the larvae and juveniles of a cyprinid fish, Rutilus rutilus (L.): implications for energy budgeting in small poikilotherms. Functional Ecology 4:233-242

Wieser W, Medgyesy N (1990b) Cost and efficiency of growth in the larvae of two species of fish with widely differing metabolic rates. Proceedings of the Royal Society of London, Series B: Biological Sciences 242:51-56

Yamashita Y, Bailey KM (1989) A laboratory study of the bioenergetics of larval Walleye Pollock, Theragra chalcogramma. Fishery Bulletin 87:525-536 


\section{Appendix: Formulae used for the calculation of oxygen}

\section{concentration}

From: Forstner, H, and E Gnaiger (1983). Appendix A: Calculation of equilibrium oxygen concentration. In Forstner, H, and E Gnaiger (eds.), Polarographic Oxygen Sensors. Springer-Verlag, Berlin. pp. 321-333.

1) The 'unit standard concentration' of atmospheric oxygen in pure water and 1 atmosphere pressure (Forstner \& Gnaiger 1983: eq. 7, p. 323):

$$
C^{*}=\exp [11.1538 \cdot 1.31403 \cdot \ln (t+45.93)]
$$

where,

$$
\begin{aligned}
& \mathrm{C}^{*}=\text { oxygen concentration }\left(\mu \mathrm{mol} \cdot \mathrm{L}^{-1}\right) \\
& \mathrm{t}=\text { temperature }\left({ }^{\circ} \mathrm{C}\right) .
\end{aligned}
$$

2) Solubility coefficient of oxygen in pure water and 1 atmosphere (Forstner \& Gnaiger 1983: eq. 5, p. 322)

$$
\mathbf{S}_{\mathrm{s}}=\mathbf{C}^{*} /\left(\mathbf{P}_{\mathrm{O}}-\mathbf{P}_{\mathrm{H} 20}\right) \cdot \phi_{\mathrm{O} 2}
$$

where,

$$
\begin{aligned}
& \mathrm{S}_{\mathrm{s}}=\text { solubility coefficient of oxygen in pure water }\left(\mu \mathrm{mol} \cdot \mathrm{L}^{-1} \cdot \mathrm{kPa}^{-1}\right) \\
& \mathrm{P}_{\mathrm{O}}=\text { total gas pressure at one atmosphere }(\text { gas }+ \text { water vapor })=101.325 \mathrm{kPa} \\
& \mathrm{P}_{\mathrm{H} 20}=\text { partial pressure of water vapor }(\mathrm{kPa})=\exp [(-216961 \cdot(1 / \mathrm{T})-3840.7) \cdot(1 / \mathrm{T})+ \\
& \quad 16.4754] \text { (eq. } 19, \text { p. } 326) \\
& \mathrm{T}=\text { temperature }(\text { Kelvin) } \\
& \phi_{\mathrm{O} 2}=\text { volume fraction of atmospheric oxygen in dry air }=0.20946 .
\end{aligned}
$$


3) Solubility coefficient of oxygen in electrolyte and 1 atmosphere (Forstner \& Gnaiger 1983: eq. 11, p. 324)

$$
\mathrm{S}_{\mathrm{e}}=\mathrm{S}_{\mathrm{s}} \cdot \exp \left(\left[-[\mathrm{CI}] \%_{0} *\left(-0.1288+(53.44 / \mathrm{T})-0.04442 \cdot \ln (\mathrm{T})+7.145 \cdot 10^{-4} \cdot \mathrm{T}\right)\right.\right.
$$

where,

$$
\mathrm{S}_{\mathrm{e}}=\text { solubility coefficient of oxygen in electrolyte }\left(\mu \mathrm{mol} \cdot \mathrm{L}^{-1} \cdot \mathrm{kPa}^{-1}\right) \text {. }
$$

4) Oxygen concentration in seawater and 1 atmosphere

$$
\mathbf{C}^{\mathrm{e}^{*}}=\mathbf{C}^{*} \cdot\left(\mathbf{S}_{\mathrm{e}} / \mathbf{S}_{\mathrm{s}}\right) \cdot\left[\left(\mathbf{P}_{\mathrm{O}}-\mathbf{P}_{\mathrm{H} 20}^{\mathrm{e}}\right) /\left(\mathbf{P}_{\mathrm{O}}-\mathbf{P}_{\mathrm{H} 20}\right)\right]
$$

where,

$$
\begin{aligned}
& \mathrm{C}^{\mathrm{e}^{*}}=\text { oxygen concentration }\left(\mu \mathrm{mol} \cdot \mathrm{L}^{-1}\right) \\
& \mathrm{P}_{\mathrm{H} 20}^{\mathrm{e}}=\text { water vapor pressure in seawater; the term }\left[\left(1-\mathrm{P}_{\mathrm{H} 20} / \mathrm{b}\right) /\left(1-\mathrm{P}_{\mathrm{H} 20} / \mathrm{P}_{\mathrm{O}}\right)\right] \approx 0 .
\end{aligned}
$$

5) Concentration of atmospheric oxygen in pure water and non-standard atmosphere (Forstner \& Gnaiger 1983: eq. 18, p. 325)

$$
\mathrm{C}_{\mathrm{c}}=\mathrm{C}^{*} \cdot{ }_{\mathrm{b}} \mathrm{P} / \mathrm{Po} \cdot\left[\left(1-\mathbf{P}_{\mathrm{H} 20} / \mathrm{P}\right) /\left(1-\mathbf{P}_{\mathrm{H} 20} / \mathbf{P}_{\mathrm{O}}\right)\right]
$$

where,

$$
\mathrm{C}_{\mathrm{c}}=\text { oxygen concentration at saturation }\left(\mu \mathrm{mol} \cdot \mathrm{L}^{-1}\right)
$$

${ }_{b} \mathrm{P}=$ barometric pressure $(\mathrm{kPa})$.

6) Similarly, the concentration of atmospheric oxygen in seawater and non-standard atmosphere (Forstner \& Gnaiger 1983: eq. 18, p. 325):

$$
\mathrm{C}_{\mathrm{c}}^{\mathrm{e}}=\mathrm{C}^{\mathrm{e}^{*}} \cdot{ }_{\mathrm{b}} \mathbf{P} / \mathbf{P o} \cdot\left[\left(\mathbf{1}-\mathbf{P}_{\mathrm{H} 20} /{ }_{\mathrm{b}} \mathbf{P}\right) /\left(\mathbf{1}-\mathbf{P}_{\mathrm{H} 20} / \mathbf{P}_{\mathrm{O}}\right)\right]
$$

